\title{
AVALIAÇÃO DO PROCESSO DE CONVERGÊNCIA DA PRODUTIVIDADE DA TERRA NA AGRICULTURA BRASILEIRA NO PERÍODO DE 1960 A 2001
}

\author{
JANETE LEIGE LOPES
}

Tese apresentada à Escola Superior de Agricultura "Luiz de Queiroz", Universidade de São Paulo, para obtenção do título de Doutor em Ciências, Área de Concentração: Economia Aplicada.

\author{
P I R A C I C A B A \\ Estado de São Paulo - Brasil \\ Novembro - 2004
}




\title{
AVALIAÇÃO DO PROCESSO DE CONVERGÊNCIA DA PRODUTIVIDADE DA TERRA NA AGRICULTURA BRASILEIRA NO PERÍODO DE 1960 A 2001
}

\author{
JANETE LEIGE LOPES \\ Bacharel em Ciências Econômicas \\ Orientador: Prof. Dr. CARLOS JOSÉ CAETANO BACHA
}

Tese apresentada à Escola Superior de Agricultura "Luiz de Queiroz", Universidade de São Paulo, para obtenção do título de Doutor em Ciências, Área de Concentração: Economia Aplicada.

\author{
P I R A C I C A B A \\ Estado de São Paulo - Brasil \\ Novembro - 2004
}


Dados Internacionais de Catalogação na Publicação (CIP) DIVISÃO DE BIBLIOTECA E DOCUMENTAÇÃO - ESALQ/USP

\section{Lopes, Janete Leige}

Avaliação do processo de convergência da produtividade da terra na agricultura brasileira no período de 1960 a 2001 / Janete Leige Lopes. - - Piracicaba, 2004.

$193 \mathrm{p}$.

Tese (Doutorado) - - Escola Superior de Agricultura Luiz de Queiroz, 2004. Bibliografia.

1. Agricultura - Aspectos econômicos 2. Capital humano 3. Convergência 4. Desenvolvimento econômico 5. Inovação tecnológica 6. Modernização da agricultura 7. Produção agrícola 8. Produtividade da terra 9. Renda per capita I. Título 


\section{DEDICO}

Ao MEU ESPOSO E FILHOS 


\section{AGRADECIMENTOS}

À Deus, por me permitir cumprir mais essa jornada.

Ao meu esposo e filhos, por seu amor e apoio.

Ao meu orientador, Carlos José Caetano Bacha, por sua dedicação durante a realização desse trabalho.

Aos meus amigos especiais, Ricardo Shirota, Roberto Arruda de Lima, Marcelo Pereira da Cunha e Maielli, que nunca me faltaram com seu apoio.

A todos os meus colegas do curso de pós-graduação do Departamento de Economia, Administração e Sociologia, obrigada pela amizade e companheirismo. 


\section{SUMÁRIO}

Página

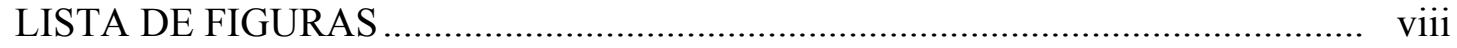

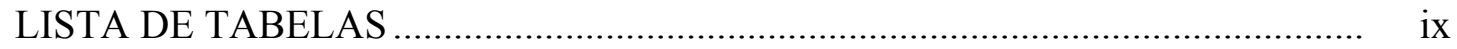

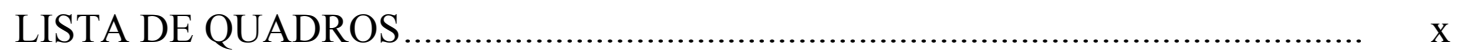

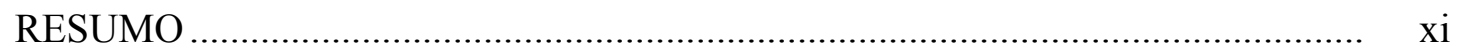

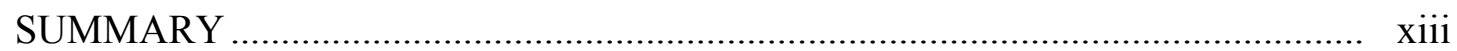

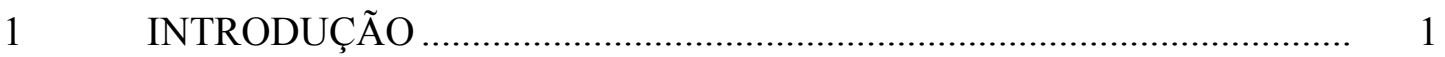

$1.1 \quad$ O problema de pesquisa ................................................................... 1

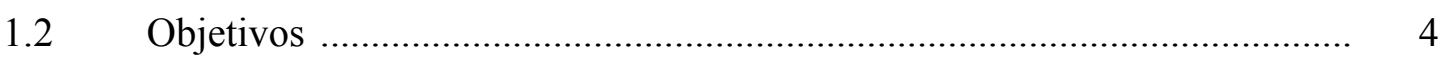

1.3 Importância do trabalho ........................................................................... 5

$1.4 \quad$ Organização do trabalho ......................................................................... 5

2 REVISÃO DE LITERATURA ......................................................... 7

2.1 Convergência: origens e evidências empíricas sobre o tema......................... 8

2.2 Modelos teóricos de crescimento e convergência......................................... 11

2.2.1 Modelo de Solow ................................................................................ 13

2.2.1.1 Modelo de Solow sem tecnologia .............................................................. 13

2.2.1.2 Modelo de Solow com tecnologia.................................................................. 21

2.2.2 Convergência no modelo de Barro e Sala-i-Martin ...................................... 23

2.2.2.1 Modelos de convergência $\beta$ e $\sigma$.................................................................. 23

2.2.2.2 Modelo de convergência $\beta$ condicional ..................................................... 28

2.2.3 Evidências econométricas sobre convergência no mundo........................... 29

2.2.4 Evidências econométricas sobre convergência no Brasil ............................ 30 
ANÁLISE DO PROCESSO DE CRESCIMENTO E MODERNIZAÇÃO

DA AGRICULTURA BRASILEIRA

DINÂMICA DAS CULTURAS ESTUDADAS E CONDIÇÕES PARA

A OCORRÊNCIA (OU NÃO) DE CONVERGÊNCIA DA PRODUTIVIDADE DA TERRA

4.1 Cultura do algodão herbáceo

4.2 Cultura do arroz 48

4.3 Cultura da batata-inglesa 50

4.4 Cultura do café 52

$4.5 \quad$ Cultura da cana-de-açúcar................................................................... 55

4.6 Cultura do feijão ................................................................................. 58

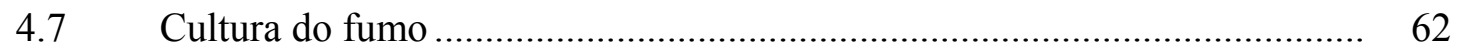

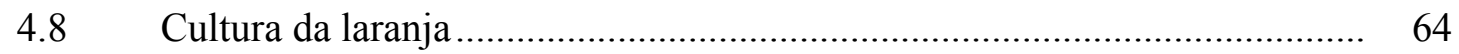

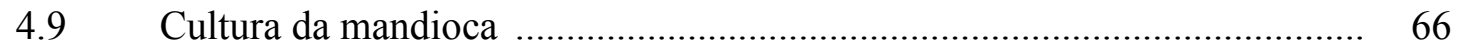

4.10 Cultura do milho ................................................................................ 68

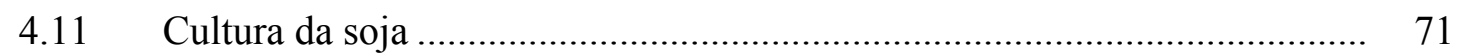

5 MODELO TEÓRICO SOBRE CONVERGÊNCIA DA PRODUTIVIDADE DA TERRA ........................................................... 75

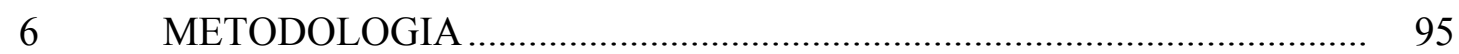

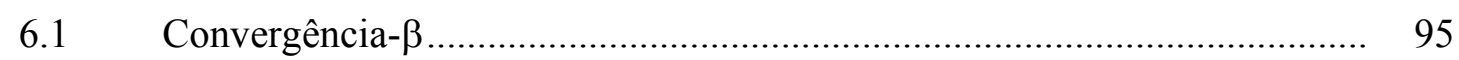

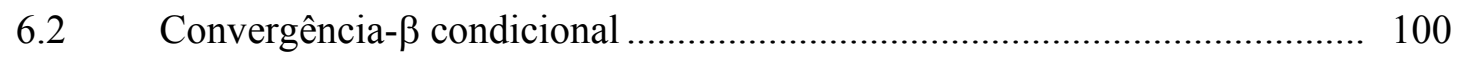

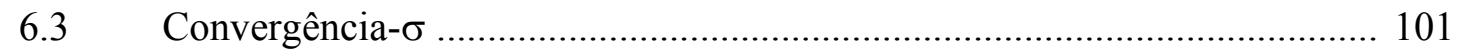

6.4 Abrangência e fonte de dados ................................................................ 102

$7 \quad$ RESULTADOS E DISCUSSÃO ……..................................................... 104

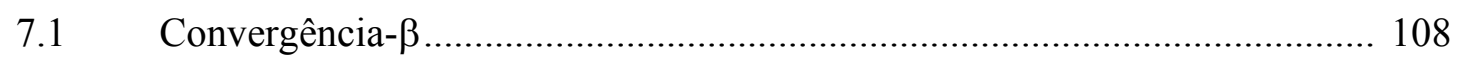

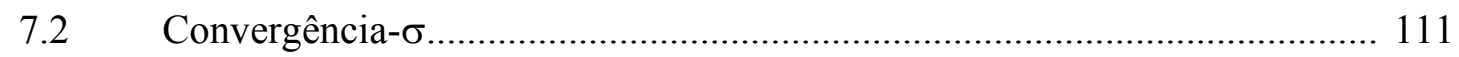

7.3 Convergência- $\beta$ absoluta para formação de grupos de convergência............. 114

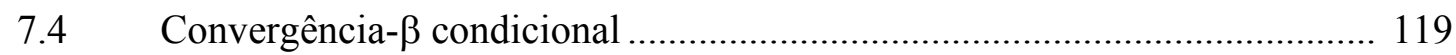

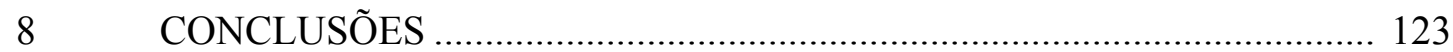




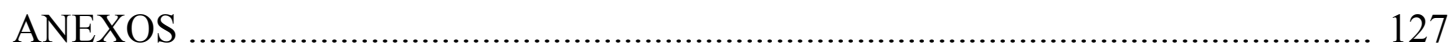

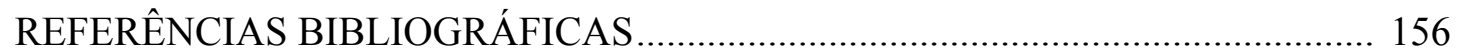

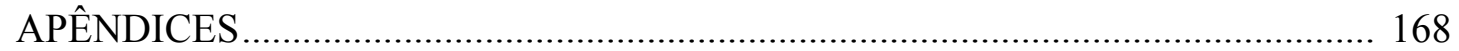




\section{LISTA DE FIGURAS}

Página

1 Convergência no Modelo de Solow ....................................................................... 18

2 Efeitos do aumento da taxa de investimento (s) no Modelo de Solow ................ 19

3 Evolução dos valores de crédito rural concedido, 1970-2002 ........................... 36

4 Evolução da área e produtividade das 38 principais culturas do Brasil,

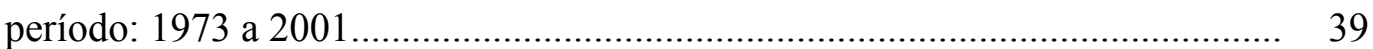

5 Evolução da área e produtividade das 37 principais culturas no Brasil,

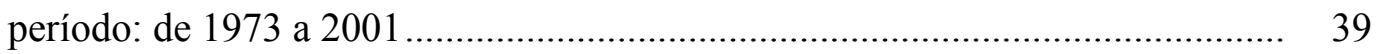

6 Evolução da área e produtividade do algodão herbáceo: 1960-2001.................. 45

7 Evolução da área e produtividade do arroz: 1960-2001 .................................... 48

8 Evolução da área e produtividade da batata-inglesa: 1960-2001 ........................ 51

9 Evolução da área e produtividade do café em côco: 1960-2001 ......................... 54

10 Evolução da área e produtividade da cultura da cana-de-açúcar: 1960-2001..... 56

11 Evolução da área e produtividade da cultura do feijão: 1960-2001 ..................... 59

12 Evolução da área e produtividade da cultura do fumo: 1960-2001 .................... 63

13 Evolução da área e produtividade da cultura da laranja: 1960-2001 .................. 65

14 Evolução da área e produtividade da cultura da mandioca: 1960-2001 ............. 67

15 Evolução da área e produtividade da cultura do milho: 1960-2001 .................... 70

16 Evolução da área e produtividade da cultura da soja: 1960-2001 ....................... 73

17 Ilustração gráfica representativa da equação de Mitscherlich ............................. 77 


\section{LISTA DE TABELAS}

Página

1 Indicadores censitários sobre a agropecuária brasileira

2 Taxas geométricas de crescimento da área colhida e da produtividade para culturas específicas (valores em \%) - período 1965-1986

3 Decomposição do produto real da agricultura: Brasil, 1990-2001

4 Taxas anuais de crescimento da produtividade do trabalho e seus componentes $(\%)$

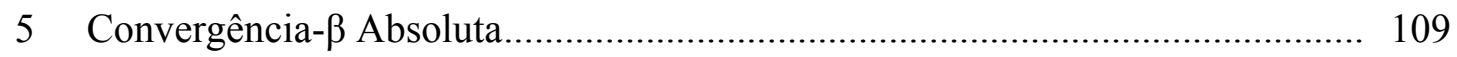

6 Evolução das estimativas da convergência- $\sigma$ por cultura e por período.............. 112

7 Convergência- $\beta$ absoluta e a formação de grupos de convergência .................... 117

8 Estimativas da convergência- $\beta$ condicional..................................................... 120 


\section{LISTA DE QUADROS}

Página

1 Principais inovações tecnológicas ocorridas com a cultura da cana-de-açúcar .... 58

2 Estados produtores considerados na análise de convergência- $\beta$ absoluta por culturas e por períodos ................................................................................... 105

3 Estados produtores considerados na análise de grupos de convergência.............. 116 


\title{
AVALIAÇÃO DO PROCESSO DE CONVERGÊNCIA DA PRODUTIVIDADE DA TERRA NA AGRICULTURA BRASILEIRA NO PERÍODO DE 1960 A 2001
}

\author{
Autor: JANETE LEIGE LOPES \\ Orientador: Prof. Dr. CARLOS JOSÉ CAETANO BACHA
}

\section{RESUMO}

Este trabalho analisou o comportamento da produtividade da terra na agricultura brasileira, avaliando se há ou não convergência na evolução dessa variável. A análise compreende o período de 1960 a 2001 e alguns sub-períodos desses 42 anos, mais precisamente, os sub-períodos de 1970 a 2001, 1975 a 2001 e 1980 a 2001 . A convergência é um processo em que uma mesma variável (por exemplo, renda per capita, produtividade da terra) apresenta diferentes valores entre países, regiões ou estados, mas essa diferença se reduz ao longo do tempo, indicando que a desigualdade diminui. As razões para haver o processo de convergência são várias, destacando-se as mudanças estruturais no processo de produção, a difusão tecnológica, a retirada de obstáculos ao crescimento da produção, dentre outras. A ocorrência da convergência da produtividade torna mais homogênea, do ponto de vista da modernidade, a agricultura do país. Para atingir o objetivo proposto na tese, desenvolveu-se um modelo teórico sobre convergência da produtividade da terra, tomando como base o modelo de Barro e Sala-i-Martin (1990). Quatro indicadores de convergência foram testados, os quais são: convergência- $\beta$ absoluta, convergência $\sigma$, grupos de convergência e convergência- $\beta$ 
condicional. Os dados utilizados referem-se às produtividades das culturas de algodão herbáceo, arroz, batata-inglesa, café, cana-de-açúcar, feijão, fumo, laranja, mandioca, milho e soja, coletados no Anuário Estatístico do Brasil. Inicialmente, testou-se a presença de convergência- $\beta$ absoluta para as onze culturas supracitadas. Apenas seis culturas apresentaram essa convergência (café, cana-de-açúcar, fumo, laranja, mandioca e soja). Para as mesmas onze culturas foi testada a presença de convergência- $\sigma$ e apenas a cultura da soja a apresentou para todos os sub-períodos analisados e as culturas da laranja e mandioca para o período de 1960 a 2001. Isto não invalida o resultado da convergência- $\beta$ absoluta, pois a literatura mostra que se houver convergência $\sigma$, necessariamente haverá convergência- $\beta$ absoluta, mas não o inverso. Para as culturas de algodão-herbáceo, arroz, batata-inglesa, feijão e milho foi testada a presença de grupos de convergência, diagnosticando-os para as culturas do algodão-herbáceo, batata-inglesa e feijão a convergência- $\beta$ absoluta para os estados com maior produtividade. Finalmente, para a cinco culturas que não apresentaram convergência- $\beta$ absoluta, testouse a presença de convergência- $\beta$ condicional, usando como variáveis explicativas a produtividade inicial da cultura, a deficiência hídrica e o capital humano. Bons resultados econométricos foram obtidos para a convergência- $\beta$ condicional da produtividade do algodão-herbáceo, da batata-inglesa e do feijão. No entanto, não se obteve resultados satisfatórios para as culturas do arroz e do milho. A partir desses resultados, o trabalho sugere algumas medidas de política econômica capazes de melhorar a convergência da produtividade da terra na agricultura brasileira, em especial para as culturas do arroz e do milho. Isto permitiria uma modernidade mais homogênea na agricultura nacional. 


\section{EVALUATION OF LAND PRODUCTIVITY CONVERGENCE IN BRAZILIAN AGRICULTURE - TIME PERIOD FROM 1960 TO 2001}

Author: JANETE LEIGE LOPES

Adviser: Prof. Dr. CARLOS JOSÉ CAETANO BACHA

\section{SUMMARY}

This work analyzed the behavior of land productivity in the Brazilian agriculture, evaluating if there is or not convergence in the evolution of this variable. The analysis is taken in the time period from 1960 to 2001 and also in some sub-periods of these 42 years, more precisely, the sub-periods of 1970-2001, 1975-2001 and 19802001. The convergence is a process in which the same variable (for example, per capita income, land productivity) presents different values among countries, regions and states, but this difference is reduced during the time, indicating that the inequality decreases. There are several reasons to appear a convergence process, especially the structural changes in the production process, technological diffusion, removal of obstacles in the production growth, among others. The occurrence of the productivity convergence becomes more homogenous the country's agriculture, from the modernity point of view. To reach the objective proposed in the thesis, a theoretical model about convergence in the land productivity was developed, based on Barro and Sala-i-Martin model (1990). Four convergence indicators were used, which are: $\beta$ - convergence, $\sigma$-convergence, groups of convergence and $\beta$-conditional convergence. The data used refer to the productivity of herbaceous cotton, rice, potato, sugar cane, 
beans, tobacco, orange, manioc, corn and soybeans crops, collected from Brazilian Annual Statistical Yearbook. Initially, the presence of $\beta$-convergence was tested for the eleven crops commented above. Only six crops presented this convergence (coffee, sugar cane, tobacco, orange, manioc and soybeans). For the same eleven crops, the presence of $\sigma$-convergence was tested and only soybeans presented it for all the subperiods analyzed and the orange and manioc crops for the period of 1960-2001. This does not invalidate the $\beta$-convergence result, because the literature shows that if there is $\sigma$-convergence, the $\beta$-convergence will necessarily happen, but not vice-versa. For cotton, rice, potato, beans and corn crops the presence of convergence groups was tested, and it was diagnosed for cotton, potato and beans crops that $\beta$-convergence appear among the states with highest productivities. Finally, for the five crops which did not present $\beta$-convergence, the presence of $\beta$-conditional convergence was tested, using initial value of land productivity, hydric deficiency and human capital as explicative variables. Good econometric results were obtained for the cotton, potato and for beans. However, for corn and rice crops not satisfying results were obtained. From these results, the work suggests some policies that are able to improve land productivity convergence in the Brazilian agriculture, especially for rice and corn crops. This would allow a more homogenous modernity in the domestic agriculture. 


\section{INTRODUÇÃO}

\subsection{O problema de pesquisa}

Este trabalho analisa o comportamento da produtividade da terra na agricultura brasileira, avaliando se há ou não convergência na evolução dessa produtividade.

A produtividade pode ser considerada em seu conceito médio e marginal e pode ser avaliada em relação a um fator de produção específico (caso da produtividade parcial) ou a um conjunto de fatores (caso da produtividade total dos fatores). O presente trabalho atém-se à análise da produtividade média e parcial da terra (doravante chamada apenas de produtividade da terra) bem como à análise do comportamento dessa variável nas lavouras brasileiras.

A convergência é um processo em que uma mesma variável (por exemplo, renda per capita, produtividade da terra) apresenta diferentes valores entre países, regiões ou estados, mas essa diferença se reduz ao longo do tempo, indicando que a desigualdade diminui.

As razões para haver um processo de convergência são várias, destacando-se as mudanças estruturais no processo de produção, a difusão tecnológica, a retirada de obstáculos ao crescimento da produção, dentre outras.

Considere o caso da produtividade da terra para uma cultura em um país com diferentes realidades de estrutura de produção e condições de clima, solo e topografia como é o caso da soja, café e cana-de-açúcar no Brasil. O que se espera é o 
desenvolvimento de tecnologias diferentes para distintas realidades regionais, as quais façam com que uma mesma cultura seja lucrativa em diferentes regiões.

Para mensurar convergência, a literatura do crescimento econômico tem usado muitas alternativas. Este estudo utilizará três dessas alternativas ${ }^{1}$ : a convergência$\beta$-absoluta, a convergência- $\sigma$ e a convergência- $\beta$ condicional. Esses modos de definir e medir convergência foram propostos por Barro e Sala-i-Martin (1990, 1991). A seguir, estes conceitos são expostos considerando a variável renda per capita.

Existe convergência- $\beta$ absoluta quando as economias pobres tendem a crescer mais do que as ricas. A suposição chave que está por trás deste conceito é de que tanto os países ricos quanto os pobres possuem preferências, tecnologias e instituições políticas idênticas e que existe um nível de renda de estado-estacionário comum a estes dois grupos de países. Se houver diferenças desses parâmetros entre as economias, o conceito de convergência deve ser modificado através de um modelo no qual se leve em consideração a inclusão de variáveis que possam captar tais diferenças, pois não haveria mais possibilidade de se verificar a existência de convergência- $\beta$ absoluta, mas sim a existência de convergência- $\beta$ condicional.

No entanto, para Sala-i-Martin (1996), quando se considera regiões ou estados dentro de um mesmo país ou grupo de países semelhantes, como é o caso da Organização para Cooperação e Desenvolvimento Econômico (OECD), diferenças institucionais, tecnológicas ou preferenciais são mesmos acentuadas. Portanto, a hipótese de estado-estacionário comum, pode ainda ser considerada.

Defini-se convergência- $\sigma$ como sendo uma queda da dispersão de uma variável (por exemplo, renda per capita), mensurada em termos de desvio-padrão do logaritmo da variável através de um grupo de países ou regiões, ou seja, $\sigma_{t+1}<\sigma_{t}$, onde $\sigma_{\mathrm{t}}$ é o desvio padrão do log da variável de um país determinado no tempo t.

\footnotetext{
${ }^{1}$ Quah (1993), por exemplo, analisa convergência sob a perspectiva da Falácia de Galton.
} 
Embora haja uma relação entre os conceitos de convergência- $\beta$ e convergência- $\sigma$, eles respondem a questões diferentes. Convergência- $\beta$ absoluta mostra se os países ou regiões que estão abaixo de seu estado estacionário crescem mais rápido. Enquanto que convergência- $\sigma$ analisa a tendência da dispersão da variável em análise (por exemplo renda per capita) através do tempo. Isso significa dizer que convergência$\beta$ é condição necessária, mas não suficiente para a ocorrência de convergência- $\sigma$. Portanto, podem ocorrer casos onde se encontre convergência- $\beta$ absoluta, mas não convergência- $\sigma$.

Há um consenso entre os pesquisadores de que a agricultura brasileira, a partir da década de 60 , com maior intensidade na década ${ }^{2}$ de 70 - tem sido marcada por desempenho espetacular em termos de crescimento da produtividade, o qual é decorrente da crescente modernização desse setor. Essa modernização tem sido caracterizada pela adoção de novas inovações tecnológicas e maior uso de capital.

No entanto, o processo de modernização e os ganhos de produtividade não foram homogêneos entre culturas e estados [Dias e Amaral (2001), Bacha (2004)]. É dentro deste contexto que se enxerga a importância deste estudo, em função dele permitir verificar, através da hipótese de convergência, se o esforço conjunto empreendido em prol da modernização da agricultura brasileira conduziu a uma maior igualdade em termos de produtividade das culturas nos estados brasileiros, ou se caminhou no sentido de ampliar o hiato que havia entre eles, particularmente antes da década de 1960 .

\footnotetext{
${ }^{2}$ Veja, por exemplo, Rezende (1989), Gonzales e Costa (1998), Dias e Amaral (2001) Goldin e Rezende (1993), dentre outros.
} 


\subsection{Objetivos}

O objetivo geral desse trabalho é analisar a evolução da produtividade da terra nas 11 principais culturas brasileiras, avaliando o processo de convergência dessa variável entre os principais estados produtores.

A análise compreende o período de 1960 a 2001 e alguns sub-períodos desses 42 anos. Esses sub-períodos são de 1970 a 2001, 1975 a 2001 e de 1980 a 2001. Procurou-se selecionar períodos para os quais há séries consistentes de dados.

As culturas analisadas são: algodão herbáceo, arroz, batata-inglesa, café, cana-de-açúcar, feijão, fumo, laranja, mandioca, milho e soja. A escolha dessas culturas é devido ao fato delas serem as mais importantes em termos de área e valor da produção na agricultura. De acordo com os dados do Censo Agropecuário de 1995/96, realizado pelo Instituto Brasileiro de Geografia e Estatística (IBGE), essas onze culturas foram responsáveis por, aproximadamente, $89 \%$ da área colhida com lavouras.

Especificamente, pretende-se:

i) Descrever e analisar os modelos que formalizaram a idéia de convergência bem como as evidências empíricas contidas nestes modelos, tendo como ponto de partida o estudo pioneiro de Solow (1956);

ii) Analisar a evolução da produtividade e da tecnologia ocorridas na agricultura brasileira, no período de 1960 a 2001;

iii) Analisar preliminarmente as culturas consideradas no estudo e destacar as condições para a ocorrência de convergência da produtividade da terra.

iv) Definir um modelo teórico de convergência da produtividade da terra;

v) Estimar e analisar os resultados do modelo teórico definido em (iv), utilizando os conceitos de convergência- $\beta$, convergência- $\sigma$ e convergência- $\beta$ condicional. 


\subsection{Importância do trabalho}

Espera-se, ao final deste estudo, poder contribuir com a literatura sobre convergência, assim como lançar alguma luz sobre o hiato (se houver), entre os estados brasileiros, no que tange à produtividade agrícola.

Em sendo assim, acredita-se que os resultados desse estudo são importantes na medida em que poderão contribuir para a adoção de políticas agrícolas adequadas que enfatizem as especificidades de cada região. Políticas que levem em consideração os diferentes graus de dificuldades e potencialidades que os setores produtivos das regiões têm.

\subsection{Organização do trabalho}

Para atingir os objetivos propostos, este estudo está organizado em 7 capítulos, incluindo esta introdução. No capítulo 2 faz-se uma revisão dos modelos sobre a hipótese da convergência. Este capítulo teve como ponto de partida o modelo teórico de Solow (1956), no qual a idéia de convergência foi, pela primeira vez, formalizada. A partir deste modelo, acompanhou-se a evolução do tema verificando todas as modificações sugeridas por parte dos pesquisadores, quer quanto aos modelos quer quanto a metodologia adotada. Neste capítulo, procurou-se também verificar como evoluiu a produção científica sobre o tema, no mundo e no Brasil. Em especial, voltouse a atenção para os testes empíricos, com o interesse de observar as semelhanças e diferenças entre as economias analisadas. O capítulo 3 apresenta uma análise da evolução da agricultura brasileira, dando ênfase à evolução tecnológica e da produtividade que ocorreram no período. No capítulo 4 procura-se traçar uma análise preliminar da dinâmica ocorrida com cada uma das onze culturas, consideradas neste estudo. O propósito do capítulo é analisar as condições para a ocorrência, ou não, de convergência da produtividade da terra. No capítulo 5 é desenvolvido um modelo teórico para explicar o processo de convergência da produtividade da terra. O próximo passo é 
apresentar a metodologia, assunto do capítulo 6, assim como os dados sobre as culturas e o período de abrangência da análise. O capítulo 7 apresenta os resultados e as discussões, seguindo a metodologia definida no capítulo 6. Finalmente, o capítulo 8 apresenta as conclusões desse trabalho. 


\section{REVISÃO DE LITERATURA}

Por muito tempo, a teoria convencional do crescimento econômico, cujo paradigma básico havia sido proposto por Solow (1957), considerou que se os países são similares com respeito aos seus parâmetros estruturais, preferências e tecnologias, as taxas de crescimento do capital per capita deveriam estar inversamente relacionadas com seus níveis iniciais de renda per capita (Barro, 1991). Nesse sentido, países ou regiões mais pobres tenderiam a crescer mais do que os países ou regiões ricas. Haveria forças que promoveriam a convergência da renda per capita através dos países ou regiões.

A preocupação com o crescimento econômico declinou durante a década de 1970, ressurgindo nos anos de 1980 e início dos anos de 1990. Insatisfeitos com muitas das implicações do modelo neoclássico de crescimento, que conflitavam com os fatos importantes do mundo real ${ }^{3}$, a hipótese da convergência tornou-se assunto polêmico e de interesse para muitos pesquisadores. Nos últimos anos, muitos economistas têm dedicado especial atenção a esta questão, porque as evidências têm mostrado que a convergência não tem sido uniforme. Romer (1986), Lucas (1988) e Rebelo (1991) deram origem à teoria do crescimento, originando a chamada Teoria do Crescimento Endógeno ${ }^{4}$ ou Nova Teoria do Crescimento.

A Teoria do Crescimento Endógeno (TCE) mostrou que a convergência da renda per capita entre diferentes países não ocorreria de forma automática, como era suposto na teoria tradicional. Aquela teoria incorporou o conceito do capital humano

\footnotetext{
${ }^{3}$ Um dos problemas é o fato da mudança tecnológica ser exógena, cai do céu sem nenhuma explicação.

${ }^{4}$ Para um panorama geral sobre as Teorias do Crescimento Endógeno veja Jones e Manuelli (1997)
} 
como um dos determinantes do crescimento econômico. Muitos dos trabalhos que compõem a TCE têm explorado as implicações dos retornos crescentes e os determinantes da taxa de progresso técnico, chegando a algumas conclusões que, em alguns casos, diferem daquelas alcançadas pelos modelos tradicionais.

Desde 1990, uma grande quantidade de pesquisas sobre crescimento econômico tem analisado a hipótese da convergência da renda per capita, assim como gerado evidências sobre a ocorrência da convergência- $\beta$, convergência- $\sigma$, convergência$\beta$ condicional e da formação de grupos de convergência. A formação de grupos de convergência ocorre quando se observa dentro de um mesmo país a tendência de formação de grupos de estados que convergem entre si, mas como um todo estes estados não convergem o valor de uma variável entre si.

Este capítulo tem como objetivo expor os trabalhos que deram origem à hipótese da convergência, bem como os modelos teóricos que discutiram o assunto e a metodologia que sugeriram. Na seqüência apresenta-se um breve comentário de alguns estudos que analisaram a validade da hipótese da convergência no mundo, porém, ênfase maior será dada para as pesquisas realizadas na economia brasileira. $\mathrm{O}$ interesse deste procedimento é demonstrar que no Brasil, quase todos os estudos realizados estão voltados para a análise da convergência da renda per capita.

\subsection{Convergência: origens e evidências empíricas sobre o tema}

O Modelo de Solow (1957) foi o primeiro modelo de crescimento econômico a mostrar a possibilidade de convergência. Segundo Barro (1993): 
"A predição chave deste modelo (o de Solow) é de que economias mais pobres, inicialmente, com valores mais baixos de capital $\left(K_{0}\right)$ e produto $\left(Y_{0}\right)$ tendem a alcançar aquelas que eram inicialmente mais ricas. As diferenças no estoque de capital e produto são gradualmente eliminadas quando a economia aproxima-se do valor do estadoestacionário comum, $K^{*}$ e $Y^{*}$. Esta tendência para a convergência significa que quanto mais baixos os valores iniciais de $K$ e $Y$, mais alta será a taxa média de crescimento durante a transição". (Barro, 1993, p.279)

Portanto as economias pobres crescerão, em média, mais rapidamente que as economias ricas.

As implicações do modelo neoclássico de crescimento geraram a insatisfação de muitos pesquisadores, em face do conflito existente entre suas predições e os fatos do mundo real. Houve convergência entre os níveis de renda dos estados dos Estados Unidos e entre as regiões da Europa Ocidental. No entanto, vários países da África e alguns países mais pobres da Ásia ficaram ainda mais para trás dos países avançados nos últimos 50 anos. Os níveis de renda relativa dos principais países latinoamericanos caíram em comparação aos da Europa Ocidental e dos Estados Unidos (Gordon, 2000).

Por causa desses resultados diferentes, a hipótese da convergência tem atraído a atenção de muitos pesquisadores, com o objetivo de verificar a existência (ou não) da convergência no mundo real. Um dos primeiros economistas a apresentar evidências estatísticas documentando a convergência entre alguns países e divergência entre outros foi Baumol (1986). Utilizando uma amostra de 16 países ${ }^{5}$ e os dados de Maddison $(1982)^{6}$, o autor, através de uma ilustração gráfica representando o PIB per

\footnotetext{
${ }^{5}$ Austrália, Reino Unido, Bélgica, Canadá, Estados Unidos, Itália, Alemanha Ocidental, França, Noruega, Finlândia, Japão, Suíça, Países baixos, Dinamarca, Noruega e Suécia.

${ }^{6}$ Ver Baumol (1986)
} 
capita para várias economias industrializadas no período de 1870 a 1979, mostra claramente o estreitamento do hiato do PIB entre países. Países que eram relativamente ricos, em 1885, cresceram mais lentamente, enquanto os países que eram relativamente mais pobres cresceram a uma velocidade maior.

De Long (1988) discorda dos resultados de Baumol argumentando que ele havia incorrido num viés de seleção ao escolher 16 economias que já haviam assimilado modernas tecnologias e, portanto, convergido. Quando a amostra considerada por Baumol é ampliada para incluir mais sete nações ${ }^{7}$, os resultados de Baumol não se sustentam, e a convergência não se verifica.

Dentro dessa polêmica, Baumol e Wolf (1988) verificaram que a hipótese de convergência não se sustentava quando a amostra usada por Baumol (1986) era ampliada. No entanto, aqueles autores observaram que há convergência entre grupos de países homogêneos, ou seja, surgem grupos de convergência.

A existência de grupos de convergência foi confirmada por Summers e Heston (1991). Esses autores mostram a taxa de crescimento médio através do tempo na OECD e no mundo durante o período de 1960-85. Eles constataram o declínio na taxa de crescimento após 1973. Observaram também que a performance dos países ricos tem sido bem melhor quando comparada ao total da amostra.

Fuente (1997) analisou dois casos extremos de grupos de países, chamados de Milagres e Desastres do Crescimento. No caso dos Milagres estavam o Japão, Coréia do Sul, Singapura, Hong Kong, Taiwan e Botsuwana. No caso do grupo Desastres do Crescimento estão Moçambique, Angola, Zâmbia, Chad e Madagascar. Do Milagre fazem parte os países que têm mantido, durante muitas décadas, altas taxas de crescimento como é o caso da Coréia do Sul e outros países do sudeste asiático. Já dos Desastres encontramos um importante grupo de países da África que já tinham, antes de 1960, uma renda relativa abaixo da média e que declinou dramaticamente através do

\footnotetext{
${ }^{7}$ De Long (1988) amplia a amostra de Baumol (1986) para incluir as economias da Argentina, Chile, Irlanda, Nova Zelândia, Portugal, Espanha e Alemanha Oriental mas o Japão é excluído da amostra inicial.
} 
período. Observou-se que a dispersão da renda per capita tem aumentado através do tempo. Entretanto, essa desigualdade tem caído significativamente se a análise for restrita a um grupo de países ricos, dentre os quais a convergência tem se verificado.

\subsection{Modelos teóricos de crescimento e convergência}

Após o surgimento do Modelo de Solow e de suas ramificações houve poucas construções teóricas relacionando crescimento e convergência, em especial na década de 1970. O ressurgimento desse tipo de modelo se deu na década de 1980, com os trabalhos de Romer (1986) e Lucas (1988). A partir de então, a teoria do crescimento ressurge com um enfoque diferente, dando origem à Nova Teoria do Crescimento. Ao considerar o progresso técnico como endógeno - que nos modelos tradicionais era tomado como exógeno - esta teoria revolucionou a análise dos determinantes do crescimento econômico de longo prazo. A Nova Teoria do Crescimento mostrou que a convergência da renda per capita entre diferentes países não ocorreria de forma automática (como era suposto na teoria tradicional) e incorporou o conceito do capital humano como um dos determinantes do crescimento econômico.

Muitos dos trabalhos da Nova Teoria do Crescimento têm explorado as implicações dos retornos crescentes e os determinantes da taxa de progresso técnico, chegando a algumas conclusões que, em alguns casos, diferem daquelas alcançadas pelos modelos tradicionais. Ao endogenizar as fontes de crescimento, esta teoria atribuiu o crescimento na produção a externalidades criadas por investimentos em capital humano e tecnologia. Esse é o caso dos trabalhos de Romer $(1986,1987)$ e Lucas (1988).

Romer (1986) argumenta que economias de escala agregadas podem inverter as predições neoclássicas de taxas de crescimento decrescente e convergência entre os países. Isso porque, com retornos crescentes dos fatores reproduzíveis, o retorno do 
investimento é uma função crescente do estoque de capital acumulado. Como um resultado, a taxa de crescimento aumentará com o tempo e com o nível de renda.

Esta análise é aperfeiçoada por Lucas (1988), ao acrescentar o "capital humano" - soma de todo o conhecimento humano de uma nação. O capital físico é livre para se movimentar entre países, mas o capital humano não é. Então, como um país pobre poderá enriquecer se tiver pouco capital humano, uma vez que este ficará sob a dependência apenas do acumulo em capital físico? Para Lucas, o investimento em pesquisa e educação é a chave para obter o crescimento econômico.

Após a publicação do trabalho pioneiro de Romer (1986), um renovado interesse emergiu por parte dos pesquisadores, impulsionados pelas idéias sobre a ausência de retornos decrescentes do capital, uma vez que este era o motivo para a ocorrência de convergência.

Entre os anos de 1990 e 1992, Barro e Sala-i-Martin publicam três $\operatorname{artigos}^{8}$ sobre convergência e crescimento econômico, nos quais os autores discutem três conceitos de convergência: Convergência- $\beta$, Convergência- $\sigma$ e Convergência- $\beta$ Condicional. Estes conceitos acabariam por se tornar a base da discussão de muitos trabalhos que se seguiram e em vários países do mundo.

Também no início da década de 1990, Mankiw et al. (1992) expandiam o modelo de Solow (1957) de modo a incluir o capital humano e avaliar o processo de convergência.

Nos próximos dois itens são expostos os modelos de Solow (1956 e 1957) e Barro e Sala-i-Martin (1990, 1991 e 1992). O objetivo é ressaltar de que modo eles consideraram a convergência, qual é a equação básica a ser estimada e como esses modelos se relacionam entre si.

\footnotetext{
${ }^{8}$ Estes artigos constam das "Referências Bibliografias" e foram publicados em 1990, 1991 e 1992.
} 


\subsubsection{Modelo de Solow}

Solow desenvolveu dois modelos de crescimento econômico que são o ponto de partida dos demais modelos de crescimento econômico que tratam da questão da convergência. O primeiro modelo de Solow (Solow, 1956) não considerava a tecnologia na função de produção e mostra a convergência de uma economia para o seu estado estacionário, ou seja, a convergência de uma economia para um certo nível de produto per capita. O segundo modelo de Solow (Solow, 1957) incorpora a inovação tecnológica na função de produção e gera o que ficou conhecido na literatura econômica como "Resíduo de Solow".

A importância do estudo desses dois modelos de Solow está no fato de que, a partir deles, muitos autores passaram a discutir o tema convergência considerando diversas variantes dos modelos de Solow, ora confirmando ora negando a existência de convergência. Barro e Sala-i-Martin (1990 e 1992) utilizando uma função de produção que considera a inovação tecnológica desenvolvem, a partir do Modelo de Solow (1956), uma expressão algébrica para medir convergência- $\beta$, convergência- $\sigma$ e convergênciacondicional, o que até então havia sido ilustrada apenas graficamente.

\subsubsection{Modelo de Solow sem tecnologia}

No primeiro modelo, composto por duas equações básicas, Solow (1956) considera que a economia produz e consome uma única mercadoria. Considera-se que a produção, designada por $Y(t)$, é em parte consumida e o restante é poupado e investido.

Designando a fração poupada do produto por uma constante s, o fluxo de poupança pode ser representado por $s \cdot Y(t)$ e o estoque de capital, na forma de acumulação do capital, por $K(t)$. O investimento é, então, o aumento neste estoque de

capital, dado por $\frac{d K}{d(t)}$ ou $\Delta K$. Logo, a equação para a taxa de crescimento do capital, 
menos uma fração constante $\delta$ do capital, que é a depreciação a cada período de tempo $(\delta \cdot K)$, é dada por:

$$
\Delta K=s \cdot Y-\delta \cdot K
$$

O produto, produzido com a ajuda de apenas dois insumos - capital $(K)$ e trabalho $(L)$ - é definido pela equação:

$$
Y=F(K, L)
$$

Trata-se de uma função de produção que apresenta retornos constantes à escala, implicando que $F(\alpha K, \alpha L)=\alpha Y$, ou seja, duplicando os insumos, o produto dobrará.

Os produtos marginais do capital e do trabalho são positivos, mas decrescentes, significando que $F_{K}=\frac{\partial Y}{\partial K}>0$ e $F_{L}=\frac{\partial Y}{\partial L}>0 \quad$ e $\quad F_{K K}=\frac{\partial^{2} Y}{\partial K^{2}}<0$ e $F_{L L}=\frac{\partial^{2} Y}{\partial L^{2}}<0$. Não há recursos não aproveitáveis, não há comércio internacional e nem progresso técnico, e pelas condições de Inada, $\lim _{K \rightarrow 0}\left(F_{K}\right)=\lim _{L \rightarrow 0}\left(F_{L}\right)=\infty \quad \mathrm{e}$ $\lim _{K \rightarrow \infty}\left(F_{K}\right)=\lim _{L \rightarrow \infty}\left(F_{L}\right)=0$.

Substituindo a equação (2) na equação (1), obtém-se:

$$
\Delta K=s \cdot F(K, L)-\delta \cdot K
$$

Considerando que o crescimento da população, $\Delta L / L$, é exógeno e que a força de trabalho aumenta a uma taxa constante relativa $n$, então, na ausência de progresso técnico, $n$ será a taxa natural de crescimento de Harrod (1939). Tem-se:

$$
L(t)=L_{0} \cdot e^{n-t}
$$


Substituindo a equação (4) na equação (3), tem-se que:

$$
\Delta K=s \cdot F\left(K, L_{0} \cdot e^{n \cdot t}\right)-\delta \cdot K
$$

Esta expressão determina, a qualquer tempo, a acumulação de capital que pode ser atingida se todo trabalho disponível estiver sendo empregado.

Expressando a função de produção em termos per capita e chamando $\kappa=\frac{K}{L}$ e $y=\frac{Y}{L}$, representando, respectivamente, o capital e o produto per capita, a equação (2) pode ser reescrita como:

$$
y=f(\kappa)
$$

Esta expressão mostra que o produto per capita é função do capital per capita. Assim, para que $y$ aumente, é preciso aumentar o estoque de capital per capita.

Da equação (3) tem-se que $\Delta K=s \cdot F(K, L)-\delta \cdot K$. Em termos per capita, fica:

$$
\frac{\Delta K}{L}=s \cdot y-\delta \cdot \kappa
$$

Por definição, tem-se que a expressão do capital per capita é dado por $\frac{K}{L}=\kappa$

Tomando-se o logaritmo neperiano de ambos os lados, tem-se: $\ln K-\ln L=\ln K$. Diferenciando-a em relação ao tempo, tem-se:

$$
\frac{\partial \ln K}{\partial t}-\frac{\partial \ln L}{\partial t}=\frac{\partial \ln \kappa}{\partial t} \Rightarrow \frac{\Delta K}{K}-\frac{\Delta L}{L}=\frac{\Delta \kappa}{\kappa} \quad \text { ou }
$$




$$
\frac{\Delta K}{K}=\frac{\Delta K}{K}-\frac{\Delta L}{L}
$$

ou seja, a taxa de crescimento do capital per capita é igual a taxa de crescimento do capital menos a taxa de crescimento da população. Como $\frac{\Delta L}{L}=n$, então,

$$
\frac{\Delta \kappa}{\kappa}=\frac{\Delta K}{K}-n
$$

Multiplicando os três membros da equação (9) por $K$ e dividindo por $L$, obtém-se:

$$
\frac{\Delta \kappa}{\kappa} \cdot \frac{K}{L}=\frac{\Delta K}{K} \cdot \frac{K}{L}-n \cdot \frac{K}{L}
$$

Eliminando os termos em comum, tem-se:

$$
\begin{aligned}
& \Delta \kappa=\frac{\Delta K}{L}-n \cdot \frac{K}{L} \quad \text { ou, } \\
& \Delta \kappa+n \cdot \frac{K}{L}=\frac{\Delta K}{L}
\end{aligned}
$$

Da equação (7) tem-se que $\frac{\Delta K}{L}=s \cdot y-\delta \cdot \kappa$. Substituindo-a na equação (10) tem-se:

$$
\Delta \kappa+n \cdot \frac{K}{L}=s \cdot y-\delta \cdot k
$$

Rearranjando os termos, tem-se:

$$
\Delta k=s \cdot y-(n+\delta) \cdot k
$$

Da equação (11), conclui-se que: 
(i) se, $s \cdot y>(n+\delta) \cdot \kappa \Rightarrow \Delta \kappa>0$;

(ii) se, $s . y<(n+\delta) . \kappa \Rightarrow \Delta \kappa<0$; e,

(iii) se, s.y $=(n+\delta) \cdot \kappa \Rightarrow \Delta \kappa=0$.

Dito de outra forma, se o investimento bruto for maior que o crescimento da população mais a depreciação do capital, como em (i), o valor do capital per capita aumentará, ocorrendo o contrário no caso (ii). Mas, em (iii), se o investimento bruto crescer na mesma proporção da soma do crescimento da população e da depreciação, o valor do capital per capita permanecerá estável.

No modelo de Solow, a economia irá convergir para a equação (iii). Graficamente é possível analisar este processo de convergência. Considere a Figura 1: 


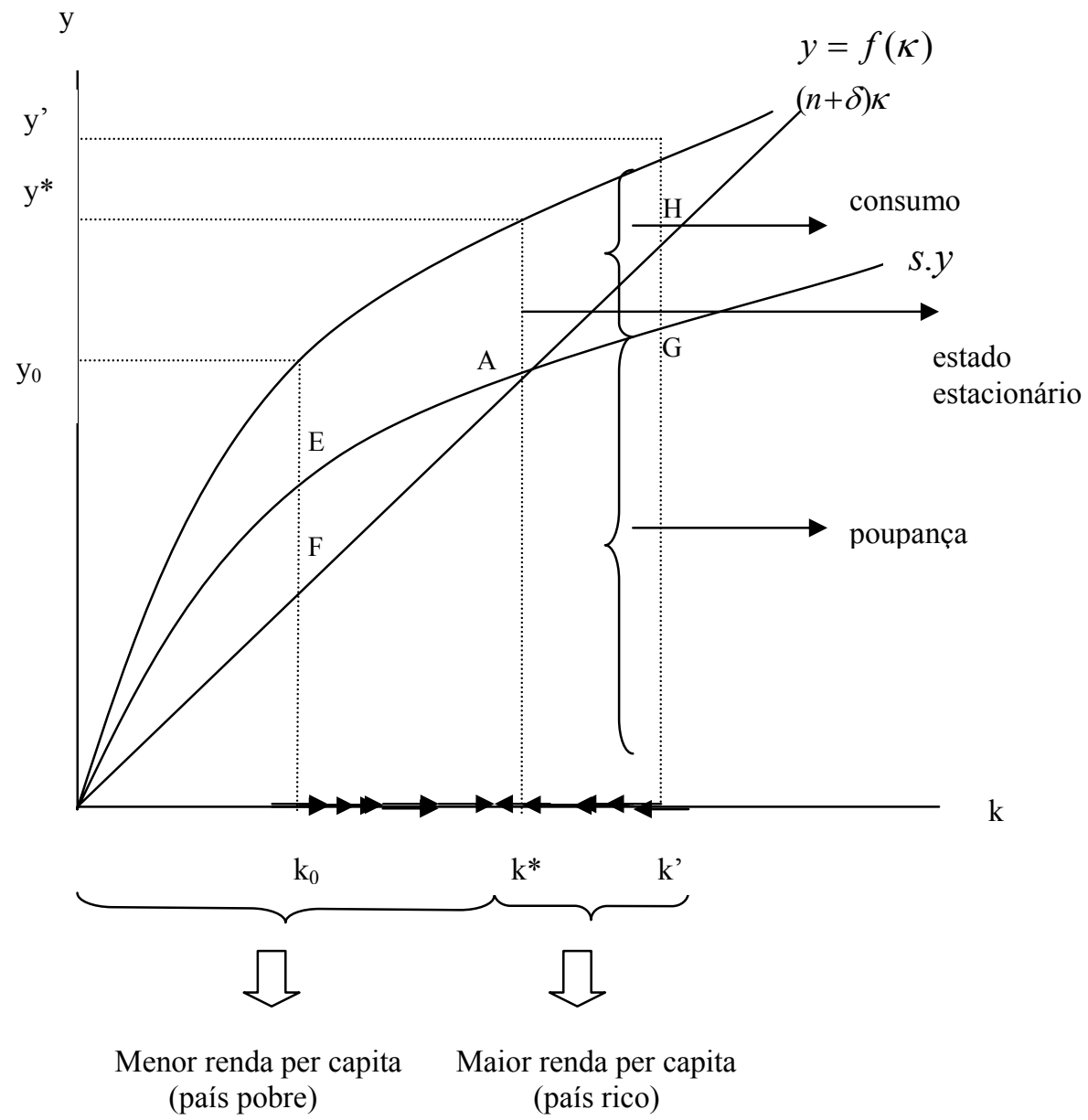

Figura 1 - Convergência no Modelo de Solow

Fonte: Jones (2000)

Dado o valor $\mathrm{k}_{0}$, o montante de investimento/trabalhador (ponto E) é superior ao necessário para manter constante o capital per capita (ponto F), então, $\mathrm{k}$ aumentará ao longo do tempo até que se torne igual a $\mathrm{k}^{*}$, ou, no ponto em que $s \cdot y=(n+\delta) \kappa$, de modo que $\Delta \mathrm{k}=0$. Este ponto (ponto A) é denominado de Estado Estacionário. À direita de $\mathrm{k}^{*}$, em $\mathrm{k}^{\prime}$, tem-se $\mathrm{o}$ inverso, o montante de investimento/trabalhador (ponto $G$ ) é menor do que a quantidade que a economia 
necessita para manter constante o capital por trabalhador (ponto $\mathrm{H}$ ). Neste caso, o montante de capital per capita começa a se reduzir até $\mathrm{k}^{*}$.

Os países pobres se encontram em pontos como $\mathrm{E}$ e $\mathrm{F}$ e os países ricos em pontos como G e H. Para ambos convergirem para o ponto A (e terem a mesma renda per capita, $\left.\mathrm{y}^{*}\right)$ é necessário que os países pobres cresçam a ritmo maior que os países ricos.

Mas o estado-estacionário da Figura 1 (ponto A) pode ser alterado no tempo.

Suponha, agora, que a economia se encontra em seu estado estacionário (ponto A na Figura 2) e que seus consumidores decidem aumentar a taxa de investimento, ou seja, aumentar s. O que acontecerá com $\kappa$ e y? A Figura 2 responde essa questão.

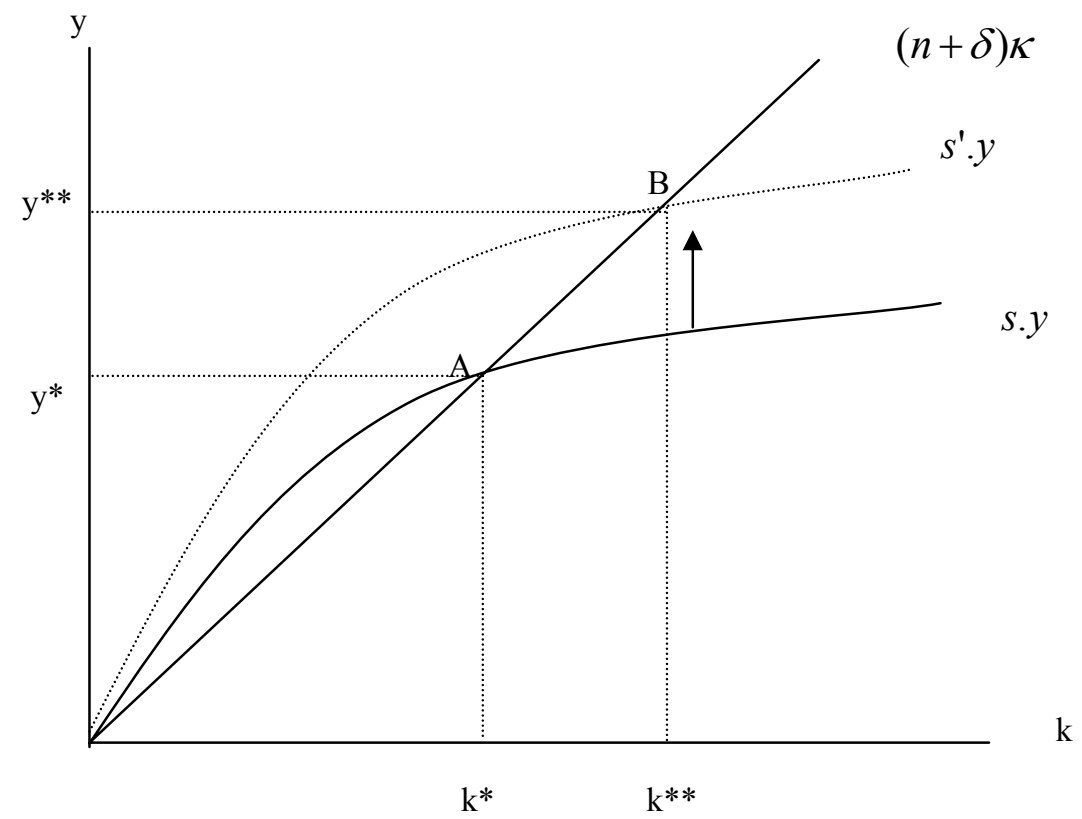

Figura 2 - Efeitos do aumento da taxa de investimento (s) no Modelo de Solow Fonte: Jones (2000) 
$\mathrm{O}$ aumento na taxa de poupança (aumento de s) provoca um deslocamento da curva $s \cdot y$ para cima, que passa a ser agora representada pela linha pontilhada $s^{\prime} \cdot y$. Neste novo cenário, quando se tem $\mathrm{k}^{*}$, obtém-se ${ }_{s^{\prime} y>(n+\delta) \kappa}$. Logo, a taxa de crescimento do capital per capita se expandirá, até o ponto em que $s^{\prime} \cdot y=(n+\delta) \kappa$. Veja que um estoque maior de capital por trabalhador $\left(\mathrm{k}^{* *}\right)$ gera um produto per capita maior $\left(\mathrm{y}^{* *}\right)$. Portanto, a economia tornou-se mais rica que antes.

Considere agora um aumento na taxa de crescimento da população (aumento em $n$ ). Neste caso, o investimento por trabalhador é insuficiente para manter constante a razão capital-trabalho. Sendo assim, a razão capital-produto se reduz e o país, por conseqüência, torna-se mais pobre do que era antes.

O modelo de Solow deixa evidente que os países que possuem um nível de poupança mais elevado terão, certamente, um nível de renda maior. Contudo, em função do produto por trabalhador ser constante no estado-estacionário, o modelo de Solow não gera crescimento sustentado na renda per capita, ou seja, se a economia estiver experimentando um estoque de capital por trabalhador inferior ao exigido no estado estacionário, $\kappa$ e y crescerão, mas este crescimento tornar-se-á menos acentuado quanto mais próxima do estado-estacionário estiver a economia até, finalmente, parar. Esta desaceleração no crescimento ocorre porque quando $\kappa$ aumenta, tornando menor a relação $y / \kappa$ decorrente dos retornos decrescentes.

Observe que Solow (1956) demonstra esta tendência de convergência para o estado estacionário utilizando-se apenas da análise gráfica. Além disso, não se considera a presença do progresso tecnológico na explicação do crescimento do produto per capita. 


\subsubsection{Modelo de Solow com tecnologia}

Solow (1957) expandiu o modelo desenvolvido em 1956 para considerar a tecnologia. Embora reconhecendo que existe progresso técnico o modelo não explica a origem da tecnologia.

O modelo de Solow (1957) utiliza uma função de produção do tipo $Y=K^{\alpha}(A L)^{1-\alpha}$ no qual o crescimento do produto ocorre a partir da soma do capital (K), trabalho (L) e tecnologia (A). Tomando o logaritmo neperiano dessa expressão e diferenciando em relação ao tempo, tem-se ${ }^{9}$.

$$
\frac{\Delta Y}{Y}=\alpha \frac{\Delta K}{K}+(1-\alpha)\left(\frac{\Delta L}{L}+\frac{\Delta A}{A}\right)
$$

Considere $\left(\frac{\Delta A}{A}\right)=\mathrm{g}$, onde $\mathrm{g}$ é um parâmetro que representa a taxa de crescimento tecnológico. Suponha que $g=A_{0} \cdot e^{g_{A} \cdot t}$, ou seja, existe um nível tecnológico que cresce à taxa g ao longo do tempo.

Reescrevendo a função de produção em termos per capita temos,

$$
\begin{aligned}
& \frac{Y}{L}=\left(\frac{K}{L}\right)^{\alpha}\left(\frac{A L}{L}\right)^{1-\alpha} \text { ou seja, } \\
& y=k^{\alpha} A^{1-\alpha}
\end{aligned}
$$

Tirando os logaritmos neperianos de ambos os lados da equação (13) acima e derivando em relação ao tempo, tem-se:

$$
\frac{\Delta y}{y}=\alpha \frac{\Delta \kappa}{\kappa}+(1-\alpha) \frac{\Delta A}{A}
$$

\footnotetext{
${ }^{9}$ Ao se aplicar a equação (12) para explicar o crescimento da economia norte-americana, constatou-se que muito pouco do crescimento se deve à acumulação de capital $(0,8 \%)$, pouco mais de $1 \%$ à força de trabalho e $1,1 \%$ permaneceu inexplicado (atribuído à variável $\mathrm{A}$ ). Essa tecnologia (A), principal fator que gera crescimento econômico, não é explicada, e é chamada de Resíduo de Solow.
} 
chamando:

$$
g_{y}=\frac{\Delta y}{y}, \quad g_{\mathrm{K}}=\frac{\Delta \mathrm{K}}{\mathrm{K}} \quad \text { e } \quad g=\frac{\Delta A}{A} \quad \text { e substituindo na equação (14), }
$$

temos que:

$$
g_{y}=\alpha \cdot g_{\kappa}+(1-\alpha) \cdot g
$$

Como no estado estacionário $\frac{\Delta y}{y}=\frac{\Delta \kappa}{\kappa}$, segue-se que $\mathrm{g}_{\mathrm{y}}=\mathrm{g}_{\mathrm{k}}, \operatorname{logo}$, a equação (15) pode ser escrita como:

$$
\begin{aligned}
& g_{y}=\alpha \cdot g_{y}+(1-\alpha) \cdot g \\
& (1-\alpha) \mathrm{g}_{\mathrm{y}}=(1-\alpha) \mathrm{g} \\
& \mathrm{g}_{\mathrm{y}}=\mathrm{g}
\end{aligned}
$$

Da equação (16) conclui-se que a taxa de crescimento da renda per capita é igual à taxa de crescimento da tecnologia. A acumulação de fatores conduz a economia mais rapidamente para o estado-estacionário, mas seu nível de estado-estacionário só irá se alterar se ocorrer mudança tecnológica. O modelo revela, portanto, que a tecnologia é a fonte do crescimento do produto per capita sustentado. 


\subsubsection{Convergência no Modelo de Barro e Sala-i-Martin}

A partir das pressuposições teóricas do Modelo de Solow ${ }^{10}$ (1956), Barro e Sala-i-Martin (1990, 1991), assumindo uma função de produção com inovação tecnológica, introduziram duas formas de medir convergência, denominadas de convergência- $\beta$ e convergência- $\sigma$. Através desses conceitos, Barro e Sala-i-Martin (1990, 1991) procuraram destacar as diferenças e similaridades dos vários tipos de convergência.

Para apresentar a contribuição desses autores para a teoria da convergência, dividiu-se este item em duas partes. Inicialmente, apresenta-se o Modelo de Barro e Sala-i-Martin (1990) que trata dos Modelos de convergência- $\beta$ e $\sigma$ e em seguida apresenta-se o trabalho de Barro e Sala-i-Martin (1991) onde os autores formularam os Modelos de convergência- $\beta$ e $\sigma$ condicionais.

\subsubsection{Modelos de convergência $\beta$ e $\sigma$}

Barro e Sala-i-Martin (1990), analisaram o crescimento da renda e do produto per capita de 48 estados dos Estados Unidos. Os dados analisados sobre a renda e o produto per capita correspondem ao período de 1880 a1990.

O objetivo dos autores (Barro e Sala-i-Martin) era encontrar evidências a favor da hipótese da convergência predita pelas teorias do crescimento neoclássico, ou seja, "(...) se as regiões ou países pobres tendem a crescer mais rápido que as ricas: há forças automáticas que conduzem à convergência nos níveis de renda e produto, através do tempo?” Barro e Sala-i-Martin (1990, p.1).

A função de produção utilizada por Barro e Sala-i-Martin (1990) foi:

$$
Y=F\left(K, L e^{g t}\right)
$$

\footnotetext{
${ }^{10}$ No modelo de Solow (1956) apenas a hipótese de convergência- $\beta$ foi analisada através de instrumental gráfico, porém, a função de produção utilizada por Solow (1956) não considerava a tecnologia.
} 
onde, $Y$ é o fluxo do produto e $K$ é o estoque de capital, $e^{\text {gt }}$ representa o efeito do progresso tecnológico exógeno, aumentador de trabalho e L é a força de trabalho. Como a escolha entre trabalho e lazer é negligenciada, o modelo assume pleno emprego da força de trabalho. Para os autores, a "chave" para o entendimento da convergência são os retornos decrescentes do capital. Sendo assim, o modelo satisfaz a condição de que $f^{\prime}>0$ e $f^{\prime \prime}<0$, tanto quanto os retornos constantes à escala.

Como se trata de uma economia fechada, então, o produto é investido ou é consumido, C. O consumidor maximiza sua utilidade através de:

$$
\operatorname{Max} U=\int_{0}^{\infty} u(c) e^{n t} e^{\rho t} d t
$$

Sujeito a: $\quad \Delta \widetilde{k}=f(\widetilde{k})-\widetilde{c}-(n+g+\delta) \widetilde{k}$

A letra minúscula e o acento til $(\sim)$ indicam que a variável está em termos de unidades de eficiência. Além disso, supõe-se que na equação (18) $c=\mathrm{C} / \mathrm{L}, \rho$ é a taxa de desconto intertemporal e $u(c)=\frac{c^{1-\theta}-1}{1-\theta}$ sendo $\theta>0$ de modo que a utilidade marginal, $u^{\prime}(c)$, tem elasticidade constante $\theta$ com respeito a $c$ e na equação (19) $\widetilde{c}=\frac{C}{L_{0} \cdot e^{n . t}}, n$ é a taxa exógena de crescimento da população e, portanto, da força de trabalho L, g é a taxa de progresso tecnológico e $\delta$ é a taxa de depreciação do capital.

Pelas condições de $1^{\underline{a}}$ ordem da equação (18), tem-se que:

$$
\frac{\Delta c}{c}=\left(\frac{1}{\theta}\right) \cdot\left[f^{\prime}(\tilde{k})-\delta-P\right]
$$

Barro e Sala-i-Martin (1990) utilizam uma função de produção tipo CobbDouglas, da seguinte forma:

$$
\tilde{y}=f(\widetilde{k})=(\widetilde{k})^{\alpha}
$$


A solução para a renda em unidades de eficiência, $\log [\widetilde{y}(t)]$ é:

$$
\log [\widetilde{y}(t)]=\log [\widetilde{y}(0)] \cdot e^{-\beta t}+\log \left(\widetilde{y}^{*}\right) \cdot\left(1-e^{-\beta t}\right)
$$

O parâmetro positivo $\beta$, que determina a velocidade de convergência, é dado pela expressão ${ }^{11}$ :

$$
2 \beta=\left\{h^{2}+4\left(\frac{1-\alpha}{\theta}\right) \cdot(P+\delta+\theta g) \cdot\left[\frac{P+\delta+\theta g}{\alpha}-(n+\delta+g)\right]\right\}^{1 / 2}-h
$$

onde, $\mathrm{h}=\mathrm{P}-\mathrm{n}-(1-\theta) \mathrm{g}>0$.

A equação (23) expressa a dependência de $\beta$ que está por trás dos parâmetros, indicando a natureza desses relacionamentos. Como já mencionado, os elementos cruciais nos modelos neoclássicos para a convergência são os retornos decrescentes de capital definido pela extensão da participação do capital (coeficiente $\alpha$ ) na função de produção (21). A extensão dos retornos decrescentes tem um forte efeito sobre o parâmetro $\beta$. Quanto menor o valor do coeficiente $\alpha$ maior será o valor de $\beta$ e, portanto, mais rápida a convergência. Isto implica que a metade do hiato entre o log da taxa de crescimento da renda no tempo zero $\left[\log \hat{y}\left(t_{0}\right)\right]$ e o $\log$ da taxa de crescimento de estado-estacionário $\left\lfloor\log \left(\hat{y}^{*}\right)\right\rfloor$ desaparecerá em menos tempo (definido em anos) do que se o coeficiente $\alpha$ for maior e o valor de $\beta$ menor.

A taxa média de crescimento do produto per capita, y, entre o intervalo 0 e $\mathrm{T}$ é dada por:

$$
\frac{1}{T} \cdot \log \left[\frac{y(T)}{y(t o)}\right]=g+\frac{\left(1-e^{-\beta t}\right)}{T} \cdot\left[\log \left(\frac{\tilde{y}^{*}}{\tilde{y}(t o)}\right)\right]
$$

\footnotetext{
${ }^{11}$ Para melhor entendimento da linearização efetuada por Barro e Sala-i-Martin (1990) recomenda-se a leitura do trabalho de Ferreira e Ellery Junior (1994) onde o processo foi realizado passo a passo.
} 
Dado $\widetilde{y}^{*}$, ou o produto por unidade efetiva de trabalho de estado estacionário, a taxa de crescimento será mais alta quanto mais baixo for o valor de $\log \left[\tilde{y}\left(t_{0}\right)\right]$ Quanto mais alto o valor de $\beta$, afetando a expressão $\frac{\left(1-e^{-\beta t}\right)}{T}$, menor será o tempo (definido em anos) para que a economia se aproxime de seu estado-estacionário, ou seja, mais rapidamente ocorrerá a convergência entre $\log \left(\widetilde{y}^{*}\right)$ e $\log \left(\widetilde{y}\left(t_{0}\right)\right)$.

Dois conceitos de convergência emergem dos trabalhos de Barro e Sala-iMartin e têm sido alvos de discussões sobre crescimento econômico através dos países ou regiões: o primeiro tipo, conforme já mencionado, é denominado de convergência- $\beta$. A estimativa desse parâmetro numa regressão é interpretado como a velocidade de convergência, ou a taxa ao qual $\tilde{y}_{i, t}$ aproxima-se de seu estado estacionário $\tilde{y}_{i}{ }^{*}$, onde $\mathrm{i}=1,2,3, \ldots, \mathrm{n}$ que pode representar país, região ou estado. $\mathrm{O}$ segundo conceito, chamado de convergência- $\sigma$, refere-se à dispersão cross-section dos valores de uma variável. Neste contexto, convergência ocorre se a dispersão, medida pelo desvio padrão do logaritmo de uma variável (por exemplo, da renda per capita ou produto de um grupo de países ou região), declinar através do tempo ${ }^{12}$.

Considere uma versão da equação (24), aplicada para períodos discretos e expandida para incluir um distúrbio, da forma:

$$
\frac{1}{T} \cdot \log \left[\frac{y_{i, t}}{y_{i, t-1}}\right]=a_{i}-\left(1-e^{-\beta}\right) \cdot\left[\log \left(y_{i, t-1}\right)-g_{i} \cdot(t-1)\right]+u_{i t}
$$

onde, $a_{i}=a=$ constante, implicando que no estado-estacionário o valor de $\widetilde{y}_{i}^{*}$ é o mesmo para todas as economias. $\mu_{\text {it }}$ é um distúrbio aleatório que tem média zero e variância $\sigma_{u}{ }^{2}$ e é distribuído independentemente do $\log y_{i, t-1}$. A tendência no tempo,

\footnotetext{
12 Em Barro e Sala-i-Martin (1992) e Sala-i-Martin (1996) o conceito de convergência- $\beta$ e de convergência- $\sigma$ são também discutidos.
} 
definida como sendo $g_{i} \cdot(t-1)$, que reflete o progresso tecnológico exógeno, é também assumido como sendo o mesmo para todas as economias.

As hipóteses de que $a_{i}=a$ e $\mathrm{g}_{\mathrm{i}}=\mathrm{g}$ (mesmo estado-estacionário e mesmo taxa de progresso tecnológico para todas as economias) implicam que as economias que são pobres tenderão a crescer incondicionalmente mais do que as economias ricas se $\beta>$ 0 , com $\beta$ entre zero e um. Dito de outra forma, se $\beta>0$, então se está diante do tipo de convergência- $\beta$ absoluta mas o fato de $\beta>0$ não significa que a dispersão do $\log \left(y_{i, t}\right)$ decline através do tempo.

Se $\mu_{\mathrm{it}}$ é distribuído independentemente através do tempo com média zero e variância $\sigma_{\mathrm{u}}^{2}$, então, a dispersão do $\log _{i, t}$ entre as economias, denotado por $\sigma_{\mathrm{t}}^{2}$, evolui da forma:

$$
\sigma_{t}^{2}=\left(e^{-2 \beta}\right) \sigma_{t-1}^{2}+\sigma_{u}^{2}
$$

se $\sigma_{\text {ut }}^{2}$ é igual a uma constante $\sigma_{u}^{2}$ e $\sigma^{2}{ }_{0}$ é a variância do $\log _{i_{i_{0}}}$ então a solução de diferenças-primeira da equação (26) é:

$$
\sigma_{t}^{2}=\frac{\sigma_{u}^{2}}{1-e^{-2 \beta}}+\left(\sigma_{0}^{2}-\frac{\sigma_{2 u}}{1-e^{-2 \beta}}\right) e^{-2 \beta t}
$$

Esta equação implica que $\sigma_{\mathrm{t}}^{2}$ aproxima-se do valor de estado-estacionário $\sigma^{2}=\frac{\sigma_{u}^{2}}{1-e^{-\beta}}$

Um valor positivo de $\beta$ é condição necessária, mas, não suficiente para convergência- $\sigma$, ou seja, a dispersão da renda pode decrescer somente se os países pobres crescerem, em média, mais do que os ricos. 
A estimativa empírica de $\beta$ para os estados norte-americanos, obtida por Barro e Sala-i-Martin (1990), foi de pouco mais de $2 \%$ ao ano. Quanto à Convergência$\sigma$, ou ao comportamento do desvio padrão $\left(\sigma_{t}\right)$ do $\log$ da renda per capita $\left(\log \mathrm{y}_{\mathrm{it}}\right)$, observou-se que a dispersão declinou entre 1880 e 1920. De 1920 a 1930 houve aumento da dispersão devido ao choque dos preços agrícolas, assim como a partir de 1980, justificado pelo aumento o preço relativo do petróleo. Ao se considerar o período como um todo (1880-1990) pode-se afirmar que a tendência geral foi de queda da dispersão.

\subsubsection{Modelo de Convergência - $\beta$ Condicional}

Barro e Sala-i-Martin (1991) e Sala-i-Martin (1996) ${ }^{13}$ aplicaram a mesma estrutura do modelo de Barro e Sala-i-Martin (1990) para analisar os países da OECD. A diferença entre o trabalho de 1990 e 1991, é que este último implica uma forma de convergência- $\beta$-condicional ${ }^{14}$.

Para testar a hipótese de convergência- $\beta$ condicional, estima-se a equação:

$$
\left.\frac{1}{T} \operatorname{lo} \oint \frac{y_{T}}{y_{0}}\right)=g+\frac{\left(1-e^{\lambda T}\right)}{T} \log y_{0}{ }_{0}+\frac{\left(e^{\lambda T}-1\right)}{T} \log y_{0}+\text { outras variáveis }+\varepsilon_{0, T}
$$

Esta equação, conforme salienta Sala-i-Martin (1996), sugere a estimação de regressão múltipla, onde a variável dependente corresponde à taxa média de crescimento do produto per capita, y, entre o intervalo 0 e $\mathrm{T}, g+\frac{\left(1-e^{\lambda T}\right)}{T} \log y_{0}{ }_{0}=$ constante, $\frac{\left(e^{\lambda T}-1\right)}{T}=\beta, \lambda$ representa o tempo que levará para que uma economia aproxime-se de seu estado-estacionário e a inclusão das variáveis adicionais (outras variáveis) vai depender do tipo de análise que se pretende. Diferentes modelos sugerem diferentes variáveis adicionais.

\footnotetext{
${ }^{13}$ Veja Sala-i-Martin (1996), onde o autor retoma a discussão sobre convergência regional.

${ }^{14}$ Em Barro e Sala-i-Martin (1992) o conceito de convergência- $\beta$ condicional é também discutido.
} 
De acordo com Sala-i-Martin (1996), mais de 50 variáveis têm sido consideradas pelos autores. Contudo a suposição de estado-estacionário, comum para todas as economias, ainda é mantida.

Ao estimar a equação (28) os resultados obtidos pelos autores em 1991 foram similares aos já obtidos em 1990 para os estados dos Estados Unidos, ou seja, a velocidade de convergência- $\beta$ através das economias da OECD gira em torno de $2 \%$ ao ano ${ }^{15}$.

Para o caso da Alemanha, Reino Unido, Itália, França e Espanha, salvo em alguns períodos onde a dispersão aumentou, nota-se um padrão global de declínio de $\sigma^{2}{ }_{t}$ através do tempo, para cada país considerado.

\subsubsection{Evidências econométricas sobre convergência no mundo}

Há uma ampla literatura estimando econometricamente o processo de convergência. Os quadros numerados de 4 a 10 do anexo A trazem alguns exemplos desses trabalhos. A maioria desses trabalhos se preocupou com a convergência da renda per capita e estimou a equação (25), definida em Barro e Sala-i-Martin (1990). Confirmando as análises gráficas ressaltadas no item 2.1, os trabalhos econométricos comentados nos Quadro 4 a 10 também não são conclusivos sobre a presença ou não de convergência. Esta é confirmada em alguns casos (como entre os estados da Suécia entre 1911 e 1993), mas não em outros casos (como na Turquia, entre 1980 e 1997). Também há casos em que a convergência da renda per capita ocorre em dado sub-período, mas não no outro (caso de Portugal, com convergência da renda per capita em nível da União Européia nos sub-períodos de 1951 a 1973 e de 1986 e 1993, mas não no sub-período de 1974 a 1985).

\footnotetext{
${ }^{15}$ Ortigueira e Santos (1997) publicaram um artigo sobre a velocidade de convergência nos modelos de Crescimento Endógenos e verificaram que ele é muito menor do que aquele predito pelos modelos neoclássicos, em particular o resultado predito no modelo de Barro e Sala -i - Martin (1991).
} 
É importante ressaltar que alguns trabalhos combinam a equação básica de Barro e Sala-i-Martin com outras equações que buscam explicar o porque da convergência. Este é o caso, por exemplo, do trabalho de Michelis, Papadopulos e Papanikis (1992) sobre convergência de renda per capita entre as regiões da Grécia no período de 1981 a 1991. Esses autores estimaram, primeiro, o valor da convergência- $\beta$ e, depois, esse valor foi utilizado em outro modelo para, junto com as outras variáveis independentes, explicarem a taxa média de crescimento da renda em cada região.

A convergência da produtividade da terra foi também considerada em dois trabalhos. O trabalho de Lusigi e Thirtle (1998) analisa a convergência da Produtividade Total dos Fatores (PTF) para um conjunto de 32 países africanos nos anos de 1970 a 1991. O trabalho de Suhariyanto e Thirtle (2001) analisa a convergência da Produtividade Total dos Fatores para países asiáticos no período de 1965 a 1996. O primeiro trabalho (Lusigi e Thirtle, 1998) considera uma equação em que se mede basicamente, os desvios da produtividade em função de seus valores defasados. No caso do segundo trabalho (Suhariyanto e Thirtle, 2001) utiliza-se uma equação em que a taxa de crescimento da PTF é função do diferencial da PTF no passado entre os países. Tratase de um modelo para captar o efeito catch-up. Esses dois trabalhos são distintos em suas conclusões. Lusigi e Thirtle (1998) encontraram convergência da PTF entre países africanos, mas Suhariyanto e Thirtle (2001) não encontraram evidências de convergência da PTF entre países asiáticos.

\subsubsection{Evidências econométricas sobre convergência no Brasil}

Os quadros numerados de 11 a 16 do anexo B apresentam um resumo dos trabalhos que analisaram convergência no Brasil. De modo similar à literatura internacional (analisada no item anterior) a maioria dos trabalhos analisa a convergência da renda per capita e utiliza a equação básica (equação 25 do item 2.2.2.1) de Barro e Sala-i-Martin (1990). Há um relativo consenso sobre a existência de convergência da renda per capita, em especial nas décadas de 70, 80 e 90. 
Azzoni (1994) constatou que pouca evidência de convergência surge até a década de 60, havendo fortes sinais de convergência de 1970 a 1990. Ferreira e Ellery Junior (1996) e Cançado (1999) concluíram também que houve convergência da renda per capita dos estados brasileiros nas décadas de 70 e 80. Já Ribeiro e Pôrto Junior (2003) ao analisarem apenas os municípios da região sul no período de 1985 a 1998, confirmaram apenas a existência de formação de grupos de convergência mas não de convergência- $\beta$ absoluta.

Martins (1999) - com o objetivo de verificar se a lei de repasse do ICMS, "Lei Robin Hood", de fato havia contribuído para reduzir as desigualdades econômicas e sociais entre as regiões de Minas Gerais - testou a hipótese de convergência- $\sigma$, analisando os anos de 1995, 1996 e 1997. O ponto central deste trabalho é verificar a dispersão do ICMS utilizando-se como metodologia o índice ji e Índice de L-Theil. Se o volume de repasse para as regiões mais pobres estiver se aproximando do valor de repasse das regiões mais ricas então as desigualdades estarão se reduzindo. A autora constatou que os efeitos da lei "Robin Hood" ainda não têm sido observados, mais já é possível verificar um processo de convergência em andamento.

Observa-se no exame da literatura acima mencionada que nenhum trabalho surgiu no Brasil analisando a convergência da produtividade na agricultura. 


\section{ANÁlise do PROCESSO DE CRESCIMENTO E MODERNIZAÇÃO DA AGRICULTURA BRASILEIRA}

Até meados da década de 60 , as mudanças estruturais que se verificaram na economia brasileira foram devidas, principalmente, à intervenção do Estado dentro de um modelo de substituição de importações em prol da indústria. Ao setor agrícola coube cumprir a função de gerador de divisas (com câmbio normalmente sobrevalorizado) e liberar mão-de-obra para o setor urbano, mantendo uma oferta de alimentos de baixo custo.

Com receio de que o atraso na agricultura pudesse impor limites ao desenvolvimento, ao implementar o Programa de Ação Econômica do Governo (Paeg), em 1964, os governantes definiram como uma das metas modernizar o setor agropecuário.

Uma nova dinâmica se configurava no setor agrícola, principalmente a partir de 1964, quando as mudanças na política cambial e a crescente liberalização do comércio exterior reduziram as transferências líquidas da agricultura para a indústria e a política de minidesvalorização periódica adotada a partir de 1968 reduziu o desestímulo que a sobrevalorização impunha, até então, às exportações (Goldin e Rezende, 1993).

Embora as bases da modernização da agricultura brasileira tenham sido estrategicamente montadas, em meados da década de 1960, foi somente nos anos 70 que se verificou um aprofundamento maior nas transformações do setor agropecuário brasileiro. Neste período, a agricultura - apoiada por um amplo esquema de incentivos fiscais, de crédito rural com taxas de juros subsidiadas e de programas de sustentação de 
preços mínimos financiados pelo governo federal - passou a cumprir também a função de aquisição dos chamados insumos modernos (especialmente fertilizantes, tratores e equipamentos mecânicos), dinamizando sua produção nacional.

A Tabela 1 mostra a evolução ocorrida no processo de modernização a partir da década de 1960.

Tabela 1. Indicadores censitários sobre a agropecuária brasileira

\begin{tabular}{lrrrr}
\hline Indicador & \multicolumn{1}{c}{1960} & \multicolumn{1}{c}{1970} & \multicolumn{1}{c}{1980} & \multicolumn{1}{c}{1985} \\
\hline Número de Estabelecimentos & 3.337 .769 & 4.924 .019 & 5.159 .851 & 5.801 .809 \\
Área total (1000 ha) & 249.862 & 294.145 & 364.854 & 374.925 \\
Área com lavouras temporárias (ha) & 20.914 .721 & 25.999 .728 & 38.632 .128 & 42.244 .221 \\
Área com lavouras permanentes (ha) & 7.797 .488 & 7.984 .068 & 10.472 .135 & 9.903 .487 \\
Número de tratores & 61.345 & 165.870 & 545.205 & 665.280 \\
Índice de Mecanização (ha/tratores) & 4.070 & 1.770 & 670 & 560 \\
Relação consumo fertilizante/área com & 10,6 & 29,4 & 85,5 & 61,3 \\
lavouras (kg/ha) & & & & \\
\hline
\end{tabular}

Fonte: Bacha (2004)

Observa-se que o número de estabelecimentos agropecuários em 1985 aumentou em 74\% comparativamente a 1960, bem como a área total, que no mesmo período aumentou em 125 milhões hectares. Os dados sobre o índice de mecanização deixam nítido o processo de modernização da agricultura brasileira. Nota-se que em 1960 a relação era de 4.070 hectares para cada trator e em 1985 havia 560 hectares para cada trator. Outro indicador de modernização é o consumo de fertilizante por hectare de lavouras. Este indicador passou de 29,4 kg de nutrientes/ha em 1970 para 61,3 kg de nutrientes/ha com lavouras em 1985. 
De acordo com Bacha (2004), a ampliação da mecanização e do uso de fertilizantes foi possível, em parte, devido aos créditos subsidiados que eram concedidos aos agricultores para aquisição de equipamentos e insumos agropecuários.

Os números registrados pelo setor agrícola não deixavam dúvidas do seu dinamismo, porém, conforme constatou Bacha (2004), este crescimento não foi homogêneo entre os produtos e as regiões. A Tabela 2, abaixo, mostra que o período foi marcado pela dicotomia entre o crescimento da agricultura para o mercado interno e o da agricultura de exportação.

Tabela 2. Taxas geométricas de crescimento da área colhida e da produtividade para culturas específicas (valores em \%) - período 1965-1986

Destino principal Culturas

1965 a 1986

\begin{tabular}{llrc} 
& Área & Produtividade \\
\hline \multirow{4}{*}{ Mercado interno } & Arroz & 1,41 & 0,46 \\
& Feijão & 2,43 & $-2,58$ \\
& Mandioca & 0,83 & $-1,63$ \\
& Batata Inglesa & $-1,23$ & 3,48 \\
& Milho & 1,62 & 1,63 \\
& & & \\
Algodão & $-1,05$ & 1,24 \\
& Cacau & 1,29 & 3,53 \\
& Café & $-1,31$ & 1,52 \\
Cancado externo-de-açucar & 4,44 & 1,75 \\
& Laranja & 8,30 & 1,74 \\
& Soja & 17,83 & 2,46 \\
& Trigo & 6,24 & 1,81 \\
\hline
\end{tabular}

Fonte: Bacha (2004)

Constata-se que as culturas orientadas para o mercado externo ou que substituem importações (como cana-de-açúcar e trigo) tiveram maior expansão de área 
do que as culturas de mercado interno. Lavouras como a cana-de-açúcar, a laranja, o soja e o trigo registraram crescimento da área colhida da ordem de 4,44\%, 8,30\%, 17,83\% e $6,24 \%$ ao ano, respectivamente, contra crescimento de $1,41 \%$ ao ano na área colhida de arroz, $2,43 \%$ ao ano de feijão, $0,83 \%$ ao ano de mandioca e $1,62 \%$ ao ano de milho.

Apesar do esforço empreendido a partir de 1965, Cunha e Daguer (1982) não têm dúvidas em afirmar que, no período compreendido entre os anos de 1967-1979, o processo de modernização da agricultura deixou de produzir os esperados ganhos de produtividade da terra. $\mathrm{O}$ estudo desses autores apontou para a nítida preponderância do “efeito-área". Das 23 culturas ${ }^{16}$ investigadas, em 9 delas a participação do efeito-área foi a principal fonte de variação da produção.

O crescimento da agricultura brasileira, de meados da década de 1960 a meados da década de 1980, pode ser explicado, principalmente, por dois instrumentos que passaram a serem utilizados mais intensamente pelo governo a partir de 1965: o crédito rural e a política de garantia de preços mínimos.

O Sistema Nacional de Crédito Rural (SNCR), resultado da ampliação do sistema de crédito rural instituído pelo Banco do Brasil em 1937, foi o responsável, segundo Goldin e Rezende (1993), pelo suprimento de aproximadamente 85\% do total do crédito rural concedido à agricultura na década de 70 .

A Figura 3 permite visualizar mais nitidamente a expansão do volume crédito rural concedido na década de 70 e sua drástica redução a partir da década de 80 .

\footnotetext{
${ }^{16}$ As 23 culturas investigadas foram: arroz, feijão, milho, mandioca, trigo, banana, laranja, abacaxi, uva, tomate, cebola, batata-doce, batata-inglesa, algodão, sisal, amendoim, soja, mamona, cana-de-açúcar, côco, café, cacau e fumo. As culturas onde o efeito-área determinou o aumento na produção foram: canade-açúcar, arroz, trigo, laranja, soja, milho, bata-doce, amendoim e café.
} 


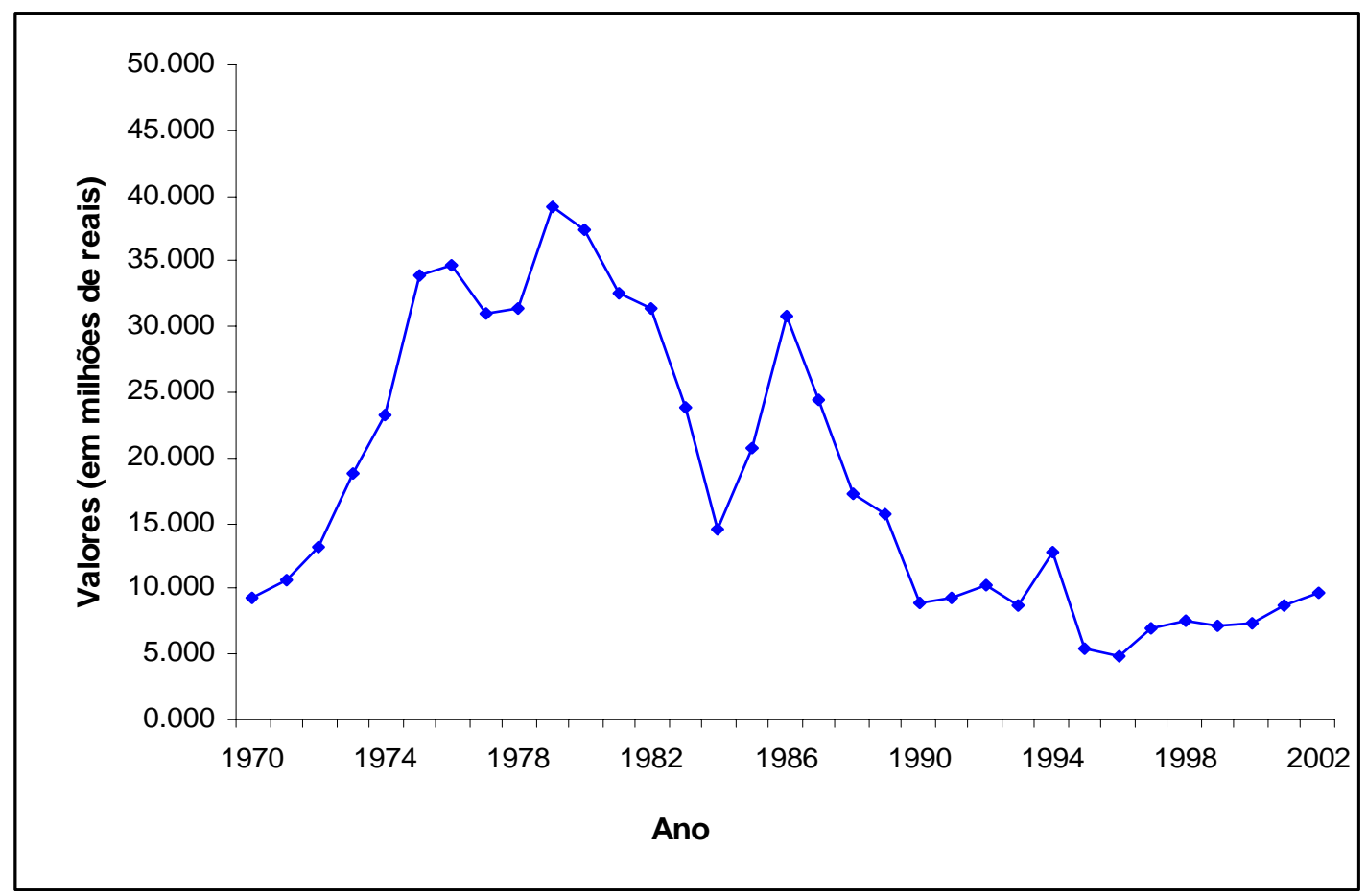

Figura 3 - Evolução dos valores de crédito rural concedido, 1970-2002

Fonte: Bacha (2004)

Nota: valores em reais de agosto de 1994

Observa-se que de 1973 até 1979 o crédito rural foi aumentando até atingir o mais alto valor, que foi de $\mathrm{R} \$ 39$ bilhões (a preços de agosto de 1994). A partir de então, o volume de crédito rural começa a declinar, deixando evidente que a década de 1980 inicia-se em um contexto de profunda crise e deterioração do sistema de crédito rural. Durante os anos 80, os recursos do governo que sustentavam o processo de modernização, com exceção do ano de 1986, sofreram uma queda vertiginosa, registrando em 2002 o mesmo valor de 1970, ou seja, pouco mais de R\$ 9 bilhões (a preços de agosto de 1994).

Além do crédito rural, também a política de preços mínimos, lançada em 1943 através da criação da Comissão de Financiamento da produção (CFP), atualmente transformada na Companhia Nacional de Abastecimento (CONAB), desempenhou papel 
importante no que diz respeito ao apoio à agricultura no final dos anos 70. A política de garantia de preços mínimos (PGPM) é um mecanismo específico de política de rendas que visa minimizar as flutuações de preços recebidas pelos produtores rurais, no qual o agricultor tem a opção de vender seu produto ao mercado ou ao governo, pelo preço mínimo fixado.

Na década de 80, o PGPM sofreu várias modificações para não ser arruinado devido à inflação crescente. Como os preços mínimos eram fixados em termos nominais, vários meses antes da colheita, os agricultores enfrentavam grande incerteza sobre o nível efetivo do preço mínimo na época da comercialização. A primeira modificação foi feita em 1981, quando o preço mínimo passou a ser indexado com base em um índice geral de inflação. Em 1986, o programa de preços mínimos passa a ser baseado nos preços dos insumos agrícolas. Em 1987, uma nova modificação trouxe de volta o sistema de indexação que era praticado em 1986, juntamente com o novo sistema de regras de comercialização que tinha por objetivo disciplinar as vendas dos estoques do governo com vistas a reduzir o risco de estocagem de produtos agrícolas.

Goldin e Rezende (1993, p. 57) comentam que as "regras de intervenção" e do crédito para estocagem, aliada a preços externos mais altos, contribuiu para a elevação dos preços agrícolas no segundo semestre de 1988, permitindo, inclusive, que os agricultores se apropriassem dos ganhos dessa recuperação. Para os mesmos autores essas modificações, em seu conjunto, elevaram substancialmente a efetividade do programa convertendo-se, inclusive, num fator chave para explicar o desempenho relativamente satisfatório do setor agrícola na década de 80 .

A década de 1990, apesar de ter se iniciado em um contexto de forte redução do crédito rural e efetividade da PGPM, foi marcada por um desempenho satisfatório da produção agrícola. Porém, seu padrão de crescimento era agora distinto daquele observado na década de 70 . O aumento da produção que antes centrava-se na expansão da área cultivada passa a ser decorrente do aumento da produtividade. 
Para analisar mais detalhadamente o crescimento da produção agrícola, Gasques e Bastos (2003) fizeram a decomposição do produto real agropecuário em variação do produto por área $-\Delta(\mathrm{P} / \mathrm{A}) /(\mathrm{P} / \mathrm{A})$, variação da relação área/homem - $\Delta(\mathrm{A} / \mathrm{N})$ / (A/N) e variação de quantidade de mão-de-obra rural - $\Delta \mathrm{N} / \mathrm{N}$, e expressaram o resultado conforme apresentado na Tabela 3.

Tabela 3. Decomposição do produto real da agricultura: Brasil, 1990-2001

\begin{tabular}{lc}
\hline Especificação & $\begin{array}{c}\text { Período } \\
1990-2001\end{array}$ \\
\hline Taxa anual de crescimento do produto $\Delta(\mathrm{P} / \mathrm{P})$ & 2,42 \\
Variação do produto por área - $\Delta(\mathrm{P} / \mathrm{A}) /(\mathrm{P} / \mathrm{A})$, & 2,77 \\
Variação da relação área/homem - $\Delta(\mathrm{A} / \mathrm{N}) /(\mathrm{A} / \mathrm{N})$ & 0,68 \\
Variação de quantidade de mão-de-obra rural - $\Delta \mathrm{N} / \mathrm{N}$ & $-1,02$ \\
\hline
\end{tabular}

Fonte: Gasques e Bastos (2003)

Os dados da Tabela 3 não deixam dúvidas de que o crescimento do produto, no período considerado, se deu, predominantemente, em decorrência do aumento da produtividade da terra, cuja taxa anual foi de $2,77 \%$.

As Figuras 4 e 5, apresentadas por Bacha (2004), permitem que se visualize de forma nítida a evolução da produtividade e da área colhida das 38 e 37 principais culturas no Brasil, respectivamente, incluindo e excluindo a cana-de-açúcar. 


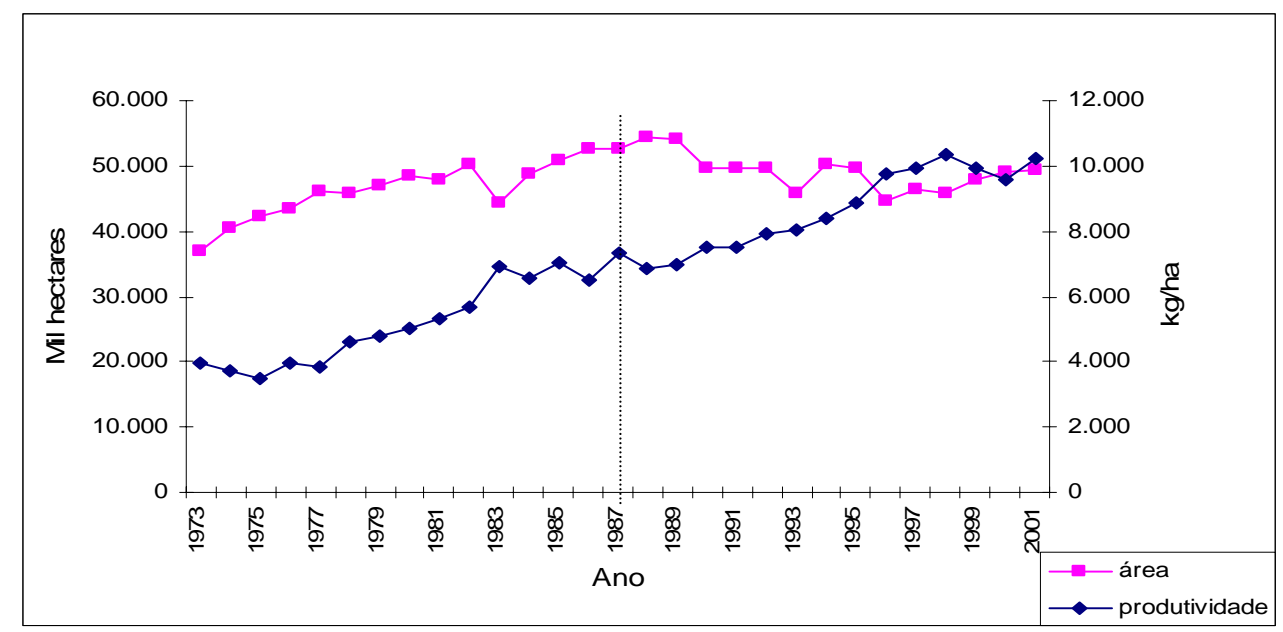

Figura 4 - Evolução da área e produtividade das 38 principais culturas do Brasil, período: 1973 a 2001

Fonte: Bacha (2004)

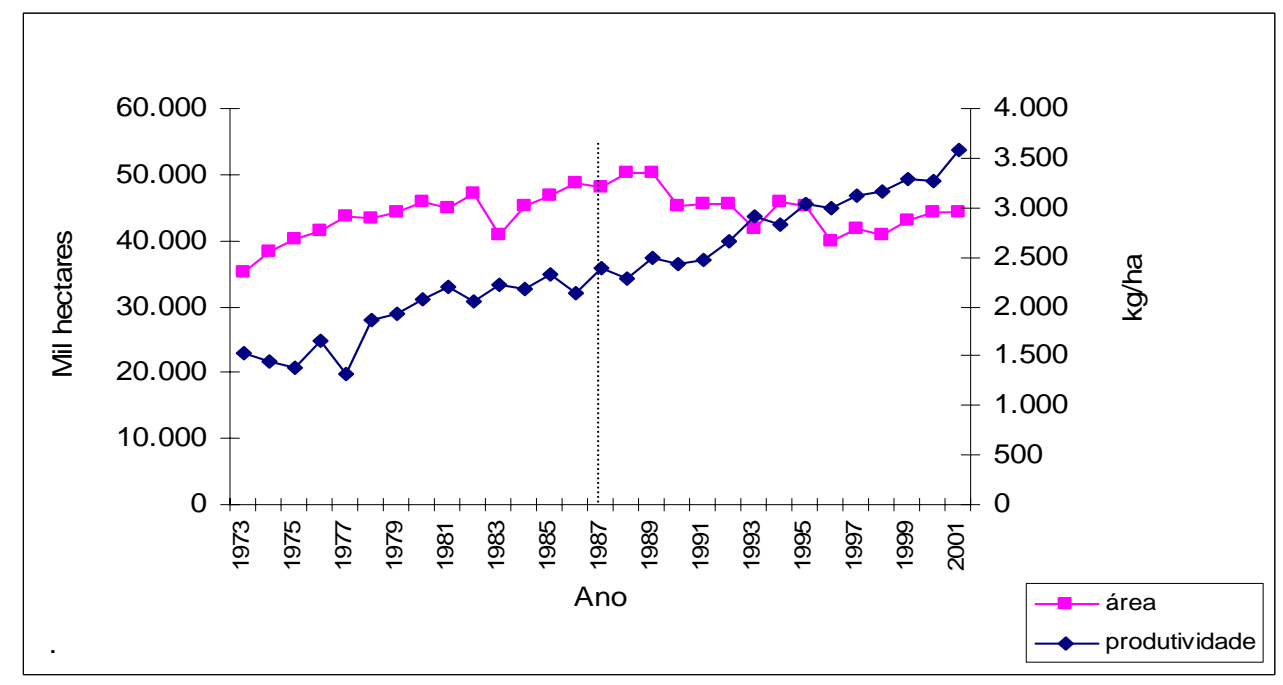

Figura 5 - Evolução da área e produtividade das 37 principais culturas no Brasil, período: de 1973 a 2001

Fonte: Bacha (2004) 
Não há dúvidas de que o período a partir de 1987 é marcado pelo crescimento da produtividade e redução da área colhida. Em 1986, comenta Bacha (2004), foram produzidas 343 milhões de toneladas em 52,5 milhões de hectares contra 503 milhões de toneladas produzidas em 49,2 milhões de hectares em 2001. Isto representa aumento de $46,6 \%$ na produção física e redução de $6,3 \%$ na área colhida com as culturas analisadas entre 1986 e 2001. Para Bacha (2004) o que possibilitou este cenário foi o aumento da produtividade da terra, que incrementou em 56,6\% de 1986 para 2001.

As Figuras 4 e 5 também evidenciam outro fato. Até aproximadamente o ano de 1978, as culturas brasileiras mostraram um comportamento oscilante em termos de produtividade apresentando, a partir de então, um crescimento contínuo.

A partir da $2^{\text {a }}$ metade da década de 1980 , as diferenças de crescimento da produtividade das culturas voltadas ao mercado interno e externo foram reduzidas, desaparecendo em certos casos. Do ponto de vista de Dias e Amaral (2001), o que fez com que as produtividades da terra apresentassem dinâmica semelhante foi $o$ extraordinário desempenho verificado em algumas culturas do mercado doméstico, como por exemplo, o feijão (que registrou um crescimento na produtividade de $58 \%$ entre 1987 e 1998). Na opinião dos autores, os dados sugerem que a agricultura tomou uma direção mais orientada para atender o mercado interno do que para mercado externo.

Mas não foi somente a produtividade da terra que aumentou na agricultura brasileira. A produtividade do trabalho também cresceu. De acordo com Gasques e Conceição (2000, p.29), no período de 1970-95 a produtividade da terra e do trabalho têm crescido a taxas próximas. Os autores desagregaram a produtividade em dois componentes: relação terra/homem - número de hectares que uma unidade de trabalho consegue operar e tem uma relação direta com o grau de mecanização num dado período de tempo - e produtividade da terra. Conforme mostrado na Tabela 4, nota-se não só o quão próximas têm crescido as produtividades da terra e do trabalho, mas também que 
seu crescimento têm sido superior ao da produtividade total dos fatores (PTF). A PTF cresceu a 2,33\%, a produtividade do trabalho a 3,35\% e da produtividade da terra a $3,39 \%$. Ainda nas palavras dos autores, o crescimento da produtividade do trabalho vem ocorrendo quase que exclusivamente pelo aumento da produtividade da terra (Y/A)

Tabela 4. Taxas anuais de crescimento da produtividade do trabalho e seus componentes $(\%)$

\begin{tabular}{lccc}
\hline Especificação & $1970 / 1980$ & $1985 / 1995$ & $1970 / 1995$ \\
\hline Produtividade do trabalho (Y/L) & 5,37 & 1,91 & 3,35 \\
Produtividade terra/homem (A/L) & 0,36 & 0,29 & $-0,03$ \\
Produtividade da terra (Y/A) & 4,95 & 1,61 & 3,39 \\
\hline
\end{tabular}

Fonte: Gasques e Conceição (2000)

Há que se destacar que o crescimento elevado da produtividade da terra foi favorecido, de acordo com a visão de Dias e Amaral (2001), por dois fatores muito importantes: o papel desempenhado pelas instituições de pesquisa, públicas e privadas, e pelo aumento do capital humano.

No tocante à pesquisa agropecuária, há que se destacar o trabalho realizado pela Embrapa, criada em 1973. Conforme destacam Bonelli e Pessoa (1998), o aumento das despesas efetuadas por essa agência nos anos 70 , tanto em termos reais quando em relação ao PIB agrícola, produziam importantes inovações nas áreas de tecnologias bioquímicas, técnicas de manejo de solo e adaptações no cultivo para as condições agroecológicas prevalecentes no Brasil ${ }^{17}$.

Griliches $(1957,1960)$ tem também destacado a importância da tecnologia e do capital humano como fontes propulsoras do crescimento econômico. Desde seu

\footnotetext{
${ }^{17}$ A bem sucedida adaptação das variedades de soja do cerrado se constitui num exemplo dessa visão.
} 
estudo clássico sobre milho híbrido, Griliches (1957) tem dedicado especial atenção ao processo de difusão de uma inovação tecnológica e o seu relacionamento com o capital humano. Estudar com que velocidade uma nova tecnologia é dotada foi e tem sido objeto de interesse não só de Griliches (1960, 1994 e 1997) mas também de outros pesquisadores como por exemplo, Dixon (1980).

Para Griliches (1960, 1994, 1997), a aceitação da nova variedade depende não só dos ganhos de produtividade e, portanto, de rentabilidade que esta nova variedade permitia mas, também, do entendimento do agricultor de que esta nova tecnologia é melhor do que aquela que está posta. Nesse caso, comenta Griliches, o grau de aceitação vai depender do nível de educação do indivíduo. Para o autor, é o nível de escolaridade que faz com que as pessoas entendam, aceitem e difundam mais rapidamente uma nova tecnologia.

Há muito se percebeu a importância entre o desenvolvimento de uma nova tecnologia e sua correlação com a qualificação da mão-de-obra como fontes do crescimento de longo prazo. Stern (1991) listou seis fatores como sendo os principais determinantes do crescimento econômico: (1) acumulação de capital, (2) capital humano, (3) pesquisa, desenvolvimento e inovação, (4) infraestrutura, (5) capacidade administrativa e organizacional, e (6) alocação do produto diretamente entre os setores produtivos.

A partir dos determinantes do crescimento econômico, definidos por Stern (1991), Barros (1999) oferece uma discussão a respeito do relacionamento tecnologia/capital humano com o desempenho da agricultura brasileira a partir dos anos de 1980. Um dos pontos principais dessa discussão centra-se na importância das instituições como veículo de divulgação dos resultados obtidos com as pesquisas.

Do que foi exposto sobre o desempenho da agricultura brasileira a partir de 1960, pode-se afirmar que o aumento nos investimentos em pesquisa e desenvolvimento (tornando rentável uma mesma cultura em diferentes regiões), assim como na qualificação de sua mão-de-obra e a acumulação de capital físico objetivavam, 
primordialmente, a modernização da agricultura, e que se traduziu em aumentos de produtividade. Contudo, é de se esperar que a aceitação e a adoção de uma nova técnica leve algum tempo para ser assimilada. Portanto, os frutos da modernização iniciada nos anos de 1970 só seriam "colhidos" após transcorrer um certo período de tempo. O avanço tecnológico verificado na agricultura nos anos de 1990 dão conta de confirmar o quão importante foram os investimentos em pesquisa e educação, não só nas décadas de 60 e 70, mas também nos anos que se seguiram.

Diante disso, acredita-se que todo o esforço empreendido em prol do aumento da produtividade agrícola tenha contribuído para reduzir as desigualdades estaduais e regionais no Brasil no que diz respeito à produtividade da terra. Esta é, portanto, a principal razão que nos incentivou a estudar e testar a hipótese da convergência da produtividade da terra na agricultura brasileira. No entanto, a convergência da produtividade pode ter tido comportamento diferente entre as culturas, pois o processo de pesquisa e desenvolvimento, assim como o capital humano aplicado em cada uma delas, é distinto. Assim, o próximo capítulo discute detalhadamente algumas características das onze culturas aqui analisadas, dando atenção à evolução de sua produtividade e de seu progresso tecnológico. 


\section{DINÂMICA DAS CULTURAS ESTUdAdAS E CONDIÇÕES PARA A OCORRÊNCIA (OU NÃO) DE CONVERGÊNCIA DA PRODUTIVIDADE DA TERRA}

Este capítulo destina-se a fazer uma análise preliminar das culturas analisadas neste estudo, particularmente a partir da década de 1970. O objetivo é verificar a dinâmica ocorrida com as mesmas, assim como as razões pelas quais acredita-se, ou não, porque determinada cultura deverá apresentar convergência de produtividade da terra.

Para tanto, o capítulo está estruturado da seguinte forma: para cada produto será apresentada a evolução da área e produtividade ocorrida durante o período de 19602001, observando as tendências dessas variáveis. Terão destaque também as mudanças ocorridas em termos de área adubada, plantio simples e área colhida com menos de 10 hectares, procurando-se observar semelhanças e diferenças entre as regiões produtoras. Esta última análise será feita a partir dos dados censitários de 1970, 1980 e 1995. Finalmente, serão apontadas as razões porque se acredita que deva ocorrer, ou não, convergência de produtividade da terra para as culturas analisadas. Supõe-se que a aproximação das regiões produtoras em termos de adubação, uso de plantio simples e similaridade de tamanho de lavouras são fatores que facilitam a convergência de produtividade, em especial para culturas que tenham um centro gerador e difusor de tecnologia e para culturas com o mesmo destino primordial (mercado interno, mercado externo ou consumo próprio do produtor). 


\subsection{Cultura do algodão herbáceo}

O algodão herbáceo é uma planta originária da Índia e do Paquistão. No Brasil o primeiro estado produtor foi o Maranhão, que já no ano de 1760 exportou para a Europa 130 sacas do produto. Sua principal finalidade é a produção têxtil.

A Figura 6 permite visualizar o que ocorreu com esta cultura em termos de área e produtividade. Até 1970 houve aumento da área. No entanto, a partir de 1971 há nítida tendência de queda da área, ao mesmo tempo em que a produtividade começou a aumentar, principalmente a partir da segunda metade da década de 1990.

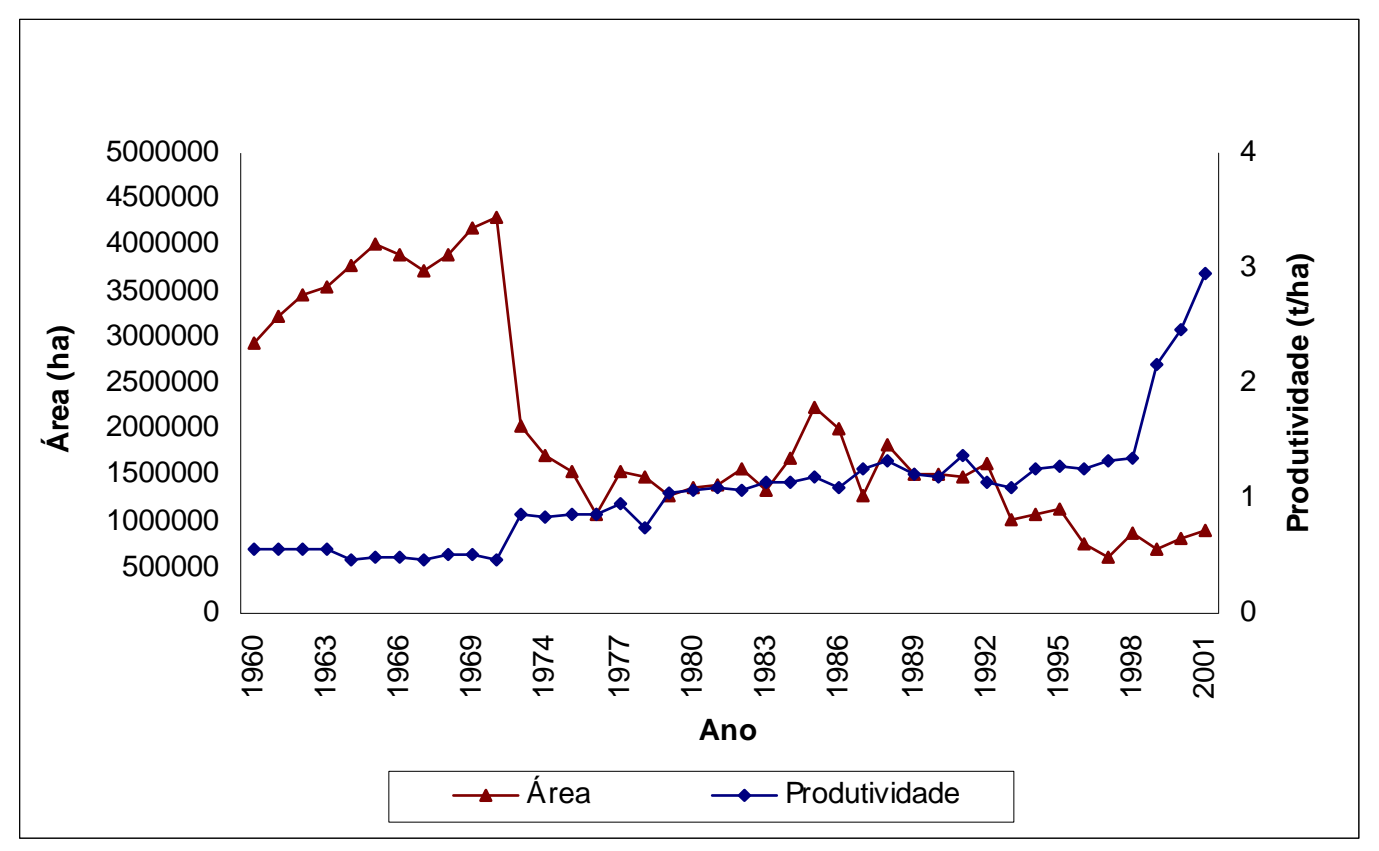

Figura 6 - Evolução da área e produtividade do algodão herbáceo: 1960-2001 Fonte: IBGE (1960, 2001) 
Para Ferreira Filho e De Zen (1999), a cultura do algodão no Brasil tem passado por transformações, que modificaram no passado o recente padrão de produção da cultura no país. O aparecimento de uma praga conhecida como o "bicudo do algodoeiro" nos anos 80 e a abertura comercial dos anos 90 foram responsáveis não só pelo desaparecimento do algodão arbóreo na região nordestina, como também pela mudança na estrutura produtiva da cultura do algodão herbáceo que de pequenas e médias propriedades passa a ser praticado em áreas maiores, originárias da cultura da soja. Dessa forma a produção de algodão no Brasil hoje, segundo Ferreira Filho e De Zen (1999):

$$
\begin{aligned}
& \text { "é praticado em áreas médias maiores, nos estados do } \\
& \text { Mato Grosso do Sul, Mato Grosso e Goiás, por produtores } \\
& \text { que são, em geral, originados da cultura da soja, trazendo } \\
& \text { para o algodão os hábitos comerciais e administrativos } \\
& \text { desta cultura e que diferem substancialmente dos } \\
& \text { produtores tradicionais do estado de São Paulo e Paraná. } \\
& \text { São produtores com atitudes empresariais e que praticam } \\
& \text { um tipo de agricultura com mais capital intensivo do que } \\
& \text { seus antecessores" (Ferreira Filho e De Zen, 1999, p.1). }
\end{aligned}
$$

Na safra 2001/02 é possível perceber a formação de dois grupos de estados em termos de produtividade: do primeiro fazem parte os estados com produtividade inferior a $80 \%$ da média nacional que é de 2.690 toneladas por hectare; e do segundo grupo os estados que registraram produtividade igual ou superior a $80 \%$ da média nacional. Fazem parte do primeiro grupo: Piauí, Ceará, Rio Grande do Norte, Paraíba, Pernambuco e Alagoas. Fazem parte do segundo grupo: Rondônia, Maranhão, Bahia, Minas Gerais, São Paulo, Paraná, Mato Grosso Sul, Mato Grosso e Goiás. 
As mudanças ocorridas com a cultura do algodão também podem ser verificadas através do padrão tecnológico, do tipo de cultivo e da estrutura de produção, adotados, apresentados quadro 17 do Anexo C.

Conforme pode ser observado no quadro 17 parte (A), em 1970 as regiões sudeste e nordeste eram as principais regiões produtoras de algodão no Brasil, mas o percentual da área que era adubada diferia sensivelmente entre estas regiões. Enquanto a região sudeste adubava $50 \%$ de sua área plantada, o nordeste usava adubo em apenas $1 \%$. Outro fato que se pode constatar é a migração da cultura das regiões tradicionais para a região centro-oeste, ocorrida nos anos 90. Nesta década, tanto as regiões sudeste e nordeste como a sul tiveram sua área plantada reduzida, enquanto que o centro-oeste teve sua área aumentada.

Na parte B do quadro 17 é possível verificar também que as regiões sudeste e sul utilizam, em quase a totalidade da área plantada, o sistema de plantio simples, já na região nordestina isto ocorre apenas na década de 1990.

Com relação à estrutura fundiária, parte $\mathrm{C}$ do quadro 17 , nota-se que na região nordestina ainda predomina a pequena lavoura do algodoeiro. Contrariamente, na região sudeste as lavouras com menos de 10 hectares representam $21 \%$ do total da área plantada. Quando comparamos os censos agropecuários de 1970 e 1995, nota-se que houve redução gradativa da área plantada com menos de 10 hectares na região centrooeste. Nessa nova fronteira do algodoeiro predominam médias e grandes lavouras.

Com base no que foi exposto acima e considerando o período como um todo (1960-2001) não se acredita que ocorrerá convergência da produtividade da terra para a cultura do algodoeiro. A partir dos anos 90, período em que ocorre a migração desta cultura para a região centro-oeste, configura-se uma nova dinâmica de produção, caracterizada pelo uso intensivo de capital. Assim, o que se espera é a formação, não de estados produtores convergindo para um mesmo nível de produtividade, mas de dois grupos distintos: um com alta e outro com baixa produtividade, cada qual convergindo entre si, individualmente. 


\subsection{Cultura do arroz}

O arroz é um produto originário da China e no Brasil seu cultivo remonta ao início da colonização, em especial na capitania de São Vicente (1530-1540). Como lavoura empresarial, essa cultura foi plantada em Pelotas-RS em 1904. Sua principal finalidade é servir como alimento.

A Figura 7 permite visualizar o que ocorreu com a cultura do arroz em termos de área colhida e produtividade ao longo do período de 1960-2001. Até meados da década de 1970 a área cresceu e a produtividade esteve estagnada. A partir de 1977, a área colhida tende a diminuir e a produtividade a aumentar. Este aumento da produtividade ocorreu, principalmente, devido ao deslocamento da cultura do arroz para a região sul do país, que possui uma topografia que possibilita produtividades mais elevadas.

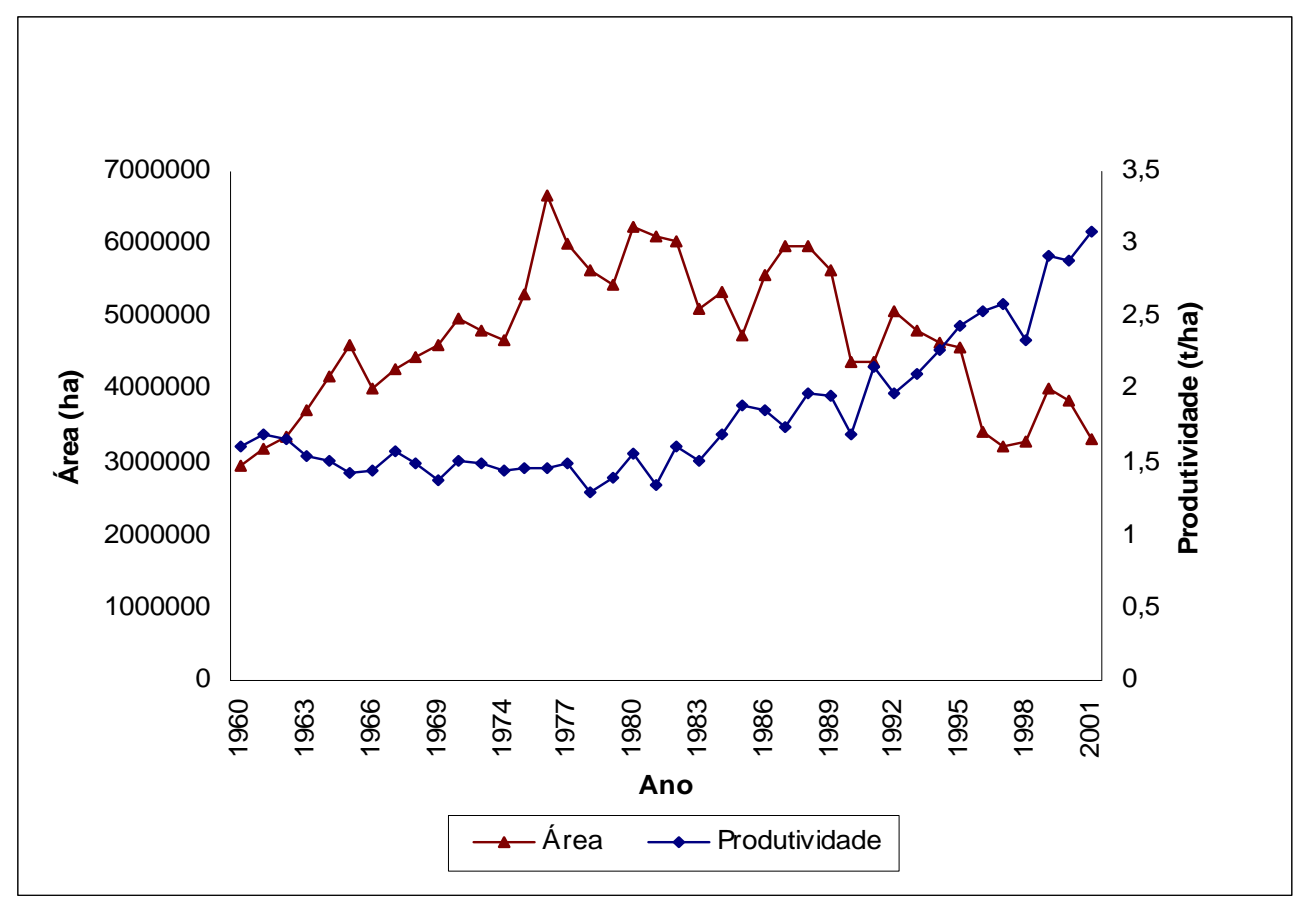

Figura 7 - Evolução da área e produtividade do arroz: 1960-2001

Fonte: IBGE (1960, 2001) 
Existe uma grande variação de produtividade entre os estados produtores de arroz no Brasil. Contudo há que se destacar que este fato está associado ao arroz de sequeiro, que tem produtividade relativamente mais baixa que o arroz irrigado. Em 2001, a produtividade dos maiores estados produtores dentro de cada região foi: Pará (38,46 ton/ha), Maranhão (35,46 ton/ha), Minas Gerais (43,87 ton/ha), Mato Grosso do Sul (46,97 ton/ha) e Rio Grande do Sul (130 ton/ha).

O Brasil ocupa hoje a $10^{\mathrm{a}}$ posição no cenário mundial. Os lideres do ranking mundial na produção de arroz são a China, Índia, Indonésia, Bangladesh, Tailândia, Burma, Japão e Vietnã. Mesmo figurando entre os dez primeiros produtores mundiais, a produtividade brasileira ainda é muito baixa, $3.303 \mathrm{~kg} / \mathrm{ha}$, enquanto que no Japão e na China a produtividade é de $6.582 \mathrm{~kg} / \mathrm{ha}$ e $6.265 \mathrm{~kg} / \mathrm{ha}$, respectivamente.

As mudanças ocorridas com a cultura do arroz também podem ser verificadas através do uso de adubação, do tipo de cultivo e da estrutura de produção, adotados, tal como se observa no quadro 18 do anexo $\mathrm{C}$.

Ao analisar a parte (A) do quadro 18 pode-se observar que não há uma regularidade no uso de adubação na cultura do arroz por parte das regiões produtoras. Em 1970, nota-se que a cultura do arroz é muito pouco adubada em todas as regiões. Neste ano, quem mais utilizou adubo foram os produtores da região sul, adubando $39 \%$ de sua área total. Em 1980 e 1995, as regiões norte e nordeste continuam ainda a utilizar pouco adubo, mas a situação se inverte com relação às regiões sul, centro-oeste e sudeste, que de sua área total plantada passam a adubar $92 \%, 81 \%$ e $58 \%$, respectivamente, em 1995.

Com relação ao tipo de cultivo, mostrado na parte B quadro 18 , observa-se que as principais regiões produtoras - sul, centro-oeste e sudeste - optam pelo plantio simples. No censo de 1995, estas regiões adotaram este tipo de cultivo em 99\%, 97\% e $96 \%$ de sua área total plantada, respectivamente. 
Conforme é mostrado na parte $\mathrm{C}$ quadro 18 , as regiões norte, nordeste e sudeste caracterizam-se por pequenas lavouras de arroz, enquanto que nas regiões centro-oeste e sul a área de lavouras com menos de 10 hectares correspondiam a apenas $21 \%$ e $11 \%$ do total da área plantada, respectivamente, em 1995. Este fato deixa evidente a presença de pequenos produtores convivendo com produtores maiores que adotam tecnologia mais avançada.

Não se espera, com base na dinâmica ocorrida com esta cultura que ocorra convergência da produtividade da terra. Por tratar-se de uma cultura na qual a maioria dos estados produtores adota baixa tecnologia e possui característica de agricultura familiar, acredita-se que sua produtividade é ainda muito baixa.

\subsection{Cultura da batata-inglesa}

Procedente originalmente dos Andes, a batata-inglesa é produzida no Brasil em todas as regiões, exceto no Norte. Do total produzido, parte é comercializada innatura e parte é destinada à agroindústria, principalmente para fabricantes de snacks e fast-foods.

Com exceção do norte, todas as regiões brasileiras cultivam a batata-inglesa. Mas as regiões sul e sudeste representam, desde os anos 70, mais de $85 \%$ da área colhida no Brasil. Nos últimos 30 anos não houve grande deslocamento geográfico dessa cultura no Brasil.

Na década de 70, o Brasil ocupava a $22^{\underline{a}}$ posição na produção de batatainglesa no mundo. De um total de 298 milhões de toneladas produzidas no mundo, 212 milhões de toneladas eram produzidas pela URSS, Polônia, Alemanha, China e Estados Unidos. O Brasil participava com 1.500 toneladas. No ano de 2002, a produção mundial se eleva para 307,5 milhões de toneladas em uma área de 19,2 milhões de hectares, com produtividade média de 16,13 ton/ha. Neste cenário, o Brasil acupa a 19a posição, produzindo 2,865 milhões de toneladas com uma produtividade de 18,7 t/ha. Os maiores 
produtores mundiais são: China, Rússia, Índia, Estados Unidos, Ucrânia, Polônia e Alemanha.

A Figura 8 permite visualizar o que ocorreu com a cultura da batata-inglesa em termos de área e produtividade. A partir da década de 1970 há tendência de redução da área colhida e aumento acentuado da produtividade. Embora a produtividade brasileira tenha aumentado consideravelmente desde os anos 60, passando de 5.598 $\mathrm{kg} / \mathrm{ha}$ em 1960 para $18.476 \mathrm{Kg} / \mathrm{ha}$ em 2001, ela ainda é muito baixa quando comparada com a Holanda que é de 45,8 t/ha.

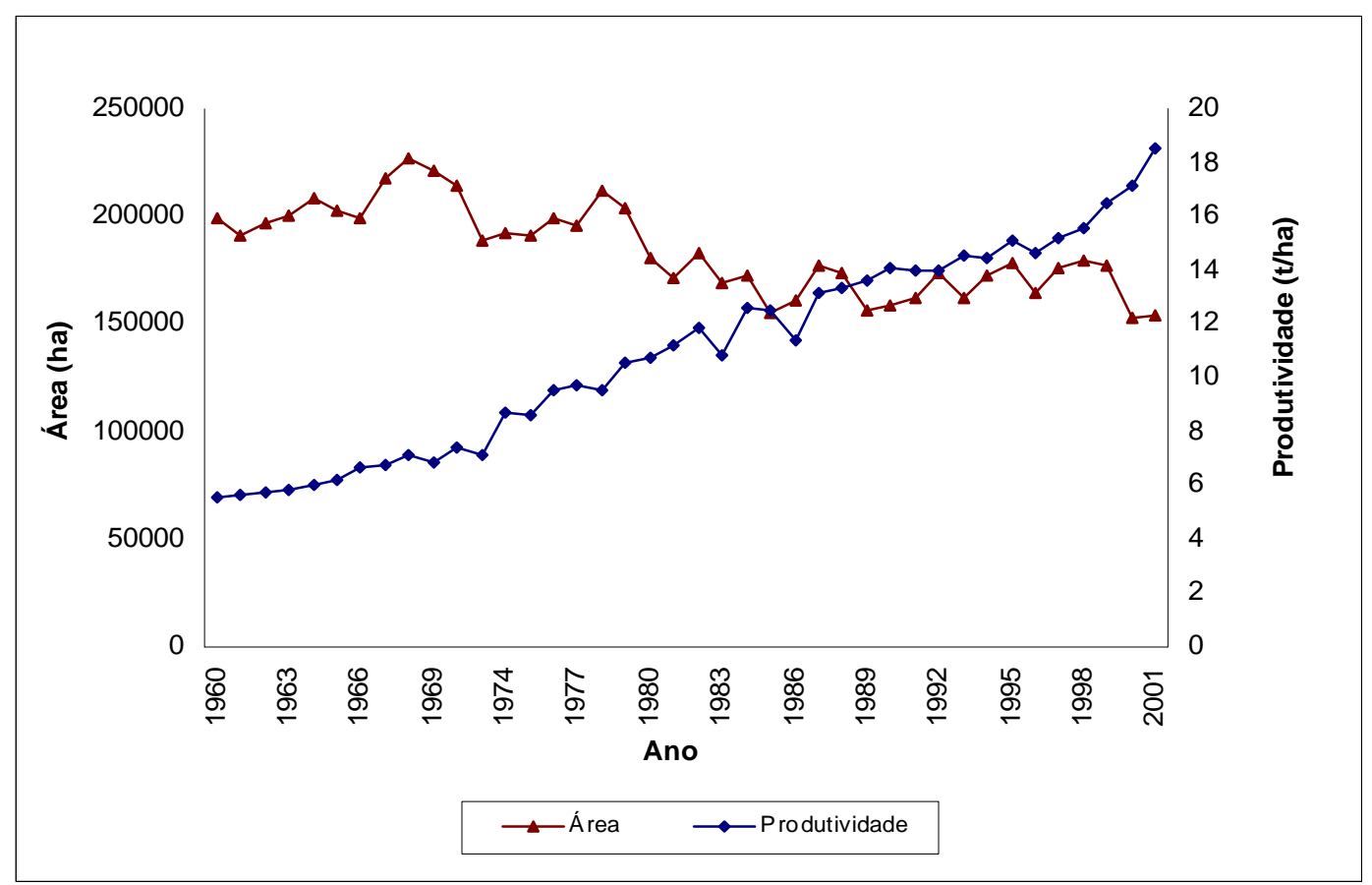

Figura 8 - Evolução da área e produtividade da batata-inglesa: 1960-2001 Fonte: IBGE (1960, 2001) 
As mudanças ocorridas com a cultura da batata-inglesa também podem ser verificadas através do uso de adubação, do tipo de cultivo e da estrutura de produção adotados, apresentados quadro 19 , no anexo $\mathrm{C}$.

Observa-se, na parte A do quadro 19, que as principais regiões produtoras de batata-inglesa - sul e sudeste - adubam quase a totalidade de sua área plantada.

Outro fato que se pode notar é o tipo de cultivo utilizado (parte B do quadro 19). Com exceção da região nordeste no ano de 1970, onde o cultivo simples ocupou $50 \%$ da área total plantada, nas demais regiões e períodos a opção pelo cultivo simples superou os $75 \%$ da área plantada.

Por último é possível constatar ,na parte C do quadro 19, que esta é uma cultura característica de pequenas lavouras, pois mais de $40 \%$ da área total plantada é composta por lavouras com menos de 10 hectares.

O fato da produtividade média da bataticultura estar crescendo desde 1960 e o padrão tecnológico das duas principais regiões produtoras (sudeste e sul) ser similar, são indicadores favoráveis à ocorrência de convergência entre os estados da produtividade da terra. No entanto, o fato de predominar pequenas lavouras na região sul e médias lavouras na região sudeste poderá contrapor os argumentos acima sobre tendência da convergência em nível de Brasil e permitir o surgimento de grupos de convergência.

\subsection{Cultura do café}

A cafeicultura no Brasil teve início em 1727, no Pará, com o plantio de sementes e mudas trazidas da América Central. Sua principal finalidade é a indústria de torrefação e moagem, a indústria de café solúvel e o mercado externo. 
O café representa para o Brasil um importante produto na pauta de exportações. Em 2001, a receita de exportação do café (em grão e solúvel) totalizou US\$ 1,396 bilhão, representando 9\% do total exportado de commodities no Brasil (Agrianual, 2002).

O Brasil é o maior país exportador de café, seguido do Vietnã, Colômbia, Indonésia e México. Em 2001, as exportações brasileiras totalizaram 1.255.973 toneladas, representando um crescimento de 26\% em relação a 1998 (que foi de 995.712 toneladas). Neste mesmo ano as produções do Brasil e do mundo foram de 1.819.569 toneladas e 7.203.340 toneladas, respectivamente. O que representa uma participação brasileira de $25 \%$ na produção mundial.

A Figura 9 permite visualizar o que ocorreu com a cultura café em termos de área colhida e produtividade no período de 1960-2001. A área diminuiu de 1963 a 1976, aumentou de 1977 a 1989, reduzindo de 1990 a 1996 e voltando a aumentar a partir de 1997. No período como um todo, a área colhida em 2001 é inferir à de 1960. De outro lado, há tendência de aumento da produtividade, em especial a partir da segunda metade de 1970. A cultura do cafeeiro é bastante marcada pelo ciclo bianual de produção (um ano de produção alta é seguido de um ano de produção baixa), o que explica a grande flutuação da produtividade de um ano a outro. 


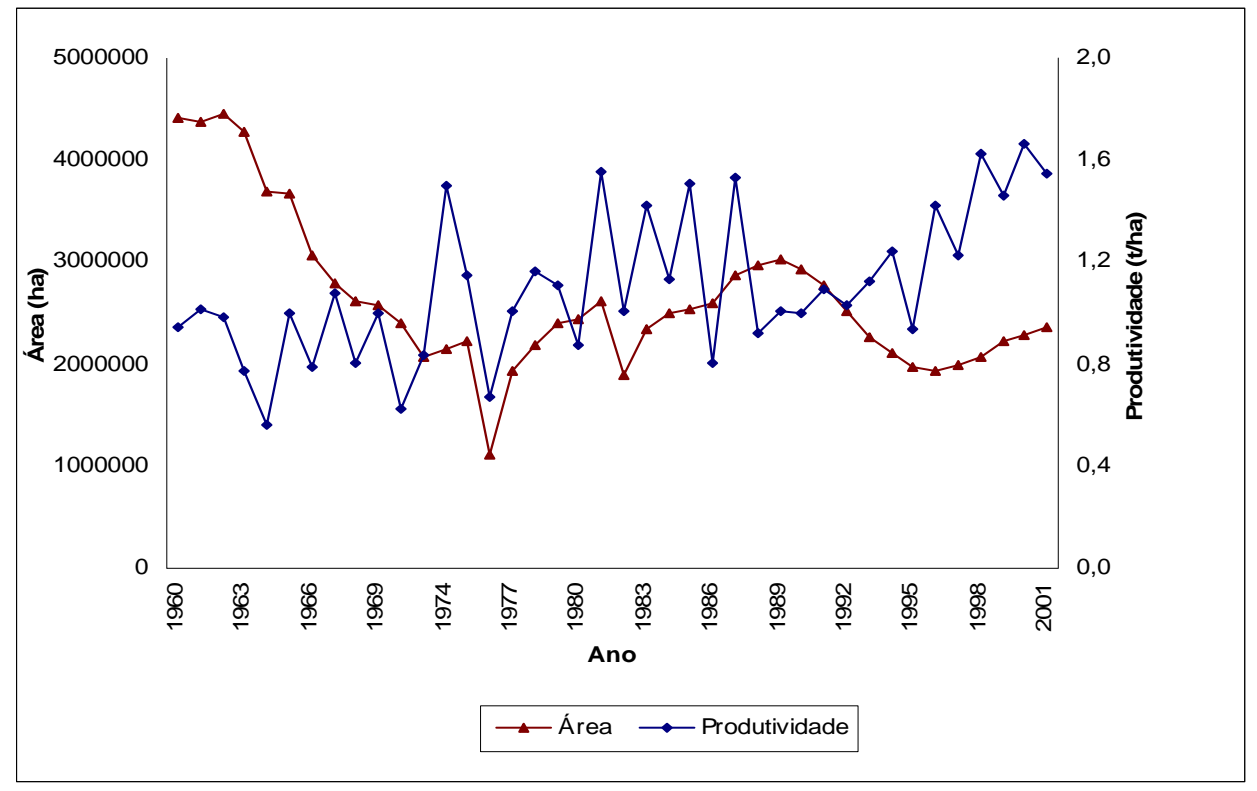

Figura 9 - Evolução da área e produtividade do café em côco: 1960-2001 Fonte: IBGE $(1960,2001)$

O padrão tecnológico (uso de adubação e sistema de plantio) é muito similar entre as regiões sudeste e sul até a década de 1980 (quadro 20, anexo C). Entretanto, na região sul há maior predominância de pequenas lavouras do que na região sudeste.

A cultura do cafeeiro sempre contou com várias instituições realizando pesquisas e órgãos para difundir essas pesquisas.

Entre os órgãos de pesquisa se destacam o Instituto Agronômico de Campinas, a Empresa de Pesquisa Agropecuária de Minas Gerais (EPAMIG), o Instituto Agronômico do Paraná (IAPAR) e a Empresa Brasileira de Pesquisa Agropecuária (EMBRAPA). Em 1998, a pesquisa do café foi unificada. Foi instituído o Consórcio Brasileiro de Pesquisa e Desenvolvimento do Café (CBP\&D/Café), coordenado pela EMBRAPA, que passou a executar o Programa Nacional de Pesquisa e Desenvolvimento do Café. No Estado de São Paulo, a Coordenadoria de Assistência Técnica Integral (CATI) é o órgão responsável pela extensão e assistência técnica. O Estado conta com vários pesquisadores trabalhando na área de café no Instituto 
Agronômico de Campinas (IAC) e em outros institutos como Universidade de São Paulo (USP), Universidade de Campinas (UNICAMP), Universidade Estadual Paulista Julio de Mesquita Filho (UNESP), Instituto de Tecnologia de Alimentos (ITAL), Instituto de Economia Agrícola (IEA), Instituições Privadas e outros.

Desde a década de 1970, diversas inovações tecnológicas têm surgido na cafeicultura brasileira, tais como: (i) o plantio adensado casado com a utilização de irrigação, nas regiões do Cerrado; (ii) uso de colheita mecânica, que reduz os custos de mão-de-obra, em terrenos de baixa declividade; (iii) descascador de cerejas (retira a polpa do café cereja e separa os grãos verdes e bóias); (iv) uso racional de defensivos (granulados de solo ou via foliar); (v) introdução de novos cultivares apropriados às regiões produtoras, como o Acaiá, uma variedade derivada do Mundo Novo, específica para o cerrado e o Oeiras, resistente à ferrugem; (vi) plantio de mudas em tubetes, método que apresenta maior resistência às pragas; (vii) o crescimento da utilização de métodos gerenciais modernos (inclusive com a informatização).

As inovações acima mencionadas têm se difundido entre os estados produtores e explicam, em grande parte, o crescimento da produtividade, evidenciado na Figura 9.

Com base no que foi exposto acredita-se que ocorrerá convergência de produtividade da terra, para a cultura do café, entre os estados produtores.

\subsection{Cultura da cana-de-açúcar}

A cana-de-açúcar é uma planta originária da Ilha da Madeira e as primeiras mudas chegaram ao Brasil no ano de 1502. A cana-de-açúcar é destinada a produção de açúcar e álcool, gerando sub-produtos de grande utilização, tais como: bagaço, vinhaça e torta de filtro. 
A cana-de-açúcar é cultura que teve crescimento quase que contínuo da área colhida e da produtividade no período de 1960-2001 (ver Figura 10). Dois sub-períodos, em particular, se destacam nessa tendência: 1975 a 1989 (no qual existiram os incentivos do proálcool) e 1993 a 2001 (no qual com menos incentivos ocorreu grande crescimento da área). Nesse último período a expansão da lavoura canavieira foi mais generalizada no Brasil.

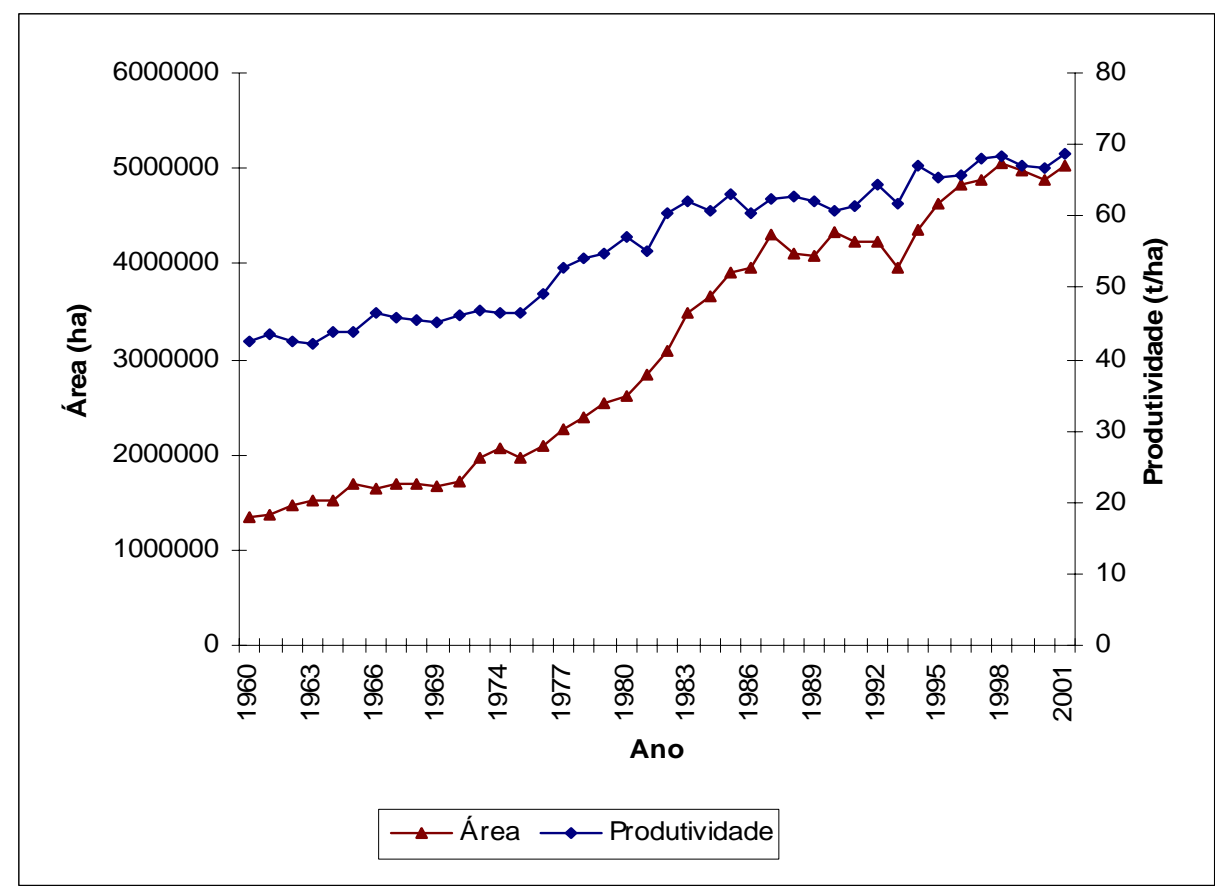

Figura 10 - Evolução da área e produtividade da cultura da cana-de-açúcar: 1960-2001 Fonte: IBGE (1960, 2001)

Em relação às mudanças ocorridas com a lavoura da cana-de-açúcar observa-se, no quadro 21 do anexo $\mathrm{C}$, que houve aumento significativo na área plantada em todas as regiões do Brasil, quando se compara o ano de 1970 com o de 1995. O padrão tecnológico se aproximou mais, na década de 1990, entre os principais estados produtores, situados no sudeste, nordeste e centro-oeste. Nota-se que os produtores das 
principais regiões produtoras utilizavam adubo em mais de $90 \%$ da área plantada com cana-de-açúcar em 1995.

Outro fato que se pode notar é a predominância do cultivo simples. Em todas as regiões do Brasil, com exceção da região norte no ano de 1970, este tipo de cultivo representa mais de $90 \%$ do total da área plantada. Estes dados constam na parte B do quadro 21. O uso do plantio simples facilita a disseminação de tecnologia entre os estados produtores

Por último, é possível constatar na parte $\mathrm{C}$ do quadro 21 do anexo $\mathrm{C}$ que apenas nas regiões norte e sul (que não são as principais regiões produtoras) ainda existem um pouco mais de lavouras com menos de 10 hectares plantadas com cana-deaçúcar. Nas demais regiões, o percentual dessas lavouras em relação ao total da área plantada é bastante reduzido. Nas regiões nordeste, sudeste e centro-oeste, no ano de 1995, elas representaram apenas 6\%,6\% e 1\%, respectivamente, da área plantada com cana-de-açúcar. A predominância de grandes lavouras facilita a difusão da tecnologia gerada para a cultura da cana-de-açúcar.

O extinto Instituto do Açúcar e do Álcool (IAA) foi o principal fomentador e produtor de pesquisa do setor, tendo contribuído de forma significativa em muitas áreas do conhecimento da cana, e especialmente ao melhoramento genético. No âmbito estadual, podem ser destacados o Instituto Agronômico de Campinas (IAC) e a ESALQ. O IAC vem contribuindo efetivamente na pesquisa e desenvolvimento de novas variedades, além das já conhecidas recomendações de adubação e outros tratos culturais.

O Quadro 1 sintetiza as principais inovações ocorridas na lavoura de canade-açúcar no Estado de São Paulo e que foram difundidas a outros estados. 


\begin{tabular}{|l|c|c|}
\hline & Década de 1970 & Atualidade \\
\hline Principais Variedades & $\begin{array}{c}\text { NA 56-79, CB41-76 } \\
\text { CB49-260 }\end{array}$ & RB72-454, SP81-3250, SP80-1842 \\
\hline Corte (\% de mecanização) & Menos de 5\% & $30 \%$ \\
\hline Sub-produtos & bagaço & $\begin{array}{c}\text { Bagaço, fertirrigação com vinhaça, } \\
\text { aplicação de torta de filtro }\end{array}$ \\
\hline Uso de tratores & mínimo & Mais intensivo \\
\hline Transporte & $100 \%$ mecanizado & $100 \%$ mecanizado \\
\hline Informatização & inexistente & $\begin{array}{c}\text { Utilizado no planejamento de } \\
\text { colheita, gerenciamento da } \\
\text { produção, automação na indústria, } \\
\text { por exemplo. }\end{array}$ \\
\hline
\end{tabular}

Quadro 1 - Principais inovações tecnológicas ocorridas com a cultura da cana-de-açúcar Fonte: CONAB (2004) e Cooperativa dos Produtores de Cana, açúcar e Álcool (COPERSUCAR) (2003)

Com base no que foi exposto, acredita-se que haverá convergência de produtividade da terra para a cultura da cana-de-açúcar no Brasil.

\subsection{Cultura do feijão}

A importância do feijão no Brasil deve-se ao fato dele se constituir um dos alimentos básicos da população brasileira, além de ser um dos principais produtos fornecedores de proteína na dieta alimentar dos extratos sociais menos favorecidos (Embrapa - Arroz e Feijão).

O feijão é cultivado em praticamente todos os estados brasileiros, sendo que na década de 70 os maiores produtores foram: Paraná, Minas Gerais, Rio Grande do Sul, Bahia, São Paulo, e Goiás. No ano de 2001 não houve mudança na distribuição 
geográfica. Os maiores estados produtores na década de 70 permanecem sendo os mesmos em 2001.

A Figura 11 apresenta a evolução da área colhida e da produtividade na cultura do feijoeiro. A área colhida aumentou de 1960 a 1994, sendo que este crescimento foi mais intenso no período de 1960 a 1982. A partir de 1995, a área colhida com feijoeiro tem diminuído.

A produtividade da lavoura do feijoeiro diminuiu de 1960 a 1983, aumentando de 1984 a 2001.

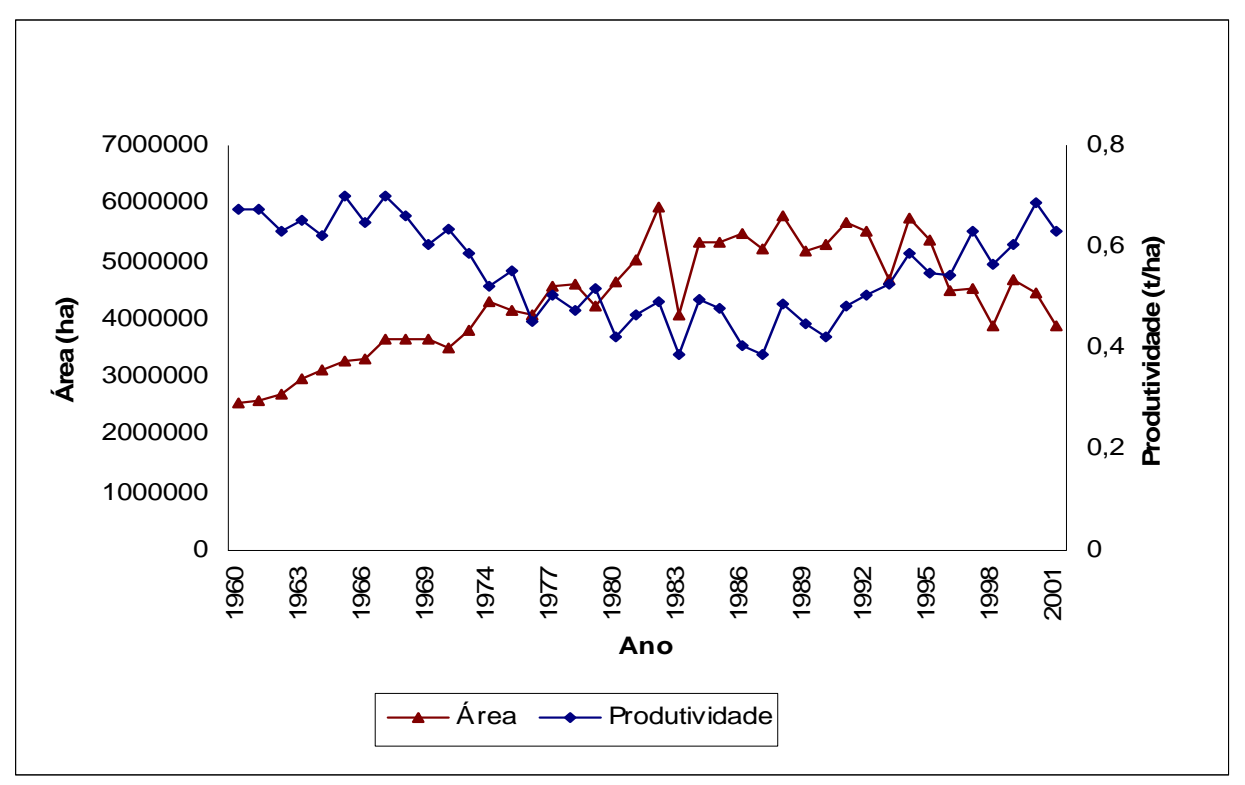

Figura 11 - Evolução da área e produtividade da cultura do feijão: 1960-2001 Fonte: IBGE $(1960,2001)$

A cultura o feijoeiro, além de sua quebra de tendência de área e produtividade, é marcada por distintas tecnologias e estruturas de produção que refletem diferentes níveis de produtividade entre os estados produtores. 
$\mathrm{Na}$ década de 70 , a produtividade dos principais estados produtores foi: Bahia 0,81 t/ha, Minas 0,56 t/ha, São Paulo 0,64 t/ha, Paraná 0,92 t/ha, Rio Grande do Sul 0,94 t/ha e Goiás $0,68 \mathrm{t} / \mathrm{ha}$. No ano de 2001, as produtividades registradas foram: Bahia 0,36 t/ha, Minas Gerais 0,93 t/ha, São Paulo 1,46 t/ha, Paraná 1,07 t/ha, Rio Grande do Sul 0,97 t/ha e Goiás 1,70 t/ha.

Em relação ao uso de adubos, ao tipo de cultivo e à estrutura de produção, adotados na cultura do feijoeiro, observa-se, na parte A do quadro 22 do anexo C, que houve redução significativa na área plantada com esta cultura nas regiões sudeste, centro-oeste e sul, particularmente quando se compara os anos de 1980 e 1995. Mas o inverso ocorreu com as regiões norte e nordeste. Nota-se, também, que as regiões sudeste, centro-oeste e sul são as que adubam um percentual maior de sua área total, quando comparadas às regiões nordeste e norte.

Outro fato que se pode notar na parte B do quadro 22, é que até 1980 pouco ocorria o plantio simples, no entanto, ele passa a predominar na década de 1990. No ano de 1995 as regiões norte, centro-oeste e sul adotaram o plantio simples em $60 \%, 82 \%$ e $80 \%$ de sua área total com feijoeiro, respectivamente.

Por último é possível constatar na parte $\mathrm{C}$ do quadro 22 que há a predominância de propriedades onde o cultivo do feijão é realizado em menos de 10 hectares. Com exceção do ano de 1970 na região sudeste e do ano de 1995 na região centro-oeste, onde a representatividade das lavouras com menos de 10 hectares, em relação à área total plantada representou $47 \%$ e $29 \%$, respectivamente, nos demais anos e regiões as pequenas lavouras têm representado mais de $50 \%$ do total da área plantada com a cultura do feijão.

De acordo com Pessoa (2004):

"a cultura do feijão no Brasil vem passando por profundas mudanças nos últimos anos. Até bem pouco tempo caracterizava-se por cultivos em áreas pequenas, 
com pouca utilização de tecnologia, voltada para a subsistência ou apostando na verdadeira "loteria" que era o mercado de feijão. O baixo uso de tecnologia e a fragilidade agronômica da lavoura, que não resiste bem à seca, ao excesso de chuvas e ainda é facilmente acometida por pragas e doenças, provocavam frustrações freqüentes de safra, que resultavam em disparadas de preços seguidas de superofertas na safra seguinte. Esse excesso deprimia os preços e desestimulava novamente os produtores. Esse comportamento e a possibilidade de produção de feijão em todos os estados, em várias épocas do ano, começaram a despertar o interesse de um outro perfil de produtores, que entraram na atividade com um sistema produtivo mais tecnificado.

Atualmente, os produtores de feijão podem ser classificados em dois grupos: os pequenos, que ainda usam baixa tecnologia e têm sua renda associada às condições climáticas, concentrados na produção das águas (primeira safra); e um segundo grupo, que usa produção mais tecnificada, com alta produtividade, plantio irrigado por pivô-central, concentrado nas safras da seca e do inverno (segunda e terceira safra)" Pessoa, (2004, p. 1).

Com base no que foi exposto acredita-se que não haverá convergência de produtividade da terra para a cultura do feijão no período de 1960-2001, por tratar-se de cultura, conforme já citado, onde convivem dois grupos de produtores: os pequenos, que ainda usam baixa tecnologia e têm sua renda associada às condições climáticas, 
concentrados na produção das águas (primeira safra); e um segundo grupo, que usa produção mais tecnificada, com alta produtividade, plantio irrigado por pivô-central, concentrado nas safras da seca e do inverno (segunda e terceira safra). No entanto, considerando os estados produtores com tecnologia e estrutura de produção similar poderá ocorrer grupos de convergência.

\subsection{Cultura do fumo}

De 1993 a 2002, o Brasil ocupou a primeira posição no cenário mundial como exportador do fumo em folha. Somente em 2003 é que o Brasil perde esta posição e é ultrapassado pela China. Em 2001, o Brasil exportou 435.395 toneladas de fumo, que geraram uma receita de US\$ 921,1 milhões. Como produtor, o Brasil ocupa a $3^{\text {a }}$ posição, perdendo apenas para a China e a Índia. Em 2003, a produção mundial foi de $6.607,8$ mil toneladas e do Brasil foi de 635,8 mil toneladas, isto é, 9,6\% do total mundial.

Apesar dessa boa performance no setor externo, a área colhida com fumo no Brasil sofreu grandes oscilações ao longo do tempo, com tendência ascendente (ver Figura 12). A produtividade também teve tendência ascendente com menor flutuação do que a ocorrida na área. A produtividade da fumicultura passou de $757 \mathrm{~kg} / \mathrm{ha}$ em 1960 para $1.860 \mathrm{~kg} / \mathrm{ha} \mathrm{em} 2001$. 


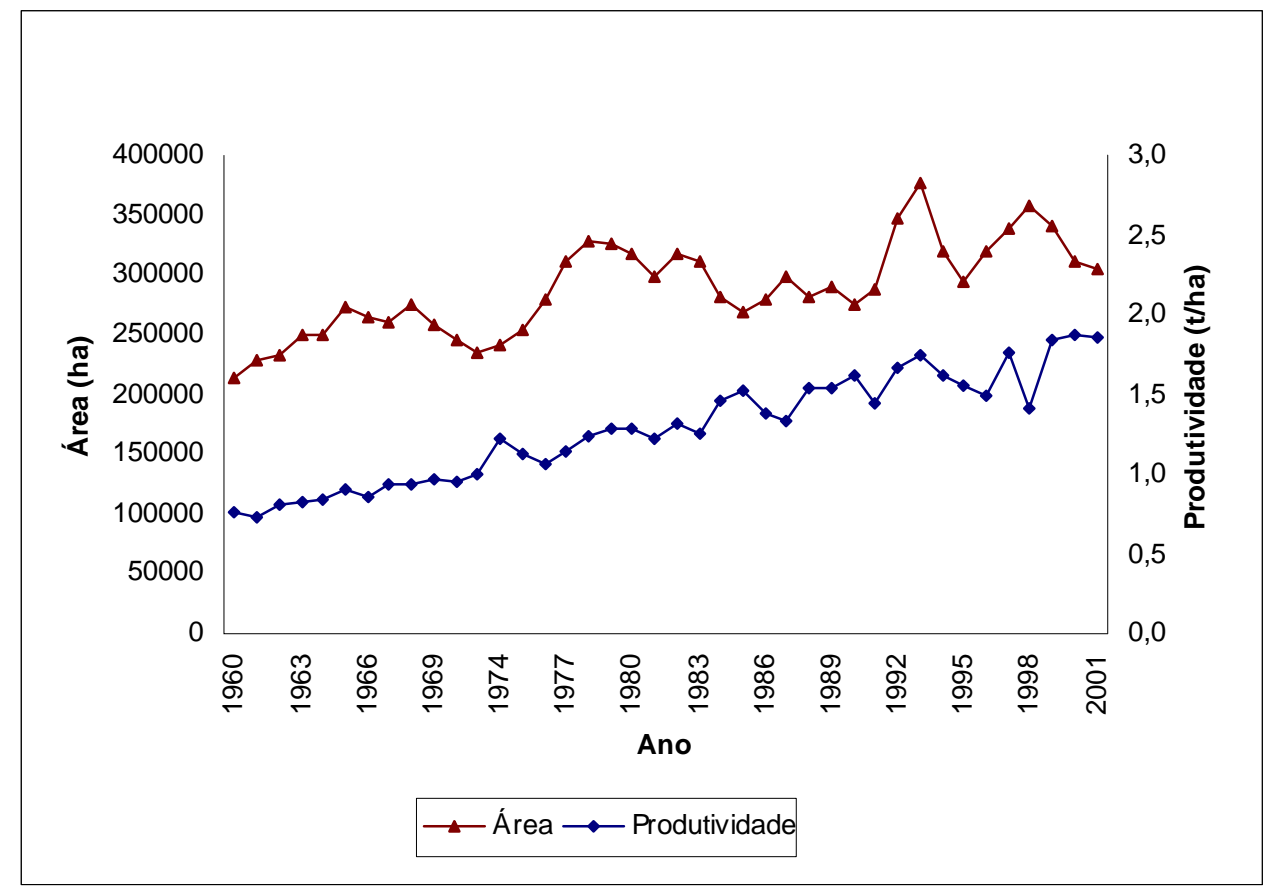

Figura 12 - Evolução da área e produtividade da cultura do fumo: 1960-2001 Fonte: IBGE (1960, 2001)

Observa-se, na parte A do quadro 23, do anexo $\mathrm{C}$ que as principais regiões produtoras de fumo - nordeste e sul - adubam mais de $80 \%$ de sua área total. Nota-se também que nestas regiões a opção dos produtores é pelo cultivo simples. A região sul adotou este tipo de cultivo em 98\% de sua área total plantada nos anos de 1980 e 1995 e o nordeste em 63\% em 1995.

Apesar do nível de adubação e da ocorrência de plantio simples ser menor nos estados do nordeste do que no sul do Brasil, essas práticas têm aumentado nos estados nordestinos e reduzido a diferença em relação aos estados sulinos.

Por último, é possível constatar na parte $\mathrm{C}$ do quadro 23 do anexo $\mathrm{C}$ a predominância de propriedades onde o cultivo do fumo é realizado em áreas com menos de 10 hectares. Essa predominância de pequenas lavouras associada ao predomínio do plantio simples facilitou a difusão de tecnologia entre os estados produtores. 
Assim, com base no que foi exposto, acredita-se que haverá convergência de produtividade da terra para a cultura do fumo. Embora a predominância seja de pequenos produtores, trata-se de uma cultura voltada para o mercado externo com produtores adotando a mesma tecnologia, recomendada e acompanhada pelas indústrias de cigarro.

\subsection{Cultura da laranja}

De acordo com Food and Agriculture Organization (FAO, 1998), o Brasil vem mantendo a liderança no mercado mundial de laranja deste 1990, sendo o estado de São Paulo responsável por 35\% da produção mundial. Na safra de 2002/2003, o Brasil produziu 16.524.000 toneladas. O $2^{\circ}$ maior produtor - os Estados Unidos - produziu 9.565.000 toneladas, o que representou $21,0 \%$ do mercado mundial, em seguida tem-se a China com 7,9\% da produção, México com 7,8\% e a Espanha com 6,3\%.

A produção brasileira de laranja é voltada para o mercado externo, gerando para o Brasil receitas da ordem de US\$ 1,5 bilhão ao ano, empregando diretamente 400 mil pessoas e respondendo por 1,6 milhão de empregos indiretos em todo o país (Abecitrus, 2004).

Conforme pode ser observado na Figura 13, a área colhida com laranja aumentou significativamente de 1960 até 1992, passando de 112.241 ha. em 1960 para 997.403 ha em 1992. Em 1993 houve forte redução da área colhida com laranja, com recuperação da mesma até 1999. Em 2000 e 2001, a área colhida com laranja voltou a cair.

A produtividade da citricultura estava estagnada na década de 1960, apresentando tendência ascendente a partir da $2^{-}$metade da década de 1970. 


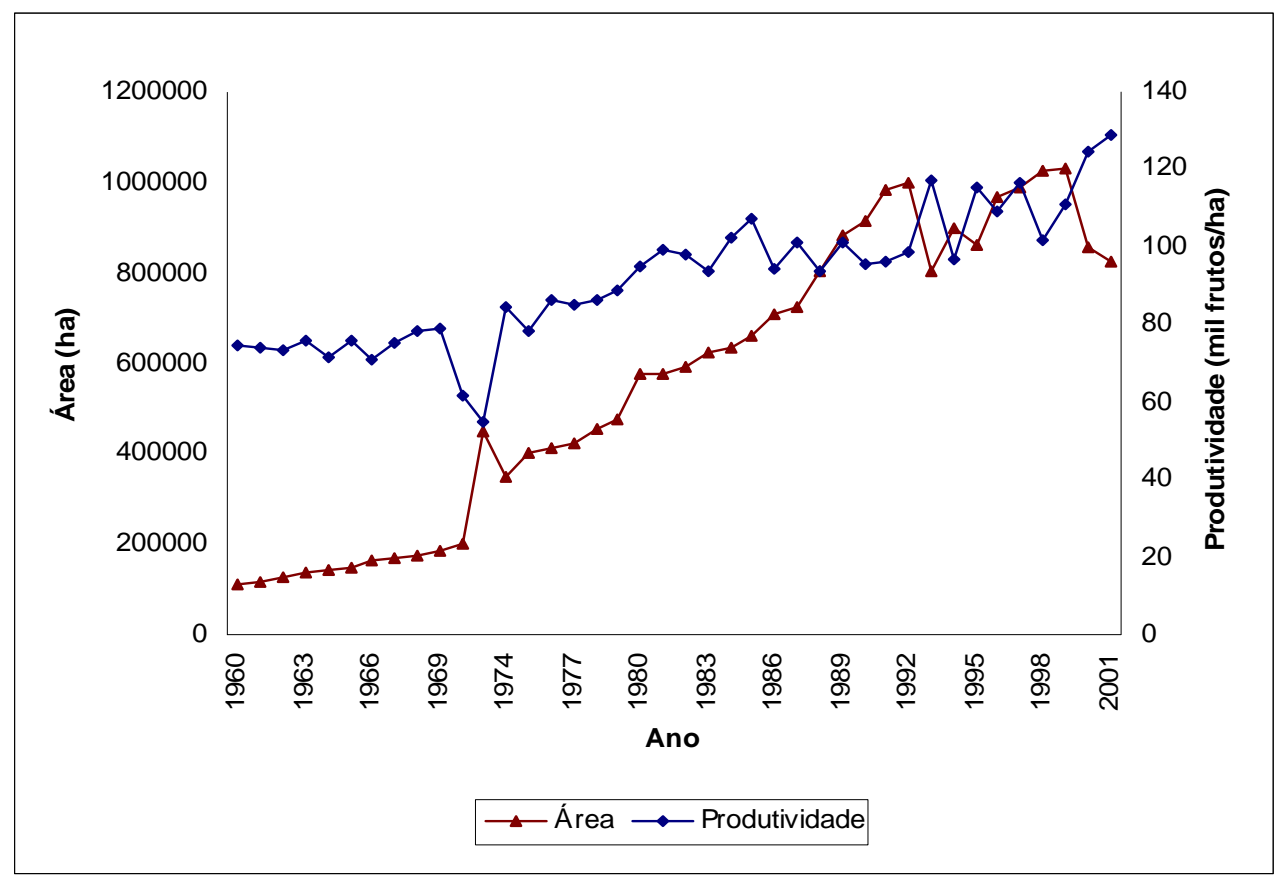

Figura 13 - Evolução da área e produtividade da cultura da laranja: 1960-2001 Fonte: IBGE $(1960,2001)$

A principal região produtora de laranja no Brasil é o sudeste, onde se destaca o Estado de São Paulo. Na parte A do quadro 24 do anexo C constata-se que o nível de adubação das lavouras de laranja ampliou nas regiões brasileiras na década de 1970, sendo que esta prática se homogeniza em intensidade nas regiões nordeste, sudeste, centro-oeste e sul em 1995.

A citricultura tem sido praticada em plantio simples em todas as regiões do Brasil, o que favorece a difusão tecnológica.

A dimensão das lavouras distingue-se entre as regiões. Em 1995, as lavouras com menos de 10 hectares representavam 39\% da área plantada no sudeste, $36 \%$ no centro-oeste, $59 \%$ no nordeste e $82 \%$ no sul. Isto, no entanto, não impede a divulgação da tecnologia, a qual é elaborada, principalmente, no Estado de São Paulo pela Estação Experimental de Citricultura de Bebedouro (EEBC), Fundo de Defesa da Citricultura 
(FUNDECITRUS), Centro de Citricultura Silvio Moreira /IAC e o grupo de Consultores em Citrus (GCONCI).

Com base no que foi exposto acredita-se que haverá convergência de produtividade da terra para a cultura da laranja. Embora exista a predominância de pequenos produtores em algumas regiões, trata-se de uma cultura voltada para o mercado externo com produtores adotando alta tecnologia.

\subsection{Cultura da mandioca}

A cultura da mandioca é originária do Brasil. Sua principal finalidade é a alimentação humana e animal além do seu uso industrial, particularmente de fécula. A mandioca é considerada a mais importante fonte de carboidrato para as populações pobres, principalmente do Brasil e da África.

Nigéria, Brasil e Tailândia são os países que dominam a produção mundial, sendo que o Brasil ocupa a segunda posição. A produção africana tem caráter apenas de subsistência, contrariamente, na Tailândia a produção tem caráter apenas comercial. No Brasil, a produção de mandioca é destinada à subsistência e ao comércio. No triênio 1999-2001 a produtividade mundial foi de 10,3 t/ha, enquanto que a produtividade do Brasil, Nigéria e Tailândia foram de 13,6 t/ha, 10,7 t/ha e 16,1 t/ha, respectivamente.

Como se observa na Figura 14, a área colhida com mandioca aumentou até 1982, sendo que este crescimento foi mais intenso até 1973. Essa área diminuiu de 1983 a 1996, voltando a aumentar a partir de 1997. A produtividade aumentou de 1960 a 1969, diminuiu de 1970 a 1983, voltando a aumentar a partir de 1984. 


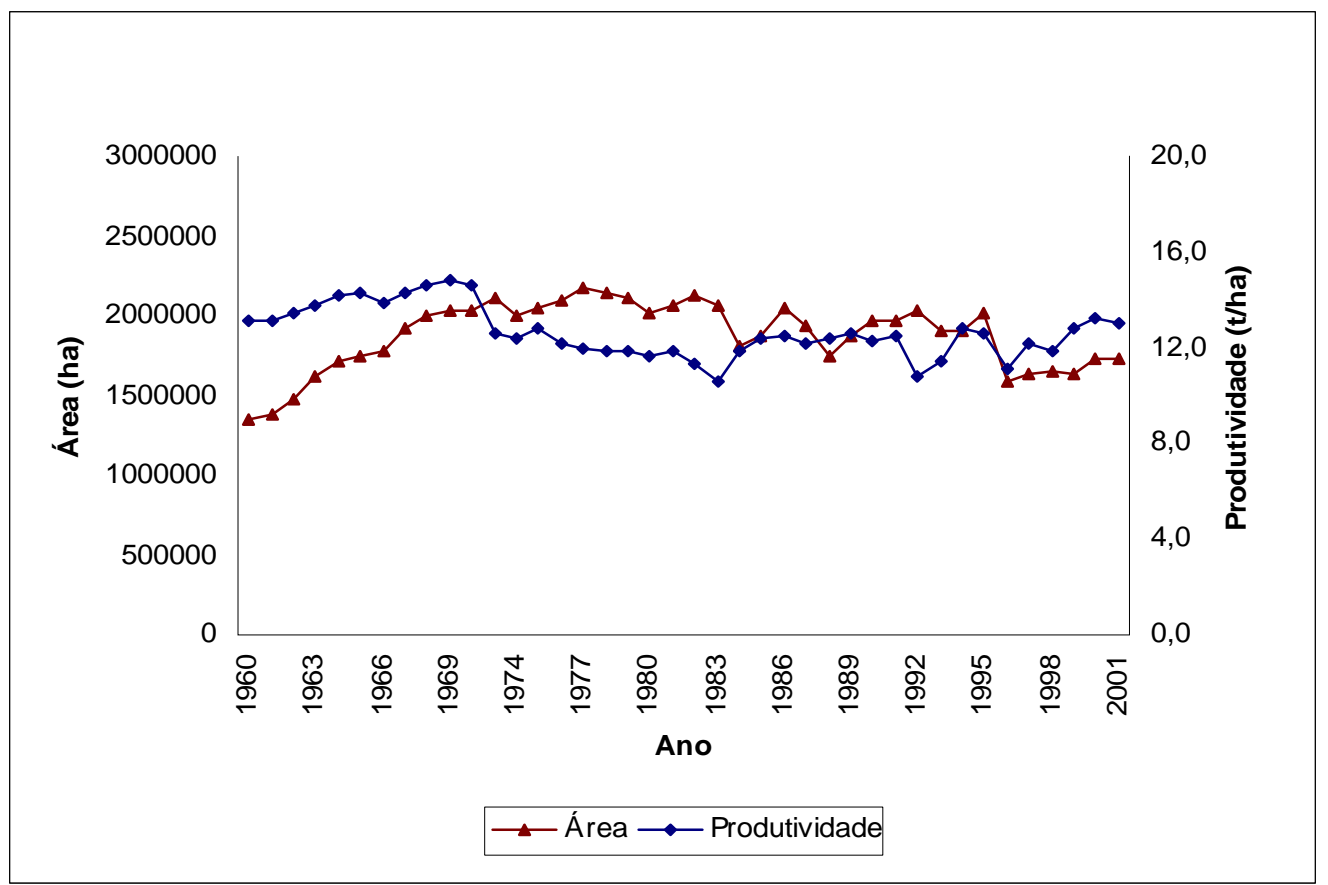

Figura 14 - Evolução da área e produtividade da cultura da mandioca: 1960-2001 Fonte: IBGE (1960, 2001)

A cultura da mandioca não tem sido dinâmica no Brasil. O nível de adubação dessa cultura é baixo. Apesar de adaptada a solos de baixa fertilidade, a mandioca somente atinge seu potencial máximo de produção com adubação adequada. Dentre os macronutrientes, o fósforo é o que permite resposta mais acentuada em termos de produtividade.

A variedade é um dos componentes do sistema de produção que contribui para o aumento da produtividade sem elevar os custos de produção. O grande número de variedades existentes no Brasil permite a escolha de variedades de acordo com a região e a finalidade de exploração da cultura. (EMBRAPA, 2004).

Observa-se, na parte A do quadro 25 no anexo $C$, que as regiões sudeste e sul foram as que mais utilizaram adubo, principalmente nos anos de 1980 e 1995 . No 
ano de 1995 o percentual da área adubada em relação à área total foi de $27 \%$ e 28\%, respectivamente, nessas regiões, o que é considerado um nível baixo.

Quando ao tipo de cultivo, parte B do quadro 25, observa-se que no ano de 1995 houve aumento de área com opção pelo plantio simples, tanto na região norte, como nas regiões sudeste, centro-oeste e sul. Isto tem facilitado a difusão de tecnologia entre os estados.

Com relação à dimensão das lavouras, nota-se, na parte $\mathrm{C}$ do quadro 25 , que existe predominância de áreas plantadas com menos de 10 hectares. No entanto, nos últimos anos há redução da importância dessas lavouras, conseqüentemente, aumento das lavouras médias e grandes que utilizam melhor tecnologia.

Com base no que foi exposto acredita-se que haverá convergência de produtividade da terra para a cultura da mandioca. Embora tenha se verificado uma mudança com esta cultura em termos de tecnologia, o padrão que ainda se verifica é a mandioca sendo cultivada principalmente por produtores de pequeno porte com pouco ou nenhum uso de tecnologia moderna, especialmente de adubos. Nesse sentido, esperase que todos os estados convirjam em termos de produtividade, em função de todos estarem usando baixa tecnologia.

\subsection{Cultura do milho}

Provavelmente, o milho é a mais importante planta comercial com origem nas Américas. Há indicações de que sua origem tenha sido no México, América Central ou Sudoeste dos Estados Unidos. É uma das culturas mais antigas do mundo, havendo provas, através de escavações arqueológicas e geológicas, e através de medições por desintegração radioativa, de que é cultivado há pelo menos 5.000 anos. Logo depois do descobrimento da América, o milho foi levado para a Europa, onde era cultivado em 
jardins, até que seu valor alimentício tornou-se conhecido. Passou, então, a ser plantado em escala comercial e espalhou-se pelo mundo (Embrapa, 2004).

A importância econômica do milho é caracterizada pelas diversas formas de sua utilização, que vai desde a alimentação animal até a indústria de alta tecnologia. No entanto, o uso do milho em grão como alimentação animal representa a maior parte do consumo desse cereal, isto é, cerca de $70 \%$ no mundo. Nos Estados Unidos, cerca de $50 \%$ da produção de milho é destinada a esse fim, enquanto que no Brasil varia de 60 a $80 \%$, dependendo da fonte da estimativa e de ano para ano. Apesar de não ter uma participação muito grande no uso de milho em grão, a alimentação humana, com derivados de milho, constitui fator importante de uso desse cereal em regiões com baixa renda. Em algumas situações, o milho constitui a ração diária de alimentação, por exemplo: no Nordeste do Brasil, o milho é a fonte de energia para muitas pessoas que vivem no semi-árido.

O Brasil é o terceiro maior produtor mundial de milho, responsável por $6 \%$ da produção mundial (35 milhões de toneladas de milho na safra 2001/02) atrás apenas dos Estados Unidos, com 41\% (241,5 milhões de toneladas) e da China (114 milhões de toneladas), com $19 \%$, sendo estes os principais países na produção mundial do cereal (593 milhões de toneladas) US Department of Agriculture, (USDA) (data).

Quanto à produtividade brasileira na cultura do milho, apesar do acréscimo ao longo dos últimos 30 anos (2,82 t/ha em 2001), ela é pequena se comparada à norteamericana $(8,60 \mathrm{t} / \mathrm{ha}$ em 2001) que se beneficia de zonas edafoclimáticas mais adequadas á produção do cereal, ou a Argentina (5,69 t/ha em 2001) que possui solos extremamente férteis.

Em relação à área colhida com milho constata-se, conforme Figura 15, que esta aumentou até 1994, diminuiu de 1995 a 1998 e voltou a aumentar a partir de 1999. A produtividade permaneceu praticamente estagnada até a década de 1960 aumentando a partir de 1970, em especial na década de 1990. 


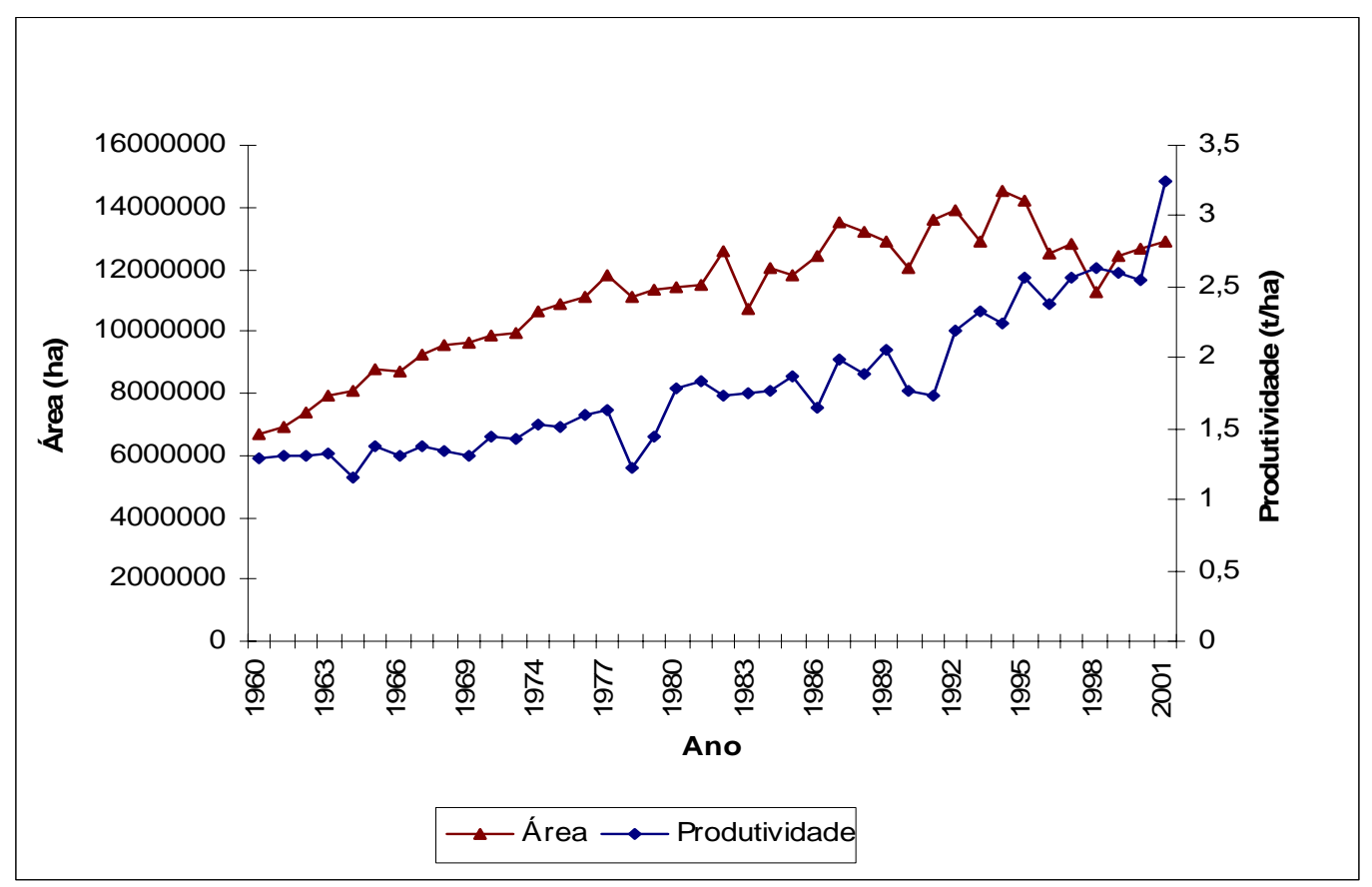

Figura 15 - Evolução da área e produtividade da cultura do milho: 1960-2001

Fonte: IBGE (1960, 2001)

Apesar da expansão da cultura do milho e de seu plantio em todos os estados do Brasil, a produtividade e tecnologia são diferentes entre os estados.

No ano de 2001 nota-se que as diferenças de produtividades entre as regiões produtoras foram bastante acentuadas. Na região norte a produtividade média foi de 1,53 ton/ha. Na região nordeste a produtividade média foi de 0,42 ton/ha. Nas regiões sudeste, sul e centro oeste, as produtividades médias foram 2,27 ton/ha, 4,21 ton/ha e 3,88 ton/ha, respectivamente.

Quanto às mudanças ocorridas com a cultura do milho em relação ao uso de adubo, ao tipo de cultivo e à estrutura de produção, observa-se na parte (A) do quadro 26, anexo C, que a prática de adubação das lavouras de milho vem ampliando, mas ainda é bem distinta entre as regiões produtoras. Em 1995, 84\% da área plantada com milho no 
sudeste era adubada. No centro-oeste e Sul eram $88 \%$ e $85 \%$, mas no norte e nordeste o percentual da área adubada em relação à área total foi de $8 \%$ e $12 \%$, respectivamente.

A prática do plantio simples também vem aumentando, mas é mais intensa no centro-oeste, sudeste e sul. Em 1995, 97\% dos plantios de milho no centro-oeste eram com plantio simples. No sudeste, sul, norte e nordeste essa percentagem era, respectivamente, $84 \%, 89 \%, 57 \%$ e $26 \%$.

No centro-oeste, sudeste e sul predominam médias e grandes lavouras de milho, enquanto que no norte e nordeste são pequenas lavouras as predominantes. Essa diferença do tamanho das lavouras dificulta a homogeneidade de tecnologia, pois parte expressiva das produções de milho no norte e nordeste é para consumo próprio dos produtores.

Com base no que foi exposto acredita-se que não haverá convergência de produtividade da terra para a cultura do milho. Embora tenha se verificado uma mudança com esta cultura em termos de tecnologia, ainda se observa a convivência de pequenos produtores, cultivando com baixa tecnologia e consumo próprio, com grandes produtores cultivando em áreas maiores, com uma tecnologia mais avançada e produção voltada ao mercado. Assim, o que espera é, não a convergência de todos os estados produtores para um nível comum de produtividade, mas a formação de grupos de estados - com baixa e alta tecnologia - convergindo entre si.

\subsection{Cultura da soja}

Originária da China, o soja chegou no Brasil em 1882, trazido dos Estados Unidos. Contudo foi somente no ano de 1900 e 1901 que o IAC distribuiu aos produtores as primeiras sementes para serem plantadas.

O soja é um grão muito versátil que dá origem a produtos e subprodutos muito usados pela agroindústria, indústria química e de alimentos. Na alimentação 
humana, o soja entra na composição de vários produtos e seu uso mais conhecido, no entanto, é como óleo refinado, obtido a partir do óleo bruto. Nesse processo, também é produzida a lecitina, um agente emulsificante (substância que faz a ligação entre a fase aquosa e oleosa dos produtos), muito usada na fabricação de salsichas, maioneses, achocolatados, entre outros produtos. Recentemente, o soja vem crescendo também como fonte alternativa de combustível.

No ano de 2003 a produção mundial de soja foi de 195,82 milhões de toneladas, numa área plantada de 81,221 milhões de hectares. Esta produção atende um Complexo Agroindustrial que movimenta aproximadamente US\$ 215 bilhões/ano. Os Estados Unidos é o maior produtor mundial do grão. Sua produção é de 74,29 milhões de toneladas numa área plantada de 29,27 milhões de hectares. A produtividade norteamericana é de $2,25 \mathrm{mil} \mathrm{kg} / \mathrm{ha}$. O Brasil é o segundo maior produtor do mundo. No ano de 2001 sua produção foi de 37,9 milhões de toneladas numa área colhida de 13,99 milhões de hectares, com produtividade de $2,71 \mathrm{mil} \mathrm{kg} / \mathrm{ha}$. A produção brasileira atendeu, neste mesmo ano, um Complexo Agroindustrial que movimentou US\$ 30 bilhões. Sua produtividade média foi de $2.340 \mathrm{~kg} / \mathrm{ha}$. Figuram também como maiores produtores, a Argentina e a China e Índia (Embrapa Soja).

Conforme pode ser observado na Figura 16, a área colhida com soja tem crescido quase que continuamente, em especial a partir da década de 1970. Em 1960 a área colhida com soja foi de 171.440 hectares, no ano de 1970 foi de 1.318 .809 hectares e nos anos de 1990 e 2001 foram de 11.584 .734 e 13.988 .351 hectares, respectivamente. Esse grande crescimento da área também veio acompanhado de grande crescimento de produtividade. 


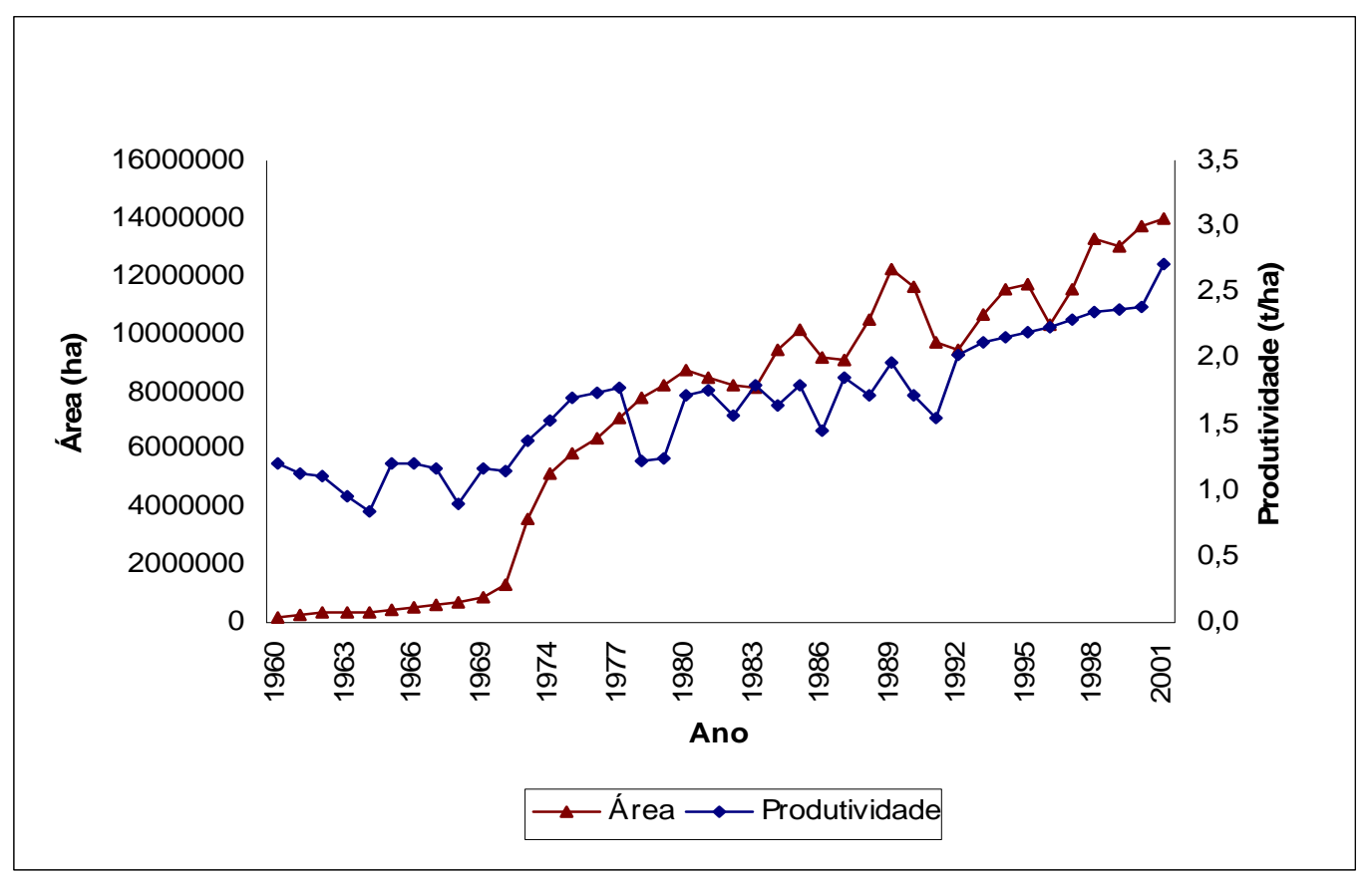

Figura 16 - Evolução da área e produtividade da cultura da soja: 1960-2001

Fonte: IBGE $(1960,2001)$

Os principais estados produtores em 1970, com suas respectivas produção e área, foram: Paraná (368.006 ton. em 304.211 ha), São Paulo (90.086 ton. em 62.152 ha), Rio Grande do Sul (976.807 ton. em 871.202 ha) e Santa Catarina (52.998 ton. em 65.956 ha).

No ano de 2001, além dos estados já citados, passaram também a figurar no cenário nacional, como maiores produtores, os estados de Minas Gerais, Mato Grosso, Goiás, Bahia e Maranhão. A produção e a área dos principais estados em 2001 foram: Paraná (8.615.187 ton. em 2.818.080 ha), São Paulo (1.355.680 ton. em 530.000 ha), Minas Gerais (1.390.635 ton. em 632.418 ha), Rio Grande do Sul (6.951.830 ton. em 2.976.498 ha) e Santa Catarina (534.321 ton. em 198.853 ha), Mato Grosso + Mato Grosso do Sul (12.648.316 ton. em 4.186.434 ha), Goiás + Tocantins (4.240.395 ton. em 1.621.086 ha), Bahia (1.407.600 ton. em 690.000 ha) e Maranhão (491.083 ton. em 213.436 ha). 
Não há uma diferença tão grande em termos de produtividade entre os principais estados produtores de soja tal como surge no milho. De acordo com a Embrapa Soja, isto é devido à constante preocupação deste órgão em desenvolver cultivares adaptados às diferentes realidades estaduais e/ou regionais. A produtividade observada no ano de 2001, nos principais estados produtores, foi: Paraná 4,49 ton/ha, São Paulo 3,74 ton/ha, Minas Gerais 3,31 ton.ha, Santa Catarina 4,40 ton/ha, Rio Grande do Sul 3,66 ton/ha, Mato Grosso 3,61 ton/ha e Goiás 4,38 ton/ha.

A freqüência de adubação nas lavouras do soja cresceram e são, atualmente, muito próximas nas principais regiões produtoras. Observa-se, na parte A do quadro 27 (anexo C), que as principais regiões produtoras - sudeste, centro-oeste e sul - utilizam adubo em mais de $95 \%$ de sua área total.

Nota-se também que, independente da ordem de classificação das regiões em relação à produção nacional, todas elas adotam o tipo de cultivo simples na maior parte da área total plantada (parte B, do quadro 27)

A cultura do soja tem sido realizada em médias e grandes lavouras, sendo que as pequenas lavouras (até 10 hectares) têm diminuído. Apenas na região sul elas existem, mas passaram de 19\% da área plantada em 1970 para 11\% em 1995 (parte C do quadro 27). Essa homogenização no tamanho das lavouras entre os estados produtores facilita a difusão de tecnologia.

Com base no que foi exposto acredita-se que haverá convergência de produtividade da terra para a cultura do soja. 


\section{MODELO TEÓRICO SOBRE CONVERGÊNCIA DA PRODUTIVIDADE DA TERRA}

Este capítulo desenvolve um modelo teórico, tomando como base o modelo de Barro e Sala-i-Martin (1990) e a apresentação de Valdéz (1999), para explicar o processo de convergência da produtividade da terra. Para tanto, define-se um modelo composto de três equações, para uma economia na qual apenas o setor agropecuário é considerado, ou seja: uma função de produção, uma função de acumulação de capital e uma função para a taxa de crescimento da população. A economia produz e consome uma única mercadoria. Assim, da produção, designada por Y (t), uma parte é consumida e o restante é poupado e investido.

Se designarmos a fração poupada do produto por uma constante s, então, a taxa de poupança pode ser representada por $s \mathrm{Y}(\mathrm{t})$ e o estoque de capital, na forma de acumulação do capital, por $\mathrm{K}(\mathrm{t})$. O investimento líquido será, então, o aumento neste estoque de capital dado por $\Delta K$. Logo, a equação para o crescimento do capital é o investimento total (sY) menos a depreciação, que corresponde a uma fração constante do capital a cada período de tempo, designada por $\delta \mathrm{K}$. Tem-se: ${ }^{18}$ :

$$
\Delta K=s Y-\delta K
$$

\footnotetext{
${ }^{18}$ A hipótese de igual taxas de depreciação para todos os tipos de capital decorre do fato de ser este um parâmetro não observável que varia com o uso e a idade do bem. Ball et al. (1993) tentaram contornar o problema introduzindo um método que assume diferentes taxas de depreciação para diferentes tipos de capital, porém, não resolveram o problema. Assim, este estudo assumirá taxas iguais de depreciação para todos os tipos de capital.
} 
O produto $(\mathrm{Y})$ é produzido com a ajuda de apenas três insumos: capital $\left(\mathrm{K}_{\mathrm{t}}\right)$, terra $\left(\mathrm{S}_{\mathrm{t}}\right)$ e trabalho $\left(\mathrm{L}_{\mathrm{t}}\right)$.

Definindo a função de produção como sendo:

$$
\mathrm{Y}=\mathrm{F}(\mathrm{K}, \mathrm{L}, \mathrm{S})
$$

Trata-se de uma função de produção que apresenta retornos constantes à escala $^{19}$, implicando que $\mathrm{F}(\alpha \mathrm{K}, \alpha \mathrm{L}, \alpha \mathrm{S})=\alpha \mathrm{Y}$, ou seja, duplicando os insumos, o produto dobrará. Os produtos marginais do capital, da terra e do trabalho são positivos, mas decrescentes, significando que $F_{K}=\frac{\partial Y}{\partial K}>0 \quad F_{L}=\frac{\partial Y}{\partial L}>0$ e $F_{T}=\frac{\partial Y}{\partial S}>0$ assim como, $F_{K}^{\prime}=\frac{\partial^{2} Y}{\partial K^{2}}<0 \quad F_{T}^{\prime}=\frac{\partial^{2} Y}{\partial S^{2}}<0$ e $F_{L}^{\prime}=\frac{\partial^{2} Y}{\partial L^{2}}<0$. Além dessas características, é uma função homogênea de grau um. Não há recursos não aproveitáveis, não há comércio internacional e nem progresso técnico.

A quantidade de terra produtiva no tempo é dada pela equação que consta da $1^{a}$ lei de Mitscherlich (ver Mahl et. al, 2000), ou seja:

$$
S_{t}=S^{\max }\left[1-e^{-b(t+\theta)}\right]
$$

Na equação (31) $S_{t}$ representa a terra produtiva no tempo t, $S^{\max }$ corresponde à quantidade total de área apta para a agricultura, $\theta$ descreve o valor de $\mathrm{S}_{0}$ ou o valor de terra produtiva inicial, e b é o parâmetro da curva.

A representação gráfica da equação de Mitscherlich é dada pela Figura 17, abaixo:

\footnotetext{
${ }^{19}$ A suposição de uma função de produção com retornos constantes à escala tem, recentemente, recebido suporte empírico de Mundlak et.al. (1997). Eles mostraram que a soma da elasticidade dos inputs numa regressão sem restrição entre países, é praticamente 1. Bernard e Jones (1996) estimaram o coeficiente de convergência para 6 setores dos Estados Unidos incluindo a agricultura e consideraram competição perfeita e retornos constantes à escala.
} 


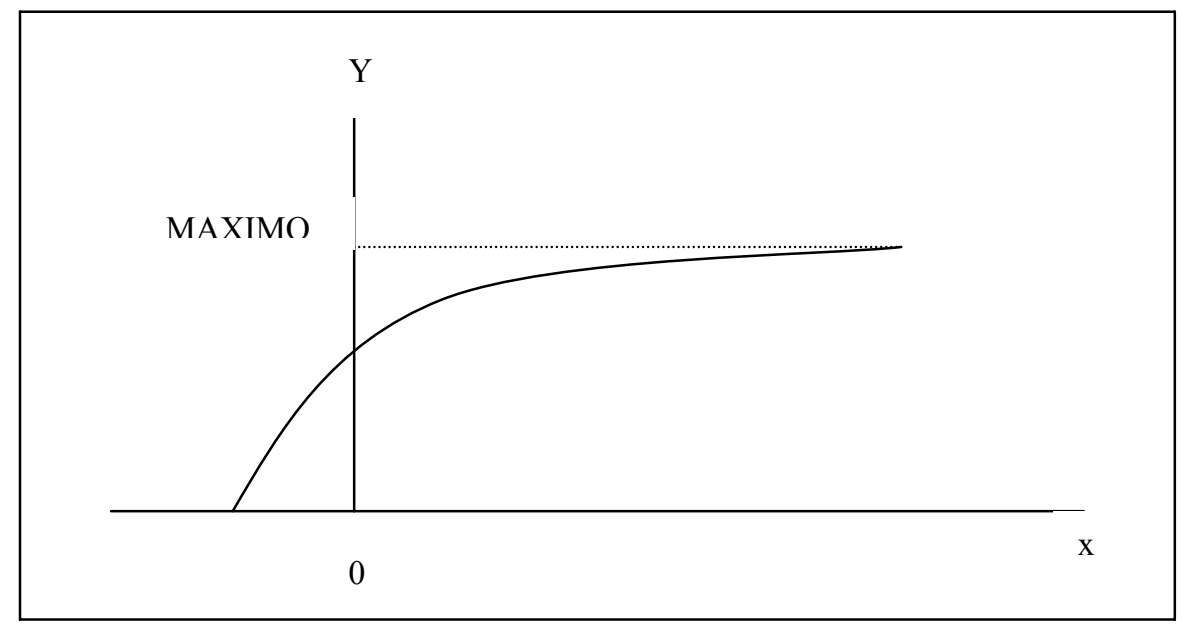

Figura 17 - Ilustração gráfica representativa da equação de Mitscherlich

A escolha dessa expressão decorre do fato de que a evolução de ocupação de terras no Brasil seguiu um comportamento similar ao gráfico que representa esta equação. Por esta razão, acredita-se ser apropriada considerá-la como representativa da quantidade de terra produtiva no tempo.

Derivando a equação (31) em relação ao tempo (t), tem-se:

$$
\begin{aligned}
& \frac{d S_{t}}{d t}=S^{\max }\left[-e^{-b(t+\theta)}(-b)\right] \\
& \frac{d S_{t}}{d t}=b \cdot S^{\max }\left[e^{-b(t+\theta)}\right] \\
& \frac{d S_{t}}{d t}=\frac{b \cdot S^{\max }}{e^{b(t+\theta)}}
\end{aligned}
$$

Considerando que o crescimento da população é exógeno e que a força de trabalho agrícola aumenta a uma taxa constante relativa $n$, tem-se:

$$
L(t)=L_{0} e^{n \cdot t}
$$


Ao definir esta função levou-se em consideração o fato de que ela é válida para certos períodos de tempo, onde $n$ é fixo em um dos períodos, mas ele pode diferir de um período a outro.

Substituindo a equação (31) e (33 ) na equação (29), obtém-se:

$$
\Delta K=s F\left[K, L_{0} e^{n t}, S^{\max }\left(1-e^{-b(t+\theta)}\right)\right]-\delta K
$$

Reescrevendo a função de produção definida pela equação (30) em termos da terra, tem-se que:

$$
\frac{Y}{S}=F\left(\frac{K}{S}, \frac{L}{S}, \frac{S}{S}\right)=F\left(\frac{K}{S}, \frac{L}{S}, 1\right)
$$

Chamando, $k=K / S, y=Y / S$ e $l=L / S$ que representam, respectivamente, o capital por hectare, o produto por hectare ou produtividade da terra e o trabalho por hectare, a equação (35) pode ser reescrita como:

$$
y=f(k, l)
$$

Esta expressão informa que a produtividade da terra está em função do capital por hectare e do número de trabalhadores por hectare. Logo, para que $y$ aumente, é preciso aumentar tanto o estoque de capital quanto de trabalho por hectare.

De (29) tínhamos $\Delta K=s(Y)-\delta K$, que dividindo pela terra nos dá a acumulação de capital por hectare, assim:

$$
\begin{aligned}
& \frac{\Delta K}{S}=s \frac{Y}{S}-\delta \frac{K}{S} \\
& \frac{\Delta K}{S}=s \cdot y-\delta k
\end{aligned}
$$


Por definição $\frac{K}{S}=k$. Extraindo o logaritmo dessa expressão e derivando com relação ao tempo obtém-se a taxa de crescimento do capital por hectare, dada por:

$$
\begin{aligned}
& \ln K-\ln S=\ln k \\
& \frac{\partial \ln K}{d t}-\frac{\partial \ln S}{d t}=\frac{\partial \ln k}{d t} \quad \text { ou, } \\
& \frac{1}{k} \cdot \frac{d k}{d t}=\frac{1}{K} \cdot \frac{d K}{d t}-\frac{1}{S} \cdot \frac{d S}{d t} \\
& \frac{\Delta k}{k}=\frac{\Delta K}{K}-\frac{\Delta S}{S}
\end{aligned}
$$

ou seja, a taxa de crescimento do capital por hectare é igual a taxa de crescimento do capital menos a taxa de crescimento da terra.

Mas, a taxa de crescimento da quantidade produtiva de terra (S) no tempo é dada por:

$$
\begin{aligned}
\frac{\Delta S}{S} & =\frac{b \cdot S^{\max }}{e^{b(t+\theta)}} \cdot \frac{1}{S^{\max }\left[1-e^{-b(t+\theta)}\right]} \\
\frac{\Delta S}{S} & =\frac{b}{e^{b(t+\theta)}\left[1-e^{-b(t+\theta)}\right]} \\
\frac{\Delta S}{S} & =\frac{b}{e^{b(t+\theta)}-1}
\end{aligned}
$$

Substituindo a equação (40) na equação (39), temos que:

$$
\frac{\Delta k}{k}=\frac{\Delta K}{K}-\frac{b}{\left(e^{b(t+\theta)}-1\right)}
$$


Multiplicando ambos lados da expressão (41) por $K$, ficamos com:

$\bar{S}$

$\frac{\Delta k}{k} \cdot \frac{K}{S}=\frac{\Delta K}{K} \cdot \frac{K}{S}-\frac{b}{\left(e^{b(t+\theta)}-1\right)} \cdot \frac{K}{S}$ que após eliminar os termos comuns,

gera:

$\Delta k=\frac{\Delta K}{S}-\frac{b}{\left(e^{b(t+\theta)}-1\right)} \cdot k$

mas, da equação (37), tem-se que: $\frac{\Delta K}{S}=s\left(\frac{Y}{S}\right)-\delta\left(\frac{K}{S}\right)=s(y)-\delta k$.

Substituindo esta informação na equação (42), obtém-se:

$\Delta k=s y-\delta . k-\frac{b}{\left(e^{b(t+\theta)}-1\right)} . k$

Rearranjando os termos, obtém-se:

$\Delta k=s y-\left(\frac{b}{\left(e^{b(t+\theta)}-1\right)}+\delta\right) k$

A expressão (43) nos dá o aumento da relação K/S.

Assumindo agora uma função de produção Cobb-Douglas ampliada para considerar a tecnologia tem-se que:

$$
Y=A \cdot\left(K^{\alpha} L^{\beta} S^{1-\alpha-\beta}\right)
$$

onde,

$\mathrm{A}=\mathrm{A}_{0} \mathrm{e}^{\mathrm{gt}}$

Derivando a equação (45) em relação ao tempo, tem-se que: 


$$
\begin{aligned}
& \Delta A=g \cdot A_{0} e^{g t}=g \cdot A \text { então, } \\
& \frac{\Delta A}{A}=g
\end{aligned}
$$

onde g é o parâmetro que representa a taxa de crescimento tecnológico exógena.

Dividindo a equação (44) por S para expressá-la em termos de hectare, temse que:

$$
\frac{Y}{S}=\frac{A \cdot K^{\alpha} \cdot L^{\beta} \cdot S^{1-\alpha-\beta}}{S}
$$

Multiplicando e dividindo o segundo membro da expressão imediatamente acima por $S^{\alpha}$ e $S^{\beta}$, tem-se:

$$
\frac{Y}{S}=A \cdot \frac{K^{\alpha}}{S^{\alpha}} \frac{L^{\beta}}{S^{\beta}} \frac{S^{1-\alpha-\beta}}{S} \cdot S^{\alpha} \cdot S^{\beta}
$$

como, $y=Y / S \quad k=K / S$ e $\quad l=L / S$ então, a equação (47) pode ser reescrita como:

$$
y=A k^{\alpha} l^{\beta}, \text { pois } \frac{S^{1-\alpha-\beta} \cdot S^{\alpha} \cdot S^{\beta}}{S}=1
$$

Tirando o logaritmo natural da expressão (48) e derivando em relação ao tempo, obtém-se:

$$
\begin{aligned}
& \ln y=\ln A+\ln k^{\alpha}+\ln l^{\beta} \\
& \frac{\partial \ln y}{\partial t}=\frac{\partial \ln A}{\partial t}+\frac{\partial \ln k^{\alpha}}{\partial t}+\frac{\partial \ln l^{\beta}}{\partial t} \\
& \frac{1}{y} \cdot \Delta y=\frac{1}{A} \cdot \Delta A+\frac{1}{k^{\alpha}} \cdot \alpha \cdot k^{\alpha-1} \cdot \Delta k+\frac{1}{l^{\beta}} \cdot \beta \cdot l^{\beta-1} \cdot \Delta l
\end{aligned}
$$


como $\frac{\Delta A}{A}=g$ então:

$$
\frac{\Delta y}{y}=g+\alpha \frac{\Delta k}{k}+\beta \frac{\Delta l}{l}
$$

chamando: $\frac{\Delta y}{y}=g_{y}, \frac{\Delta l}{l}=g_{l}$ e $\frac{\Delta k}{k}=g_{k}$ e substituindo na equação (49) temos que:

$$
g_{y}=g+\alpha g_{k}+\beta g_{l}
$$

Da equação (50) conclui-se que a taxa de crescimento do produto por hectare $\left(\mathrm{g}_{\mathrm{y}}\right)$ é igual à soma da taxa de crescimento da tecnologia $(\mathrm{g})$, da taxa de crescimento do capital por hectare $\left(\mathrm{g}_{\mathrm{K}}\right)$ e da taxa de crescimento do trabalho por hectare $\left(\mathrm{g}_{\mathrm{l}}\right)$, esses dois últimos ponderados por sua participação na função de produção.

Definindo o capital por hectare em termos de tecnologia como sendo, $\widetilde{k}_{t}=\frac{k_{t}}{A_{t}}$, o produto por hectare em termos de tecnologia como sendo, $\tilde{y}_{t}=\frac{y_{t}}{A_{t}}$ e o trabalho por hectare em termos de tecnologia como sendo, $\tilde{l}_{t}=\frac{l_{t}}{A_{t}}$. Neste caso, temos que: $k_{t}=\widetilde{k}_{t} A_{t}$ assim como, $y_{t}=\widetilde{y}_{t} A_{t} \quad$ e $\quad l_{t}=\widetilde{l}_{t} A_{t}$.

A taxa de crescimento da produtividade da terra em termos tecnológico, definida por $\hat{\widetilde{y}}$, é dada por:

$$
\hat{\tilde{y}}=\frac{\Delta \widetilde{y}}{\widetilde{y}}
$$

mas, $\tilde{y}=\frac{y}{A}=\frac{A \cdot k^{\alpha} \cdot l^{\beta}}{A} \quad$ portanto, 


$$
\widetilde{y}=k^{\alpha} l^{\beta}
$$

Derivando a equação (52) em relação ao tempo, tem-se que:

$$
\begin{aligned}
& \frac{d \widetilde{y}}{d t}=\frac{d\left(k^{\alpha} l^{\beta}\right)}{d t}=\frac{d k^{\alpha}}{d t} \cdot l^{\beta}+k^{\alpha} \frac{d l^{\beta}}{d t} \\
& \frac{d \widetilde{y}}{d t}=\alpha \cdot k^{\alpha-1} \cdot \Delta k \cdot l^{\beta}+k^{\alpha} \cdot \beta \cdot l^{\beta-1} \cdot \Delta l \\
& \frac{d \widetilde{y}}{d t}=k^{\alpha} l^{\beta}\left[\alpha \cdot k^{-1} \cdot \Delta k+\beta \cdot l^{-1} \cdot \Delta l\right]
\end{aligned}
$$

A partir da equação (53) obtém-se a taxa de crescimento do produto por hectare em termos de tecnologia $(\hat{\tilde{y}})$, que é dado por:

$$
\begin{aligned}
& \hat{\tilde{y}}=\frac{\frac{d \widetilde{y}}{d t}}{\widetilde{y}}=\frac{k^{\alpha} l^{\beta} \cdot\left[\alpha \cdot k^{-1} \cdot \Delta k+\beta \cdot l^{-1} \cdot \Delta l\right]}{k^{\alpha} l^{\beta}}, \text { então, } \\
& \hat{\tilde{y}}=\frac{\frac{d \tilde{y}}{d t}}{\tilde{y}}=\alpha \cdot \frac{\Delta k}{k}+\beta \cdot \frac{\Delta l}{l}
\end{aligned}
$$

Esta expressão informa que a taxa de crescimento da produtividade agrícola, medida em termos tecnológicos, depende da taxa de crescimento do capital/hectare e da taxa de crescimento do trabalho/hectare, ambos ponderados por sua participação na função de produção.

Substituindo a equação (54) na equação (49) obtém-se:

$$
\frac{\Delta y}{y}=\hat{y}=g+\hat{\tilde{y}}
$$


De modo análogo, obtém-se:

$$
\begin{aligned}
& \hat{k}=g+\hat{\widetilde{k}} \\
& \hat{l}=g+\hat{\widetilde{l}}
\end{aligned}
$$

Da equação (36) tínhamos que $y=f(k, l)$. Dividindo esta expressão pela tecnologia (A), tem-se que, $\frac{y}{A}=f\left(\frac{k}{A}, \frac{l}{A}\right)$ a partir da qual se obtém:

$$
\tilde{y}=f(\tilde{k}, \tilde{l})
$$

então:

$$
\begin{aligned}
& \hat{\tilde{y}}=\frac{d \tilde{y} / d t}{\widetilde{y}}=\frac{(d f / d \tilde{k}) \cdot(d \tilde{k} / d t)+(d f / d \tilde{l}) \cdot(d \tilde{l} / d t)}{f(\widetilde{k} \tilde{l})} \\
& \hat{\tilde{y}}=\frac{d \widetilde{y} / \mathrm{dt}}{\widetilde{y}}=\frac{\mathrm{f}^{\prime}(\tilde{\mathrm{k}}) \cdot(\mathrm{d} \tilde{\mathrm{k}} / \mathrm{dt})+\mathrm{f}^{\prime}(\tilde{\mathrm{l}}) \cdot(\mathrm{d} \tilde{\mathrm{l}} / \mathrm{dt})}{\mathrm{f}(\tilde{\mathrm{k}} \tilde{\mathrm{l}})}
\end{aligned}
$$

mas, $f^{\prime}(\widetilde{k})=P M_{\mathrm{g}} K$, que é o produto marginal do capital e $\mathrm{f}^{\prime}(\widetilde{1})=\mathrm{PM}_{\mathrm{g}} \mathrm{L}$, o produto marginal do trabalho. Substituindo estas informações na expressão (59), tem-se que:

$$
\hat{\tilde{y}}=\frac{d \widetilde{y} / d t}{\widetilde{y}}=\frac{P M_{g} K \cdot(d \tilde{k} / d t)}{f(\widetilde{k} \tilde{1})}+\frac{P M_{g} L \cdot(d \tilde{l} / d t)}{f(\widetilde{k} \tilde{1})}
$$

Multiplicando o numerador e o denominador da $1^{\mathrm{a}}$ parcela do $2^{\mathrm{o}}$ membro da equação (60) por $\widetilde{k}$ e a $2^{\text {a }}$ parcela do $2^{\circ}$ membro por $\widetilde{l}$, obtemos: 


$$
\hat{\tilde{y}}=\frac{\tilde{k} \cdot P M_{g} K \cdot(d \tilde{k} / d t)}{f(\tilde{k} \widetilde{1}) \cdot \widetilde{k}}+\frac{\tilde{1} \cdot P M_{g} L \cdot(d \tilde{l} / d t)}{f(\tilde{k} \widetilde{1}) \cdot \widetilde{1}}
$$

e utilizando a informação de que, $\frac{d \widetilde{k} / d t}{\widetilde{k}}=\hat{\widetilde{k}}, \frac{d \tilde{l} / d t}{\widetilde{l}}=\hat{\widetilde{l}}$ além de que: $f(\widetilde{k} \widetilde{l})=\frac{Y}{A S}$, $\tilde{\mathrm{k}}=\frac{\mathrm{K}}{\mathrm{AS}}$ e $\tilde{l}=\frac{L}{A S}$, a expressão (61) pode ser reescrita como:

$$
\hat{\tilde{y}}=\frac{(\mathrm{K} / \mathrm{AS}) \cdot \mathrm{PM}_{\mathrm{g}} \mathrm{K} \cdot \hat{\tilde{\mathrm{k}}}}{\mathrm{Y} / \mathrm{AS}}+\frac{\left(\mathrm{L} / \mathrm{AS}^{\mathrm{S}}\right) \mathrm{PM}_{\mathrm{g}} \mathrm{L} \cdot \hat{\tilde{1}}}{\mathrm{Y} / \mathrm{AS}}
$$

Após eliminar os termos comuns e usando o fato de que $\mathrm{K} \cdot \mathrm{PM}_{\mathrm{g}} \mathrm{K}=\boldsymbol{\pi}=$ montante de remuneração do capital e L.PMgL $=\mathrm{W}=$ montante de remuneração do trabalho, pode-se reescrever (62) como sendo:

$$
\hat{\tilde{y}}=\frac{\pi}{Y} \hat{\widetilde{k}}+\frac{W}{Y} \hat{\widetilde{l}}
$$

ou,

$$
\hat{\tilde{y}}=s_{K} \cdot \hat{\tilde{k}}+S_{L} \cdot \hat{\tilde{l}}
$$

onde $S_{K}$ é a participação da remuneração do capital no produto agropecuário e $S_{L}$ é a participação da remuneração do trabalho no produto agropecuário.

Da equação (55) tínhamos que $\hat{y}=g+\hat{\tilde{y}}$. Substituindo a equação (63) nesta expressão, obtém-se:

$$
\hat{y}=g+s_{K} \hat{\widetilde{k}}+s_{L} \hat{\tilde{l}}
$$


Pela equação (43) tínhamos que $\Delta k=s y-\left(\frac{b}{\left(e^{b(t+\theta)}-1\right)}+\delta\right) k$. Expressando esta equação em termos tecnológicos obtém-se:

$$
\frac{\Delta k}{A}=s \tilde{y}-\left(\frac{b}{e^{b(t+\theta)}-1}+\delta\right) \widetilde{k}
$$

como, $\widetilde{k}=\frac{k}{A}$ então,

$$
\Delta \widetilde{k}=\frac{\Delta k \cdot A-k \cdot \Delta A}{A^{2}}
$$

Substituindo a equação (46) na equação acima, tem-se:

$$
\Delta \widetilde{k}=\frac{\Delta k \cdot A}{A \cdot A}-\frac{k \cdot g \cdot A}{A \cdot A}, \text { eliminando os termos comuns dessa expressão, obtém- }
$$

se:

$$
\frac{\Delta k}{A}=\Delta \widetilde{k}+\widetilde{k} \cdot g
$$

Substituindo a equação (66) na equação (65) tem-se que,

$$
\Delta \widetilde{k}+\widetilde{k} \cdot g=s \tilde{y}-\left(\frac{b}{e^{b(t+\theta)}-1}+\delta\right) \widetilde{k} \text {. Rearranjando esta expressão obtém-se a }
$$
expressão da acumulação de capital por hectare, medida em termos tecnológicos, definida por:

$$
\Delta \widetilde{k}=s \tilde{y}-\left(\frac{b}{e^{b(t+\theta)}-1}+\delta+g\right) \cdot \widetilde{k}
$$

Dividindo a equação (67) por $\tilde{k}$, obtém-se a equação para a taxa de crescimento do capital tecnológico $(\hat{\tilde{k}})$, dada por: 


$$
\frac{\Delta \widetilde{k}}{\widetilde{k}}=\hat{\widetilde{k}}=\frac{s \tilde{y}}{\widetilde{k}}-\frac{b}{e^{b(t+\theta)}-1}-\delta-g
$$

A partir da informação de que $\tilde{l}=\frac{l}{A}$, sabe-se que a taxa de crescimento do trabalho, medido em termos tecnológicos, é definido como sendo, $\hat{\widetilde{l}}=\frac{\Delta \tilde{l}}{\tilde{l}}$, então:

$$
\begin{aligned}
& \Delta \widetilde{l}=\Delta\left(\frac{l}{A}\right)=\frac{\Delta l \cdot A-l \cdot \Delta A}{A^{2}}=\frac{\Delta l \cdot A}{A \cdot A}-\frac{l \cdot g \cdot A}{A \cdot A} \\
& \Delta \widetilde{l}=\frac{\Delta l}{A}-\tilde{l} \cdot g
\end{aligned}
$$

sabe-se que:

$$
\Delta l=\frac{d l}{d t}=\frac{d\left(\frac{L}{S}\right)}{d t}=\frac{\Delta L \cdot S-L \cdot \Delta S}{S^{2}}
$$

Sabendo que $\Delta \mathrm{L}=\mathrm{n} . \mathrm{L}$, tomando a equação (31) para $\mathrm{S}^{\mathrm{MAX}}$ e a equação (32) para $\Delta \mathrm{S}$, tem-se:

$$
\Delta l=\frac{n \cdot L \cdot S}{S \cdot S}-\frac{L \cdot b \cdot S^{\max }}{e^{b(t+\theta)}\left(S^{\max }\right)^{2} \cdot\left[1-e^{-b(t+\theta)}\right]^{2}}
$$

Após simplificações de variáveis que aparecem no numerador e denominador, tem-se:

$$
\Delta l=n \cdot l-\frac{b \cdot L}{e^{b(t+\theta)} \cdot S^{\max }\left[1-e^{-b(t+\theta)}\right] \cdot\left[1-e^{-b(t+\theta)}\right]}
$$

Da equação (31) tem-se que $S_{t}=S^{\max }\left[1-e^{-b(t+\theta)}\right]$. Além disso, $e^{b(t+\theta)} \cdot\left[1-e^{-b(t+\theta)}\right]=e^{b(t+\theta)}-1$. Logo: 


$$
\begin{aligned}
& \Delta l=n . l-\frac{b . l}{e^{b(t+\theta)}-1} \\
& \Delta l=l\left[n-\frac{b}{e^{b(t+\theta)}-1}\right]
\end{aligned}
$$

Dividindo a expressão (70) pela tecnologia (A), obtém-se:

$$
\frac{\Delta l}{A}=\tilde{l}\left[n-\frac{b}{e^{b(t+\theta)}-1}\right]
$$

Da expressão (69) sabe-se que:

$$
\begin{aligned}
& \Delta \widetilde{l}=\frac{\Delta l}{A}-\tilde{l} \cdot g \cdot \text { Rearranjando esta equação obtém-se: } \\
& \frac{\Delta l}{A}=\Delta \widetilde{l}+\tilde{l} \cdot g
\end{aligned}
$$

Substituindo a equação (72) na equação (71), tem-se:

$$
\begin{aligned}
& \Delta \tilde{l}+\tilde{l} \cdot g=\tilde{l}\left[n-\frac{b}{e^{b(t+\theta)}-1}\right] \quad \text { ou, } \\
& \Delta \tilde{l}=\tilde{l}\left[n-g-\frac{b}{e^{b(t+\theta)}-1}\right]
\end{aligned}
$$

Finalmente, dividindo a equação (73) por $\tilde{l}$, obtém a taxa de crescimento da força de trabalho por hectare, em termos tecnológicos, dada por:

$$
\frac{\Delta \tilde{l}}{\widetilde{l}}=\hat{\tilde{l}}=\left[n-g-\frac{b}{e^{b(t+\theta)}-1}\right]
$$

Nesta expressão a taxa de crescimento da força de trabalho agrícola depende positivamente do crescimento da população e negativamente do crescimento da tecnologia e do crescimento da quantidade de terra medida em termos tecnológicos. 
Substituindo as equações (74) e (68) na expressão (63) obtém-se a taxa de crescimento da produtividade da terra, especificada em termos tecnológicos $(\hat{\tilde{y}})$, ou seja:

$$
\hat{\tilde{y}}=s_{K}\left[\frac{s \tilde{y}}{\widetilde{k}}-\frac{b}{e^{b(t+\theta)}-1}-\delta-g\right]+s_{L}\left[n-\frac{b}{e^{b(t+\theta)}-1}-g\right]
$$

Substituindo a expressão (75) na expressão (55), obtém-se a taxa de crescimento da produtividade da terra $(\hat{y})$.

$$
\hat{y}=g+s_{K}\left[\frac{\tilde{y}}{\widetilde{k}}-\frac{b}{e^{b(t+\theta)}-1}-\delta-g\right]+s_{L}\left[n-\frac{b}{e^{b(t+\theta)}-1}-g\right]
$$

Sabe-se que $S_{K}=\alpha$ e $S_{L}=\beta$, onde $\alpha$ e $\beta$ são parâmetros da função de produção (equação 44). Veja o anexo D para esta demonstração.

Então, a equação (76) pode ser reescrita da seguinte forma:

$$
\hat{y}=g+\alpha\left[\frac{s \widetilde{y}}{\widetilde{k}}-\frac{b}{e^{b(t+\theta)}-1}-\delta-g\right]+\beta\left[n-\frac{b}{e^{b(t+\theta)}-1}-g\right]
$$

A partir da informação de que $\frac{\tilde{y}}{\widetilde{k}}=\frac{y / A}{k / A}$ implicando que $\frac{\widetilde{y}}{\widetilde{k}}=\frac{y}{k}=\frac{Y / S}{K / S}=\frac{Y}{K}$, então: $\frac{\widetilde{y}}{\widetilde{k}}=\frac{Y}{K}$.

Mas, da equação (105) do anexo D sabe-se que $\frac{Y}{K}=\left(A y^{\alpha-1} l^{\beta}\right)^{1 / \alpha}$, portanto:

$$
\frac{\widetilde{y}}{\widetilde{k}}=\left(A y^{\alpha-1} l^{\beta}\right)^{1 / \alpha}
$$

Substituindo a expressão (78) na equação (77) 


$$
\hat{y}=g+\alpha\left[s\left(A y^{\alpha-1} l^{\beta}\right)^{\frac{1}{\alpha}}-\frac{b}{e^{b(t+\theta)}-1}-\delta-g\right]+\beta\left[n-g-\frac{b}{e^{b(t+\theta)}-1}\right]
$$

Considerando o fato de que $y\left(\frac{\alpha-1}{\alpha}\right)=e^{\ln y\left(\frac{\alpha-1}{\alpha}\right)}$ então a equação (79) pode ser reescrita da forma:

$$
\hat{y}=g+\alpha\left[s\left(A^{\frac{1}{\alpha}} e^{\ln y^{\left(\frac{\alpha-1}{\alpha}\right)}} l^{\frac{\beta}{\alpha}}\right)-\frac{b}{e^{b(t+\theta)}-1}-\delta-g\right]+\beta\left[n-g-\frac{b}{e^{b(t+\theta)}-1}\right]
$$

Não se conhece a forma funcional dessa expressão. Contudo, pode-se supor que, no longo prazo, se os estados forem semelhantes em termos de nível tecnológico, taxa de poupança (ou investimento) e depreciação, existe um estado estacionário para o qual a produtividade agrícola dos estados convergirá. Este estado estacionário ocorre quando na equação (67) $s \tilde{y}=\left(\frac{b}{e^{b(t+\theta)}-1}+\delta+g\right) \cdot \tilde{k}$, neste ponto $\tilde{y}$ é constante, implicando que $\frac{d \widetilde{y}}{d t}=0$. Como $\frac{d \widetilde{y}}{d t}=0$, então a taxa de crescimento da produtividade tecnológica, definida como sendo $\hat{\tilde{y}}=\frac{d \tilde{y}}{\widetilde{y}}$, stá igual a zero. Mas, pela equação (55), $\hat{y}=g+\hat{\tilde{y}}$, como $\hat{\tilde{y}}=0$ no estado estacionário, então $\hat{y}=g$, ou seja, a produtividade crescerá à taxa do progresso tecnológico.

Supondo que o ponto estacionário exista, então, na equação (81) será feito a expansão de Taylor $^{20}$ de primeira ordem para descrever a trajetória de $y$ ao redor de seu estado estacionário definido por $y^{*}$ da forma:

\footnotetext{
20 A idéia do polinômio de Taylor é de que, dada uma função que possua uma forma funcional "desconhecida", é possível estimar o valor desta função expandindo a função em torno de um ponto qualquer, conhecido. A ordem do polinômio vai depender do objetivo do estudo.
} 


$$
\begin{aligned}
& \hat{y}=[\hat{y}]_{y=y^{*}}+\left(\frac{d \hat{y}}{d \log y}\right)_{\log y-\log y^{*}} \quad\left(\log y-\log y^{*}\right) \\
& \frac{d \hat{y}}{d \log y}=\alpha \cdot s \cdot A^{\frac{1}{\alpha}} \cdot e^{\log y^{\left(\frac{\alpha-1}{\alpha}\right)}} \cdot \frac{\alpha-1}{\alpha} \cdot l^{\frac{\beta}{\alpha}} \\
& \frac{\mathrm{d} \hat{\mathrm{y}}}{\mathrm{d} \log \mathrm{y}}=\mathrm{s} \cdot \mathrm{A}^{\frac{1}{\alpha}} \cdot \mathrm{y}^{\left(\frac{\alpha-1}{\alpha}\right)}(\alpha-1) \cdot 1^{\frac{\beta}{\alpha}}
\end{aligned}
$$

Substituindo a equação (82) na equação (81), obtém-se que:

$$
\hat{y}=g+(\alpha-1)\left(\operatorname{sA}^{\frac{1}{\alpha}} y^{\left(\frac{\alpha-1}{\alpha}\right)} 1^{\frac{\beta}{\alpha}}\right)\left(\log y-\log y^{*}\right)
$$

Da equação (63) tem-se que $\hat{\tilde{y}}=s_{K} \cdot \hat{\widetilde{k}}+s_{L} \cdot \hat{\widetilde{l}}$. Mas no estado estacionário $\hat{\tilde{y}}=0, \operatorname{logo}:$

$$
S_{K} \hat{\tilde{k}}=-S_{L} \hat{\tilde{l}}
$$

mas, pelas equações (68) e (74) sabe-se que $\frac{\Delta \widetilde{k}}{\widetilde{k}}=\hat{\tilde{k}}=\frac{s \tilde{y}}{\widetilde{k}}-\frac{b}{e^{b(t+\theta)}-1}-\delta-g$, e que $\frac{\Delta \widetilde{l}}{\widetilde{l}}=\hat{\widetilde{l}}=\left[n-g-\frac{b}{e^{b(++\theta)}-1}\right]$ além do que $s_{K}=\alpha$ e $s_{L}=\beta$ conforme provado no anexo D. Então, substituindo estas informações na expressão (84), tem-se que:

$$
\alpha\left[\frac{s \tilde{y}}{\widetilde{k}}-\frac{b}{e^{b(t+\theta)}-1}-\delta-g\right]=-\beta\left[n-g-\frac{b}{e^{b(t+\theta)}-1}\right]
$$

Isolando o termo $\frac{s \tilde{y}}{\widetilde{k}}$ da equação (85), chega-se a: 


$$
\frac{s \widetilde{y}}{\widetilde{k}}=\frac{\beta}{\alpha}\left[g+\frac{b}{e^{b(t+\theta)}-1}-n\right]+\frac{b}{e^{b(t+\theta)}-1}+\delta+g
$$

Mas, pela equação (78) sabe-se que $s \frac{\tilde{y}}{\widetilde{k}}=s\left(A y^{\alpha-1} l^{\beta}\right)^{1 / \alpha}$, então, comparando esta última com a expressão (86), concluí-se que:

$$
s\left(A y^{\alpha-1} l^{\beta}\right)^{1 / \alpha}=\frac{\beta}{\alpha}\left[g+\frac{b}{e^{b(t+\theta)}-1}-n\right]+\frac{b}{e^{b(t+\theta)}-1}+\delta+g
$$

A equação (87) pode ser substituída na equação (83) para se obter:

$$
\hat{y}=g+(\alpha-1)\left(\frac{\beta}{\alpha}\left[g+\frac{b}{e^{b(t+\theta)}-1}-n\right]+\frac{b}{e^{b(t+\theta)}-1}+\delta+g\right)\left(\log y-\log y^{*}\right)
$$

No longo prazo (isto é, quando $\mathrm{t} \rightarrow \infty$ ), $\frac{b}{e^{b(t+\theta)}-1}=\frac{\Delta S}{S}$ tenderá para zero. Significa dizer que $\Delta S=0$, portanto, $S \rightarrow S^{\max }$. Sendo assim a equação (88) pode ser reescrita da forma:

$$
\hat{y}=g+(\alpha-1)\left(\frac{\beta}{\alpha}(g-n)+\delta+g\right)\left(\log y-\log y^{*}\right)
$$

A equação (89) mostra que a taxa de crescimento da produtividade da terra $(\hat{y})$ é afetada:

- positivamente pela relação K/S. Se essa relação aumenta, há aumento de $\alpha$ ou redução de $\beta$. Aumentando $\alpha, \hat{y}$ aumenta. Esse resultado é consistente com o observado na agricultura brasileira, pois o índice de mecanização tem aumentado e a quantidade de mão-de-obra utilizada tem diminuído;

- o aumento de $n$ implica diminuição de $\hat{y}$, isto porque o aumento de $n$ leva a uma redução na relação $\mathrm{K} / \mathrm{L}$; 
- o aumento da taxa de inovação tecnológica (g) implica aumentar a taxa de crescimento do produto médio da terra $\hat{y}$.

É importante, no entanto, ressaltar que a equação (89) surge a partir de várias hipóteses, tais como:

- considera-se uma função de produção com rendimentos constantes à escala e produtos marginais decrescentes dos fatores de produção (ver equação 44). Esta hipótese é também considerada em modelos clássicos de crescimento econômico, como os de Solow (1956, 1957);

- as equações de comportamento do fator terra e trabalho, assumem os formatos definidos pelas equações (31) e (33), os quais são amplamente usados na literatura de crescimento econômico;

- considera-se que há um estado estacionário para o qual convergirão as produtividades agrícolas dos estados.

Chamando $(\alpha-1)\left(\frac{\beta}{\alpha}(g-n)+\delta+g\right)=\lambda \quad$ a equação (89) pode ser expressa da forma:

$$
\hat{y}=g+\lambda\left(\log y-\log y^{*}\right)
$$

Observe que $\log \mathrm{y}-\log \mathrm{y}^{*}$ mede a distância (em termos de produtividade) que separa uma região de seu estado estacionário, assim:

i) se $\left(\log \mathrm{y}-\log \mathrm{y}^{*}\right)=0$, a região já se encontra em seu estado estacionário e portanto, a produtividade $y$ desta região crescerá à taxa do progresso tecnológico ou seja, $\hat{y}=g$; 
ii) se $\left(\log \mathrm{y}-\log \mathrm{y}^{*}\right)<0$, a produtividade está abaixo do seu nível de estado estacionário de longo prazo. Portanto, a produtividade da região crescerá a uma taxa maior que a taxa g, ou seja, $\hat{y}>g$;

iii) se $(\log \mathrm{y}-\log \mathrm{y} *)>0$, a produtividade está acima do seu nível de estado estacionário de longo prazo e, portanto, crescerá a uma taxa menor que a taxa g ou seja, $\hat{y}<g$. 


\section{METODOLOGIA}

Vários métodos têm sido utilizados pelos pesquisadores para medir convergência, quer entre países quer entre regiões ou estados dentro de um mesmo país. Entre estes métodos cita-se, por exemplo, o método de Barro e Sala-i-Martin (1990, 1991), o método de Bairam e McRae (1999), o método de Ben-David (1993), o método de Bernard e Jones (1996), dentre outros.

Este estudo seguirá a metodologia sugerida por Barro e Sala-i-Martin $(1990,1991)$ testando as hipóteses de Convergência- $\beta$, Convergência- $\beta$ condicional e Convergência- $\sigma$.

\subsection{Convergência- $\beta$}

O teste de convergência- $\beta$ parte da equação (90), desenvolvida no capítulo 5, definida como: $\hat{y}=g+\lambda\left(\log y-\log y^{*}\right)$

Para passar esta expressão de tempo contínuo para o tempo discreto aproximamos o $\hat{y}=\frac{d \log y}{d t}=\log y_{t+1}-\log y_{t}$ assim,

$$
\begin{aligned}
& \log y_{t+1}-\log y_{t}=g+\lambda\left(\log y_{t}-\log y^{*}\right) \\
& \log y_{t+1}=g+\lambda\left(\log y_{t}-\log y^{*}\right)+\log y_{t}
\end{aligned}
$$


$\log y_{t+1}=g-\lambda \log y^{*},+(1+\lambda) \log y_{t}$

A equação (91) é uma equação de diferenças de $1^{\underline{a}}$ ordem no $\log \mathrm{y}_{\mathrm{t}}$. Entretanto, sua natureza é de difícil resolução, pois o termo independente não é constante. Assim, torna-se necessário transformá-lo em constante.

Como: $y_{t}=A_{t} \tilde{y}_{t}$ para todo $\mathrm{t}, y_{t+1}=A_{t+1} \cdot \tilde{y}_{t+1}$ assim como, $y^{*}=A_{t} \tilde{y}_{t}^{*}$. Tomando a expressão $y_{t+1}=A_{t+1} \cdot \tilde{y}_{t+1}$ e tomando o logaritmo neperiano, tem-se

$$
\log y_{t+1}=\log A_{t+1}+\log \tilde{y}_{t+1}
$$

Substituindo a equação (91) na equação (92), tem-se:

$$
\begin{aligned}
& \log A_{t+1}+\log \tilde{y}_{t+1}=g-\lambda \log \left(A_{t} \tilde{y}_{t}^{*}\right)+(1+\lambda) \log \left(A_{t} \tilde{y}_{t}\right) \\
& \log \tilde{y}_{t+1}=g-\lambda \log \tilde{y}_{t}^{*}-\lambda \log A_{t}+(1+\lambda) \log \tilde{y}_{t}+(1+\lambda) \log A_{t}-\log A_{t+1} \\
& \log \tilde{y}_{t+1}=g-\lambda \log \tilde{y}^{*}{ }_{t}+\log A_{t}+(1+\lambda) \log \tilde{y}_{t}-\log A_{t+1}
\end{aligned}
$$

Na equação (93) o termo $\log A_{t+1}=\log \left(A_{t} \cdot e^{g}\right)=\log e^{g}+\log A_{t}=g+\log A_{t}$

Substituindo esta informação na equação (93), tem-se que:

$$
\log \widetilde{y}_{t+1}=g-\lambda \log \widetilde{y}^{*}+\log A_{t}+(1+\lambda) \log \widetilde{y}_{t}-g-\log A_{t}
$$

Eliminando os termos comuns na equação (94) obtém-se:

$$
\log \tilde{y}_{t+1}=-\lambda \log \tilde{y}^{*}{ }_{t}+(1+\lambda) \log \tilde{y}_{t}
$$


A expressão (95) é uma equação de diferença de $1^{\text {a }}$ ordem com um termo constante igual a $\left(-\lambda \log \tilde{y}^{*}\right)$. A partir da equação (95), obtém-se ${ }^{21}$ :

$$
\log \tilde{y}_{T}=e^{\lambda T} \log \tilde{y}_{0}+\left(1-e^{\lambda T}\right) \log \tilde{y}_{t}^{*}
$$

Onde T é o número de anos definido pela série (por exemplo, se a série corresponde ao período de 1960 a 2001 tem-se, $\mathrm{T}=42$ anos) e 0 corresponde à $1^{\mathrm{a}}$ observação da série de tempo (as observações correspondentes ao ano de 1960).

Não há dados sobre a produtividade da terra em termos tecnológicos $\left(y^{*}\right)$, mas sabemos que $\tilde{y}_{T}=\left(y_{T} / A_{T}\right), \quad \tilde{y}_{0}=\left(y_{0} / A_{0}\right)$ e $\tilde{y}_{0}^{*}=\left(y^{*}{ }^{*} / A_{0}\right)$. Substituindo ficamos com:

$$
\begin{aligned}
& \log \frac{y_{T}}{A_{T}}=e^{\lambda T} \log \frac{y_{0}}{A_{0}}+\left(1-e^{\lambda T}\right) \log \frac{y_{0}^{*}}{A_{0}} \\
& \log y_{T}-\log A_{T}=e^{\lambda t}\left(\log y_{0}-\log A_{0}\right)+\left(1-e^{\lambda t}\right)\left(\log y^{*}{ }_{0}-\log A_{0}\right) \\
& \log y_{T}-\log A_{T}=e^{\lambda t} \log y_{0}-e^{\lambda t} \log A_{0}+\left(1-e^{\lambda t}\right) \log y^{*}{ }_{0}-\log A_{0}+e^{\lambda t} \log A_{0} \\
& \log y_{T}=e^{\lambda T} \log y_{0}-e^{\lambda T} \log A_{0}+\left(1-e^{\lambda T}\right) \log y^{*}{ }^{*}+\log A_{T}-\log A_{0}+e^{\lambda T} \log A_{0}
\end{aligned}
$$

As parcelas em destaque da equação imediatamente acima podem ser reescritas como: $\log A_{T}-\log A_{0}=\log \frac{A_{T}}{A_{0}}=\log \frac{A_{0} e^{g t}}{A_{0}}=g T$. Substituindo esta informação, temse que:

$$
\log y_{T}=g T+\left(1-e^{\lambda T}\right) \log y^{*}{ }_{0}+e^{\lambda T} \log y_{0}
$$

Na expressão (97) pode-se subtrair o $\log \mathrm{y}_{0}$ de ambos os membros, obtendo:

\footnotetext{
${ }^{21}$ A passagem da equação (95) para a equação (96) encontra-se no anexo E.
} 


$$
\begin{aligned}
& \log y_{T}-\log y_{0}=g T+\left(1-e^{\lambda T}\right) \cdot \log y_{0}{ }^{*}+e^{\lambda T} \cdot \log y_{0}-\log y_{0} \\
& \log \left(\frac{y_{T}}{y_{0}}\right)=g T+\left(1-e^{\lambda T}\right) \cdot \log y_{0}{ }^{*}+\left(e^{\lambda T}-1\right) \cdot \log y_{0}
\end{aligned}
$$

Dividindo a equação (98) em ambos os lados pelo tempo $\mathrm{T}$, chegamos à expressão para a taxa média anual de crescimento da produtividade da terra, dada por:

$$
\frac{1}{T} \log \left(\frac{y_{T}}{y_{0}}\right)=g+\frac{\left(1-e^{\lambda T}\right)}{T} \log y_{0}{ }_{0}+\frac{\left(e^{\lambda T}-1\right)}{T} \log y_{0}+\varepsilon_{0, T}
$$

$\mathrm{Na}$ equação (99):

$$
\begin{aligned}
& g+\frac{\left(1-e^{\lambda T}\right)}{T} \log y_{0}^{*}=a \text { que é uma constante } \mathrm{e}, \\
& \frac{\left(e^{\lambda T}-1\right)}{T}=\beta, \text { onde } \beta \text { é parâmetro de convergência a ser estimado e } \lambda
\end{aligned}
$$
corresponde ao percentual de redução do tempo que levará para que a produtividade de um estado se aproxime de seu de estado-estacionário ou, conforme este estudo, do nível de produtividade comum a todos os estados produtores de determinada cultura. $\mathrm{Na}$ literatura sobre Crescimento Econômico e Convergência, o coeficiente $\lambda$ é chamado de "velocidade de convergência".

Assim a equação (100) pode ser reescrita da forma:

$$
\frac{1}{T} \log \left(\frac{y_{T}}{y_{0}}\right)=a+\beta \log y_{0}+\varepsilon_{0, T}
$$

A equação (100) é uma equação linear denominada de "Barro Regressão". Se o coeficiente $\beta$ a ser estimado for menor que zero, ou seja, $\beta<0$, existe indicação de convergência ou que está ocorrendo convergência da produtividade entre os estados produtores de determinada cultura. Dito de outra forma, se para uma determinada cultura a taxa de crescimento da produtividade da terra entre o período $[0, \mathrm{~T}]$ relacionar-se 
negativamente com o ln da produtividade no período inicial [0], então diz-se que está ocorrendo convergência de produtividade entre os estados analisados para esta cultura específica. Contrariamente, se $\beta>0$, não existe convergência da produtividade de uma determinada cultura entre estados.

A partir da estimativa do parâmetro $\beta$ pode-se computar o valor de $\lambda$. $O$ valor de $\lambda$ é negativo se $\beta$ é negativo. Por exemplo, se $\lambda=-0,05$ por ano, então $5 \%$ da diferença entre $y_{t}$ (produtividade inicial) e $y^{*}{ }_{t}$ ( nível de produtividade máxima ou de estado-estacionário) desaparecerá a cada ano. Portanto, 14 anos são necessários para que $50 \%$ da diferença entre $y_{t}$ e $y^{*}{ }_{t}$ seja eliminada, e 28 anos são necessários para eliminar $75 \%$ dessa diferença (Valdés, 1999).

A taxa de crescimento entre o período $[0, \mathrm{~T}]$ designada por $\frac{1}{T} \log \left(\frac{y_{T}}{y_{0}}\right)$ é a variável dependente e o logaritmo da produtividade da terra no período inicial $(\mathrm{t})$, ou seja, $\log y_{0}$ é a variável independente.

Neste método supõe-se que a taxa de progresso tecnológico é a mesma para cada estado e que há um estado estacionário da produtividade da terra, que é comum às regiões produtoras. A restrição desse método centra-se no fato de se considerar que as regiões, no longo prazo, atingirão um nível de produtividade que se repetirá tornando-se estacionário e que este nível de produtividade será comum a uma determinada cultura em todos os estados que a produzem. Ou seja, é um método que não leva em consideração as diferenças existentes entre as regiões.

$$
\begin{aligned}
\text { Assim: } & \mathrm{i}=1,2, \ldots, \mathrm{N}(\text { estados }) \quad \text { e, } \quad \varepsilon_{i[0, T]} \sim N\left(0, \sigma^{2}{ }_{\varepsilon}\right) \\
\mathrm{t} & =0,1, \ldots, \mathrm{T}
\end{aligned}
$$




\subsection{Convergência- $\beta$ Condicional}

$O$ argumento chave na análise da convergência- $\beta$ é de que os estados diferem apenas em relação ao seu nível inicial de produtividade. Na verdade, esta pode não ser uma suposição muito realista para o caso brasileiro, no qual os estados podem diferir por vários motivos, tais como: seu nível tecnológico, sua propensão marginal a poupar, sua taxa de crescimento populacional, clima, solo, por exemplo. Barro (1991) comenta que mais de 50 variáveis têm sido escolhidas pelos pesquisadores para captar os seus efeitos nos estudos de convergência. A escolha das variáveis explicativas vai depender de qual é a variável dependente a ser explicada.

Sendo assim, este estudo ampliou a equação (100) para incluir variáveis que se acredita, a princípio, possam afetar o processo de convergência da produtividade da terra entre os estados brasileiros. Entre essas variáveis estão a taxa de déficit hídrico e os anos médio de estudo do trabalhador na agropecuária, aqui denominado, simplesmente, de capital humano.

Nesse sentido, a equação (100) passa a ser descrita da seguinte forma:

$$
\frac{1}{T} \log \left(\frac{y_{T}}{y_{0}}\right)=\alpha+\beta \log y_{0}+\psi D H_{i}+\omega C H+\varepsilon_{0, T}
$$

Nesta equação, além das variáveis já definidas anteriormente, tem-se:

$D H_{i}$ é a variável que representa a deficiência hídrica média, por estado.

$\mathrm{CH}$, é a variável que representa os anos médios de escolaridade no trabalhador na agropecuária.

$\alpha, \beta, \psi$ e $\omega$ são parâmetros a serem estimados.

$\varepsilon_{i[0, T]} \sim N\left(0, \sigma_{\varepsilon}^{2}\right)$ é o termo erro. 
Como antes, espera-se que o relacionamento entre a taxa de crescimento da produtividade entre o tempo 0 e $\mathrm{T}$ e o logaritmo neperiano da produtividade no período 0 seja negativo, ou seja, que o coeficiente estimado $\beta$ seja negativo.

Quanto ao coeficiente $\psi$, que se refere à deficiência hídrica $(D H)$, espera-se um sinal negativo, pois se a quantidade de água no solo não for suficiente para atender às necessidades das culturas, menor será o crescimento da produtividade destas.

Quanto ao coeficiente da variável anos de estudos dos trabalhadores $(\mathrm{CH})$, definido pelo coeficiente $\omega$, espera-se que este seja positivo, indicando que quanto mais estudado for o trabalhador na agropecuária melhor será sua capacidade para assimilar novas técnicas e quanto mais rápido uma nova técnica seja instalada, maiores serão os ganhos obtidos com esta, principalmente em termos de produtividade.

\subsection{Convergência- $\sigma$}

Define-se convergência- $\sigma$ como sendo uma queda da dispersão, mensurada em termos de desvio-padrão do logaritmo da produtividade agrícola, através de um grupo de estados, ou seja, $\sigma_{\mathrm{t}+\mathrm{T}}<\sigma_{\mathrm{t}}$, em que, $\sigma_{\mathrm{t}}$ é o desvio padrão do log da produtividade de um estado qualquer, no tempo t.

Embora haja uma relação entre os conceitos de convergência- $\beta$ e convergência- $\sigma$, eles respondem a questões diferentes: convergência- $\beta$ mostra se os países ou regiões que estão abaixo de seu estado estacionário crescem mais rápido, enquanto que convergência- $\sigma$ analisa a tendência da dispersão da variável produtividade, através do tempo. Significa dizer que convergência- $\beta$ é condição necessária, mas não suficiente para a ocorrência de convergência- $\sigma$.

Para testar a hipótese de convergência- $\sigma$ será adotado o procedimento descrito por McCunn e Huffman (2000), ou seja, 


$$
\operatorname{Var}(\ln \text { Produtividade })=\psi_{1}+\psi_{2} t+\varepsilon_{t}
$$

onde, Var é variância, $\psi_{1}$ é a constante e $\psi_{2}$ é o parâmetro de convergência. Se $\psi_{2}<0$, então a variância do logaritmo da produtividade entre os estados produtores de determinada cultura está se reduzindo ao longo do tempo. $\varepsilon_{\mathrm{t}}$ é o termo distúrbio com média zero.

As equações (100) e (102) foram estimadas usando o Excel e para a estimação da equação (101) foi utilizado o programa SAS system.

\subsection{Abrangência e fonte de dados}

O período de abrangência deste estudo é de 1960-2001.

i) Obtenção dos dados referentes à produtividade da terra.

Os dados referentes à produtividade das culturas por estado brasileiro foram obtidos junto ao IBGE, através do Anuário Estatístico do Brasil. As culturas selecionadas para a pesquisa são: algodão herbáceo, arroz, batata-inglesa, café, cana-deaçúcar, feijão, fumo, laranja, mandioca, milho e soja. Essas informações constam nos apêndices A.1 a A.11.

ii) Obtenção dos dados referentes aos anos médios de escolaridade dos trabalhadores na agrocupecuária - Capital Humano.

Para captar o efeito da escolaridade dos trabalhadores na agropecuária, considerou-se os anos médios de estudo dos trabalhadores com 10 anos ou mais de idade, nos anos de 1970, 1980, 1991, 1999, dos quais obteve-se a taxa de crescimento. Estes dados foram compilados com base em Freitas et al (2004). Estes dados estão no apêndice A.12.

iii) Obtenção dos dados referentes a variável Deficiência Hídrica 
A deficiência hídrica corresponde à diferença entre a evapotranspiração potencial e a evapotranspiração real do solo e se constitui em uma variável importante da determinação da produtividade da terra.

A evapotranspiração potencial corresponde à água que seria necessária devido as condições de evaporação do solo e transpiração das plantas. A evapotranspiração real corresponde à quantidade de água que efetivamente se evapora.

Quando se confrontam os dados sobre a precipitação, que corresponde o abastecimento de água e a evapotranspiração, que representa a perda de água, tem-se a disponibilidade de água no solo. O resultado desse exercício é denominado de balanço hídrico.

Os balanços hídricos de todas as estações metereológicas do Brasil foram calculados pelo Departamento de Ciências Exatas da Escola Superior de Agricultura "Luiz de Queiroz"/USP no Programa de Pós-Graduação em Física do Ambiente Agrícola, a partir dos dados das Normais Climatológicas, média de 30 anos (1961-1990), de responsabilidade do Ministério da Agricultura e Reforma Agrária, Secretaria Nacional de Irrigação e Departamento Nacional de Metereologia.

Para agregar as deficiências hídricas dos diversos postos metereológicos dentro de cada unidade da federação ${ }^{22}$, optou-se pela média aritmética simples das observações existentes dentro de cada estado. Estes dados estão no apêndice A.13.

\footnotetext{
${ }^{22}$ Inicialmente pensou-se em calcular o balanço hídrico para cada cultura e por unidade da federação, mas o Departamento de Ciências Exatas da ESALQ/USP, informou que não haveria possibilidade de realizar tal tarefa em função de que este exercício resultaria num balanço hídrico pra cada posto metereológico e para as 11 culturas. Dito de outra forma, teria que ser calculado 501 (total de balanços hídricos no Brasil) balanços hídricos x 11 culturas. Silva (1982) agregou as deficiências locais a partir da média ponderada, com base nas áreas cultivadas das regiões representadas por cada posto metereológico.
} 


\section{RESULTADOS E DISCUSSÃO}

No item 7.1 são apresentados os testes de convergência- $\beta$ absoluta e no item 7.2 os testes da convergência- $\sigma$. Para as culturas que não apresentaram convergência- $\beta$ absoluta foram feitos testes para verificar a ocorrência de formação de grupos de convergência - os resultados desse teste são apresentados no item 7.3 - assim como de convergência- $\beta$ condicional (item 7.4).

O quadro 2 apresenta, para cada cultura, os estados considerados em cada sub-período. Os valores correspondentes à área e produção do Estado de Tocantins foram somados aos estados de Goiás, o mesmo ocorrendo com o Estado do Mato Grosso do Sul, (somados ao Mato Grosso) exceto para o período de 1980 a 2001. Assim, a produtividade de Goiás inclui a de Tocantins e a do Mato Grosso inclui a do Mato Grosso do Sul.

Constata-se que diferentes grupos de estados são considerados para análise de uma mesma cultura em diferentes períodos. A não homogeneização dos grupos em diferentes períodos deve-se ao fato de que alguns estados que eram importantes produtores deixaram de ser, enquanto que outros que não eram considerados importantes produtores de determinado produto, passaram a ser. 


\begin{tabular}{|c|c|c|c|c|c|c|c|c|c|c|c|c|c|c|c|c|}
\hline \multirow{3}{*}{ Estados Produtores } & \multicolumn{4}{|c|}{ Algodão Herbáceo } & \multicolumn{4}{|c|}{ Arroz } & \multicolumn{4}{|c|}{ Batata-Inglesa } & \multicolumn{4}{|c|}{ Café } \\
\hline & \multicolumn{4}{|c|}{ Períodos } & \multicolumn{4}{|c|}{ Períodos } & \multicolumn{4}{|c|}{ Períodos } & \multicolumn{4}{|c|}{ Períodos } \\
\hline & $\begin{array}{c}1960 \\
\mathrm{a} \\
2001\end{array}$ & $\begin{array}{c}1970 \\
\mathrm{a} \\
2001\end{array}$ & $\begin{array}{c}1975 \\
\mathrm{a} \\
2001\end{array}$ & $\begin{array}{c}1980 \\
\mathrm{a} \\
2001\end{array}$ & $\begin{array}{c}1960 \\
a \\
2001\end{array}$ & $\begin{array}{c}1970 \\
\mathrm{a} \\
2001\end{array}$ & $\begin{array}{c}1975 \\
\mathrm{a} \\
2001\end{array}$ & $\begin{array}{c}1980 \\
\mathrm{a} \\
2001\end{array}$ & $\begin{array}{c}1960 \\
\mathrm{a} \\
2001\end{array}$ & $\begin{array}{c}1970 \\
\mathrm{a} \\
2001\end{array}$ & $\begin{array}{c}1975 \\
\text { a } \\
2001\end{array}$ & $\begin{array}{c}1980 \\
\text { a } \\
2001\end{array}$ & $\begin{array}{c}1960 \\
\text { a } \\
2001\end{array}$ & $\begin{array}{c}1970 \\
\mathrm{a} \\
2001\end{array}$ & $\begin{array}{c}1975 \\
\mathrm{a} \\
2001\end{array}$ & $\begin{array}{c}1980 \\
\mathrm{a} \\
2001\end{array}$ \\
\hline Rondônia & & & $\mathrm{X}$ & $\mathrm{X}$ & $\mathrm{X}$ & $\mathrm{X}$ & $\mathrm{X}$ & $\mathrm{X}$ & & & & & & $\mathrm{x}$ & $\mathrm{X}$ & $\mathrm{X}$ \\
\hline Acre & & & & & $\mathrm{x}$ & $\mathrm{x}$ & $\mathrm{X}$ & $\mathrm{x}$ & & & & & $\mathrm{x}$ & $\mathrm{x}$ & $\mathrm{X}$ & $\mathrm{X}$ \\
\hline Amazonas & & & & & $\mathrm{X}$ & $\mathrm{x}$ & $\mathrm{x}$ & $\mathrm{x}$ & & & & & $\mathrm{X}$ & $\mathrm{X}$ & $\mathrm{X}$ & $\mathrm{X}$ \\
\hline Roraima & & & & & $\mathrm{X}$ & $\mathrm{x}$ & $\mathrm{X}$ & $\mathrm{x}$ & & & & & & & & \\
\hline Pará & $\mathrm{x}$ & $\mathrm{x}$ & $\mathrm{x}$ & $\mathrm{X}$ & $\mathrm{X}$ & $\mathrm{x}$ & $\mathrm{X}$ & $\mathrm{x}$ & & & & & $\mathrm{X}$ & $\mathrm{x}$ & $\mathrm{X}$ & $\mathrm{X}$ \\
\hline Amapá & & & & & $\mathrm{x}$ & $\mathrm{x}$ & $\mathrm{x}$ & $\mathrm{x}$ & & & & & & $\mathrm{x}$ & $\mathrm{x}$ & \\
\hline Maranhão & $\mathrm{x}$ & $\mathrm{x}$ & $\mathrm{x}$ & $\mathrm{X}$ & $\mathrm{X}$ & $\mathrm{x}$ & $\mathrm{X}$ & $\mathrm{x}$ & & & & & $\mathrm{x}$ & $\mathrm{x}$ & $\mathrm{X}$ & $\mathrm{X}$ \\
\hline Piauí & $\mathrm{x}$ & $\mathrm{X}$ & $\mathrm{X}$ & $\mathrm{X}$ & $\mathrm{X}$ & $\mathrm{X}$ & $\mathrm{X}$ & $\mathrm{x}$ & & & & & $\mathrm{X}$ & $\mathrm{X}$ & $\mathrm{X}$ & \\
\hline Ceará & $\mathrm{x}$ & $\mathrm{x}$ & $\mathrm{x}$ & $\mathrm{X}$ & $\mathrm{X}$ & $\mathrm{x}$ & $\mathrm{x}$ & $\mathrm{x}$ & $\mathrm{x}$ & $\mathrm{X}$ & $\mathrm{x}$ & $\mathrm{X}$ & & $\mathrm{X}$ & $\mathrm{x}$ & $\mathrm{X}$ \\
\hline Rio Grande do Norte & $\mathrm{X}$ & $\mathrm{X}$ & $\mathrm{x}$ & $\mathrm{X}$ & $\mathrm{x}$ & $\mathrm{x}$ & $\mathrm{X}$ & $\mathrm{x}$ & & $\mathrm{X}$ & & & & & & \\
\hline Paraíba & $\mathrm{x}$ & $\mathrm{x}$ & $\mathrm{x}$ & $\mathrm{X}$ & $\mathrm{X}$ & $\mathrm{x}$ & $\mathrm{x}$ & $\mathrm{x}$ & $\mathrm{x}$ & $\mathrm{x}$ & $\mathrm{x}$ & $\mathrm{X}$ & $\mathrm{X}$ & $\mathrm{x}$ & $\mathrm{X}$ & $\mathrm{X}$ \\
\hline Pernambuco & $\mathrm{x}$ & $\mathrm{x}$ & $\mathrm{x}$ & $\mathrm{X}$ & $\mathrm{x}$ & $\mathrm{x}$ & $\mathrm{X}$ & $\mathrm{x}$ & $\mathrm{x}$ & $\mathrm{x}$ & $\mathrm{x}$ & & $\mathrm{X}$ & $\mathrm{X}$ & $\mathrm{X}$ & $\mathrm{x}$ \\
\hline Alagoas & $\mathrm{x}$ & $\mathrm{x}$ & $\mathrm{x}$ & $\mathrm{X}$ & $\mathrm{X}$ & $\mathrm{x}$ & $\mathrm{x}$ & $\mathrm{x}$ & $\mathrm{X}$ & $\mathrm{X}$ & & & $\mathrm{X}$ & $\mathrm{x}$ & $\mathrm{X}$ & \\
\hline Sergipe & $\mathrm{X}$ & $\mathrm{X}$ & $\mathrm{X}$ & $\mathrm{X}$ & $\mathrm{X}$ & $\mathrm{X}$ & $\mathrm{X}$ & $\mathrm{X}$ & $\mathrm{X}$ & $\mathrm{X}$ & $\mathrm{x}$ & $\mathrm{x}$ & $\mathrm{X}$ & $\mathrm{X}$ & $\mathrm{X}$ & \\
\hline Bahia & $\mathrm{x}$ & $\mathrm{x}$ & $\mathrm{x}$ & $\mathrm{X}$ & $\mathrm{x}$ & $\mathrm{x}$ & $\mathrm{X}$ & $\mathrm{x}$ & $\mathrm{X}$ & $\mathrm{X}$ & $\mathrm{x}$ & $\mathrm{x}$ & $\mathrm{X}$ & $\mathrm{X}$ & $\mathrm{X}$ & $\mathrm{x}$ \\
\hline Minas Gerais & $\mathrm{X}$ & $\mathrm{X}$ & $\mathrm{X}$ & $\mathrm{X}$ & $\mathrm{X}$ & $\mathrm{X}$ & $\mathrm{X}$ & $\mathrm{x}$ & $\mathrm{X}$ & $\mathrm{X}$ & $\mathrm{x}$ & $\mathrm{x}$ & $\mathrm{X}$ & $\mathrm{X}$ & $\mathrm{X}$ & $\mathrm{x}$ \\
\hline Espírito Santo & $\mathrm{X}$ & $\mathrm{X}$ & $\mathrm{X}$ & & $x$ & $\mathrm{X}$ & $\mathrm{X}$ & $\mathrm{x}$ & $\mathrm{X}$ & $\mathrm{X}$ & $\mathrm{x}$ & $\mathrm{X}$ & $\mathrm{X}$ & $\mathrm{X}$ & $\mathrm{X}$ & $\mathrm{x}$ \\
\hline Rio de Janeiro & $\mathrm{x}$ & $\mathrm{x}$ & $\mathrm{x}$ & $\mathrm{x}$ & $\mathrm{x}$ & $\mathrm{x}$ & $\mathrm{X}$ & $\mathrm{x}$ & $\mathrm{x}$ & $\mathrm{X}$ & $\mathrm{x}$ & $\mathrm{x}$ & $\mathrm{X}$ & $\mathrm{X}$ & $\mathrm{x}$ & $\mathrm{x}$ \\
\hline São Paulo & $\mathrm{X}$ & $\mathrm{X}$ & $\mathrm{X}$ & $\mathrm{X}$ & $\mathrm{X}$ & $\mathrm{X}$ & $\mathrm{X}$ & $\mathrm{x}$ & $\mathrm{X}$ & $\mathrm{X}$ & $\mathrm{x}$ & $\mathrm{X}$ & $\mathrm{X}$ & $\mathrm{X}$ & $\mathrm{X}$ & $\mathrm{x}$ \\
\hline Paraná & $\mathrm{X}$ & $\mathrm{X}$ & $\mathrm{x}$ & $\mathrm{X}$ & $\mathrm{X}$ & $\mathrm{X}$ & $\mathrm{X}$ & $\mathrm{x}$ & $\mathrm{X}$ & $\mathrm{X}$ & $\mathrm{x}$ & $\mathrm{x}$ & $\mathrm{X}$ & $\mathrm{x}$ & $\mathrm{X}$ & $\mathrm{x}$ \\
\hline Santa Catarina & & & & & $\mathrm{X}$ & $\mathrm{x}$ & $\mathrm{X}$ & $\mathrm{x}$ & $\mathrm{X}$ & $\mathrm{x}$ & $\mathrm{x}$ & $\mathrm{x}$ & $\mathrm{x}$ & $\mathrm{x}$ & $\mathrm{x}$ & $\mathrm{x}$ \\
\hline Rio Grande do Sul & & & & & $\mathrm{X}$ & $\mathrm{X}$ & $\mathrm{X}$ & $\mathrm{X}$ & $\mathrm{X}$ & $\mathrm{X}$ & $\mathrm{x}$ & $\mathrm{X}$ & & & & \\
\hline * Mato Grosso do Sul & & & & $\mathrm{X}$ & & & & $\mathrm{X}$ & & & & & & & & $\mathrm{x}$ \\
\hline Mato Grosso & $\mathrm{x}$ & $\mathrm{x}$ & $\mathrm{x}$ & $\mathrm{x}$ & $\mathrm{x}$ & $\mathrm{x}$ & $\mathrm{x}$ & $\mathrm{x}$ & $\mathrm{x}$ & $\mathrm{x}$ & $\mathrm{x}$ & & $\mathrm{X}$ & $\mathrm{X}$ & $\mathrm{X}$ & $\mathrm{x}$ \\
\hline Goiás & $\mathrm{X}$ & $\mathrm{x}$ & $\mathrm{x}$ & $\mathrm{x}$ & $\mathrm{x}$ & $\mathrm{x}$ & $\mathrm{x}$ & $\mathrm{x}$ & $\mathrm{X}$ & $\mathrm{X}$ & $\mathrm{x}$ & $\mathrm{x}$ & $\mathrm{X}$ & $\mathrm{X}$ & $\mathrm{x}$ & $\mathrm{x}$ \\
\hline Distrito Federal & & & & & & $\mathrm{x}$ & $\mathrm{x}$ & $\mathrm{x}$ & & $\mathrm{x}$ & $\mathrm{x}$ & $\mathrm{x}$ & & $\mathrm{x}$ & $\mathrm{x}$ & $\mathrm{X}$ \\
\hline
\end{tabular}

Quadro 2 - Estados produtores considerados na análise de convergência- $\beta$ absoluta por culturas e por períodos

* o Estado do Mato Grosso do Sul foi considerado somente no período de 1980 a 2001 


\begin{tabular}{|c|c|c|c|c|c|c|c|c|c|c|c|c|c|c|c|c|}
\hline \multirow{3}{*}{ Estados Produtores } & \multicolumn{4}{|c|}{ cana-de-açúcar } & \multicolumn{4}{|c|}{ Feijão } & \multicolumn{4}{|c|}{ Fumo } & \multicolumn{4}{|c|}{ Laranja } \\
\hline & \multicolumn{4}{|c|}{ Períodos } & \multicolumn{4}{|c|}{ Períodos } & & & & & & & & \\
\hline & $\begin{array}{c}1960 \\
a \\
2001\end{array}$ & $\begin{array}{c}1970 \\
a \\
2001\end{array}$ & $\begin{array}{c}1975 \\
\text { a } \\
2001\end{array}$ & $\begin{array}{c}1980 \\
\mathrm{a} \\
2001\end{array}$ & $\begin{array}{c}1960 \\
a \\
2001\end{array}$ & \begin{tabular}{|c}
1970 \\
$\mathrm{a}$ \\
2001
\end{tabular} & $\begin{array}{c}1975 \\
\text { a } \\
2001\end{array}$ & $\begin{array}{c}1980 \\
a \\
2001\end{array}$ & $\begin{array}{c}1960 \\
\mathrm{a} \\
2001\end{array}$ & $\begin{array}{c}1970 \\
\text { a } \\
2001\end{array}$ & $\begin{array}{c}1975 \\
\text { a } \\
2001\end{array}$ & $\begin{array}{c}1980 \\
\mathrm{a} \\
2001\end{array}$ & $\begin{array}{c}1960 \\
\mathrm{a} \\
2001\end{array}$ & $\begin{array}{c}1970 \\
\text { a } \\
2001\end{array}$ & $\begin{array}{c}1975 \\
\mathrm{a} \\
2001\end{array}$ & $\begin{array}{c}1980 \\
\text { a } \\
2001\end{array}$ \\
\hline Rondônia & $\mathrm{X}$ & $\mathrm{X}$ & $\mathrm{X}$ & $\mathrm{X}$ & $\mathrm{X}$ & $\mathrm{X}$ & $\mathrm{X}$ & $\mathrm{X}$ & $\mathrm{X}$ & & $\mathrm{X}$ & & $\mathrm{X}$ & $\mathrm{X}$ & $\mathrm{X}$ & $\mathrm{X}$ \\
\hline Acre & $\mathrm{X}$ & $\mathrm{X}$ & $\mathrm{X}$ & $\mathrm{X}$ & $\mathrm{X}$ & $\mathrm{X}$ & $\mathrm{X}$ & $\mathrm{X}$ & $\mathrm{x}$ & $\mathrm{X}$ & & $\mathrm{X}$ & $\mathrm{X}$ & $\mathrm{X}$ & $\mathrm{X}$ & $\mathrm{X}$ \\
\hline Amazonas & $\mathrm{X}$ & $\mathrm{X}$ & $\mathrm{X}$ & $\mathrm{X}$ & $\mathrm{X}$ & $\mathrm{X}$ & $\mathrm{X}$ & $\mathrm{X}$ & $\mathrm{X}$ & $\mathrm{X}$ & $\mathrm{X}$ & $\mathrm{X}$ & $\mathrm{X}$ & $\mathrm{X}$ & $\mathrm{X}$ & $\mathrm{X}$ \\
\hline Roraima & $\mathrm{x}$ & $\mathrm{X}$ & $\mathrm{X}$ & & $\mathrm{X}$ & $\mathrm{X}$ & $\mathrm{X}$ & $\mathrm{X}$ & $\mathrm{x}$ & $\mathrm{X}$ & & $\mathrm{X}$ & & $\mathrm{X}$ & $\mathrm{X}$ & $\mathrm{X}$ \\
\hline Pará & $\mathrm{X}$ & $\mathrm{X}$ & $\mathrm{X}$ & $\mathrm{X}$ & $\mathrm{X}$ & $\mathrm{X}$ & $\mathrm{X}$ & $\mathrm{X}$ & $\mathrm{X}$ & $\mathrm{X}$ & $\mathrm{X}$ & $\mathrm{X}$ & $\mathrm{x}$ & $\mathrm{X}$ & $\mathrm{X}$ & $\mathrm{X}$ \\
\hline Amapá & $\mathrm{X}$ & $\mathrm{X}$ & $\mathrm{X}$ & $\mathrm{X}$ & $\mathrm{X}$ & $\mathrm{X}$ & $\mathrm{X}$ & $\mathrm{X}$ & $\mathrm{X}$ & $\mathrm{X}$ & & $\mathrm{X}$ & $\mathrm{x}$ & $\mathrm{X}$ & $\mathrm{X}$ & $\mathrm{X}$ \\
\hline Maranhão & $\mathrm{x}$ & $\mathrm{X}$ & $\mathrm{X}$ & $\mathrm{X}$ & $\mathrm{X}$ & $\mathrm{x}$ & $\mathrm{X}$ & $\mathrm{X}$ & $\mathrm{x}$ & $\mathrm{X}$ & $\mathrm{X}$ & $\mathrm{X}$ & $\mathrm{x}$ & $\mathrm{X}$ & $\mathrm{X}$ & $\mathrm{X}$ \\
\hline Piauí & $\mathrm{X}$ & $\mathrm{X}$ & $\mathrm{X}$ & $\mathrm{X}$ & $\mathrm{X}$ & $\mathrm{X}$ & $\mathrm{X}$ & $\mathrm{X}$ & $\mathrm{X}$ & $\mathrm{X}$ & $\mathrm{X}$ & $\mathrm{X}$ & $\mathrm{X}$ & $\mathrm{X}$ & $\mathrm{X}$ & $\mathrm{X}$ \\
\hline Ceará & $\mathrm{x}$ & $\mathrm{X}$ & $\mathrm{X}$ & $\mathrm{X}$ & $\mathrm{X}$ & $\mathrm{X}$ & $\mathrm{X}$ & $\mathrm{X}$ & $\mathrm{x}$ & $\mathrm{X}$ & $\mathrm{X}$ & $\mathrm{X}$ & $\mathrm{X}$ & $\mathrm{X}$ & $\mathrm{X}$ & $\mathrm{X}$ \\
\hline Rio Grande do Norte & $\mathrm{x}$ & $\mathrm{X}$ & $\mathrm{X}$ & $\mathrm{X}$ & $\mathrm{X}$ & $\mathrm{X}$ & $\mathrm{X}$ & $\mathrm{x}$ & $\mathrm{x}$ & $\mathrm{X}$ & $\mathrm{X}$ & $\mathrm{X}$ & $\mathrm{x}$ & $\mathrm{X}$ & $\mathrm{X}$ & $\mathrm{X}$ \\
\hline Paraíba & $\mathrm{x}$ & $\mathrm{X}$ & $\mathrm{X}$ & $\mathrm{X}$ & $\mathrm{X}$ & $\mathrm{X}$ & $\mathrm{X}$ & $\mathrm{X}$ & $\mathrm{x}$ & $\mathrm{X}$ & $\mathrm{X}$ & $\mathrm{X}$ & $\mathrm{x}$ & $\mathrm{X}$ & $\mathrm{X}$ & $\mathrm{X}$ \\
\hline Pernambuco & $\mathrm{x}$ & $\mathrm{X}$ & $\mathrm{X}$ & $\mathrm{X}$ & $\mathrm{X}$ & $\mathrm{X}$ & $\mathrm{X}$ & $\mathrm{X}$ & $\mathrm{x}$ & $\mathrm{X}$ & $\mathrm{X}$ & $\mathrm{X}$ & $\mathrm{x}$ & $\mathrm{X}$ & $\mathrm{X}$ & $\mathrm{X}$ \\
\hline Alagoas & $\mathrm{X}$ & $\mathrm{X}$ & $\mathrm{X}$ & $\mathrm{X}$ & $\mathrm{X}$ & $\mathrm{X}$ & $\mathrm{X}$ & $\mathrm{X}$ & $\mathrm{X}$ & $\mathrm{X}$ & $\mathrm{X}$ & $\mathrm{X}$ & $\mathrm{X}$ & $\mathrm{X}$ & $\mathrm{X}$ & $\mathrm{X}$ \\
\hline Sergipe & $\mathrm{x}$ & $\mathrm{X}$ & $\mathrm{X}$ & $\mathrm{X}$ & $\mathrm{X}$ & $\mathrm{X}$ & $\mathrm{X}$ & $\mathrm{X}$ & $\mathrm{x}$ & $\mathrm{X}$ & $\mathrm{X}$ & $\mathrm{X}$ & $\mathrm{x}$ & $\mathrm{X}$ & $\mathrm{X}$ & $\mathrm{X}$ \\
\hline Bahia & $\mathrm{X}$ & $\mathrm{X}$ & $\mathrm{X}$ & $\mathrm{X}$ & $\mathrm{X}$ & $\mathrm{X}$ & $\mathrm{X}$ & $\mathrm{X}$ & $\mathrm{X}$ & $\mathrm{X}$ & $\mathrm{X}$ & $\mathrm{X}$ & $\mathrm{X}$ & $\mathrm{X}$ & $\mathrm{X}$ & $\mathrm{X}$ \\
\hline Minas Gerais & $\mathrm{X}$ & $\mathrm{X}$ & $\mathrm{X}$ & $\mathrm{X}$ & $\mathrm{X}$ & $\mathrm{X}$ & $\mathrm{X}$ & $\mathrm{X}$ & $\mathrm{X}$ & $\mathrm{X}$ & $\mathrm{X}$ & $\mathrm{X}$ & $\mathrm{X}$ & $\mathrm{X}$ & $\mathrm{X}$ & $\mathrm{X}$ \\
\hline Espírito Santo & $\mathrm{x}$ & $\mathrm{X}$ & $\mathrm{X}$ & $\mathrm{X}$ & $\mathrm{X}$ & $\mathrm{X}$ & $\mathrm{X}$ & $\mathrm{X}$ & $\mathrm{x}$ & $\mathrm{X}$ & $\mathrm{X}$ & $\mathrm{X}$ & $\mathrm{x}$ & $\mathrm{X}$ & $\mathrm{X}$ & $\mathrm{X}$ \\
\hline Rio de Janeiro & $\mathrm{x}$ & $\mathrm{X}$ & $\mathrm{X}$ & $\mathrm{X}$ & $\mathrm{X}$ & $\mathrm{X}$ & $\mathrm{X}$ & $\mathrm{X}$ & $\mathrm{X}$ & $\mathrm{X}$ & $\mathrm{X}$ & $\mathrm{X}$ & $\mathrm{x}$ & $\mathrm{X}$ & $\mathrm{x}$ & $\mathrm{X}$ \\
\hline São Paulo & $\mathrm{x}$ & $\mathrm{X}$ & $\mathrm{x}$ & $\mathrm{X}$ & $\mathrm{X}$ & $\mathrm{X}$ & $\mathrm{X}$ & $\mathrm{X}$ & $\mathrm{X}$ & $\mathrm{X}$ & $\mathrm{X}$ & $\mathrm{X}$ & $\mathrm{X}$ & $\mathrm{X}$ & $\mathrm{X}$ & $\mathrm{X}$ \\
\hline Paraná & $\mathrm{x}$ & $\mathrm{X}$ & $\mathrm{X}$ & $\mathrm{X}$ & $\mathrm{X}$ & $\mathrm{X}$ & $\mathrm{X}$ & $\mathrm{X}$ & $\mathrm{x}$ & $\mathrm{x}$ & $\mathrm{X}$ & $\mathrm{X}$ & $\mathrm{x}$ & $\mathrm{x}$ & $\mathrm{X}$ & $\mathrm{X}$ \\
\hline Santa Catarina & $\mathrm{x}$ & $\mathrm{x}$ & $\mathrm{x}$ & $\mathrm{X}$ & $\mathrm{x}$ & $\mathrm{X}$ & $\mathrm{X}$ & $\mathrm{x}$ & $\mathrm{x}$ & $\mathrm{x}$ & $\mathrm{x}$ & $\mathrm{X}$ & $\mathrm{x}$ & $\mathrm{x}$ & $\mathrm{x}$ & $\mathrm{x}$ \\
\hline Rio Grande do Sul & $\mathrm{x}$ & $\mathrm{X}$ & $\mathrm{X}$ & $\mathrm{X}$ & $\mathrm{X}$ & $\mathrm{X}$ & $\mathrm{X}$ & $\mathrm{X}$ & $\mathrm{X}$ & $\mathrm{x}$ & $\mathrm{X}$ & $\mathrm{X}$ & $\mathrm{X}$ & $\mathrm{x}$ & $\mathrm{X}$ & $\mathrm{X}$ \\
\hline * Mato Grosso do Sul & & & & $\mathrm{X}$ & & & & $\mathrm{X}$ & & & & & & & & $\mathrm{x}$ \\
\hline Mato Grosso & $\mathrm{x}$ & $\mathrm{X}$ & $\mathrm{X}$ & $\mathrm{x}$ & $\mathrm{X}$ & $\mathrm{X}$ & $\mathrm{X}$ & $\mathrm{X}$ & $\mathrm{x}$ & $\mathrm{x}$ & $\mathrm{X}$ & $\mathrm{X}$ & $\mathrm{X}$ & $\mathrm{X}$ & $\mathrm{X}$ & $\mathrm{X}$ \\
\hline Goiás & $\mathrm{x}$ & $\mathrm{X}$ & $\mathrm{X}$ & $\mathrm{X}$ & $\mathrm{X}$ & $\mathrm{X}$ & $\mathrm{X}$ & $\mathrm{X}$ & $\mathrm{x}$ & $\mathrm{x}$ & $\mathrm{X}$ & $\mathrm{X}$ & $\mathrm{X}$ & $\mathrm{x}$ & $\mathrm{X}$ & $\mathrm{X}$ \\
\hline Distrito Federal & & $\mathrm{X}$ & $\mathrm{X}$ & $\mathrm{x}$ & & $\mathrm{X}$ & $\mathrm{X}$ & $\mathrm{X}$ & & & & & & $\mathrm{x}$ & $\mathrm{X}$ & $\mathrm{X}$ \\
\hline
\end{tabular}

Quadro 2 - Estados produtores considerados na análise de convergência- $\beta$ absoluta por culturas e por períodos

* o Estado do Mato Grosso do Sul foi considerado somente no período de 1980 a 2001 


\begin{tabular}{|c|c|c|c|c|c|c|c|c|c|c|c|c|}
\hline \multirow{5}{*}{ Estados Produtores } & \multicolumn{4}{|c|}{ Mandioca } & \multicolumn{4}{|c|}{ Milho } & \multicolumn{4}{|c|}{ Soja } \\
\hline & \multicolumn{4}{|c|}{ Períodos } & \multicolumn{4}{|c|}{ Períodos } & & & & \\
\hline & 1960 & 1970 & 1975 & 1980 & 1960 & 1970 & 1975 & 1980 & 1960 & 1970 & 1975 & 1980 \\
\hline & $\mathrm{a}$ & $\mathrm{a}$ & $\mathrm{a}$ & $\mathrm{a}$ & $\mathrm{a}$ & $\mathrm{a}$ & $\mathrm{a}$ & $\mathrm{a}$ & $\mathrm{a}$ & $\mathrm{a}$ & a & $\mathrm{a}$ \\
\hline & 2001 & 2001 & 2001 & 2001 & 2001 & 2001 & 2001 & 2001 & 2001 & 2001 & 2001 & 2001 \\
\hline Rondônia & $\mathrm{x}$ & $\mathrm{x}$ & $\mathrm{X}$ & $\mathrm{X}$ & $\mathrm{X}$ & $\mathrm{X}$ & $\mathrm{x}$ & $\mathrm{X}$ & & & & \\
\hline Acre & $\mathrm{x}$ & $\mathrm{x}$ & $\mathrm{X}$ & $\mathrm{X}$ & $\mathrm{X}$ & $\mathrm{X}$ & $\mathrm{X}$ & $\mathrm{X}$ & & & & \\
\hline Amazonas & $\mathrm{x}$ & $\mathrm{x}$ & $\mathrm{X}$ & $\mathrm{X}$ & $\mathrm{x}$ & $\mathrm{x}$ & $\mathrm{x}$ & $\mathrm{x}$ & & & & \\
\hline Roraima & $\mathrm{x}$ & $\mathrm{x}$ & $\mathrm{X}$ & $\mathrm{X}$ & $\mathrm{X}$ & $\mathrm{X}$ & $\mathrm{X}$ & $\mathrm{x}$ & & & & \\
\hline Pará & $\mathrm{X}$ & $\mathrm{X}$ & $\mathrm{X}$ & $\mathrm{X}$ & $\mathrm{X}$ & $\mathrm{X}$ & $\mathrm{X}$ & $\mathrm{X}$ & & & & \\
\hline Amapá & $\mathrm{X}$ & $\mathrm{X}$ & $\mathrm{X}$ & & $\mathrm{X}$ & $\mathrm{X}$ & $\mathrm{X}$ & $\mathrm{X}$ & & & & \\
\hline Maranhão & $\mathrm{x}$ & $\mathrm{x}$ & $\mathrm{X}$ & & $\mathrm{X}$ & $\mathrm{X}$ & $\mathrm{X}$ & $\mathrm{X}$ & & & & \\
\hline Piauí & $\mathrm{X}$ & $\mathrm{X}$ & $\mathrm{X}$ & $\mathrm{X}$ & $\mathrm{X}$ & $\mathrm{X}$ & $\mathrm{X}$ & $\mathrm{X}$ & & & & \\
\hline Ceará & $\mathrm{x}$ & $\mathrm{X}$ & $\mathrm{X}$ & & $\mathrm{X}$ & $\mathrm{X}$ & $\mathrm{X}$ & $\mathrm{X}$ & & & & \\
\hline Rio Grande do Norte & $\mathrm{x}$ & $\mathrm{X}$ & $\mathrm{X}$ & & $\mathrm{X}$ & $\mathrm{X}$ & $\mathrm{x}$ & $\mathrm{x}$ & & & & \\
\hline Paraíba & $\mathrm{x}$ & $\mathrm{X}$ & $\mathrm{X}$ & & $\mathrm{x}$ & $\mathrm{X}$ & $\mathrm{X}$ & $\mathrm{x}$ & & & & \\
\hline Pernambuco & $\mathrm{X}$ & $\mathrm{X}$ & $\mathrm{X}$ & & $\mathrm{X}$ & $\mathrm{X}$ & $\mathrm{X}$ & $\mathrm{X}$ & & & & \\
\hline Alagoas & $\mathrm{X}$ & $\mathrm{x}$ & $\mathrm{X}$ & $\mathrm{X}$ & $\mathrm{X}$ & $\mathrm{X}$ & $\mathrm{X}$ & $\mathrm{X}$ & & & & \\
\hline Sergipe & $\mathrm{X}$ & $\mathrm{X}$ & $\mathrm{X}$ & $\mathrm{X}$ & $\mathrm{X}$ & $\mathrm{X}$ & $\mathrm{X}$ & $\mathrm{X}$ & & & & \\
\hline Bahia & $\mathrm{X}$ & $\mathrm{X}$ & $\mathrm{X}$ & $\mathrm{X}$ & $\mathrm{X}$ & $\mathrm{X}$ & $\mathrm{X}$ & $\mathrm{X}$ & $\mathrm{X}$ & $\mathrm{X}$ & $\mathrm{X}$ & $\mathrm{X}$ \\
\hline Minas Gerais & $\mathrm{x}$ & $\mathrm{X}$ & $\mathrm{X}$ & $\mathrm{X}$ & $\mathrm{X}$ & $\mathrm{X}$ & $\mathrm{X}$ & $\mathrm{X}$ & $\mathrm{X}$ & $\mathrm{X}$ & $\mathrm{X}$ & $\mathrm{X}$ \\
\hline Espírito Santo & $\mathrm{x}$ & $\mathrm{X}$ & $\mathrm{X}$ & $\mathrm{X}$ & $\mathrm{X}$ & $\mathrm{X}$ & $\mathrm{X}$ & $\mathrm{X}$ & & & & \\
\hline Rio de Janeiro & $\mathrm{x}$ & $\mathrm{X}$ & $\mathrm{X}$ & $\mathrm{X}$ & $\mathrm{X}$ & $\mathrm{X}$ & $\mathrm{X}$ & $\mathrm{X}$ & & & & \\
\hline São Paulo & $\mathrm{x}$ & $\mathrm{X}$ & $\mathrm{X}$ & $\mathrm{X}$ & $\mathrm{X}$ & $\mathrm{X}$ & $\mathrm{X}$ & $\mathrm{x}$ & $\mathrm{X}$ & $\mathrm{X}$ & $\mathrm{X}$ & $\mathrm{X}$ \\
\hline Paraná & $\mathrm{x}$ & $\mathrm{x}$ & $\mathrm{X}$ & $\mathrm{X}$ & $\mathrm{X}$ & $\mathrm{X}$ & $\mathrm{X}$ & $\mathrm{x}$ & $\mathrm{X}$ & $\mathrm{X}$ & $\mathrm{X}$ & $\mathrm{X}$ \\
\hline Santa Catarina & $\mathrm{X}$ & $\mathrm{X}$ & $\mathrm{X}$ & $\mathrm{X}$ & $\mathrm{X}$ & $\mathrm{X}$ & $\mathrm{X}$ & $\mathrm{X}$ & $\mathrm{X}$ & $\mathrm{X}$ & $\mathrm{X}$ & $\mathrm{X}$ \\
\hline Rio Grande do Sul & $\mathrm{x}$ & $\mathrm{x}$ & $\mathrm{X}$ & $\mathrm{X}$ & $\mathrm{X}$ & $\mathrm{X}$ & $\mathrm{X}$ & $\mathrm{X}$ & $\mathrm{X}$ & $\mathrm{X}$ & $\mathrm{X}$ & $\mathrm{X}$ \\
\hline * Mato Grosso do Sul & & & & $\mathrm{X}$ & & & & $\mathrm{X}$ & & & & $\mathrm{X}$ \\
\hline Mato Grosso & $\mathrm{x}$ & $\mathrm{X}$ & $\mathrm{X}$ & $\mathrm{X}$ & $\mathrm{X}$ & $\mathrm{X}$ & $\mathrm{X}$ & $\mathrm{X}$ & $\mathrm{X}$ & $\mathrm{X}$ & $\mathrm{X}$ & $\mathrm{X}$ \\
\hline Goiás & $\mathrm{x}$ & $\mathrm{X}$ & $\mathrm{X}$ & $\mathrm{X}$ & $\mathrm{X}$ & $\mathrm{X}$ & $\mathrm{X}$ & $\mathrm{X}$ & & $\mathrm{X}$ & $\mathrm{X}$ & $\mathrm{X}$ \\
\hline Distrito Federal & & $\mathrm{X}$ & $\mathrm{x}$ & $\mathrm{X}$ & & $\mathrm{X}$ & $\mathrm{X}$ & $\mathrm{X}$ & & & & $\mathrm{X}$ \\
\hline
\end{tabular}

Quadro 2 - Estados produtores considerados na análise de convergência- $\beta$ absoluta por culturas e por períodos

* o Estado do Mato Grosso do Sul foi considerado somente no período de 1980 a 2001 


\subsection{Convergência- $\beta$}

A Tabela 5 apresenta os resultados da convergência- $\beta$ absoluta, ou seja, estimativa do parâmetro $\beta$ da equação (100), bem como a velocidade de convergência, definida por $\lambda$, para os períodos de 1960 a 2001, 1970-2001, 1975-2001 e 1980-2001 e para as onze culturas consideradas no estudo. 
Tabela 5. Convergência- $\beta$ Absoluta

\begin{tabular}{|c|c|c|c|c|c|c|c|c|c|c|c|c|}
\hline Períodos & & $\begin{array}{l}\text { Algodão } \\
\text { Herbáceo }\end{array}$ & Arroz & $\begin{array}{l}\text { Batata } \\
\text { Inglesa }\end{array}$ & Café & $\begin{array}{l}\text { Cana-de- } \\
\text { Açucar }\end{array}$ & Feijão & Fumo & Laranja & Mandioca & Milho & Soja \\
\hline 1960 & $\beta=\frac{e^{\lambda \cdot T-1}}{T}$ & 0,0034 & 0,0070 & 0,0079 & $-0,0107$ & $-0,0189$ & 0,0137 & $-0,0141$ & $-0,0236$ & $-0,0164$ & 0,0321 & $-0,0197$ \\
\hline $\begin{array}{c}\mathrm{a} \\
2001\end{array}$ & $\begin{array}{c}\mathbf{t} \\
\mathrm{R}^{2} \\
\lambda\end{array}$ & $\begin{array}{c}0,3643^{\mathrm{ns}} \\
0,0088 \\
0,0032\end{array}$ & $\begin{array}{c}0,8303^{\mathrm{ns}} \\
0,0304 \\
0,0061\end{array}$ & $\begin{array}{c}0,7732^{\text {ns }} \\
0,0440 \\
0,0069\end{array}$ & $\begin{array}{r}-1,3380^{\mathrm{c}} \\
0,1006 \\
-0,0136 \\
\end{array}$ & $\begin{array}{c}-1,8618^{b} \\
0,1361 \\
-0,0364\end{array}$ & $\begin{array}{c}1,1883^{\text {ns }} \\
0,0603 \\
0,0109\end{array}$ & $\begin{array}{c}-2,8085^{\mathrm{a}} \\
0,2639 \\
-0,0210\end{array}$ & $\begin{array}{c}-4,5118^{\mathrm{a}} \\
0,4806 \\
-0,0840\end{array}$ & $\begin{array}{c}-3,8923^{\mathrm{a}} \\
0,4078 \\
-0,0272 \\
\end{array}$ & $\begin{array}{c}2,3180^{b} \\
0,1963 \\
0,0205\end{array}$ & $\begin{array}{c}-5,3914^{\mathrm{a}} \\
0,8532 \\
-0,0401\end{array}$ \\
\hline 1970 & $\beta=\frac{e^{\lambda \cdot T-1}}{T}$ & $-0,0012$ & $-0,0047$ & 0,0075 & $-0,0279$ & $-0,0273$ & 0,0009 & $-0,0240$ & $-0,0289$ & $-0,0175$ & 0,0186 & $-0,0297$ \\
\hline $\begin{array}{c}a \\
2001\end{array}$ & $\begin{array}{c}\mathbf{t} \\
\mathrm{R}^{2} \\
\lambda \\
\end{array}$ & $\begin{array}{c}-0,2152^{\mathrm{ns}} \\
0,0031 \\
-0,0013 \\
\end{array}$ & $\begin{array}{c}-0,5834^{\mathrm{ns}} \\
0,0146 \\
-0,0051 \\
\end{array}$ & $\begin{array}{c}0,7127^{\mathrm{ns}} \\
0,0328 \\
0,0067 \\
\end{array}$ & $\begin{array}{c}-4,0637^{\mathrm{a}} \\
0,4785 \\
-0,0644 \\
\end{array}$ & $\begin{array}{c}-2,2653^{\mathrm{a}} \\
0,1824 \\
-0,0605 \\
\end{array}$ & $\begin{array}{c}0,1234^{\mathrm{ns}} \\
0,0007 \\
0,0009\end{array}$ & $\begin{array}{c}-4,9151^{\mathrm{a}} \\
0,5350 \\
-0,0440\end{array}$ & $\begin{array}{c}-4,4090^{\mathrm{a}} \\
0,4580 \\
-0,0725\end{array}$ & $\begin{array}{c}-3,5212^{\mathrm{a}} \\
0,3503 \\
-0,0253\end{array}$ & $\begin{array}{c}2,5957^{\mathrm{a}} \\
0,2266 \\
0,0147\end{array}$ & $\begin{array}{r}-3,3774^{a} \\
0,6553 \\
-0,0823\end{array}$ \\
\hline 1975 & $\beta=\frac{e^{\lambda \cdot T-1}}{T}$ & $-0,0033$ & $-0,0047$ & $-0,0106$ & $-0,0336$ & $-0,0190$ & $-0,0045$ & $-0,0178$ & $-0,0315$ & $-0,0164$ & 0,0486 & $-0,0229$ \\
\hline $\begin{array}{c}\mathrm{a} \\
2001\end{array}$ & $\begin{array}{c}\mathbf{t} \\
\mathrm{R}^{2} \\
\lambda \\
\end{array}$ & $\begin{array}{c}-0,3027^{\mathrm{ns}} \\
0,0057 \\
-0,0035 \\
\end{array}$ & $\begin{array}{c}-0,3015^{\mathrm{ns}} \\
0,0040 \\
-0,0050 \\
\end{array}$ & $\begin{array}{c}-0,6594^{\mathrm{ns}} \\
0,0324 \\
-0,0124 \\
\end{array}$ & $\begin{array}{c}-3,3791^{\mathrm{a}} \\
0,3634 \\
-0,0792 \\
\end{array}$ & $\begin{array}{r}-1,5713^{\mathrm{c}} \\
0,0969 \\
-0,0261 \\
\end{array}$ & $\begin{array}{c}-0,3499^{\mathrm{ns}} \\
0,0053 \\
-0,0048 \\
\end{array}$ & $\begin{array}{c}-2,0266^{\mathrm{b}} \\
0,1777 \\
-0,0238 \\
\end{array}$ & $\begin{array}{c}-3,0396^{\mathrm{a}} \\
0,2866 \\
-0,0660 \\
\end{array}$ & $\begin{array}{c}-2,5577^{\mathrm{a}} \\
0,2214 \\
-0,0214\end{array}$ & $\begin{array}{c}3,7551^{\mathrm{a}} \\
0,3801 \\
0,0314 \\
\end{array}$ & $\begin{array}{c}-3,8743^{\mathrm{a}} \\
0,7144 \\
-0,0349 \\
\end{array}$ \\
\hline 1980 & $\beta=\frac{e^{\lambda \cdot T-1}}{T}$ & $-0,0046$ & $-0,0151$ & 0,0186 & $-0,0340$ & $-0,0241$ & $-0,0044$ & $-0,0257$ & $-0,0442$ & $-0,0199$ & 0,0070 & $-0,0339$ \\
\hline $\begin{array}{c}\mathrm{a} \\
2001\end{array}$ & $\begin{array}{c}\mathbf{t} \\
\mathrm{R}^{2} \\
\lambda\end{array}$ & $\begin{array}{c}-0,6590^{\mathrm{ns}} \\
0,0264 \\
-0,0049 \\
\end{array}$ & $\begin{array}{c}-1,5704^{\mathrm{c}} \\
0,0932 \\
-0,0182 \\
\end{array}$ & $\begin{array}{c}0,5935^{\mathrm{ns}} \\
0,0310 \\
0,0157\end{array}$ & $\begin{array}{c}-2,8813^{\mathrm{a}} \\
0,3281 \\
-0,0593\end{array}$ & $\begin{array}{c}-3,6686^{\mathrm{a}} \\
0,3691 \\
-0,0336\end{array}$ & $\begin{array}{c}-0,4903^{\mathrm{ns}} \\
0,0099 \\
-0,0046\end{array}$ & $\begin{array}{c}-2,2220^{b} \\
0,1904 \\
-0,0369\end{array}$ & $\begin{array}{c}-3,2056^{\mathrm{a}} \\
0,2998 \\
-0,1251 \\
\end{array}$ & $\begin{array}{c}-1,8418^{b} \\
0,1585 \\
-0,0258\end{array}$ & $\begin{array}{c}1,5369^{b} \\
0,0896 \\
0,0065\end{array}$ & $\begin{array}{c}-2,7019^{a} \\
0,4771 \\
-0,0593\end{array}$ \\
\hline
\end{tabular}

Nota: (a) indica que o coeficiente é significativo a $1 \%$, (b) a $5 \%$, (c) a 10\% e (ns) não significativo 
Pode-se constatar que as culturas de café, cana-de-açúcar, fumo, laranja, mandioca e soja apresentaram, para todos os períodos em análise, o sinal esperado do coeficiente estimado $\beta$ e seus testes estatísticos foram todos significativos até $10 \%$. Pode-se, portanto, concluir que essas culturas apresentam um processo de convergência$\beta$ absoluta da produtividade, o que está coerente com a exposição do capítulo 4 sobre o comportamento dessas culturas no Brasil.

Observando a Tabela 5, pode-se também constatar que as velocidades de convergência são distintas entre as seis culturas que apresentaram a convergência- $\beta$ absoluta. Essas velocidades de convergência são maiores no período de 1970 a 2001 do que no período de 1960 a 2001, exceto para a laranja, refletindo o fato da modernização da agropecuária brasileira ter se acelerado a partir da década de 1970. No entanto, no período de 1980 a 2001, observa-se a redução na velocidade de convergência para cinco das seis culturas citadas (café, cana-de-açúcar, fumo, mandioca e soja), e aumentando para a laranja.

A cultura do algodoeiro apresentou sinal positivo mas não estatisticamente significante para o coeficiente - $\beta$ no período de 1960 a 2001 e sinal negativo, mas não estatisticamente significante, nos períodos de 1970 a 2001, 1975-2001 e 1980-2001. O mesmo processo ocorreu com a cultura do arroz, com a diferença do coeficiente $\beta$, estimado ter sido estatisticamente a $10 \%$ no período de 1980 a 2001 . Pode-se acreditar que um processo de convergência absoluta de produtividade esteja em andamento para essas culturas, mas ainda não se consolidou.

A cultura da batata-inglesa apresenta um quadro oscilante para o sinal do coeficiente estimado $\beta$. Ele só foi positivo nos períodos de 1960-2001, 1970-2001 e 1980-2001 e foi negativo no período de 1975 a 2001. Não obstante, nenhum dos coeficientes estimados foi estatisticamente significante. Trata-se de uma cultura que nada se pode aferir sobre a convergência- $\beta$ absoluta da produtividade. 
A cultura o feijoeiro apresentou sinal positivo para o coeficiente $\beta$ nos períodos de 1960 a 2001, 1970 a 2001 e 1975 a 2001 e sinal negativo no período de 1980 a 2001. No entanto, em nenhum desses períodos os coeficientes foram estatisticamente significativos.

A cultura do milho apresentou, para todos os períodos analisados, sinal positivo para o coeficiente estimado $\beta$ e estatisticamente significante a $1 \%$. Há, para essa cultura, um evidente processo de divergência da produtividade.

\subsection{Convergência- $\sigma$}

Outra forma de testar a hipótese da convergência da produtividade é através da análise da dispersão, denominada de convergência- $\sigma$. A condição suficiente para a convergência é a de que o coeficiente $\psi_{2}$ da equação (102) seja negativo, ou seja, que $\psi_{2}<0$, e significativamente diferente de zero. Todavia, há que se salientar que pode-se ter $\hat{\beta}<0$ na equação de regressão (100) sem no entanto a dispersão estar diminuindo. Em outras palavras, convergência- $\sigma$ implica convergência- $\beta$, mas não o inverso (Valdéz, 1999).

A Tabela 6 mostra as estimativas obtidas a partir da equação (102). 
Tabela 6. Evolução das estimativas da convergência- $\sigma$ por cultura e por período.

\begin{tabular}{|c|c|c|c|c|c|}
\hline & & $1960-2001$ & $1970-2001$ & $1975-2001$ & $1980-2001$ \\
\hline \multirow{3}{*}{$\begin{array}{l}\text { Algodão } \\
\text { Herbáceo }\end{array}$} & $\psi_{2}$ & 0,0190 & 0,0150 & 0,0143 & 0,0071 \\
\hline & $\mathrm{t}$ & $4,8020^{\mathrm{a}}$ & $2,04545^{\mathrm{c}}$ & $1,5761^{\mathrm{c}}$ & $0,5277^{\mathrm{ns}}$ \\
\hline & $\mathrm{R}^{2}$ & 0,3776 & 0,1310 & 0,0904 & 0,0137 \\
\hline \multirow{3}{*}{ Arroz } & $\psi_{2}$ & 0,0077 & 0,0078 & 0,00081 & 0,0050 \\
\hline & $\mathrm{t}$ & $5,1469^{a}$ & $2,9320^{\mathrm{a}}$ & $2,4799^{\mathrm{a}}$ & $1,0719^{\mathrm{ns}}$ \\
\hline & $\mathrm{R}^{2}$ & 0,4107 & 0,2349 & 0,1974 & 0,0543 \\
\hline \multirow{3}{*}{ Batata-Inglesa } & $\psi_{2}$ & 0,0196 & 0,0256 & 0,00109 & 0,0088 \\
\hline & $\mathrm{t}$ & $6,5864^{\mathrm{a}}$ & $5,1478^{a}$ & $0,1328^{\mathrm{ns}}$ & $0,8644^{\mathrm{ns}}$ \\
\hline & $\mathrm{R}^{2}$ & 0,5330 & 0,4862 & 0,0007 & 0,0360 \\
\hline \multirow{3}{*}{ Café } & $\psi_{2}$ & 0,0041 & 0,0041 & 0,0067 & 0,0089 \\
\hline & $\mathrm{t}$ & $3,4284^{\mathrm{a}}$ & $2,2262^{b}$ & $4,1467^{\mathrm{a}}$ & $3,0499^{\mathrm{a}}$ \\
\hline & $\mathrm{R}^{2}$ & 0,2362 & 0,1504 & 0,4075 & 0,3137 \\
\hline \multirow{3}{*}{ Cana-de-açúcar } & $\psi_{2}$ & 0,0111 & 0,0203 & 0,0218 & 0,0255 \\
\hline & $\mathrm{t}$ & $4,1283^{\mathrm{a}}$ & $4,3430^{\mathrm{a}}$ & $3,8054^{\mathrm{a}}$ & $3,0278^{\mathrm{a}}$ \\
\hline & $\mathrm{R}^{2}$ & 0,3096 & 0,4025 & 0,3668 & 0,3143 \\
\hline \multirow{3}{*}{ Feijão } & $\psi_{2}$ & 0,0076 & 0,0098 & 0,0116 & 0,0126 \\
\hline & $\mathrm{t}$ & $3,5899^{\mathrm{a}}$ & $2,4634^{\mathrm{a}}$ & $2,3832^{b}$ & $1,8197^{\mathrm{b}}$ \\
\hline & $\mathrm{R}^{2}$ & 0,2533 & 0,1781 & 0,1851 & 0,1421 \\
\hline \multirow{3}{*}{ Fumo } & $\psi_{2}$ & 0,0014 & 0,0013 & 0,0027 & 0,0030 \\
\hline & $\mathrm{t}$ & $2,3050^{\mathrm{b}}$ & $1,1851^{\mathrm{ns}}$ & $1,9998^{\mathrm{b}}$ & $2,0429^{b}$ \\
\hline & $\mathrm{R}^{2}$ & 0,1227 & 0,0478 & 0,1379 & 0,1726 \\
\hline \multirow{3}{*}{ Laranja } & $\psi_{2}$ & $-0,0006$ & 0,0065 & 0,0078 & 0,0066 \\
\hline & $\mathrm{t}$ & $-1,3239^{c}$ & $2,3865^{b}$ & $2,3252^{b}$ & $1,3327^{\mathrm{c}}$ \\
\hline & $\mathrm{R}^{2}$ & 0,0441 & 0,1690 & 0,1778 & 0,0816 \\
\hline
\end{tabular}


Tabela 6. Evolução das estimativas da convergência- $\sigma$ por cultura e por período.

\begin{tabular}{|c|c|c|c|c|c|}
\hline & & 1960-2001 & 1970-2001 & $1975-2001$ & 1980-2001 \\
\hline \multirow{3}{*}{ Mandioca } & $\psi_{2}$ & $-0,0010$ & 0,0020 & 0,0034 & 0,0038 \\
\hline & $\mathrm{t}$ & $-0,8974^{\mathrm{ns}}$ & $1,2732^{\mathrm{ns}}$ & $1,7696^{b}$ & $1,3362^{c}$ \\
\hline & $\mathrm{R}^{2}$ & 0,0207 & 0,0547 & 0,1113 & 0,0820 \\
\hline \multirow{3}{*}{ Milho } & $\psi_{2}$ & 0,0254 & 0,0273 & 0,0277 & 0,0130 \\
\hline & $\mathrm{t}$ & $4,8526^{\mathrm{a}}$ & $2,8512^{\mathrm{a}}$ & $2,2629^{b}$ & $0,7574^{\mathrm{ns}}$ \\
\hline & $\mathrm{R}^{2}$ & 0,3826 & 0,2250 & 0,1700 & 0,0279 \\
\hline \multirow{3}{*}{ Soja } & $\psi_{2}$ & $-0,0037$ & $-0,0024$ & $-0,0043$ & $-0,0075$ \\
\hline & $\mathrm{t}$ & $-2,8603^{a}$ & $-1,2276^{\mathrm{ns}}$ & $-1,8584^{b}$ & $-2,9435^{\mathrm{a}}$ \\
\hline & $\mathrm{R}^{2}$ & 0,0771 & 0,0511 & 0,1214 & 0,3022 \\
\hline
\end{tabular}

Nota: (a) significativo a 1\%, (b) significativo a 5\%, (c) significativo a $10 \%$ e (ns) não significativo

Como esperado, as culturas do algodão herbáceo, arroz, batata-inglesa, feijão e milho não apresentaram o sinal esperado do coeficiente $\psi_{2}$, indicando que a dispersão da produtividade entre os estados produtores dessas culturas não está diminuindo. Contudo, constata-se que no período de 1980 a 2001, exceto na cultura do feijão, os testes estatísticos das culturas do algodão herbáceo, do arroz, da batata-inglesa e do milho não foram estatisticamente significantes. No caso da batata-inglesa observa-se que o teste estatístico também não foi significante no período de 1975 a 2001.

Em relação às culturas de café, cana-de-açúcar e fumo, contata-se que em todos os períodos analisados na Tabela 6 , o coeficiente de convergência $\psi_{2}$ foi positivo, indicando que não está ocorrendo redução da dispersão da produtividade e, com exceção da cultura do fumo no período de 1970 a 2001 que não apresentou significância, todos os demais períodos mostraram significância estatística. 
Para as culturas da laranja e da mandioca, nota-se no período de 1960 a 2001 havia indicação de queda da dispersão da produtividade da terra entre os estados produtores dessas culturas. O teste estatístico foi significativo para a cultura da laranja, mas não para a cultura da mandioca. Nos períodos de 1970-2001, 1975-2001 e 19802001, ocorre inversão da tendência verificada no período de 1960-2001 com as culturas da laranja e da mandioca, ou seja, o coeficiente $\psi_{2}$ passa a apresentar sinal positivo, sendo inclusive estatisticamente significante. No caso da cultura da mandioca o teste estatístico t foi significativo nos períodos de 1975 a 2001 e 1980 a 2001, já para a cultura da laranja, o teste estatístico foi significativo nos três períodos citados.

Finalmente, para a cultura da soja constata-se que o coeficiente estimado $\psi_{2}$ foi negativo em todos os períodos analisados e somente no período de 1970 a 2001 ele não foi significativo.

\subsection{Convergência- $\beta$ absoluta para a formação de grupos de convergência}

Para as culturas em que se observou um padrão divergente de produtividade ou nas quais o teste estatístico não foi estatisticamente significante (algodão herbáceo, arroz, batata-inglesa, feijão e milho), são efetuados novos testes, levando-se em consideração apenas os principais estados produtores. A realização deste teste tem como objetivo verificar a existência, ou não, de grupos de convergência. Nesse sentido pode-se constatar a existência de um grupo de estados, todos apresentando baixa produtividade, assim como a existência de um grupo de estados, apresentando alta produtividade, cada qual convergindo para seu nível, baixo ou alto de produtividade. Porém entre ambos grupos não há convergência.

Para classificar os estados entre os mais e os menos produtivos, comparou-se a produtividade de cada estado com relação à média da produtividade nacional para cada cultura. Assim, o estado só foi incluído no rol dos "mais produtivos" quando sua 
produtividade média era igual ou superior a $70 \%$ da média nacional ${ }^{23}$. No Quadro 3 constam os estados selecionados como "mais produtivos" para cada cultura.

A Tabela 7 apresenta os resultados deste exercício. Para detectar grupos de convergência estima-se o coeficiente de convergência $\beta$ da equação (100), obtendo-se, na seqüência, a velocidade de convergência definida por $\lambda$, para os períodos de 1960 a 2001, 1970-2001, 1975-2001 e 1980-2001, respectivamente.

\footnotetext{
${ }^{23}$ A análise de grupo de convergência só foi feita para grupos de estados mais produtivos. O objetivo foi verificar se os estados que possuem alta produtividade da terra formavam um clube de convergência.
} 


\begin{tabular}{|c|c|c|c|c|c|c|c|c|c|c|c|c|c|c|c|c|c|c|c|c|}
\hline \multirow{5}{*}{$\begin{array}{l}\text { Estados } \\
\text { Produtores }\end{array}$} & \multicolumn{4}{|c|}{ Algodão Herbáceo } & \multicolumn{4}{|c|}{ Arroz } & \multicolumn{4}{|c|}{ Batata-Inglesa } & \multicolumn{4}{|c|}{ Feijão } & \multicolumn{4}{|c|}{ Milho } \\
\hline & \multicolumn{4}{|c|}{ Períodos } & \multicolumn{4}{|c|}{ Períodos } & \multicolumn{4}{|c|}{ Períodos } & \multicolumn{4}{|c|}{ Períodos } & \multicolumn{4}{|c|}{ Períodos } \\
\hline & 1960 & 1970 & 1975 & 1980 & 1960 & 1970 & 1975 & 1980 & 1960 & 1970 & 1975 & 1980 & 1960 & 1970 & 1975 & 1980 & 1960 & 1970 & 1975 & 1980 \\
\hline & $\mathrm{a}$ & $\mathrm{a}$ & $\mathrm{a}$ & $\mathrm{a}$ & $\mathrm{a}$ & $\mathrm{a}$ & $\mathrm{a}$ & $\mathrm{a}$ & $\mathrm{a}$ & $\mathrm{a}$ & $\mathrm{a}$ & $\mathrm{a}$ & $\mathrm{a}$ & $\mathrm{a}$ & $\mathrm{a}$ & $a$ & $\mathrm{a}$ & $\mathrm{a}$ & $a$ & $\mathrm{a}$ \\
\hline & 2001 & 2001 & 2001 & 2001 & 2001 & 2001 & 2001 & 2001 & 2001 & 2001 & 2001 & 2001 & 2001 & 2001 & 2001 & 2001 & 2001 & 2001 & 2001 & 2001 \\
\hline Rondônia & & & $\mathrm{X}$ & $\mathrm{X}$ & & & & & & & & & $\mathrm{X}$ & $\mathrm{X}$ & $\mathrm{X}$ & $\mathrm{X}$ & $\mathrm{X}$ & $\mathrm{X}$ & $\mathrm{X}$ & $\mathrm{X}$ \\
\hline Acre & & & & & & & & & & & & & $\mathrm{X}$ & $X$ & $\mathrm{X}$ & $X$ & $X$ & & $X$ & $\mathrm{X}$ \\
\hline Amazonas & & & & & & & $\mathrm{X}$ & $X$ & & & & & $\mathrm{X}$ & $\mathrm{X}$ & $\mathrm{X}$ & $\mathrm{X}$ & $X$ & $\mathrm{X}$ & $X$ & $\mathrm{X}$ \\
\hline Roraima & & & & & $\mathrm{X}$ & $\mathrm{X}$ & & & & & & & $\mathrm{X}$ & & $\mathrm{X}$ & $\mathrm{X}$ & & & & \\
\hline Pará & & $\mathrm{X}$ & $\mathrm{X}$ & $\mathrm{X}$ & & & & & & & & & $\mathrm{X}$ & & $\mathrm{X}$ & $\mathrm{X}$ & & & & \\
\hline Amapá & & & & & & & & & & & & & & & $X$ & $X$ & & & & \\
\hline Maranhão & $\mathrm{X}$ & $\mathrm{X}$ & $\mathrm{X}$ & $\mathrm{X}$ & & & & & & & & & & & $\mathrm{X}$ & $\mathrm{X}$ & & & & \\
\hline Piauí & & & & & & & & & & & & & & & & & & & & \\
\hline Ceará & & & & & $\mathrm{X}$ & $\mathrm{X}$ & $X$ & $X$ & & & & & & & & & & & & \\
\hline Rio Grande do Norte & & & & & & & & & & & & & & & & & & & & \\
\hline Paraíba & & & & & & & & & & & $\mathrm{X}$ & & & & & & & & & \\
\hline Pernambuco & & & & & $\mathrm{X}$ & $\mathrm{X}$ & $\mathrm{X}$ & $\mathrm{X}$ & $\mathrm{X}$ & & $\mathrm{X}$ & & & & & & & & & \\
\hline Alagoas & & & & & $\mathrm{X}$ & $\mathrm{X}$ & $\mathrm{X}$ & $\mathrm{X}$ & $\mathrm{X}$ & & & & & & & & & & & \\
\hline Sergipe & & & & & $X$ & $X$ & $X$ & $X$ & $\mathrm{X}$ & & $\mathrm{X}$ & & & & $\mathrm{X}$ & $X$ & & & & \\
\hline Bahia & $\mathrm{X}$ & $X$ & $\mathrm{X}$ & $X$ & & & & & $\mathrm{X}$ & $X$ & $\mathrm{X}$ & $\mathrm{X}$ & & & $\mathrm{X}$ & $X$ & & & & \\
\hline Minas Gerais & $\mathrm{X}$ & $X$ & $\mathrm{X}$ & $\mathrm{X}$ & & & & & $\mathrm{X}$ & $\mathrm{X}$ & $\mathrm{X}$ & $\mathrm{X}$ & $\mathrm{X}$ & $\mathrm{X}$ & $\mathrm{X}$ & $\mathrm{X}$ & $\mathrm{X}$ & $\mathrm{X}$ & $\mathrm{X}$ & $\mathrm{X}$ \\
\hline Espírito Santo & & & & & $\mathrm{X}$ & $\mathrm{X}$ & $\mathrm{X}$ & $\mathrm{X}$ & $\mathrm{X}$ & $X$ & $\mathrm{X}$ & $\mathrm{X}$ & $\mathrm{X}$ & $\mathrm{X}$ & $\mathrm{X}$ & $\mathrm{X}$ & $\mathrm{X}$ & $\mathrm{X}$ & $\mathrm{X}$ & $\mathrm{X}$ \\
\hline Rio de Janeiro & & & & & $\mathrm{X}$ & $X$ & $X$ & $X$ & $X$ & $X$ & $\mathrm{X}$ & $X$ & & $\mathrm{X}$ & $\mathrm{X}$ & $X$ & $X$ & $X$ & $X$ & $\mathrm{X}$ \\
\hline São Paulo & $\mathrm{X}$ & $\mathrm{X}$ & $\mathrm{X}$ & $X$ & & & & & $\mathrm{X}$ & $X$ & $\mathrm{X}$ & $\mathrm{X}$ & $\mathrm{X}$ & $\mathrm{X}$ & $\mathrm{X}$ & $\mathrm{X}$ & $\mathrm{X}$ & $\mathrm{X}$ & $X$ & $\mathrm{X}$ \\
\hline Paraná & $\mathrm{X}$ & $X$ & $\mathrm{X}$ & $X$ & & & & & $\mathrm{X}$ & $X$ & $\mathrm{X}$ & $\mathrm{X}$ & $X$ & $\mathrm{X}$ & $\mathrm{X}$ & $X$ & $X$ & $X$ & $X$ & $\mathrm{X}$ \\
\hline Santa Catarina & & & & & $\mathrm{X}$ & $\mathrm{X}$ & $\mathrm{X}$ & $\mathrm{X}$ & $\mathrm{X}$ & $X$ & $\mathrm{X}$ & $\mathrm{X}$ & $\mathrm{X}$ & $\mathrm{X}$ & $\mathrm{X}$ & $\mathrm{X}$ & $\mathrm{X}$ & $\mathrm{X}$ & $\mathrm{X}$ & $\mathrm{X}$ \\
\hline Rio Grande do Sul & & & & & $\mathrm{X}$ & $\mathrm{X}$ & $X$ & $X$ & $\mathrm{X}$ & $X$ & $X$ & $\mathrm{X}$ & $\mathrm{X}$ & $\mathrm{X}$ & $X$ & $X$ & $X$ & $X$ & $\mathrm{X}$ & $\mathrm{X}$ \\
\hline * Mato Grosso do Sul & & & & $X$ & & & & $\mathrm{X}$ & & & & & & & & $\mathrm{X}$ & & & & $\mathrm{X}$ \\
\hline Mato Grosso & $\mathrm{X}$ & $\mathrm{X}$ & $\mathrm{X}$ & & & & & & $\mathrm{X}$ & & & & $\mathrm{X}$ & $\mathrm{X}$ & $\mathrm{X}$ & $\mathrm{X}$ & $\mathrm{X}$ & $\mathrm{X}$ & $\mathrm{X}$ & $\mathrm{X}$ \\
\hline Goiás & $\mathrm{X}$ & $\mathrm{X}$ & $\mathrm{X}$ & & & & & & $\mathrm{X}$ & $X$ & $\mathrm{X}$ & $\mathrm{X}$ & $\mathrm{X}$ & $\mathrm{X}$ & $\mathrm{X}$ & $\mathrm{X}$ & $\mathrm{X}$ & $\mathrm{X}$ & $\mathrm{X}$ & $\mathrm{X}$ \\
\hline Distrito Federal & & & & & & & & & & $X$ & $\mathrm{X}$ & $X$ & & $\mathrm{X}$ & $X$ & $X$ & & $X$ & $X$ & $X$ \\
\hline
\end{tabular}

Quadro 3 - Estados produtores considerados na análise de grupos de convergência

*O Estado do Mato Grosso do Sul foi considerado somente no período de 1980 a 2001 
Tabela 7. Convergência- $\beta$ absoluta e a formação de grupos de convergência

\begin{tabular}{|c|c|c|c|c|c|}
\hline & & $1960-2001$ & $1970-2001$ & $1975-2001$ & 1980-2001 \\
\hline \multirow{5}{*}{$\begin{array}{l}\text { Algodão } \\
\text { Herbáceo }\end{array}$} & $\beta_{-} e^{\lambda \cdot T-1}$ & $-0,0214$ & $-0,0231$ & $-0,0351$ & $-0,0289$ \\
\hline & $\beta=\frac{T}{T}$ & & & & \\
\hline & $\mathrm{t}$ & $-4,5849^{\mathrm{a}}$ & $-3,2706^{\mathrm{a}}$ & $-3,0645^{\mathrm{a}}$ & $-1,7342^{\mathrm{c}}$ \\
\hline & $\mathrm{R}^{2}$ & 0,8079 & 0,6406 & 0,5729 & 0,2732 \\
\hline & $\begin{array}{l}\lambda=\text { velocidade } \\
\text { de convergência }\end{array}$ & $-0,0514$ & $-0,0405$ & $-0,0934$ & $-0,0444$ \\
\hline \multirow{5}{*}{ Arroz } & $\beta=\frac{e^{\lambda \cdot T-1}}{2}$ & $-0,0023$ & $-0,0089$ & $-0,0117$ & - \\
\hline & t & $01267^{\mathrm{ns}}$ & $11531 \mathrm{~ns}$ & $5630 \mathrm{~ns}$ & \\
\hline & $\mathbf{D}^{2}$ & ברח & 01506 & 00123 & \\
\hline & &, $002 J$ & $0,1 J 30$ & נינד, & 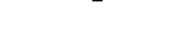 \\
\hline & $\begin{array}{c}\lambda=\text { velocidade } \\
\text { de convergência }\end{array}$ & $-0,0024$ & $-0,0104$ & $-0,0139$ & - \\
\hline \multirow{5}{*}{ Batata-Inglesa } & $\beta=\frac{e^{\lambda \cdot T-1}}{}$ & $-0,0219$ & $-0,0303$ & $-0,0328$ & $-0,0266$ \\
\hline & $T$ & & & & \\
\hline & $\mathrm{t}$ & $-2,9411^{a}$ & $-2,9692^{\mathrm{a}}$ & $-2,2247^{b}$ & $-1,9756^{b}$ \\
\hline & $\mathrm{R}^{2}$ & 0,4901 & 0,5243 & 0,3103 & 0,3279 \\
\hline & $\begin{array}{l}\lambda=\text { velocidade } \\
\text { de convergência }\end{array}$ & $-0,0553$ & $-0,0905$ & $-0,0739$ & $-0,0389$ \\
\hline \multirow{5}{*}{ Feijão } & $\beta_{-} e^{\lambda \cdot T-1}$ & $-0,0228$ & $-0,0270$ & $-0,0360$ & $-0,0409$ \\
\hline & $T$ & & & & \\
\hline & $\mathrm{t}$ & $-2,9963^{\text {a }}$ & $-1,9883^{b}$ & $-2,7796^{\mathrm{a}}$ & $-3,0506^{\mathrm{a}}$ \\
\hline & $\mathrm{R}^{2}$ & 0,4280 & 0,2478 & 0,3124 & 0,3538 \\
\hline & $\begin{array}{l}\lambda=\text { velocidade } \\
\text { de convergência }\end{array}$ & $-0,0666$ & $-0,0588$ & $-0,1051$ & $-0,0935$ \\
\hline
\end{tabular}


Tabela 7. Convergência- $\beta$ absoluta e a formação de grupos de convergência

\begin{tabular}{|c|c|c|c|c|c|}
\hline & & $1960-2001$ & $1970-2001$ & $1975-2001$ & $1980-2001$ \\
\hline & $\beta=\frac{e^{\lambda \cdot T-1}}{T}$ & $-0,0057$ & 0,0047 & $-0,0108$ & 0,0053 \\
\hline \multirow[t]{3}{*}{ Milho } & $\mathrm{t}$ & $-0,4714^{\mathrm{ns}}$ & $0,3847^{\mathrm{ns}}$ & $-0,5802^{\mathrm{ns}}$ & $0,4130^{\mathrm{ns}}$ \\
\hline & $\mathrm{R}^{2}$ & 0,0217 & 0,0146 & 0,0297 & 0,0130 \\
\hline & $\begin{array}{l}\lambda=\text { velocidade } \\
\text { de convergência }\end{array}$ & $-0,0065$ & 0,0044 & $-0,0126$ & 0,0050 \\
\hline
\end{tabular}

Nota: (a) significativo a $1 \%$, (b) significativo a $5 \%$, (c) significativo a $10 \%$ e (ns) não significativo

Constata-se que nas culturas do algodão herbáceo, da batata inglesa e do feijão existe a formação de grupos de convergência. Os estados que formaram os grupos de convergência destas culturas foram de alta produtividade, ou seja, os que apresentaram produtividade média de $70 \%$ ou acima da produtividade média nacional.

A cultura do arroz apresentou o sinal correto para o $\beta$ (indicando convergência de produtividade) nos períodos de 1960-2001, 1970-2001 e 1975-2001, porém, seu teste estatístico não foi significativo. Portanto, conclui-se que não há a formação de grupos de convergência para a cultura do arroz. No período de 1980 a 2001 , conforme pode ser observado na tabela 6 , o coeficiente estimado de convergência- $\beta$ absoluta foi negativo e estatisticamente significativo, indicando que os estados produtores de arroz começam a eliminar os diferenciais de produtividade que marcaram os períodos anteriores. Por isso, não foi estimado grupo de convergência para o arroz no período de 1980 a 2001.

A cultura do milho apresentou alternância no sinal do coeficiente estimado $\beta$, mas, os testes estatísticos não foram significantes. Os resultados indicam que não há formação de grupos de convergência para esta cultura. 


\subsection{Convergência $\beta$-condicional}

Em função de se acreditar que as culturas nas quais a convergência- $\beta$ absoluta de produtividade não se verificou (algodão herbáceo, arroz, batata-inglesa, feijão e milho) podem estar sendo afetadas por condições edafo-climáticas distintas entre os estados, por diferentes pacotes tecnológicos utilizados, assim como por diferenças regionais na estrutura produtiva, são realizados novos testes considerando a convergência- $\beta$ condicional. As variáveis independentes consideradas são o nível inicial de produtividade $\left(\mathrm{y}_{\mathrm{o}}\right)$, a deficiência hídrica $(\mathrm{DH})$ e os anos médios de escolaridade dos trabalhadores alocados na agropecuária, para o qual utilizou-se a denominação capital humano $(\mathrm{CH})$.

Inicialmente, estimou-se uma versão estendida da equação (101) onde são consideradas as variáveis: nível inicial de produtividade, deficiência hídrica, capital humano e o uso de fertilizantes. Como somente as variáveis deficiência hídrica e capital humano mostraram-se significativas na maioria das culturas, optou-se pela exclusão da variável uso de fertilizantes na especificação da equação (101).

Na Tabela 8 são apresentados os resultados das estimativas dos parâmetros $\beta, \psi$ e ๗ da equação (101). 
Tabela 8. Estimativas da convergência- $\beta$ condicional

\begin{tabular}{|c|c|c|c|}
\hline \multicolumn{4}{|c|}{ Parâmetro de convergência $(\beta)$, deficiência hídrica $(\psi)$ e capital humano $(\omega)$} \\
\hline Parâmetros & $\begin{array}{c}\text { Sinal } \\
\text { esperado }\end{array}$ & $1975-2001$ & $1980-2001$ \\
\hline 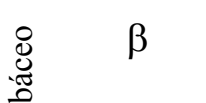 & - & $\begin{array}{c}-0,02392^{\mathrm{ns}} \\
(-1,17)\end{array}$ & $\begin{array}{c}-0,01270^{\mathrm{ns}} \\
(-1,03)\end{array}$ \\
\hline $\begin{array}{l}\frac{\overrightarrow{0}}{\frac{1}{1}} \\
\end{array}$ & - & $\begin{array}{c}-0,00007^{b} \\
(-2,00)\end{array}$ & $\begin{array}{c}-0,00003^{\mathrm{ns}} \\
(-0,98)\end{array}$ \\
\hline$\omega$ & + & $\begin{array}{c}007421 \\
(011)\end{array}$ & $\begin{array}{c}0,02812^{\mathrm{ns}} \\
(0,06)\end{array}$ \\
\hline
\end{tabular}

$\begin{array}{ccc}\text { Parâmetros } & \begin{array}{c}\text { Sinal } \\ \text { esperado }\end{array} & 1975-2001 \\ \beta & - & 0,00981^{\mathrm{ns}} \\ & & (0,54)^{\mathrm{ns}} \\ \omega & - & 0,00001^{\mathrm{ns}} \\ & & (0,63)^{\mathrm{b}} \\ & + & 0,68219^{\mathrm{b}} \\ & & (1,86)^{\mathrm{N}}\end{array}$

\begin{tabular}{|c|c|c|c|}
\hline Parâmetros & $\begin{array}{c}\text { Sinal } \\
\text { esperado }\end{array}$ & $1975-2001$ & $1980-2001$ \\
\hline 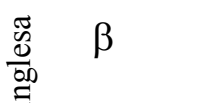 & - & $\begin{array}{c}-0,01727^{\mathrm{ns}} \\
(-0,93)\end{array}$ & $\begin{array}{c}-0,05879^{b} \\
(-1,95)\end{array}$ \\
\hline$\psi$ & - & $\begin{array}{c}-0,00001 \\
(-0,22)\end{array}$ & $\begin{array}{c}-0,00019^{\mathrm{a}} \\
(-3,00)\end{array}$ \\
\hline$\omega$ & + & $\begin{array}{c}0,59963^{\mathrm{ns}} \\
(1,09)\end{array}$ & $\begin{array}{c}1,79588^{\mathrm{b}} \\
(2,60)\end{array}$ \\
\hline
\end{tabular}

\begin{tabular}{|c|c|c|c|}
\hline Parâmetros & $\begin{array}{c}\text { Sinal } \\
\text { esperado }\end{array}$ & $1975-2001$ & $1980-2001$ \\
\hline$\beta$ & - & $\begin{array}{c}-0,03291^{\mathrm{a}} \\
(-3,85)\end{array}$ & $\begin{array}{c}-0,02781^{\mathrm{a}} \\
(-3,82)\end{array}$ \\
\hline 漓 & - & $\begin{array}{c}-0,00006^{\mathrm{a}} \\
(-4,52)\end{array}$ & $\begin{array}{c}-0,00007^{\mathrm{a}} \\
(-3,90)\end{array}$ \\
\hline$\omega$ & + & $\begin{array}{c}0,77899^{\mathrm{a}} \\
(3,79)\end{array}$ & $\begin{array}{c}0,98066^{\mathrm{a}} \\
(4,47)\end{array}$ \\
\hline
\end{tabular}


Tabela 8. Estimativas da convergência- $\beta$ condicional

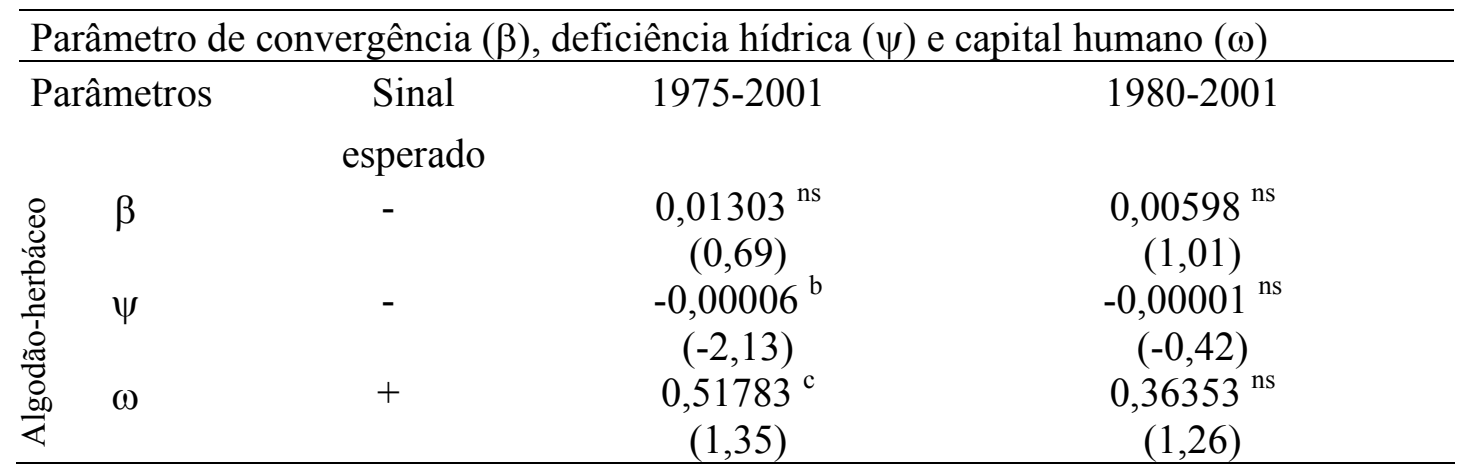

Nota: o valor entre parênteses refere-se à estatística $\mathrm{t}$

(a) indica nível de significância a 1\%, (b) a 5\%, (c) a 10\% e (ns) não significante

Para a cultura do algodão herbáceo constata-se que os coeficientes estimados apresentam os sinais esperados nas três variáveis, no entanto, o teste estatístico só foi significativo para a variável deficiência hídrica e no período de 1975 a 2001.

Para a cultura do arroz constata-se que no período de 1975 a 2001 o coeficiente estimado $\beta$ e $\psi$ não apresentaram o sinal esperado. Quanto à contribuição do capital humano para o processo de convergência da produtividade, observa-se que este apresentou o sinal esperado e seu teste estatístico foi também estatisticamente significativo.

A cultura da batata-inglesa apresentou o sinal esperado para todas as variáveis nos dois períodos. Contudo, seu teste estatístico só foi significante no período de 1980 a 2001.

A cultura do feijoeiro apresentou o sinal esperado e significância estatística para todas as variáveis e nos dois períodos analisados.

$\mathrm{Na}$ cultura do milho observa-se que, com exceção do coeficiente estimado $\beta$, as variáveis deficiência hídrica e capital humano apresentaram os sinais esperados e 
teste estatístico significativo no período de 1975 a 2001. No período de 1980 a 2001, somente a variável capital humano apresentou o sinal esperado, contudo nenhum teste estatístico desse período foi significativo. 


\section{CONCLUSÕES}

Este estudo teve como objetivo testar e analisar a hipótese da convergência sob a perspectiva da produtividade da terra. $\mathrm{O}$ aumento nos investimentos em pesquisa $\mathrm{e}$ educação, que teve início a partir da década de 60 e prosseguiu nos anos que se seguiram, conduziram à modernização da agricultura e se traduziu em aumentos de produtividade.

Contudo, é de se esperar que a aceitação e a adoção de uma nova técnica leve algum tempo para ser assimilada. Portanto, os frutos da modernização iniciada nos anos de 60 só seriam "colhidos" após transcorrer um certo período de tempo.

Diante disso, acredita-se que todo o esforço empreendido em prol da agricultura tenha contribuído para reduzir as desigualdades estaduais e regionais no Brasil, no que diz respeito à produtividade da terra. Esta é, portanto, a principal razão que nos incentivou a estudar e testar a hipótese da presença de convergência da produtividade da terra na agricultura brasileira.

Desde 1990, uma grande quantidade de pesquisas sobre crescimento econômico tem analisado a hipótese da convergência com o intuito de encontrar evidências para a convergência- $\beta$, convergência- $\sigma$ e convergência- $\beta$ condicional. Contudo, a grande maioria desses estudos tem focalizado a renda per capita como variável de análise ou variável dependente. Sendo assim, acredita-se que ao optar pela análise do processo de convergência da produtividade da terra, este estudo destaca seu caráter inovador e contribui com a literatura sobre crescimento econômico ao oferecer uma análise empírica original sobre o tema convergência. 
Além desta contribuição, destaca-se também a construção do modelo teórico do capítulo 5 para analisar o processo de convergência da produtividade da terra.

Para realizar este estudo optou-se por trabalhar com as 11 principais culturas brasileiras no período de 1960 a 2001. Elas são: algodão herbáceo, arroz, batata-inglesa, café, cana-de-açúcar, feijão, fumo, laranja, mandioca, milho e soja. Para captar as mudanças ocorridas na agricultura brasileira, ao longo deste período, optou-se também pela análise de mais três sub-períodos: 1970 a 2001, 1975 a 2001 e 1980 a 2001.

Para isso, quatro etapas foram seguidas. A primeira foi estimar a equação de convergência- $\beta$ absoluta, na qual apenas os dados sobre a produtividade das culturas são levados em consideração na análise. Se o coeficiente estimado $\beta$ apresentar sinal negativo, então, confirma-se a presença de convergência da produtividade da terra. Considera-se também, no caso da convergência- $\beta$ absoluta, que existe um estadoestacionário comum em termos de produtividade para o qual os estados produtores, de determinada cultura, convergirão. Em seguida estimou-se uma equação para o teste de convergência- $\sigma$. A base deste teste é verificar se está ocorrendo uma queda na dispersão, medida em termos do logaritmo neperiano da produtividade de determinada cultura, através do tempo e entre os principais estados produtores. Para as culturas onde não se obteve a convergência- $\beta$ absoluta foram testados a presença de grupos de convergência ( $3^{\underline{a}}$ etapa) e a convergência- $\beta$ condicional ( $4^{\mathrm{a}}$ etapa). Neste último caso, a equação de convergência- $\beta$ absoluta é expandida para acrescentar variáveis que possam explicar uma mudança de direção, se houver, na taxa de crescimento da produtividade (variável dependente). Neste estudo, a equação $\beta$ condicional considerou como variáveis explicativas o valor inicial da produtividade da terra, a deficiência hídrica e os anos médios de estudos dos trabalhadores alocados na agropecuária. Optou-se por considerar dois períodos - 1975 a 2001 e 1980 a 2001 - em função de se perceber que as séries de dados tornam-se mais consistentes a partir de 1970. 
As principais conclusões que este estudo chegou a partir dos resultados obtidos nos testes de convergência- $\beta$ absoluta, convergência- $\beta$ condicional, convergência- $\sigma$ e grupos de convergência, foram:

1 - As culturas do cafeeiro, da cana-de-açúcar, do fumo, da laranja, da mandioca e do soja, apresentaram para todos os períodos analisados (1960 a 2001, 1970 a 2001, 1975 a 2001 e 1980 a 2001) convergência- $\beta$ absoluta. No entanto, a convergência- $\sigma$ só ocorreu para a cultura do soja em todos esses períodos e para as culturas da laranja e mandioca no período de 1960 a 2001. As seis culturas supracitadas vem apresentando efeito catch-up na tecnologia, em especial o soja.

2 - Os testes de convergência- $\beta$ em grupos de convergência foram ótimos para o algodão herbáceo, a batata-inglesa e o feijão, provando que os principais estados produtores que detém uma produtividade média superior a $70 \%$ da produtividade média nacional convergem entre si, todavia, não há convergência entre estes estados e os demais.

3 - Os resultados obtidos no teste de convergência- $\beta$ condicional para as culturas da batata-inglesa e o feijoeiro foram excelentes, porém, razoáveis para o algodão herbáceo. Estes resultados mostram que de fato há convergência de produtividade entre os estados produtores dessas culturas quando se controlam os efeitos da deficiência hídrica e do capital humano sobre a produtividade. No entanto, para as culturas do arroz e do milho os resultados no teste de convergência- $\beta$ condicional, não foram favoráveis.

É importante lembrar que além das medidas de convergência aqui consideradas (convergência- $\beta$ absoluta, convergência- $\beta$ condicional e convergência- $\sigma$ ) outras também têm sido referidas na literatura, tais como: índice de Theil, índice de Wilianson, além das metodologias sugeridas por Ben David (1993), Bernard e Jones (1996), Danny Quah (1993), Drenan e Lobo (1999). Assim sendo, futuros trabalhos 
poderão usar essas metodologias para compararem seus resultados com os aqui apresentados.

$\mathrm{Na}$ obstante, os resultados supracitados evidenciaram que maiores esforços de pesquisa e difusão de tecnologia devem ser feitos para as culturas do algodão herbáceo, batata-inglesa, feijão, arroz e milho, em especial para as duas últimas. Isto permitirá uma maior homogeneidade da modernidade dessas culturas, reduzindo a dualidade técnica que existe entre os estados produtores. 
ANEXOS 
ANEXO A - Revisão da literatura sobre convergência no mundo

\begin{tabular}{|c|c|c|c|c|c|c|}
\hline Autores & $\begin{array}{c}\text { País } \\
\text { Considerado } \\
\end{array}$ & $\begin{array}{c}\text { Objetivo do } \\
\text { Trabalho }\end{array}$ & $\begin{array}{c}\text { Variável de } \\
\text { Convergência }\end{array}$ & $\begin{array}{c}\text { Período de tempo } \\
\text { Analisado }\end{array}$ & $\begin{array}{c}\text { Modelo Teórico } \\
\text { Considerado }\end{array}$ & Equação Estimada \\
\hline $\begin{array}{c}\text { Barros e } \\
\text { Garoupa } \\
(1995)\end{array}$ & Portugal & $\begin{array}{l}\text { Avaliar o padrão } \\
\text { de convergência } \\
\text { da Renda per } \\
\text { capita portuguesa } \\
\text { em relação à } \\
\text { União Européia, } \\
\text { antes e depois de } \\
\text { Portugal tornar- } \\
\text { se membro da } \\
\text { EU. }\end{array}$ & Renda Per Capita & $\begin{array}{c}1950 \text { a } 1993, \\
\text { divididos em três } \\
\text { sub-períodos: } \\
1951 \text { a } 1973,1974 \text { a } \\
1985 \text { e } 1986 \text { a } \\
1993 .\end{array}$ & $\begin{array}{l}\text { Ben-David } \\
\text { (1993) }\end{array}$ & $\begin{array}{l}\qquad \Delta Z_{j, t+1}=-k Z_{j, t} \text {, } \\
\text { em que: } k=1-\Phi \text { e } Z_{j, t} \text { é descrita como sendo: } \\
Z_{\mathrm{j}, \mathrm{t}}=\mathrm{Y}_{\mathrm{j}, \mathrm{t}}-\mathrm{Y}_{\mathrm{t}}{ }^{*} \\
\text { em que: } \Delta \text { é o operador de diferenças e } \mathrm{k} \text { é a taxa de } \\
\text { convergência e } \mathrm{Y} \text { é a renda per capita } \\
\text { Se o país j tem uma renda per capita nacional abaixo da } \\
\text { média, então } Z_{\mathrm{j}, \mathrm{t}} \text { será negativo. Se a convergência existe, } \\
\text { então, } Z_{\mathrm{j}, \mathrm{t}} \text { mostrará um padrão crescente no tempo. Isto } \\
\text { implica que } \Delta Z_{\mathrm{j}, \mathrm{t}+1}>0 \text {. } \\
\text { Dito de outra forma, se k for positivo, então está havendo } \\
\text { convergência; se k for negativo, está ocorrendo } \\
\text { divergência. }\end{array}$ \\
\hline $\begin{array}{l}\text { Principais } \\
\text { Conclusões }\end{array}$ & \multicolumn{6}{|c|}{$\begin{array}{l}\text { No período de 1951-1973, o coeficiente de convergência k é positivo e estatisticamente significante, implicando que a renda nacional portuguesa convergiu } \\
\text { para a média Européia. } \\
\text { No período de 1974-1985, o coeficiente k não foi significativo, revelando a ausência de convergência. } \\
\text { No período de 1986-1993, verificou-se convergência que, de acordo com os autores, foi devido à entrada de Portugal na União Européia. }\end{array}$} \\
\hline
\end{tabular}

Quadro 4 - Análise de convergência no mundo: Barros e Garoupa (1995) 


\begin{tabular}{|c|c|c|c|c|c|c|}
\hline Autores & $\begin{array}{c}\text { País } \\
\text { Considerado } \\
\end{array}$ & $\begin{array}{c}\text { Objetivo do } \\
\text { Trabalho }\end{array}$ & $\begin{array}{c}\text { Variável de } \\
\text { Convergência }\end{array}$ & $\begin{array}{c}\text { Período de tempo } \\
\text { Analisado }\end{array}$ & $\begin{array}{c}\text { Modelo Teórico } \\
\text { Considerado }\end{array}$ & Equação Estimada \\
\hline $\begin{array}{l}\text { Persson } \\
(1997)\end{array}$ & $\begin{array}{l}24 \text { estados da } \\
\text { Suécia }\end{array}$ & $\begin{array}{c}\text { Testar a hipótese } \\
\text { da Convergência } \\
\text { da Renda per } \\
\text { Capita, ajustando } \\
\text { a renda para } \\
\text { considerar } \\
\text { diferenças no } \\
\text { custo de vida de } \\
\text { cada estado além } \\
\text { de discutir os } \\
\text { efeitos da } \\
\text { migração inter } \\
\text { regional sobre a } \\
\text { convergência }\end{array}$ & Renda Per Capita & 1911 a 1993 & $\begin{array}{l}\text { Barro e Sala-i- } \\
\quad \text { Martin } \\
(1991,1992)\end{array}$ & $\begin{array}{l}\left(\frac{1}{T}\right) \cdot \log \left(\frac{y_{i, t}}{y_{i, t-T}}\right)=\alpha-\left[\frac{1-e^{-\beta t}}{T}\right] \cdot \log y_{i, t-T}+u_{i t} \text { em que, } \mathrm{y}_{\mathrm{it}} \mathrm{e} \mathrm{y}_{\mathrm{it}-\mathrm{T}} \\
\text { corresponde à renda per capita dos estados no tempo t } \mathrm{e} \\
\text { tempo t-T, respectivamente. } \alpha \text { é o intercepto e } \beta \text { é a taxa } \\
\text { de convergência. Um valor positivo de } \beta \text { indica } \\
\text { convergência e quanto mais alto este valor mais rápido } \\
\text { será a convergência. }\end{array}$ \\
\hline $\begin{array}{l}\text { Principais } \\
\text { Conclusões }\end{array}$ & \multicolumn{6}{|c|}{$\begin{array}{l}\text { A conclusão do autor foi de que o ajustamento da renda, em oposição aos trabalhos que não ajustam, não mudou qualitativamente os resultados sobre a a } \\
\text { convergência. O resultado obtido pelo autor foi similar aos resultados obtidos por outros pesquisadores que não fizeram o ajustamento da renda, ou seja, } \\
\text { coeficiente de convergência- } \beta \text { estimado foi de } 0,04 \text {. Quando o autor considerou a migração, nenhuma evidência foi verificada indicando que de que ela tenha } \\
\text { contribuído com o processo de convergência. }\end{array}$} \\
\hline
\end{tabular}

Quadro 5 - Análise de convergência no mundo: Persson (1997) 


\begin{tabular}{|c|c|c|c|c|c|c|}
\hline Autores & $\begin{array}{c}\text { País } \\
\text { Considerado } \\
\end{array}$ & $\begin{array}{c}\text { Objetivo do } \\
\text { Trabalho } \\
\end{array}$ & $\begin{array}{c}\text { Variável de } \\
\text { Convergência }\end{array}$ & $\begin{array}{c}\text { Período de tempo } \\
\text { Analisado }\end{array}$ & $\begin{array}{c}\text { Modelo Teórico } \\
\text { Considerado }\end{array}$ & Equação Estimada \\
\hline $\begin{array}{c}\text { Michelis, } \\
\text { Papadopoulos } \\
\text { e Papanikis } \\
\text { (1992) }\end{array}$ & Grécia & \begin{tabular}{l|} 
Analisar a \\
convergência da \\
renda regional na \\
$\quad$ Grécia
\end{tabular} & Renda per Capita & $\begin{array}{lr}\text { 1981-1991- período } \\
\text { de participação } & \text { da } \\
\text { Grécia } & \text { na } \\
\text { Comunidade } & \\
\text { Européia } & \\
& \end{array}$ & $\begin{array}{c}\text { Barro e Sala-i- } \\
\text { Martin } \\
(1991,1992) \\
\text { e } \\
\text { Levine e Renelt } \\
\text { (1992) } \\
\\
\text { O trabalho de } \\
\text { Levine e Renelt } \\
\text { (1992) adiciona } \\
\text { uma equação } \\
\text { para capturar } \\
\text { possíveis } \\
\text { diferenças entre } \\
\text { as regiões da taxa } \\
\text { de crescimento } \\
\text { da renda per } \\
\text { capita }\end{array}$ & 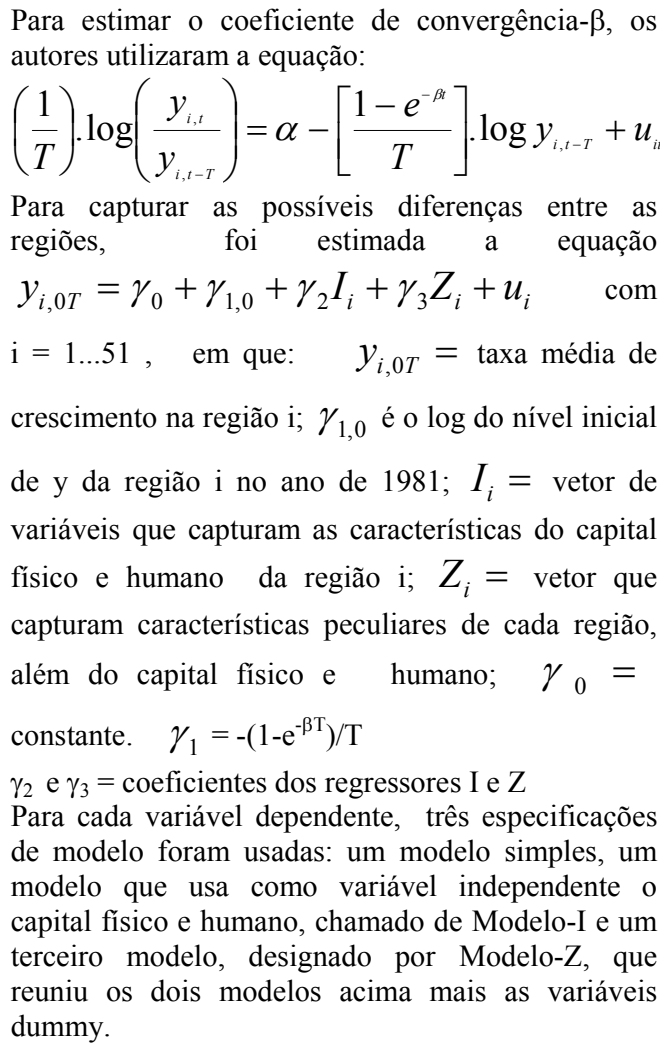 \\
\hline $\begin{array}{l}\text { Principais } \\
\text { Conclusões }\end{array}$ & \multicolumn{6}{|c|}{$\begin{array}{l}\text { A conclusão dos autores foi a de que todos os resultados suportam a hipótese da convergência. O coeficiente estimado de convergência- } \beta \text { foi similar em } \\
\text { todos os modelos, mas a velocidade de convergência é mais baixo do que os } 2 \% \text { reportado por Sala-i-Martin(1996). } \\
\text { Verificou-se também a ocorrência de convergência- } \sigma \text {, entre as } 51 \text { regiões da Grécia. }\end{array}$} \\
\hline
\end{tabular}

Quadro 6 - Análise de convergência no mundo: Michelis, Papadopoulos e Papanikis (1992) 


\begin{tabular}{|c|c|c|c|c|c|c|}
\hline Autores & $\begin{array}{c}\text { País } \\
\text { Considerado } \\
\end{array}$ & $\begin{array}{c}\text { Objetivo do } \\
\text { Trabalho }\end{array}$ & $\begin{array}{c}\text { Variável de } \\
\text { Convergência }\end{array}$ & $\begin{array}{c}\text { Período de tempo } \\
\text { Analisado } \\
\end{array}$ & $\begin{array}{c}\text { Modelo Teórico } \\
\text { Considerado }\end{array}$ & Equação Estimada \\
\hline $\begin{array}{c}\text { Gezici } \\
\text { e } \\
\text { Hewings } \\
\text { (2003) }\end{array}$ & Turquia & $\begin{array}{c}\text { Verificar a } \\
\text { ocorrência de } \\
\text { uma } \\
\text { transformação } \\
\text { das disparidades } \\
\text { inter-regionais, } \\
\text { em termos de } \\
\text { convergência da } \\
\text { renda per capita }\end{array}$ & Renda Per Capita & 1980 a 1997 & $\begin{array}{l}\text { Barro e Sala-i- } \\
\text { Martin (1996) }\end{array}$ & $\begin{array}{l}\ln \left(\frac{y_{i, t+T}}{Y_{i, t}}\right)=\alpha+\beta \ln \left(y_{i, t}\right)+\varepsilon i, t \\
\text { em que: } y_{\mathrm{i}, t} \text { é a renda per capita da província i, no } \\
\text { tempo t; } \alpha \text { é uma constante e } \beta \text { o coeficiente a ser } \\
\text { estimado. Se o valor de } \beta \text { for menor que zero, está } \\
\text { havendo convergência. Nesta equação a taxa de } \\
\text { crescimento entre t e T é a variável dependente e o } \\
\text { log da renda per capita no período inicial é a } \\
\text { variável independente. }\end{array}$ \\
\hline $\begin{array}{l}\text { Principais } \\
\text { Conclusões }\end{array}$ & vid & e convergência & Turavin co & $\beta \rho u \sigma$ f & moríd an & do. \\
\hline
\end{tabular}

Quadro 7 - Análise de convergência no mundo: Gezici e Hewings (2003) 


\begin{tabular}{|c|c|c|c|c|c|c|}
\hline Autores & $\begin{array}{c}\text { País } \\
\text { Considerado } \\
\end{array}$ & $\begin{array}{c}\text { Objetivo do } \\
\text { Trabalho }\end{array}$ & $\begin{array}{c}\text { Variável de } \\
\text { Convergência }\end{array}$ & $\begin{array}{c}\text { Período de tempo } \\
\text { Analisado }\end{array}$ & $\begin{array}{c}\text { Modelo Teórico } \\
\text { Considerado }\end{array}$ & Equação Estimada \\
\hline $\begin{array}{l}\text { Gutierrez } \\
(2000)\end{array}$ & $\begin{array}{l}\text { Estados Unidos e } \\
\text { União Européia }\end{array}$ & $\begin{array}{l}\text { Avalia a hipótese } \\
\text { da convergência } \\
\text { sob a perspectiva } \\
\text { da produtividade } \\
\text { do trabalho } \\
\text { agrícola. }\end{array}$ & $\begin{array}{l}\text { Renda per capita } \\
\text { na agricultura }\end{array}$ & 1970-1992 & $\begin{array}{l}\text { Barro e Sala-i- } \\
\quad \text { Martin } \\
(1990,1992)\end{array}$ & 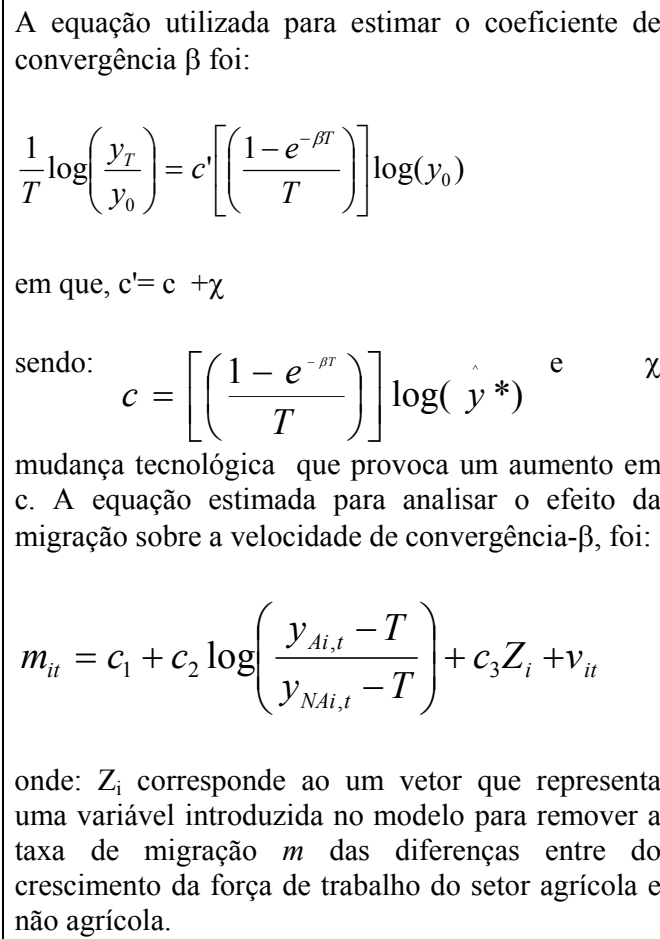 \\
\hline $\begin{array}{l}\text { Principais } \\
\text { Conclusões }\end{array}$ & \multicolumn{6}{|c|}{$\begin{array}{l}\text { O resultado encontrado pelo autor foi de convergência absoluta para os estados dos Estados Unidos mas não para os países da União Européia. } \\
\text { Quanto a convergência condicional, o resultado foi conforme o esperado, ou seja, o efeito de migração sobre a velocidade de convergência entre os setores } \\
\text { agrícola e não agrícola nos Estados Unidos foi de } 0,5 \% \text { ao ano e na União Européia o efeito exercido pela migração é alto, aumentando a velocidade de } \\
\text { convergência por } 1.0 \text { percentual ao ano. }\end{array}$} \\
\hline
\end{tabular}

Quadro 8 - Análise de convergência no mundo: Gutierrez (2000) 


\begin{tabular}{|c|c|c|c|c|c|c|}
\hline Autores & País Considerado & $\begin{array}{c}\text { Objetivo do } \\
\text { Trabalho }\end{array}$ & $\begin{array}{c}\text { Variável de } \\
\text { Convergência }\end{array}$ & $\begin{array}{c}\text { Período de tempo } \\
\text { Analisado }\end{array}$ & $\begin{array}{c}\text { Modelo Teórico } \\
\text { Considerado }\end{array}$ & Equação Estimada \\
\hline $\begin{array}{c}\text { Lusigi } \\
\text { e } \\
\text { Thirtle (1998) }\end{array}$ & $\begin{array}{c}32 \text { países do } \\
\text { continente Africano }\end{array}$ & \begin{tabular}{lr}
\multicolumn{3}{l}{ estar a hipótese de } \\
convergência da \\
renda per capita e \\
da Produtividade \\
Total dos & Fatores \\
(PTF) & na \\
agricultura.
\end{tabular} & $\begin{array}{l}\text { Renda per capita e } \\
\text { Produtividade Total } \\
\text { dos Fatores (PTF) }\end{array}$ & 1970 a 1991 & $\begin{array}{c}\text { Barro e Sala-i- } \\
\text { Martin (1995) } \\
\text { e } \\
\text { Bernard e Jones } \\
\quad(1996) .\end{array}$ & 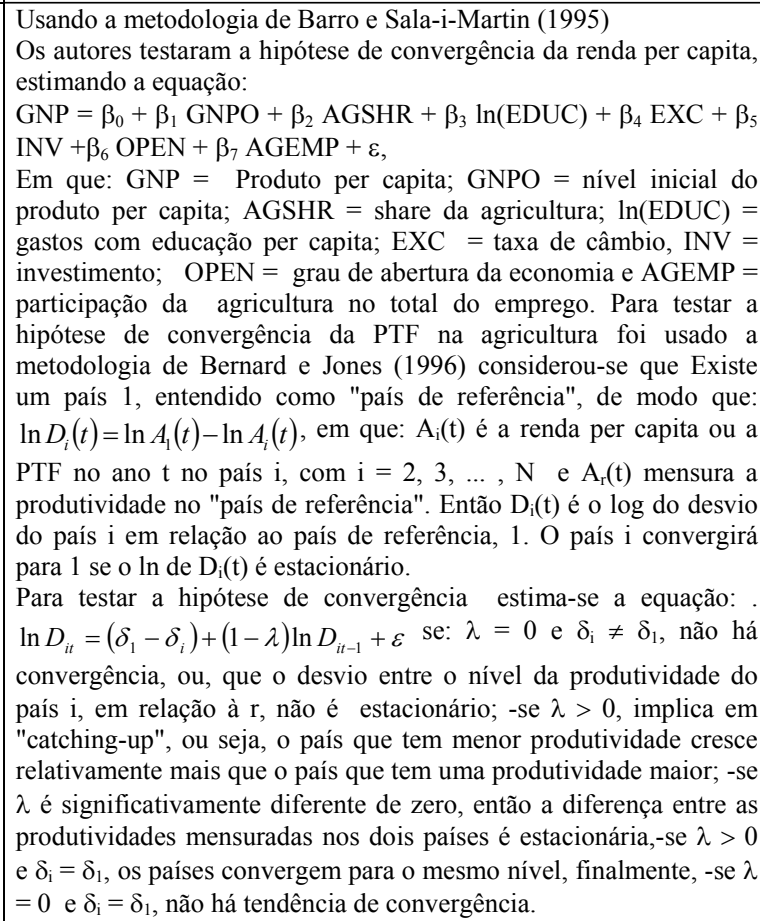 \\
\hline $\begin{array}{l}\text { Principais } \\
\text { Conclusões }\end{array}$ & \multicolumn{6}{|c|}{$\begin{array}{l}\text { Pelo método de Barro e Sala-i-Martin os resultados mostraram que as economias que tinham um nível de renda inicial mais baixo cresceram mais do que as economias mais ricas. } \\
\text { Portanto, em termos de renda per capita houve convergência. Quando à PTF na agricultura, os autores afirmaram que não houve convergência. } \\
\text { Pelo método de Bernard and Jones (1996) tanto a hipótese de convergência da renda per capita como da convergência da Produtividade Total dos Fatores foram confirmadas pelos } \\
\text { autores. Contudo, no caso da PTF na agricultura a convergência é condicional. } \\
\text { Observa-se que a convergência é condicional, desde que o crescimento seja explicado pelas variáveis: investimento, educação, participação da agricultura e emprego. }\end{array}$} \\
\hline
\end{tabular}

Quadro 9 - Análise de convergência no mundo: Lusigi e Thirtle (1998) 


\begin{tabular}{|c|c|c|c|c|c|c|}
\hline Autores & $\begin{array}{l}\text { País } \\
\text { Considerado }\end{array}$ & $\begin{array}{l}\text { Objetivo do } \\
\text { Trabalho }\end{array}$ & $\begin{array}{l}\text { Variável de } \\
\text { Convergência }\end{array}$ & $\begin{array}{l}\text { Período de } \\
\text { tempo } \\
\text { Analisado }\end{array}$ & \begin{tabular}{|c|} 
Modelo \\
Teórico \\
Considerado
\end{tabular} & Equação Estimada \\
\hline $\begin{array}{l}\text { Suhariyanto } \\
\text { e Thirtle } \\
\text { (2001) }\end{array}$ & Ásia & $\begin{array}{l}\text { Mensurar a } \\
\text { produtividad } \\
\text { e total dos } \\
\text { Fatores } \\
\text { (PTF), } \\
\text { utilizando-se } \\
\text { um produto e } \\
\text { cinco inputs: } \\
\text { terra, tra- } \\
\text { balho, } \\
\text { fertilizantes, } \\
\text { maquinaria e } \\
\text { animais. }\end{array}$ & $\begin{array}{l}\text { Produtividade } \\
\text { Total na } \\
\text { Agricultura }\end{array}$ & $\begin{array}{l}1965 \text { a } \\
1996 .\end{array}$ & $\begin{array}{c}\text { Barro e Sala- } \\
\text { i-Martin } \\
\text { (1991) }\end{array}$ & $\begin{array}{l}\text { Para analisar as diferenças na PTF da agricultura entre países, constrói-se o } \\
\text { index com respeito a uma fronteira para obter a "melhor fronteira" e assim } \\
\text { mensurar a distância de cada país em relação à sua fronteira. Uma vez } \\
\text { mensurado a PTF para os grupos de países asiáticos, os autores estimaram o } \\
\text { coeficiente de convergência- } \beta \text { e } \sigma \text { de acordo com as predições do Modelo de } \\
\text { Barro e Sala-i-Martin (1995), a PTF desenvolve-se com: } \\
\ln A_{i t}=\gamma_{i}+\lambda \ln \left(\frac{A_{f t-1}}{A_{i, t-1}}\right)+\ln A_{i, t-1}+\varepsilon_{i, t} \text {, (1) } \\
\text { em que, } \gamma_{i} \text { é a taxa de crescimento, assintótica, do país i; o parâmetro } \lambda \\
\text { caracteriza o speed catch up, ou seja, o diferencial de produtividade entre } \\
\text { os países i e f e, } \varepsilon_{\text {it é o termo erro. }} \\
\text { A equação }(1) \text { informa que PTF em cada país i pode potencialmente crescer } \\
\text { como resultado do crescimento do setor específico ou como resultado da } \\
\text { transferência de tecnologia do país fronteira. } \\
\text { Se o país i é mais produtivo, então não há transferência de tecnologia e a } \\
\text { equação (1) torna-se } \ln A_{i t}=\gamma_{f}+\ln A_{f, t-1}+\varepsilon_{f, t} \text { (equação 2). } \\
\text { Combinando as equações }(1) \text { e (2), obtém-se a expressão do crescimento da } \\
\text { PTF na qual o teste é baseado: } \\
\ln \left(\frac{A_{i t}}{A_{f t}}\right)=\left(\gamma_{i}-\gamma_{f}\right)+(1-\lambda) \ln \left(\frac{A_{i, t-1}}{A_{f, t-1}+}\right) \hat{\varepsilon_{i t}} \text { (3) } \\
\text { Se } \lambda=0 \text { não haverá evidências de convergência. } \\
\text { Se } \lambda>0, \text { a diferença nos países i e f será estacionária, indicando evidências } \\
\text { de convergência. }\end{array}$ \\
\hline $\begin{array}{l}\text { Principais } \\
\text { Conclusões }\end{array}$ & \multicolumn{6}{|c|}{$\begin{array}{l}\text { A conclusão dos autores é de que, tanto no teste de convergência- } \beta \text { da PTF quanto no teste baseado em séries temporais, "não há evidência de convergência } \\
\text { da produtividade agrícola na Ásia". Da mesma forma que não se verificou uma tendência de dispersão decrescente entre os países. Portanto, também não há } \\
\text { evidência de convergência- } \sigma \text {. }\end{array}$} \\
\hline
\end{tabular}

Quadro 10 - Análise de convergência no mundo: Suhariyanto e Thirtle (2001) 
ANEXO B - Revisão da literatura sobre convergência no Brasil

\begin{tabular}{|c|c|c|c|c|c|}
\hline Autores & $\begin{array}{l}\text { Objetivo do } \\
\text { Trabalho }\end{array}$ & $\begin{array}{c}\text { Variável de } \\
\text { Convergência }\end{array}$ & $\begin{array}{l}\text { Período de } \\
\text { tempo } \\
\text { analisado }\end{array}$ & $\begin{array}{c}\text { Modelo } \\
\text { Teórico } \\
\text { Considerado }\end{array}$ & Equação Estimada \\
\hline $\begin{array}{c}\text { Ferreira e } \\
\text { Ellery Junior } \\
\\
(1996)\end{array}$ & $\begin{array}{ll}\text { Verificar a } & \text { a } \\
\text { existência ou } \\
\text { não } \\
\text { convergência } \\
\text { entre os } 23 \\
\text { estados } \\
\text { brasileiros }\end{array}$ & $\begin{array}{l}\text { Renda per } \\
\text { capita }\end{array}$ & 1970 a 1990 & $\begin{array}{c}\text { Barro e Sala- } \\
\text { i-Martin } \\
\text { (1992) }\end{array}$ & $\begin{array}{l}\text { Para estimar o coeficiente de convergência- } \beta \text {, os autores utilizaram a } \\
\text { equação: } \\
\frac{1}{T} \cdot \log \left[\frac{y_{i t 0+T}}{y_{i, t 0}}\right]=a-\left(1-e^{-\beta T}\right) \cdot\left(\frac{1}{T}\right) \log \left(Y_{t, T-1}\right)+u_{i t} \text { Um valor positivo de } \beta \text { indica } \\
\text { convergência. } \\
\text { Primeiro estimou-se a equação acima. Em seguida, uma variável dummy } \\
\text { foi acrescentada para cada uma das } 4 \text { regiões brasileiras ( norte, sul, } \\
\text { sudeste, nordeste). Como apenas a dummy da região norte foi } \\
\text { significativa, o autor rodou uma terceira regressão considerando apenas } \\
\text { esta dummy. } \\
\text { Para estimar o coeficiente de convergência- } \sigma \text { o autor utilizou a equação: } \\
\sigma^{2}{ }_{t}=\frac{\sigma^{2}{ }_{u}}{1-e^{-2 \beta}}+\left(\sigma^{2}{ }_{0}-\frac{\sigma_{2 u}}{1-e^{-2 \beta}}\right) e^{-2 \beta t} \text { no estado-estacionário tem- } \\
\text { se: } \sigma^{2}=\frac{\sigma^{2}{ }_{u}}{1-e^{-\beta}} \text { se } \beta>0 \text {, a hipótese de convergência- } \sigma \text { só será } \\
\text { garantida se } \sigma_{0}^{2}>\sigma^{2}{ }_{0+1} \text {. Convergência- } \beta \text { é condição necessária mas não } \\
\text { suficiente para a ocorrência de convergência- } \sigma \text {. }\end{array}$ \\
\hline $\begin{array}{l}\text { Principais } \\
\text { conclusões }\end{array}$ & \multicolumn{5}{|c|}{$\begin{array}{l}\text { Existe um processo de convergência nas três regressões, com } \beta>0 \text { e altamente significativo. O coeficiente estimado de } \beta \text { foi igual a } 0,013 \text {, implicando } \\
\text { que levará } 56,4 \text { anos para que a metade do gap da renda per capita entre regiões brasileiras consideradas seja eliminado Os autores também estimaram os } \\
\text { coeficientes após dividir o período em } 2 \text { sub-períodos, bem como impondo algumas restrições ao coeficiente } \beta \text {. A conclusão é de que não se verificou } \\
\text { mudanças sensíveis nos resultados. Qualitativamente, os resultados foram mantidos. Quando à hipótese de convergência- } \sigma \text {, os autores observaram que há } \\
\text { um processo de declínio da dispersão, indicando uma proximidade da renda per capita entre os estados brasileiros. }\end{array}$} \\
\hline
\end{tabular}

Quadro 11 - Análise de convergência no Brasil: Ferreira e Ellery Junior (1996) 


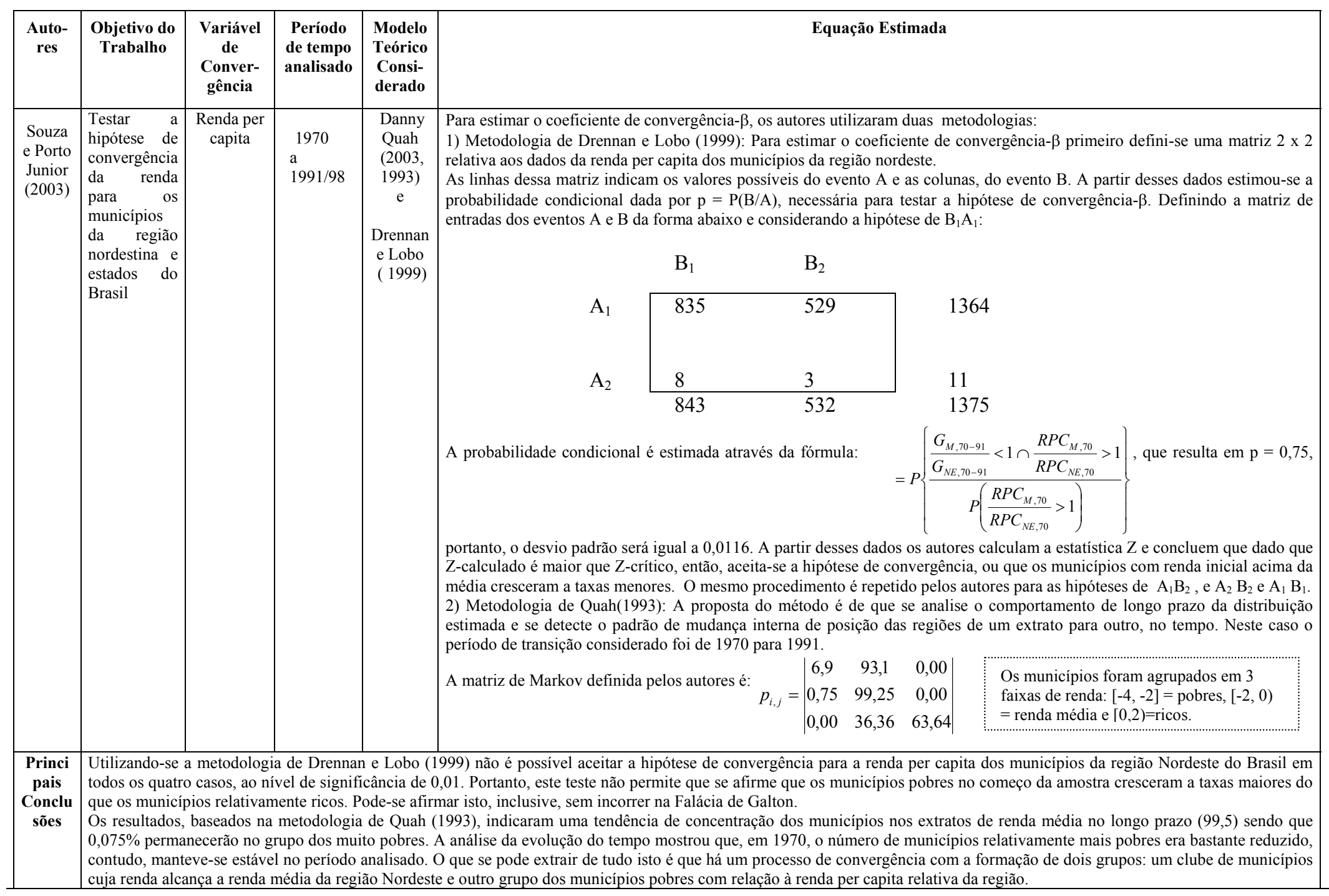

Quadro 12 - Análise de convergência no Brasil: Souza e Porto Junior (2003) 


\begin{tabular}{|c|c|c|c|c|c|}
\hline Autores & $\begin{array}{c}\text { Objetivo do } \\
\text { Trabalho }\end{array}$ & $\begin{array}{c}\text { Variável } \\
\text { de } \\
\text { Conver- } \\
\text { gência }\end{array}$ & $\begin{array}{c}\text { Período } \\
\text { de } \\
\text { tempo } \\
\text { analisa } \\
\text { do }\end{array}$ & $\begin{array}{l}\text { Modelo } \\
\text { Teórico } \\
\text { Consi- } \\
\text { derado }\end{array}$ & Equação Estimada \\
\hline $\begin{array}{c}\text { Ribeiro e } \\
\text { Pôrto } \\
\text { Junior } \\
\\
(2000)\end{array}$ & $\begin{array}{c}\text { Analisar a } \\
\text { hipótese da } \\
\text { conver- } \\
\text { gência de } \\
\text { renda per } \\
\text { capita } \\
\text { através de } \\
\text { uma análise } \\
\text { da dinâmica } \\
\text { da distribui- } \\
\text { ção de renda } \\
\text { per capita } \\
\text { entre os } \\
\text { Estados e } \\
\text { entre os } \\
\text { Municí-pios } \\
\text { da Região } \\
\text { Sul do Brasil }\end{array}$ & $\begin{array}{l}\text { Renda per } \\
\text { capita }\end{array}$ & $\begin{array}{c}1985 \mathrm{a} \\
1998\end{array}$ & $\begin{array}{c}\text { Coeficien- } \\
\text { te de } \\
\text { variação, } \\
\text { Índice de } \\
\text { Theil (I } \mathrm{I}_{\mathrm{T}} \text { ) } \\
\text { e Îndice de } \\
\text { Willianson } \\
\text { (I } \mathrm{I}_{\mathrm{W}} \text { ). } \\
\\
\text { Teste de } \\
\text { Boyke e } \\
\text { McCarthy } \\
\text { (1997). } \\
\text { Barro e } \\
\text { Sala-i- } \\
\text { Martin } \\
\\
\text { (1992) } \\
\text { Danny } \\
\text { Quah } \\
\text { (1993) }\end{array}$ & 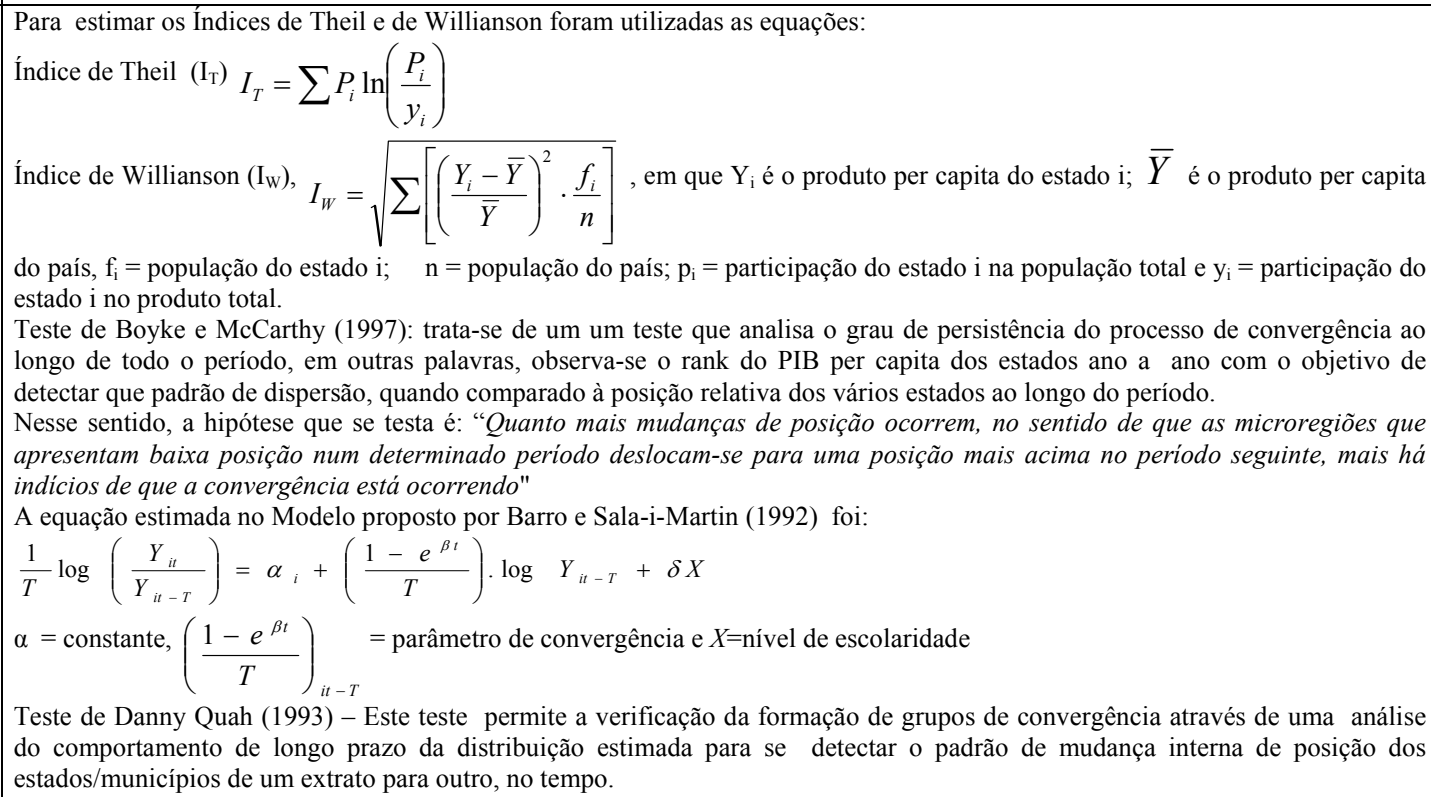 \\
\hline $\begin{array}{l}\text { Princi- } \\
\text { pais } \\
\text { Conclu- } \\
\text { sões }\end{array}$ & $\begin{array}{l}\text { As estimativa } \\
\text { uma tendência } \\
\text { A conclusão p } \\
\text { O teste de cor } \\
\text { capita no iníci } \\
\text { O teste de Da } \\
\text { renda alcança } \\
\text { Observando a }\end{array}$ & $\begin{array}{l}\text { ra o teste de } \\
\text { vergência- } \beta \\
\text { do período } \\
\text { ny Quah (19 } \\
\text { renda médi } \\
\text { enas a região }\end{array}$ & $\begin{array}{l}\text { Boyke e N } \\
\text { ndicou ev } \\
\text { cresceram } \\
\text { 93) mostro } \\
\text { de região } \\
\text { sul, os aut }\end{array}$ & $\begin{array}{l}\text { nte de variaçã } \\
\text { e } 1992 \text {, depois } \\
\text { IcCarthy }(199 \\
\text { dências de co } \\
\text { a taxas maiore } \\
\text { u uma tendên } \\
\text { Sul e outro fo } \\
\text { ores concluen }\end{array}$ & $\begin{array}{l}\text { ão e de Theil mostraram uma tendência de queda na dispersão entre os três estados da região Sul, já o índice de Willianson mostra } \\
\text { is uma queda até o final da série considerada. } \\
\text { 7) é a de que os estados brasileiros têm se mantido na mesma posição no rank, negando a hipótese de convergência. } \\
\text { onvergência- } \beta \text {, tanto entre os } 27 \text { estados brasileiros quanto para os municípios, confirmando que os estados com menor renda per } \\
\text { es. } \\
\text { chia de formação de um processo de polarização com a formação de dois grupos de convergência: um incluindo os municípios cuja } \\
\text { ormado pelos municípios pobres com relação à renda per capita relativa da região. } \\
\text { m que ao contrário dos resultados obtidos por outros estudos, não se confirmou a hipótese de convergência- } \beta \text { absoluta. }\end{array}$ \\
\hline
\end{tabular}

Quadro 13 - Análise de convergência no Brasil: Ribeiro e Pôrto Junior (2000) 


\begin{tabular}{|c|c|c|c|c|c|}
\hline Autores & $\begin{array}{c}\text { Objetivo } \\
\text { do } \\
\text { Trabalho }\end{array}$ & $\begin{array}{c}\text { Variável } \\
\text { de } \\
\text { Conver- } \\
\text { gência }\end{array}$ & $\begin{array}{c}\text { Período } \\
\text { de tempo } \\
\text { analisado }\end{array}$ & $\begin{array}{l}\text { Modelo } \\
\text { Teórico } \\
\text { Consi- } \\
\text { derado }\end{array}$ & Equação Estimada \\
\hline (1994) & $\begin{array}{c}\text { Analisar } \\
\text { o } \\
\text { problema } \\
\text { da } \\
\text { conver- } \\
\text { gência de } \\
\text { renda } \\
\text { entre as } \\
\text { regiões } \\
\text { brasileira } \\
\text { s }\end{array}$ & $\begin{array}{c}\text { Renda } \\
\text { per capita }\end{array}$ & $\begin{array}{ll}1939 & a \\
1990 & \end{array}$ & $\begin{array}{l}\text { Barro e } \\
\text { Sala-i- } \\
\text { Martin } \\
\\
(1995)\end{array}$ & $\begin{array}{l}\text { 1) Período de 1939-1990 } \\
\mathrm{O} \quad \text { primeiro indicador a ser testado foi } \quad \text { o coeficiente de convergência- } \sigma \quad \text { dado pela fórmula: } \\
V_{W}=\left(\frac{1}{y_{B R}}\right) \sqrt{\left(y_{e}-y_{B R}\right)^{2} \cdot\left(\frac{P_{e}}{P_{B R}}\right)} \text { onde, } \mathrm{e}=\text { estado; } \mathrm{BR}=\text { dado nacional; } \mathrm{y}=\text { renda per capita e } \mathrm{P}=\text { população. } \\
\text { As equações estimadas para testar as hipóteses de convergência } \beta \text {-absoluta e convergência } \beta \text {-condicional foram: } \\
\frac{1}{T} \log \left(\frac{Y_{i t}}{Y_{i t-T}}\right)=\alpha_{i}+\left(\frac{1-e^{\beta t}}{T}\right) \cdot \log Y_{i t-T}+\varepsilon_{i t} \\
\frac{1}{T} \log \left(\frac{Y_{i t}}{Y_{i t-T}}\right)=\alpha_{i}+\left(\frac{1-e^{\beta t}}{T}\right) \cdot \log Y_{i t-T}+\delta X \\
\text { 2) Período de 1939-1995 } \\
\text { Para este período o autor utilizou o Índice de Theil para estimar a convergência- } \sigma \text {, dado pela equação: } \\
J=\sum_{i=1}^{n}\left(\frac{P_{i}}{P_{b r}}\right) \ln \left[\frac{P_{i} / P_{b r}}{Y_{i} / Y_{b r}}\right]=\sum_{i=1}^{n} p_{i} \ln j_{i} \\
\text { Para os testes de convergência } \beta \text {-absoluta e convergência } \beta \text {-condicional a equação é a mesma especificada acima. }\end{array}$ \\
\hline $\begin{array}{l}\text { Princi- } \\
\text { pais } \\
\text { Conclu- } \\
\text { sões }\end{array}$ & $\begin{array}{l}\text { Quanto ao } \\
\text { já para o s } \\
\text { Incluindo } \\
\text { dummys. } \\
\text { Período d } \\
\text { 1960. Dep } \\
\text { Os resultad } \\
\text { A velocida } \\
\text { que levará } \\
\text { Pelo coefic } \\
\text { de converg }\end{array}$ & $\begin{array}{l}\text { oeficiente } \\
\text { b-período } \\
\text { ummys par } \\
\text { 1939-1995 } \\
\text { is de } 1960 \\
\text { s para con } \\
\text { e de conve } \\
\text { proximada } \\
\text { ente de var }\end{array}$ & $\begin{array}{l}\text { nvergênc } \\
\text { ta-1990, possí } \\
\text { cebe-se u } \\
\text { a aument } \\
\text { encia } \beta \text {-at } \\
\text { cia pelo n } \\
\text { e } 102 \text { e } 5 \\
\text { o, o autor } \\
\text { pelo CV }\end{array}$ & $\begin{array}{l}\text { diferen } \\
\text { centuad } \\
\text { ce aproxi } \\
\text { ta indic } \\
\text { o de Ba } \\
\text { s, respe } \\
\text { irpreend }\end{array}$ & $\begin{array}{l}\text { do coeficiente de convergência- } \sigma \text { observou-se oscilações entre os estados ao longo do período analisado, com máximos e } \\
\text { ndência recente, caracterizada pelo período após } 1970 \text {. Observou-se também que as regiões Sul, Sudeste e Centro- Oeste } \\
\text { esigualdade, enquanto que o Norte e Nordeste registram aumentos persistentes. } \\
\text { autor observou que no período como um todo (1939-1990) os sinais da existência de convergência absoluta são muito fracos, } \\
\text { is fortes. } \\
\text { entre as regiões do país, o autor comenta que não se observou grandes avanços em relação aos resultados obtidos sem as } \\
\text { cilação em termos de dispersão. Até meados da década de } 1950 \text { a dispersão aumenta e depois decresce até metade da década } \\
\text { lamente } 1968 \text { quando então se estabiliza. } \\
\text { nevidências de convergência entre os estados brasileiros neste período. } \\
\text { Sala-i-Martin foi de } 0,685 \text { para o teste de convergência- } \beta \text {, e de } 1,29 \% \text { no teste para convergência condicional. Isto significa } \\
\text { amente, para que se possa eliminar } 50 \% \text { da desigualdade regional. } \\
\text { mentando que, embora a metodologia seja diferente, esperava-se que os resultados fossem semelhantes. No entanto, o speed } \\
\text { lesmo dividindo o período em sub-períodos, não se observa um processo de convergência. Na verdade, o período é marcado }\end{array}$ \\
\hline
\end{tabular}

Quadro 14 - Análise de convergência no Brasil: Azzoni (1994) 


\begin{tabular}{|c|c|c|c|c|c|}
\hline Autores & $\begin{array}{l}\text { Objetivo do } \\
\text { Trabalho }\end{array}$ & $\begin{array}{l}\text { Variável de } \\
\text { Conver- } \\
\text { gência }\end{array}$ & $\begin{array}{c}\text { Período de } \\
\text { tempo } \\
\text { analisado }\end{array}$ & $\begin{array}{l}\text { Modelo } \\
\text { Teórico } \\
\text { Consi- } \\
\text { derado }\end{array}$ & Equação Estimada \\
\hline Cançado & $\begin{array}{c}\text { Testar a } \\
\text { hipótese de } \\
\text { convergênci } \\
\text { a da renda } \\
\text { per capita e } \\
\text { discutir o } \\
\text { papel dos } \\
\text { fluxos } \\
\text { migratórios } \\
\text { neste } \\
\text { processo, } \\
\text { determinand } \\
\text { o em que } \\
\text { medida os } \\
\text { fluxos } \\
\text { migratórios } \\
\text { internos } \\
\text { contribuem } \\
\text { para a } \\
\text { redução das } \\
\text { diferenças } \\
\text { estaduais de } \\
\text { renda per } \\
\text { capita no } \\
\text { Brasil }\end{array}$ & $\begin{array}{l}\text { Renda per } \\
\text { capita }\end{array}$ & 1960 a 1991 & $\begin{array}{c}\text { Barro e Sala- } \\
\text { i-Martin } \\
\text { (1995) }\end{array}$ & 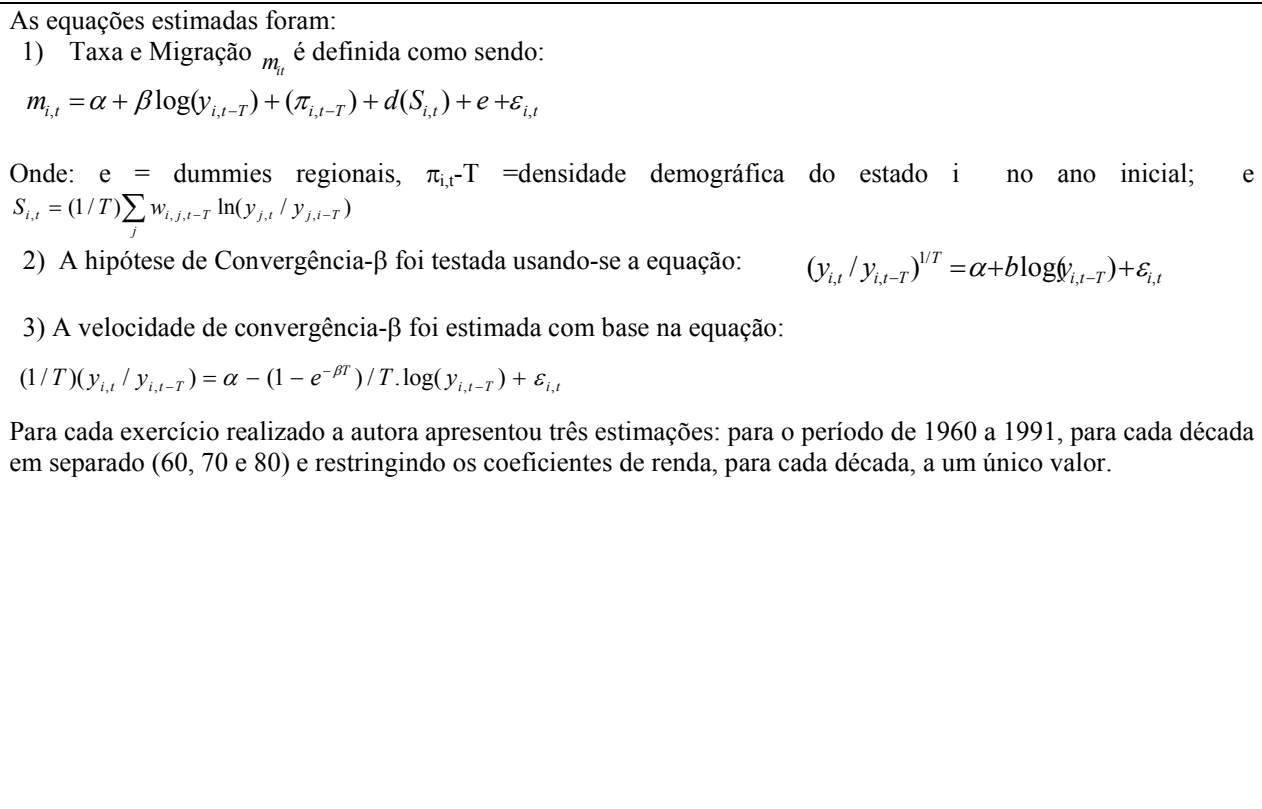 \\
\hline $\begin{array}{l}\text { Principais } \\
\text { Conclusões }\end{array}$ & \multicolumn{5}{|c|}{$\begin{array}{l}\text { Os resultados da } 1^{a} \text { equação apóiam, do ponto de vista estatístico, a proposição de que os fluxos migratórios relacionam-se positivamente com as rendas per capitas estaduais. O } \\
\text { coeficiente de renda per capita estadual é sempre positivo. } \\
\text { O coeficiente estimado } \beta \text { indicou convergência no período de } 1960-1991 \text {, nas décadas de } 70 \text { e } 80 \text { bem como para os dados de painel. Apenas na década de } 60 \text { não se verificou } \\
\text { convergência. } \\
\text { Quando ao speed de convergência, no período de } 1960 \text { a } 1991 \text { seu valor foi de } 0,007 \text {. Embora seu valor não tenha atingido } 1 \% \text {, ainda assim foi o maior valor encontrado pela } \\
\text { autora, indicando que a velocidade de convergência é bastante baixa para o caso brasileiro. Observa-se que a velocidade de convergência das rendas per capita é maior entre os } \\
\text { estados de uma mesma região do que entre o conjunto dos estados do país. } \\
\text { Ao considerar os efeitos da taxa de migração no speed de convergência a autora afirmou que o impacto dos fluxos migratórios na dinâmica das rendas per capitas estaduais é é } \\
\text { praticamente nulo, definido por uma baixa velocidade de convergência. O maior valor que esta velocidade atingiu foi de } 1,5 \% \text {, implicando que levaria } 46 \text { nos para eliminar o } \\
\text { gap entre qualquer nível de renda inicial estadual e o nível de estado-estacionário da renda per capita. }\end{array}$} \\
\hline
\end{tabular}

Quadro 15 - Análise de convergência no Brasil: Cançado (1999) 


\begin{tabular}{|c|c|c|c|c|c|}
\hline Autores & $\begin{array}{l}\text { Objetivo do } \\
\text { Trabalho }\end{array}$ & $\begin{array}{c}\text { Variável } \\
\text { de } \\
\text { Conver- } \\
\text { gência }\end{array}$ & $\begin{array}{l}\text { Período de } \\
\text { tempo } \\
\text { analisado }\end{array}$ & $\begin{array}{c}\text { Modelo Teórico } \\
\text { Consi-derado }\end{array}$ & Equação Estimada \\
\hline $\begin{array}{l}\text { Martins } \\
\text { (1999) }\end{array}$ & 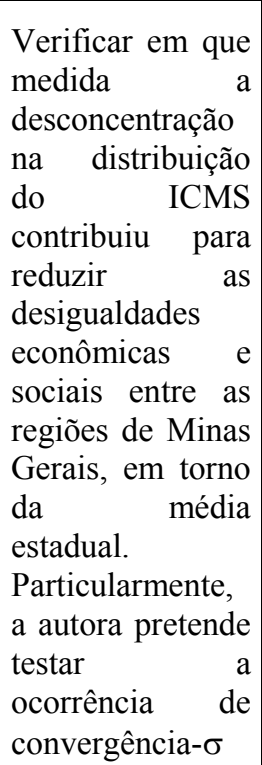 & ICMS & $\begin{array}{l}1995 \\
1996 \\
1997\end{array}$ & $\begin{array}{l}\text { Índice de } \mathrm{j} \\
\qquad \mathrm{e} \\
\text { Índice de } \\
\text { L - Theil, }\end{array}$ & $\begin{array}{l}\text { As equações utilizadas para verificar a convergência foram: } \\
\qquad \mathrm{j}=\mathrm{ji}=\mathrm{pi} \text { / yi } \\
\qquad \mathrm{L}=\sum \mathrm{pi} \ln (\mathrm{pi} / \mathrm{yi}) \\
\begin{array}{l}\text { Em que: pi é a participação da população da região i na população do Estado e yi a } \\
\text { participação do ICMS recebido pela região i no total repassado pelo estado. }\end{array}\end{array}$ \\
\hline $\begin{array}{l}\text { Principais } \\
\text { Conclusões }\end{array}$ & \multicolumn{5}{|c|}{$\begin{array}{l}\text { Os resultados mostraram que o menor índice j ficou com a região do Triângulo, portanto, a mais privilegiada em termos de recebimento de ICMS, seguido } \\
\text { da região Central, ambas assumem uma tendência convergente. Contrariamente, o maior índice ficou com a região do Jequetinhonha. Nenhum caso de } \\
\text { mudança de posição foi verificado, ou seja, de uma região ter índice maior que } 1 \text { e passar a ter índice menor que 1, e vice-versa. } \\
\text { Quanto ao índice Theil, ele mostra um decréscimo consecutivo, indicando uma redução das disparidades e, portanto, um processo de convergência das } \\
\text { desigualdades econômicas e sociais. } \\
\text { A conclusão final da autora é de que a Lei "Robin Hood" está promovendo uma equalização na distribuição do ICMS, contudo, seus efeitos em termos de } \\
\text { redução das desigualdades econômicas e sociais ainda não são observados. Contudo, espera-se que ocorra no longo prazo, uma vez que o desenvolvimento } \\
\text { social é um pressuposto para se atingir o desenvolvimento econômico. Como uma das condições para aumentar a cota-parte do ICMS é o investimento em } \\
\text { educação e saúde, acredita-se que isto deverá incentivar as regiões a investirem mais e, portando, mudar sua estrutura social. }\end{array}$} \\
\hline
\end{tabular}

Quadro 16 - Análise de convergência no Brasil: Martins (1999) 
ANEXO C - Percentuais da área adubada, de área com plantio simples e de área com plantações menores de 10 ha

\begin{tabular}{|c|c|c|c|c|c|c|c|c|c|c|}
\hline \multicolumn{11}{|c|}{ Parte (A) - Percentual da área adubada } \\
\hline & \multicolumn{2}{|c|}{ Norte } & \multicolumn{2}{|c|}{ Nordeste } & \multicolumn{2}{|c|}{ Sudeste } & \multicolumn{2}{|c|}{ Centro-Oeste } & \multicolumn{2}{|c|}{ Sul } \\
\hline & $\begin{array}{l}\text { Área } \\
\text { Total } \\
\text { (ha) }\end{array}$ & $\begin{array}{c}\text { Área } \\
\text { Adubada } \\
(\%)\end{array}$ & $\begin{array}{c}\text { Área } \\
\text { Total } \\
\text { (ha) } \\
\end{array}$ & $\begin{array}{c}\text { Área } \\
\text { Adubada } \\
(\%)\end{array}$ & $\begin{array}{c}\text { Área } \\
\text { Total } \\
\text { (ha) }\end{array}$ & $\begin{array}{c}\text { Área } \\
\text { Adubada } \\
(\%)\end{array}$ & $\begin{array}{c}\text { Área } \\
\text { Total } \\
\text { (ha) } \\
\end{array}$ & $\begin{array}{c}\text { Área } \\
\text { Adubada } \\
(\%)\end{array}$ & $\begin{array}{c}\text { Área } \\
\text { Total } \\
\text { (ha) } \\
\end{array}$ & $\begin{array}{c}\text { Área } \\
\text { Adubada } \\
(\%)\end{array}$ \\
\hline 1970 & 1093 & 000 & 426569 & 01 & 598789 & 50 & 86440 & 26 & 373287 & 07 \\
\hline 1980 & 000 & 000 & 416979 & 15 & 294337 & 85 & 60051 & 62 & 331454 & 75 \\
\hline 1995 & 3585 & 17 & 162443 & 17 & 130446 & 85 & 152105 & 87 & 171056 & 89 \\
\hline \multicolumn{11}{|c|}{ Parte (B) - Percentual da área com plantio simples } \\
\hline & $\begin{array}{l}\text { Área } \\
\text { Total } \\
\text { (ha) }\end{array}$ & $\begin{array}{c}\text { Área com } \\
\text { Plantio } \\
\text { Simples } \\
(\%)\end{array}$ & $\begin{array}{l}\text { Área } \\
\text { Total } \\
\text { (ha) }\end{array}$ & $\begin{array}{c}\text { Área com } \\
\text { Plantio } \\
\text { Simples } \\
(\%)\end{array}$ & $\begin{array}{l}\text { Área } \\
\text { Total } \\
\text { (ha) }\end{array}$ & $\begin{array}{c}\text { Área com } \\
\text { Plantio } \\
\text { Simples } \\
(\%)\end{array}$ & $\begin{array}{l}\text { Área } \\
\text { Total } \\
\text { (ha) }\end{array}$ & $\begin{array}{l}\text { Área com } \\
\text { Plantio } \\
\text { Simples } \\
(\%)\end{array}$ & $\begin{array}{l}\text { Área } \\
\text { Total } \\
\text { (ha) }\end{array}$ & $\begin{array}{c}\text { Área com } \\
\text { Plantio } \\
\text { Simples } \\
(\%)\end{array}$ \\
\hline 1970 & 1093 & 100 & 426569 & 19 & 598789 & 91 & 86440 & 89 & 373287 & 84 \\
\hline 1980 & 000 & 000 & 416979 & 46 & 294337 & 94 & 60051 & 94 & 331454 & 88 \\
\hline 1995 & 3585 & 67 & 162443 & 88 & 130446 & 97 & 152105 & 99 & 171056 & 97 \\
\hline \multicolumn{11}{|c|}{ Parte (C) - Percentual da área com plantações menores de 10 hectares } \\
\hline & $\begin{array}{l}\text { Área } \\
\text { Total } \\
\text { (ha) }\end{array}$ & $\begin{array}{c}\text { Área } \\
>10 \text { ha } \\
(\%)\end{array}$ & $\begin{array}{l}\text { Área } \\
\text { Total } \\
\text { (ha) }\end{array}$ & $\begin{array}{c}\text { Área } \\
>10 \text { ha } \\
(\%)\end{array}$ & $\begin{array}{l}\text { Área } \\
\text { Total } \\
\text { (ha) }\end{array}$ & $\begin{array}{c}\text { Área } \\
>10 \text { ha } \\
(\%)\end{array}$ & $\begin{array}{c}\text { Área } \\
\text { Total } \\
\text { (ha) }\end{array}$ & $\begin{array}{c}\text { Área } \\
>10 \text { ha } \\
(\%)\end{array}$ & $\begin{array}{c}\text { Área } \\
\text { Total } \\
\text { (ha) }\end{array}$ & $\begin{array}{c}\text { Área } \\
>10 \text { ha } \\
(\%)\end{array}$ \\
\hline 1970 & 1093 & 05 & 426569 & 65 & 598789 & 21 & 86440 & 35 & 373287 & 42 \\
\hline 1980 & 000 & 00 & 416979 & 54 & 294337 & 21 & 60051 & 26 & 331454 & 44 \\
\hline 1995 & 3585 & 86 & 162443 & 68 & 130446 & 21 & 152105 & 10 & 171056 & 37 \\
\hline
\end{tabular}

Quadro 17 - Cultura do algodão herbáceo

Fonte: IBGE (1970 - 1995) 


\begin{tabular}{|c|c|c|c|c|c|c|c|c|c|c|}
\hline \multicolumn{11}{|c|}{ Parte (A) - Percentual da área adubada } \\
\hline & \multicolumn{2}{|c|}{ Norte } & \multicolumn{2}{|c|}{ Nordeste } & \multicolumn{2}{|c|}{ Sudeste } & \multicolumn{2}{|c|}{ Centro-Oeste } & \multicolumn{2}{|c|}{ Sul } \\
\hline & $\begin{array}{l}\text { Área } \\
\text { Total } \\
\text { (ha) }\end{array}$ & $\begin{array}{c}\text { Área } \\
\text { Adubada } \\
(\%)\end{array}$ & $\begin{array}{c}\text { Área } \\
\text { Total } \\
\text { (ha) }\end{array}$ & $\begin{array}{c}\text { Área } \\
\text { Adubada } \\
(\%)\end{array}$ & $\begin{array}{c}\text { Área } \\
\text { Total } \\
\text { (ha) }\end{array}$ & $\begin{array}{c}\text { Área } \\
\text { Adubada } \\
(\%)\end{array}$ & $\begin{array}{c}\text { Área } \\
\text { Total } \\
\text { (ha) }\end{array}$ & $\begin{array}{c}\text { Área } \\
\text { Adubada } \\
(\%)\end{array}$ & $\begin{array}{c}\text { Área } \\
\text { Total } \\
\text { (ha) }\end{array}$ & $\begin{array}{c}\text { Área } \\
\text { Adubada } \\
(\%)\end{array}$ \\
\hline 1970 & 128854 & 1 & 680909 & 1 & 1264761 & 28 & 1227967 & 13 & 1009125 & 39 \\
\hline 1980 & 37202 & 50 & 1002690 & 28 & 909312 & 78 & 2465102 & 93 & 952099 & 94 \\
\hline 1995 & 436776 & 22 & 676519 & 19 & 204298 & 58 & 554256 & 81 & 1105217 & 92 \\
\hline \multicolumn{11}{|c|}{ Parte (B) - Percentual da área com plantio simples } \\
\hline & $\begin{array}{l}\text { Área } \\
\text { Total } \\
\text { (ha) }\end{array}$ & $\begin{array}{c}\text { Área com } \\
\text { Plantio } \\
\text { Simples } \\
(\%)\end{array}$ & $\begin{array}{l}\text { Área } \\
\text { Total } \\
\text { (ha) }\end{array}$ & $\begin{array}{l}\text { Área com } \\
\text { Plantio } \\
\text { Simples } \\
(\%)\end{array}$ & $\begin{array}{l}\text { Área } \\
\text { Total } \\
\text { (ha) }\end{array}$ & $\begin{array}{l}\text { Área com } \\
\text { Plantio } \\
\text { Simples } \\
(\%)\end{array}$ & $\begin{array}{l}\text { Área } \\
\text { Total } \\
\text { (ha) }\end{array}$ & $\begin{array}{c}\text { Área com } \\
\text { Plantio } \\
\text { Simples } \\
(\%)\end{array}$ & $\begin{array}{c}\text { Área } \\
\text { Total } \\
\text { (ha) }\end{array}$ & $\begin{array}{c}\text { Área com } \\
\text { Plantio } \\
\text { Simples } \\
(\%)\end{array}$ \\
\hline 1970 & 128854 & 20 & 680909 & 28 & 1264761 & 94 & 1227967 & 81 & 1009125 & 72 \\
\hline 1980 & 372024 & 55 & 1002690 & 33 & 909312 & 90 & 2465102 & 90 & 952099 & 91 \\
\hline 1995 & 436776 & 73 & 676519 & 42 & 204298 & 96 & 554256 & 97 & 1105217 & 99 \\
\hline \multicolumn{11}{|c|}{ Parte (C) - Percentual da área com plantações menores de 10 hectares } \\
\hline & $\begin{array}{l}\text { Área } \\
\text { Total } \\
\text { (ha) } \\
\end{array}$ & $\begin{array}{c}\text { Área } \\
>10 \text { ha } \\
(\%)\end{array}$ & $\begin{array}{c}\text { Área } \\
\text { Total } \\
\text { (ha) }\end{array}$ & $\begin{array}{c}\text { Área } \\
>10 \text { ha } \\
(\%)\end{array}$ & $\begin{array}{l}\text { Área } \\
\text { Total } \\
\text { (ha) }\end{array}$ & $\begin{array}{c}\text { Área } \\
>10 \text { ha } \\
(\%)\end{array}$ & $\begin{array}{l}\text { Área } \\
\text { Total } \\
\text { (ha) }\end{array}$ & $\begin{array}{c}\text { Área } \\
>10 \text { ha } \\
(\%)\end{array}$ & $\begin{array}{c}\text { Área } \\
\text { Total } \\
\text { (ha) }\end{array}$ & $\begin{array}{c}\text { Área } \\
>10 \text { ha } \\
(\%)\end{array}$ \\
\hline 1970 & 128854 & 82 & 680909 & 86 & 1264761 & 28 & 1227967 & 37 & 1009125 & 35 \\
\hline 1980 & 372024 & 72 & 1002690 & 78 & 909312 & 44 & 2465102 & 17 & 952099 & 32 \\
\hline 1995 & 436776 & 67 & 676519 & 77 & 204298 & 69 & 554256 & 21 & 1105217 & 11 \\
\hline
\end{tabular}

Quadro 18 - Cultura do arroz

Fonte: IBGE (1970 - 1995) 


\begin{tabular}{|c|c|c|c|c|c|c|c|c|c|c|}
\hline \multicolumn{11}{|c|}{ Parte (A) - Percentual da área adubada } \\
\hline & \multicolumn{2}{|c|}{ Norte } & \multicolumn{2}{|c|}{ Nordeste } & \multicolumn{2}{|c|}{ Sudeste } & \multicolumn{2}{|c|}{ Centro-Oeste } & \multicolumn{2}{|c|}{ Sul } \\
\hline & $\begin{array}{c}\text { Área } \\
\text { Total } \\
\text { (ha) }\end{array}$ & $\begin{array}{c}\text { Área } \\
\text { Adubada } \\
(\%)\end{array}$ & $\begin{array}{c}\text { Área } \\
\text { Total } \\
\text { (ha) }\end{array}$ & $\begin{array}{c}\text { Área } \\
\text { Adubada } \\
(\%)\end{array}$ & $\begin{array}{c}\text { Área } \\
\text { Total } \\
\text { (ha) }\end{array}$ & $\begin{array}{c}\text { Área } \\
\text { Adubada } \\
(\%)\end{array}$ & $\begin{array}{c}\text { Área } \\
\text { Total } \\
\text { (ha) }\end{array}$ & $\begin{array}{c}\text { Área } \\
\text { Adubada } \\
(\%)\end{array}$ & $\begin{array}{l}\text { Área } \\
\text { Total } \\
\text { (ha) }\end{array}$ & $\begin{array}{c}\text { Área } \\
\text { Adubada } \\
(\%)\end{array}$ \\
\hline 1970 & 00 & 00 & 3044 & 67 & 49453 & 92 & 435 & 45 & 94266 & 72 \\
\hline 1980 & 00 & 00 & 000 & 00 & 35022 & 99 & 000 & 00 & 33652 & 99 \\
\hline 1995 & 14 & 30 & 2738 & 90 & 50752 & 99 & 965 & 97 & 85388 & 98 \\
\hline \multicolumn{11}{|c|}{ Parte (B) - Percentual da área com plantio simples } \\
\hline & $\begin{array}{l}\text { Área } \\
\text { Total } \\
\text { (ha) }\end{array}$ & $\begin{array}{c}\text { Área com } \\
\text { Plantio } \\
\text { Simples } \\
(\%)\end{array}$ & $\begin{array}{c}\text { Área } \\
\text { Total } \\
\text { (ha) }\end{array}$ & $\begin{array}{l}\text { Área com } \\
\text { Plantio } \\
\text { Simples } \\
(\%)\end{array}$ & $\begin{array}{c}\text { Área } \\
\text { Total } \\
\text { (ha) }\end{array}$ & $\begin{array}{c}\text { Área com } \\
\text { Plantio } \\
\text { Simples } \\
(\%)\end{array}$ & $\begin{array}{c}\text { Área } \\
\text { Total } \\
\text { (ha) }\end{array}$ & $\begin{array}{c}\text { Área com } \\
\text { Plantio } \\
\text { Simples } \\
(\%)\end{array}$ & $\begin{array}{c}\text { Área } \\
\text { Total } \\
\text { (ha) }\end{array}$ & $\begin{array}{c}\text { Área com } \\
\text { Plantio } \\
\text { Simples } \\
(\%)\end{array}$ \\
\hline 1970 & 00 & 00 & 3044 & 50 & 49453 & 75 & 435 & 92 & 94266 & 89 \\
\hline 1980 & 00 & 00 & 000 & 00 & 35022 & 90 & 000 & 00 & 33652 & 95 \\
\hline 1995 & 14 & 93 & 2738 & 80 & 50752 & 97 & 965 & 99 & 85388 & 98 \\
\hline \multicolumn{11}{|c|}{ Parte (C) - Percentual da área com plantações menores de 10 hectares } \\
\hline & $\begin{array}{l}\text { Área } \\
\text { Total } \\
\text { (ha) }\end{array}$ & $\begin{array}{c}\text { Área } \\
>10 \text { ha } \\
(\%)\end{array}$ & $\begin{array}{l}\text { Área } \\
\text { Total } \\
\text { (ha) }\end{array}$ & $\begin{array}{c}\text { Área } \\
>10 \text { ha } \\
(\%)\end{array}$ & $\begin{array}{l}\text { Área } \\
\text { Total } \\
\text { (ha) }\end{array}$ & $\begin{array}{c}\text { Área } \\
>10 \text { ha } \\
(\%)\end{array}$ & $\begin{array}{l}\text { Área } \\
\text { Total } \\
\text { (ha) }\end{array}$ & $\begin{array}{c}\text { Área } \\
>10 \text { ha } \\
(\%)\end{array}$ & $\begin{array}{l}\text { Área } \\
\text { Total } \\
\text { (ha) }\end{array}$ & $\begin{array}{c}\text { Área } \\
>10 \text { ha } \\
(\%)\end{array}$ \\
\hline 1970 & 00 & 000 & 3044 & 71 & 49453 & 46 & 435 & 23 & 94266 & 54 \\
\hline 1980 & 00 & 000 & 000 & 00 & 35022 & 44 & 000 & 00 & 33652 & 92 \\
\hline 1995 & 14 & 100 & 2738 & 70 & 50752 & 42 & 965 & 10 & 85388 & 59 \\
\hline
\end{tabular}

Quadro 19 - Cultura da batata-inglesa

Fonte: IBGE (1970 - 1995) 


\begin{tabular}{|c|c|c|c|c|c|c|c|c|c|c|}
\hline \multicolumn{11}{|c|}{ Parte (A) - Percentual da área adubada } \\
\hline & \multicolumn{2}{|c|}{ Norte } & \multicolumn{2}{|c|}{ Nordeste } & \multicolumn{2}{|c|}{ Sudeste } & \multicolumn{2}{|c|}{ Centro-Oeste } & \multicolumn{2}{|c|}{ Sul } \\
\hline & $\begin{array}{c}\text { Área } \\
\text { Total } \\
\text { (ha) }\end{array}$ & $\begin{array}{c}\text { Área } \\
\text { Adubada } \\
(\%)\end{array}$ & $\begin{array}{c}\text { Área } \\
\text { Total } \\
\text { (ha) }\end{array}$ & $\begin{array}{c}\text { Área } \\
\text { Adubada } \\
(\%)\end{array}$ & $\begin{array}{c}\text { Área } \\
\text { Total } \\
\text { (ha) }\end{array}$ & $\begin{array}{c}\text { Área } \\
\text { Adubada } \\
(\%)\end{array}$ & $\begin{array}{c}\text { Área } \\
\text { Total } \\
\text { (ha) }\end{array}$ & $\begin{array}{c}\text { Área } \\
\text { Adubada } \\
(\%)\end{array}$ & $\begin{array}{c}\text { Área } \\
\text { Total } \\
\text { (ha) }\end{array}$ & $\begin{array}{c}\text { Área } \\
\text { Adubada } \\
(\%)\end{array}$ \\
\hline 1970 & 1389 & 5 & 69912 & 8 & 1189411 & 58 & 11425 & 10 & 363364 & 66 \\
\hline 1980 & 26382 & 6 & 96059 & 89 & 1643782 & 98 & 62170 & 89 & 620226 & 95 \\
\hline 1995 & 105905 & 2 & 126887 & 43 & 1454102 & 63 & 21424 & 13 & 104026 & 32 \\
\hline \multicolumn{11}{|c|}{ Parte (B) - Percentual da área com plantio simples } \\
\hline & $\begin{array}{l}\text { Área } \\
\text { Total } \\
\text { (ha) }\end{array}$ & $\begin{array}{c}\text { Área com } \\
\text { Plantio } \\
\text { Simples } \\
(\%)\end{array}$ & $\begin{array}{l}\text { Área } \\
\text { Total } \\
\text { (ha) }\end{array}$ & $\begin{array}{l}\text { Área com } \\
\text { Plantio } \\
\text { Simples } \\
(\%)\end{array}$ & $\begin{array}{l}\text { Área } \\
\text { Total } \\
\text { (ha) }\end{array}$ & $\begin{array}{c}\text { Área com } \\
\text { Plantio } \\
\text { Simples } \\
(\%)\end{array}$ & $\begin{array}{c}\text { Área } \\
\text { Total } \\
\text { (ha) }\end{array}$ & $\begin{array}{c}\text { Área com } \\
\text { Plantio } \\
\text { Simples } \\
(\%)\end{array}$ & $\begin{array}{l}\text { Área } \\
\text { Total } \\
\text { (ha) }\end{array}$ & $\begin{array}{c}\text { Área com } \\
\text { Plantio } \\
\text { Simples } \\
(\%)\end{array}$ \\
\hline 1970 & $*$ & $*$ & $*$ & $*$ & $*$ & $*$ & $*$ & $*$ & $*$ & $*$ \\
\hline 1980 & $*$ & $*$ & $*$ & $*$ & $*$ & $*$ & $*$ & $*$ & $*$ & $*$ \\
\hline 1995 & $*$ & $*$ & $*$ & $*$ & $*$ & $*$ & $*$ & $*$ & $*$ & $*$ \\
\hline \multicolumn{11}{|c|}{ Parte (C) - Percentual da área com plantações menores de 10 hectares } \\
\hline & $\begin{array}{l}\text { Área } \\
\text { Total } \\
\text { (ha) } \\
\end{array}$ & $\begin{array}{c}\text { Área } \\
>10 \text { ha } \\
(\%)\end{array}$ & $\begin{array}{l}\text { Área } \\
\text { Total } \\
\text { (ha) }\end{array}$ & $\begin{array}{c}\text { Área } \\
>10 \text { ha } \\
(\%)\end{array}$ & $\begin{array}{l}\text { Área } \\
\text { Total } \\
\text { (ha) }\end{array}$ & $\begin{array}{c}\text { Área } \\
>10 \text { ha } \\
(\%)\end{array}$ & $\begin{array}{c}\text { Área } \\
\text { Total } \\
\text { (ha) }\end{array}$ & $\begin{array}{c}\text { Área } \\
>10 \text { ha } \\
(\%)\end{array}$ & $\begin{array}{c}\text { Área } \\
\text { Total } \\
\text { (ha) } \\
\end{array}$ & $\begin{array}{c}\text { Área } \\
>10 \text { ha } \\
(\%)\end{array}$ \\
\hline 1970 & 1389 & 88 & 69912 & 60 & 1189411 & 24 & 11425 & 34 & 363364 & 54 \\
\hline 1980 & 26382 & 85 & 96059 & 35 & 1643782 & 33 & 62170 & 53 & 620226 & 39 \\
\hline 1995 & 105905 & 83 & 126887 & 34 & 1454102 & 33 & 21424 & 66 & 104026 & 52 \\
\hline
\end{tabular}

Quadro 20 - Cultura do café

Fonte: IBGE (1970 - 1995)

* Não Informado 


\begin{tabular}{|c|c|c|c|c|c|c|c|c|c|c|}
\hline \multicolumn{11}{|c|}{ Parte (A) - Percentual da área adubada } \\
\hline & \multicolumn{2}{|c|}{ Norte } & \multicolumn{2}{|c|}{ Nordeste } & \multicolumn{2}{|c|}{ Sudeste } & \multicolumn{2}{|c|}{ Centro-Oeste } & \multicolumn{2}{|c|}{ Sul } \\
\hline & $\begin{array}{l}\text { Área } \\
\text { Total } \\
\text { (ha) }\end{array}$ & $\begin{array}{c}\text { Área } \\
\text { Adubada } \\
(\%)\end{array}$ & $\begin{array}{c}\text { Área } \\
\text { Total } \\
\text { (ha) }\end{array}$ & $\begin{array}{c}\text { Área } \\
\text { Adubada } \\
(\%)\end{array}$ & $\begin{array}{c}\text { Área } \\
\text { Total } \\
\text { (ha) }\end{array}$ & $\begin{array}{c}\text { Área } \\
\text { Adubada } \\
(\%)\end{array}$ & $\begin{array}{l}\text { Área } \\
\text { Total } \\
\text { (ha) }\end{array}$ & $\begin{array}{c}\text { Área } \\
\text { Adubada } \\
(\%)\end{array}$ & $\begin{array}{l}\text { Área } \\
\text { Total } \\
\text { (ha) }\end{array}$ & $\begin{array}{c}\text { Área } \\
\text { Adubada } \\
(\%)\end{array}$ \\
\hline 1970 & 5472 & 00 & 621071 & 69 & 951160 & 76 & 14028 & 16 & 103529 & 23 \\
\hline 1980 & 00 & 00 & 977570 & 86 & 1460370 & 99 & 22116 & 98 & 87570 & 46 \\
\hline 1995 & 5698 & 39 & 1125224 & 94 & 2570231 & 95 & 301317 & 99 & 347973 & 77 \\
\hline \multicolumn{11}{|c|}{ Parte (B) - Percentual da área com plantio simples } \\
\hline & $\begin{array}{l}\text { Área } \\
\text { Total } \\
\text { (ha) }\end{array}$ & $\begin{array}{c}\text { Área com } \\
\text { Plantio } \\
\text { Simples } \\
(\%)\end{array}$ & $\begin{array}{l}\text { Área } \\
\text { Total } \\
\text { (ha) }\end{array}$ & $\begin{array}{c}\text { Área com } \\
\text { Plantio } \\
\text { Simples } \\
(\%)\end{array}$ & $\begin{array}{l}\text { Área } \\
\text { Total } \\
\text { (ha) }\end{array}$ & $\begin{array}{c}\text { Área com } \\
\text { Plantio } \\
\text { Simples } \\
(\%)\end{array}$ & $\begin{array}{l}\text { Área } \\
\text { Total } \\
\text { (ha) }\end{array}$ & $\begin{array}{c}\text { Área com } \\
\text { Plantio } \\
\text { Simples } \\
(\%)\end{array}$ & $\begin{array}{c}\text { Área } \\
\text { Total } \\
\text { (ha) }\end{array}$ & $\begin{array}{c}\text { Área com } \\
\text { Plantio } \\
\text { Simples } \\
(\%)\end{array}$ \\
\hline 1970 & 5472 & 86 & 621071 & 98 & 951159 & 96 & 14028 & 94 & 103529 & 94 \\
\hline 1980 & 00 & 00 & 977570 & 98 & 1460370 & 95 & 22116 & 99 & 87568 & 99 \\
\hline 1995 & 5698 & 96 & 1125224 & 99 & 2570231 & 99 & 301317 & 99 & 347973 & 97 \\
\hline \multicolumn{11}{|c|}{ Parte (C) - Percentual da área com plantações menores de 10 hectares } \\
\hline & $\begin{array}{l}\text { Área } \\
\text { Total } \\
\text { (ha) }\end{array}$ & $\begin{array}{c}\text { Área } \\
>10 \text { ha } \\
(\%)\end{array}$ & $\begin{array}{l}\text { Área } \\
\text { Total } \\
\text { (ha) }\end{array}$ & $\begin{array}{c}\text { Área } \\
>10 \text { ha } \\
(\%)\end{array}$ & $\begin{array}{l}\text { Área } \\
\text { Total } \\
\text { (ha) }\end{array}$ & $\begin{array}{c}\text { Área } \\
>10 \text { ha } \\
(\%)\end{array}$ & $\begin{array}{l}\text { Área } \\
\text { Total } \\
\text { (ha) }\end{array}$ & $\begin{array}{c}\text { Área } \\
>10 \text { ha } \\
(\%)\end{array}$ & $\begin{array}{l}\text { Área } \\
\text { Total } \\
\text { (ha) }\end{array}$ & $\begin{array}{c}\text { Área } \\
>10 \text { ha } \\
(\%)\end{array}$ \\
\hline 1970 & 5472 & 40 & 621071 & 12 & 951160 & 11 & 14028 & 46 & 103529 & 48 \\
\hline 1980 & 00 & 00 & 977570 & 35 & 1460370 & 6 & 22116 & 14 & 87570 & 30 \\
\hline 1995 & 5698 & 83 & 1125224 & 6 & 2570231 & 6 & 301317 & 1 & 347973 & 28 \\
\hline
\end{tabular}

Quadro 21 - Cultura da cana-de-açúcar

Fonte: IBGE (1970 - 1995) 


\begin{tabular}{|c|c|c|c|c|c|c|c|c|c|c|}
\hline \multicolumn{11}{|c|}{ Parte (A) - Percentual da área adubada } \\
\hline & \multicolumn{2}{|c|}{ Norte } & \multicolumn{2}{|c|}{ Nordeste } & \multicolumn{2}{|c|}{ Sudeste } & \multicolumn{2}{|c|}{ Centro-Oeste } & \multicolumn{2}{|c|}{ Sul } \\
\hline & $\begin{array}{l}\text { Área } \\
\text { Total } \\
\text { (ha) }\end{array}$ & $\begin{array}{c}\text { Área } \\
\text { Adubada } \\
(\%)\end{array}$ & $\begin{array}{l}\text { Área } \\
\text { Total } \\
\text { (ha) }\end{array}$ & $\begin{array}{c}\text { Área } \\
\text { Adubada } \\
(\%)\end{array}$ & $\begin{array}{l}\text { Área } \\
\text { Total } \\
\text { (ha) }\end{array}$ & $\begin{array}{c}\text { Área } \\
\text { Adubada } \\
(\%)\end{array}$ & $\begin{array}{l}\text { Área } \\
\text { Total } \\
\text { (ha) }\end{array}$ & $\begin{array}{c}\text { Área } \\
\text { Adubada } \\
(\%)\end{array}$ & $\begin{array}{l}\text { Área } \\
\text { Total } \\
\text { (ha) }\end{array}$ & $\begin{array}{c}\text { Área } \\
\text { Adubada } \\
(\%)\end{array}$ \\
\hline 1970 & 34782 & 0 & 1644441 & 3 & 783559 & 23 & 332144 & 2 & 1287190 & 9 \\
\hline 1980 & 93288 & 2 & 1721699 & 23 & 1094102 & 84 & 326087 & 62 & 1122255 & 87 \\
\hline 1995 & 148443 & 9 & 2261746 & 13 & 639192 & 73 & 115873 & 79 & 920273 & 70 \\
\hline \multicolumn{11}{|c|}{ Parte (B) - Percentual da área com plantio simples } \\
\hline & $\begin{array}{l}\text { Área } \\
\text { Total } \\
\text { (ha) }\end{array}$ & $\begin{array}{c}\text { Área com } \\
\text { Plantio } \\
\text { Simples } \\
(\%)\end{array}$ & $\begin{array}{l}\text { Área } \\
\text { Total } \\
\text { (ha) }\end{array}$ & $\begin{array}{l}\text { Área com } \\
\text { Plantio } \\
\text { Simples } \\
(\%)\end{array}$ & $\begin{array}{l}\text { Área } \\
\text { Total } \\
\text { (ha) }\end{array}$ & $\begin{array}{c}\text { Área com } \\
\text { Plantio } \\
\text { Simples } \\
(\%)\end{array}$ & $\begin{array}{l}\text { Área } \\
\text { Total } \\
\text { (ha) }\end{array}$ & $\begin{array}{l}\text { Área com } \\
\text { Plantio } \\
\text { Simples } \\
(\%)\end{array}$ & $\begin{array}{l}\text { Área } \\
\text { Total } \\
\text { (ha) }\end{array}$ & $\begin{array}{c}\text { Área com } \\
\text { Plantio } \\
\text { Simples } \\
(\%) \\
\end{array}$ \\
\hline 1970 & 34782 & 29 & 1644441 & 9 & 783559 & 22 & 332144 & 12 & 1287190 & 24 \\
\hline 1980 & 93288 & 50 & 1721699 & 16 & 1094102 & 38 & 326087 & 27 & 1122255 & 43 \\
\hline 1995 & 148443 & 60 & 2261746 & 26 & 639192 & 57 & 115870 & 82 & 920273 & 80 \\
\hline \multicolumn{11}{|c|}{ Parte (C) - Percentual da área com plantações menores de 10 hectares } \\
\hline & $\begin{array}{l}\text { Área } \\
\text { Total } \\
\text { (ha) }\end{array}$ & $\begin{array}{c}\text { Área } \\
>10 \text { ha } \\
(\%)\end{array}$ & $\begin{array}{l}\text { Área } \\
\text { Total } \\
\text { (ha) }\end{array}$ & $\begin{array}{c}\text { Área } \\
>10 \text { ha } \\
(\%)\end{array}$ & $\begin{array}{l}\text { Área } \\
\text { Total } \\
\text { (ha) }\end{array}$ & $\begin{array}{c}\text { Área } \\
>10 \text { ha } \\
(\%)\end{array}$ & $\begin{array}{l}\text { Área } \\
\text { Total } \\
\text { (ha) }\end{array}$ & $\begin{array}{c}\text { Área } \\
>10 \text { ha } \\
(\%)\end{array}$ & $\begin{array}{l}\text { Área } \\
\text { Total } \\
\text { (ha) }\end{array}$ & $\begin{array}{c}\text { Área } \\
>10 \text { ha } \\
(\%)\end{array}$ \\
\hline 1970 & 34782 & 82 & 1644441 & 70 & 783559 & 47 & 332144 & 50 & 1287190 & 65 \\
\hline 1980 & 93288 & 97 & 1721699 & 81 & 1094100 & 66 & 326087 & 63 & 1122255 & 83 \\
\hline 1995 & 148443 & 86 & 2261746 & 80 & 639192 & 62 & 115869 & 29 & 920273 & 75 \\
\hline
\end{tabular}

Quadro 22 - Cultura do feijão

Fonte: IBGE (1970 - 1995) 


\begin{tabular}{|c|c|c|c|c|c|c|c|c|c|c|}
\hline \multicolumn{11}{|c|}{ Parte (A) - Percentual da área adubada } \\
\hline & \multicolumn{2}{|c|}{ Norte } & \multicolumn{2}{|c|}{ Nordeste } & \multicolumn{2}{|c|}{ Sudeste } & \multicolumn{2}{|c|}{ Centro-Oeste } & \multicolumn{2}{|c|}{ Sul } \\
\hline & $\begin{array}{c}\text { Área } \\
\text { Total } \\
\text { (ha) }\end{array}$ & $\begin{array}{c}\text { Área } \\
\text { Adubada } \\
(\%)\end{array}$ & $\begin{array}{l}\text { Área } \\
\text { Total } \\
\text { (ha) }\end{array}$ & $\begin{array}{c}\text { Área } \\
\text { Adubada } \\
(\%)\end{array}$ & $\begin{array}{l}\text { Área } \\
\text { Total } \\
\text { (ha) }\end{array}$ & $\begin{array}{c}\text { Área } \\
\text { Adubada } \\
(\%)\end{array}$ & $\begin{array}{l}\text { Área } \\
\text { Total } \\
\text { (ha) }\end{array}$ & $\begin{array}{c}\text { Área } \\
\text { Adubada } \\
(\%)\end{array}$ & $\begin{array}{l}\text { Área } \\
\text { Total } \\
\text { (ha) }\end{array}$ & $\begin{array}{c}\text { Área } \\
\text { Adubada } \\
(\%)\end{array}$ \\
\hline 1970 & 00 & 00 & 00 & 00 & 00 & 00 & 00 & 00 & 00 & 00 \\
\hline 1980 & 00 & 00 & 47898 & 81 & 00 & 00 & 00 & 00 & 205495 & 96 \\
\hline 1995 & 967 & 21 & 34214 & 86 & 1865 & 61 & 94 & 70 & 267234 & 99 \\
\hline \multicolumn{11}{|c|}{ Parte (B) - Percentual da área com plantio simples } \\
\hline & $\begin{array}{l}\text { Área } \\
\text { Total } \\
\text { (ha) }\end{array}$ & $\begin{array}{c}\text { Área com } \\
\text { Plantio } \\
\text { Simples } \\
(\%)\end{array}$ & $\begin{array}{l}\text { Área } \\
\text { Total } \\
\text { (ha) }\end{array}$ & $\begin{array}{l}\text { Área com } \\
\text { Plantio } \\
\text { Simples } \\
(\%)\end{array}$ & $\begin{array}{l}\text { Área } \\
\text { Total } \\
\text { (ha) }\end{array}$ & $\begin{array}{l}\text { Área com } \\
\text { Plantio } \\
\text { Simples } \\
(\%)\end{array}$ & $\begin{array}{l}\text { Área } \\
\text { Total } \\
\text { (ha) }\end{array}$ & $\begin{array}{l}\text { Área com } \\
\text { Plantio } \\
\text { Simples } \\
(\%)\end{array}$ & $\begin{array}{l}\text { Área } \\
\text { Total } \\
\text { (ha) }\end{array}$ & $\begin{array}{c}\text { Área com } \\
\text { Plantio } \\
\text { Simples } \\
(\%)\end{array}$ \\
\hline 1970 & 00 & 00 & 00 & 00 & 00 & 00 & 00 & 00 & 00 & 00 \\
\hline 1980 & 00 & 00 & 47898 & 51 & 00 & 00 & 00 & 00 & 205495 & 98 \\
\hline 1995 & 967 & 84 & 34214 & 63 & 1865 & 81 & 94 & 51 & 267234 & 98 \\
\hline \multicolumn{11}{|c|}{ Parte (C) - Percentual da área com plantações menores de 10 hectares } \\
\hline & $\begin{array}{c}\text { Área } \\
\text { Total } \\
\text { (ha) }\end{array}$ & $\begin{array}{c}\text { Área } \\
>10 \text { ha } \\
(\%)\end{array}$ & $\begin{array}{l}\text { Área } \\
\text { Total } \\
\text { (ha) }\end{array}$ & $\begin{array}{c}\text { Área } \\
>10 \text { ha } \\
(\%)\end{array}$ & $\begin{array}{l}\text { Área } \\
\text { Total } \\
\text { (ha) }\end{array}$ & $\begin{array}{c}\text { Área } \\
>10 \text { ha } \\
(\%)\end{array}$ & $\begin{array}{l}\text { Área } \\
\text { Total } \\
\text { (ha) }\end{array}$ & $\begin{array}{c}\text { Área } \\
>10 \text { ha } \\
(\%)\end{array}$ & $\begin{array}{l}\text { Área } \\
\text { Total } \\
\text { (ha) }\end{array}$ & $\begin{array}{c}\text { Área } \\
>10 \text { ha } \\
(\%)\end{array}$ \\
\hline 1970 & 00 & 00 & 00 & 00 & 00 & 00 & 00 & 00 & 00 & 00 \\
\hline 1980 & 00 & 00 & 47898 & 80 & 00 & 00 & 00 & 00 & 205495 & 98 \\
\hline 1995 & 967 & 99 & 34214 & 89 & 1865 & 87 & 94 & 69 & 267234 & 75 \\
\hline
\end{tabular}

Quadro 23 - Cultura do fumo

Fonte: IBGE (1970 - 1995) 


\begin{tabular}{|c|c|c|c|c|c|c|c|c|c|c|}
\hline \multicolumn{11}{|c|}{ Parte (A) - Percentual da área adubada } \\
\hline & \multicolumn{2}{|c|}{ Norte } & \multicolumn{2}{|c|}{ Nordeste } & \multicolumn{2}{|c|}{ Sudeste } & \multicolumn{2}{|c|}{ Centro-Oeste } & \multicolumn{2}{|c|}{ Sul } \\
\hline & $\begin{array}{l}\text { Área } \\
\text { Total } \\
\text { (ha) }\end{array}$ & $\begin{array}{c}\text { Área } \\
\text { Adubada } \\
(\%)\end{array}$ & $\begin{array}{c}\text { Área } \\
\text { Total } \\
\text { (ha) }\end{array}$ & $\begin{array}{c}\text { Área } \\
\text { Adubada } \\
(\%)\end{array}$ & $\begin{array}{l}\text { Área } \\
\text { Total } \\
\text { (ha) }\end{array}$ & $\begin{array}{c}\text { Área } \\
\text { Adubada } \\
(\%)\end{array}$ & $\begin{array}{l}\text { Área } \\
\text { Total } \\
\text { (ha) }\end{array}$ & $\begin{array}{c}\text { Área } \\
\text { Adubada } \\
(\%)\end{array}$ & $\begin{array}{c}\text { Área } \\
\text { Total } \\
\text { (ha) }\end{array}$ & $\begin{array}{c}\text { Área } \\
\text { Adubada } \\
(\%)\end{array}$ \\
\hline 1970 & 1934 & 6 & 19241 & 41 & 156806 & 74 & 3202 & 22 & 26288 & 28 \\
\hline 1980 & 1532 & 3 & 31303 & 72 & 397733 & 92 & 2467 & 47 & 22079 & 25 \\
\hline 1995 & 14990 & 22 & 94081 & 43 & 779542 & 51 & 8306 & 52 & 28259 & 51 \\
\hline \multicolumn{11}{|c|}{ Parte (B) - Percentual da área com plantio simples } \\
\hline & $\begin{array}{c}\text { Área } \\
\text { Total } \\
\text { (ha) }\end{array}$ & $\begin{array}{c}\text { Área com } \\
\text { Plantio } \\
\text { Simples } \\
(\%)\end{array}$ & $\begin{array}{l}\text { Área } \\
\text { Total } \\
\text { (ha) }\end{array}$ & $\begin{array}{l}\text { Área com } \\
\text { Plantio } \\
\text { Simples } \\
(\%)\end{array}$ & $\begin{array}{l}\text { Área } \\
\text { Total } \\
\text { (ha) }\end{array}$ & $\begin{array}{c}\text { Área com } \\
\text { Plantio } \\
\text { Simples } \\
(\%)\end{array}$ & $\begin{array}{c}\text { Área } \\
\text { Total } \\
\text { (ha) }\end{array}$ & $\begin{array}{c}\text { Área com } \\
\text { Plantio } \\
\text { Simples } \\
(\%)\end{array}$ & $\begin{array}{c}\text { Área } \\
\text { Total } \\
\text { (ha) }\end{array}$ & $\begin{array}{c}\text { Área com } \\
\text { Plantio } \\
\text { Simples } \\
(\%)\end{array}$ \\
\hline 1970 & $*$ & * & * & * & $*$ & $*$ & $*$ & $*$ & $*$ & $*$ \\
\hline 1980 & $*$ & $*$ & $*$ & $*$ & $*$ & $*$ & $*$ & $*$ & $*$ & $*$ \\
\hline 1995 & $*$ & $*$ & $*$ & $*$ & $*$ & $*$ & $*$ & $*$ & $*$ & $*$ \\
\hline \multicolumn{11}{|c|}{ Parte $(C)$ - Percentual da área com plantacões menores de 10 hectares } \\
\hline & $\begin{array}{c}\text { Área } \\
\text { Total } \\
\text { (ha) }\end{array}$ & $\begin{array}{c}\text { Área } \\
>10 \text { ha } \\
(\%)\end{array}$ & $\begin{array}{c}\text { Área } \\
\text { Total } \\
\text { (ha) }\end{array}$ & $\begin{array}{c}\text { Área } \\
>10 \text { ha } \\
(\%)\end{array}$ & $\begin{array}{l}\text { Área } \\
\text { Total } \\
\text { (ha) }\end{array}$ & $\begin{array}{c}\text { Área } \\
>10 \text { ha } \\
(\%)\end{array}$ & $\begin{array}{l}\text { Área } \\
\text { Total } \\
\text { (ha) }\end{array}$ & $\begin{array}{c}\text { Área } \\
>10 \text { ha } \\
(\%)\end{array}$ & $\begin{array}{c}\text { Área } \\
\text { Total } \\
\text { (ha) }\end{array}$ & $\begin{array}{c}\text { Área } \\
>10 \text { ha } \\
(\%)\end{array}$ \\
\hline 1970 & 1934 & 43 & 19241 & 66 & 156806 & 23 & 3202 & 57 & 26288 & 21 \\
\hline 1980 & 1532 & 95 & 31303 & 69 & 397733 & 16 & 2467 & 81 & 22079 & 96 \\
\hline 1995 & 14990 & 76 & 94081 & 59 & 779542 & 39 & 8306 & 36 & 28259 & 82 \\
\hline
\end{tabular}

Quadro 24 - Cultura da laranja

Fonte: IBGE (1970 - 1995)

* Não Informado 


\begin{tabular}{|c|c|c|c|c|c|c|c|c|c|c|}
\hline \multicolumn{11}{|c|}{ Parte (A) - Percentual da área adubada } \\
\hline & \multicolumn{2}{|c|}{ Norte } & \multicolumn{2}{|c|}{ Nordeste } & \multicolumn{2}{|c|}{ Sudeste } & \multicolumn{2}{|c|}{ Centro-Oeste } & \multicolumn{2}{|c|}{ Sul } \\
\hline & $\begin{array}{l}\text { Área } \\
\text { Total } \\
\text { (ha) }\end{array}$ & $\begin{array}{c}\text { Área } \\
\text { Adubada } \\
(\%) \\
\end{array}$ & $\begin{array}{l}\text { Área } \\
\text { Total } \\
\text { (ha) }\end{array}$ & $\begin{array}{c}\text { Área } \\
\text { Adubada } \\
(\%)\end{array}$ & $\begin{array}{l}\text { Área } \\
\text { Total } \\
\text { (ha) }\end{array}$ & $\begin{array}{c}\text { Área } \\
\text { Adubada } \\
(\%)\end{array}$ & $\begin{array}{c}\text { Área } \\
\text { Total } \\
\text { (ha) }\end{array}$ & $\begin{array}{c}\text { Área } \\
\text { Adubada } \\
(\%)\end{array}$ & $\begin{array}{c}\text { Área } \\
\text { Total } \\
\text { (ha) }\end{array}$ & $\begin{array}{c}\text { Área } \\
\text { Adubada } \\
(\%) \\
\end{array}$ \\
\hline 1970 & 191668 & 0 & 836883 & 7 & 162344 & 11 & 46591 & 0 & 491174 & 14 \\
\hline 1980 & 277760 & 0 & 536348 & 17 & 77232 & 27 & 20193 & 3 & 229381 & 67 \\
\hline 1995 & 277862 & 2 & 548554 & 21 & 112806 & 27 & 40336 & 17 & 253584 & 28 \\
\hline \multicolumn{11}{|c|}{ Parte (B) - Percentual da área com plantio simples } \\
\hline & $\begin{array}{l}\text { Área } \\
\text { Total } \\
\text { (ha) }\end{array}$ & $\begin{array}{c}\text { Área com } \\
\text { Plantio } \\
\text { Simples } \\
(\%)\end{array}$ & $\begin{array}{l}\text { Área } \\
\text { Total } \\
\text { (ha) }\end{array}$ & $\begin{array}{l}\text { Área com } \\
\text { Plantio } \\
\text { Simples } \\
(\%)\end{array}$ & $\begin{array}{l}\text { Área } \\
\text { Total } \\
\text { (ha) }\end{array}$ & $\begin{array}{l}\text { Área com } \\
\text { Plantio } \\
\text { Simples } \\
(\%)\end{array}$ & $\begin{array}{l}\text { Área } \\
\text { Total } \\
\text { (ha) }\end{array}$ & $\begin{array}{l}\text { Área com } \\
\text { Plantio } \\
\text { Simples } \\
(\%)\end{array}$ & $\begin{array}{l}\text { Área } \\
\text { Total } \\
\text { (ha) }\end{array}$ & $\begin{array}{c}\text { Área com } \\
\text { Plantio } \\
\text { Simples } \\
(\%)\end{array}$ \\
\hline 1970 & 191668 & 46 & 836883 & 53 & 162344 & 85 & 46591 & 37 & 491174 & 56 \\
\hline 1980 & 277760 & 68 & 536348 & 70 & 77232 & 71 & 20193 & 66 & 229381 & 43 \\
\hline 1995 & 277862 & 74 & 548548 & 63 & 112806 & 90 & 40336 & 94 & 253584 & 92 \\
\hline \multicolumn{11}{|c|}{ Parte (C) - Percentual da área com plantações menores de 10 hectares } \\
\hline & $\begin{array}{l}\text { Área } \\
\text { Total } \\
\text { (ha) }\end{array}$ & $\begin{array}{c}\text { Área } \\
>10 \text { ha } \\
(\%)\end{array}$ & $\begin{array}{c}\text { Área } \\
\text { Total } \\
\text { (ha) }\end{array}$ & $\begin{array}{c}\text { Área } \\
>10 \text { ha } \\
(\%)\end{array}$ & $\begin{array}{l}\text { Área } \\
\text { Total } \\
\text { (ha) }\end{array}$ & $\begin{array}{c}\text { Área } \\
>10 \text { ha } \\
(\%)\end{array}$ & $\begin{array}{c}\text { Área } \\
\text { Total } \\
\text { (ha) }\end{array}$ & $\begin{array}{c}\text { Área } \\
>10 \text { ha } \\
(\%)\end{array}$ & $\begin{array}{l}\text { Área } \\
\text { Total } \\
\text { (ha) }\end{array}$ & $\begin{array}{c}\text { Área } \\
>10 \text { ha } \\
(\%)\end{array}$ \\
\hline 1970 & 191668 & 93 & 836883 & 82 & 162344 & 53 & 46591 & 75 & 491174 & 61 \\
\hline 1980 & 277760 & 94 & 536348 & 94 & 77232 & 82 & 20193 & 93 & 229381 & 95 \\
\hline 1995 & 277862 & 90 & 548554 & 89 & 112806 & 74 & 40336 & 66 & 253584 & 73 \\
\hline
\end{tabular}

Quadro 25 - Cultura da mandioca

Fonte: IBGE (1970 - 1995) 


\begin{tabular}{|c|c|c|c|c|c|c|c|c|c|c|}
\hline \multicolumn{11}{|c|}{ Parte (A) - Percentual da área adubada } \\
\hline & \multicolumn{2}{|c|}{ Norte } & \multicolumn{2}{|c|}{ Nordeste } & \multicolumn{2}{|c|}{ Sudeste } & \multicolumn{2}{|c|}{ Centro-Oeste } & \multicolumn{2}{|c|}{ Sul } \\
\hline & $\begin{array}{l}\text { Área } \\
\text { Total } \\
\text { (ha) }\end{array}$ & $\begin{array}{c}\text { Área } \\
\text { Adubada } \\
(\%)\end{array}$ & $\begin{array}{l}\text { Área } \\
\text { Total } \\
\text { (ha) }\end{array}$ & $\begin{array}{c}\text { Área } \\
\text { Adubada } \\
(\%) \\
\end{array}$ & $\begin{array}{l}\text { Área } \\
\text { Total } \\
\text { (ha) }\end{array}$ & $\begin{array}{c}\text { Área } \\
\text { Adubada } \\
(\%)\end{array}$ & $\begin{array}{l}\text { Área } \\
\text { Total } \\
\text { (ha) }\end{array}$ & $\begin{array}{c}\text { Área } \\
\text { Adubada } \\
(\%)\end{array}$ & $\begin{array}{l}\text { Área } \\
\text { Total } \\
\text { (ha) }\end{array}$ & $\begin{array}{c}\text { Área } \\
\text { Adubada } \\
(\%) \\
\end{array}$ \\
\hline 1970 & 144469 & 0 & 2062121 & 2 & 3087657 & 24 & 712144 & 03 & 4663831 & 20 \\
\hline 1980 & 273820 & 1 & 2026505 & 14 & 2779914 & 70 & 960042 & 55 & 4298290 & 43 \\
\hline 1995 & 358183 & 8 & 2354787 & 12 & 2134746 & 84 & 1680158 & 88 & 4074961 & 85 \\
\hline \multicolumn{11}{|c|}{ Parte (B) - Percentual da área com plantio simples } \\
\hline & $\begin{array}{l}\text { Área } \\
\text { Total } \\
\text { (ha) }\end{array}$ & $\begin{array}{c}\text { Área com } \\
\text { Plantio } \\
\text { Simples } \\
(\%)\end{array}$ & $\begin{array}{l}\text { Área } \\
\text { Total } \\
\text { (ha) }\end{array}$ & $\begin{array}{l}\text { Área com } \\
\text { Plantio } \\
\text { Simples } \\
(\%)\end{array}$ & $\begin{array}{l}\text { Área } \\
\text { Total } \\
\text { (ha) }\end{array}$ & $\begin{array}{l}\text { Área com } \\
\text { Plantio } \\
\text { Simples } \\
(\%)\end{array}$ & $\begin{array}{l}\text { Área } \\
\text { Total } \\
\text { (ha) }\end{array}$ & $\begin{array}{l}\text { Área com } \\
\text { Plantio } \\
\text { Simples } \\
(\%)\end{array}$ & $\begin{array}{l}\text { Área } \\
\text { Total } \\
\text { (ha) }\end{array}$ & $\begin{array}{c}\text { Área com } \\
\text { Plantio } \\
\text { Simples } \\
(\%)\end{array}$ \\
\hline 1970 & 144469 & 12 & 2062121 & 4 & 3087657 & 57 & 712144 & 32 & 4663831 & 29 \\
\hline 1980 & 273820 & 34 & 2026505 & 8 & 2779914 & 57 & 960042 & 56 & 4298290 & 42 \\
\hline 1995 & 358182 & 57 & 2354787 & 26 & 2134746 & 84 & 1680158 & 97 & 4074961 & 89 \\
\hline \multicolumn{11}{|c|}{ Parte (C) - Percentual da área com plantações menores de 10 hectares } \\
\hline & $\begin{array}{l}\text { Área } \\
\text { Total } \\
\text { (ha) }\end{array}$ & $\begin{array}{c}\text { Área } \\
>10 \text { ha } \\
(\%)\end{array}$ & $\begin{array}{c}\text { Área } \\
\text { Total } \\
\text { (ha) }\end{array}$ & $\begin{array}{c}\text { Área } \\
>10 \text { ha } \\
(\%)\end{array}$ & $\begin{array}{l}\text { Área } \\
\text { Total } \\
\text { (ha) }\end{array}$ & $\begin{array}{c}\text { Área } \\
>10 \text { ha } \\
(\%)\end{array}$ & $\begin{array}{l}\text { Área } \\
\text { Total } \\
\text { (ha) }\end{array}$ & $\begin{array}{c}\text { Área } \\
>10 \text { ha } \\
(\%)\end{array}$ & $\begin{array}{l}\text { Área } \\
\text { Total } \\
\text { (ha) }\end{array}$ & $\begin{array}{c}\text { Área } \\
>10 \text { ha } \\
(\%)\end{array}$ \\
\hline 1970 & 144469 & 85 & 2062121 & 72 & 3087657 & 33 & 712144 & 42 & 4663831 & 52 \\
\hline 1980 & 273820 & 81 & 2026505 & 79 & 2779914 & 46 & 960042 & 37 & 4298290 & 60 \\
\hline 1995 & 358182 & 77 & 2354787 & 76 & 2134746 & 33 & 1680158 & 12 & 4074961 & 45 \\
\hline
\end{tabular}

Quadro 26 - Cultura do milho

Fonte: IBGE (1970 - 1995) 


\begin{tabular}{|c|c|c|c|c|c|c|c|c|c|c|}
\hline \multicolumn{11}{|c|}{ Parte (A) - Percentual da área adubada } \\
\hline & \multicolumn{2}{|c|}{ Norte } & \multicolumn{2}{|c|}{ Nordeste } & \multicolumn{2}{|c|}{ Sudeste } & \multicolumn{2}{|c|}{ Centro-Oeste } & \multicolumn{2}{|c|}{ Sul } \\
\hline & $\begin{array}{l}\text { Área } \\
\text { Total } \\
\text { (ha) }\end{array}$ & $\begin{array}{c}\text { Área } \\
\text { Adubada } \\
(\%)\end{array}$ & $\begin{array}{c}\text { Área } \\
\text { Total } \\
\text { (ha) }\end{array}$ & $\begin{array}{c}\text { Área } \\
\text { Adubada } \\
(\%)\end{array}$ & $\begin{array}{l}\text { Área } \\
\text { Total } \\
\text { (ha) }\end{array}$ & $\begin{array}{c}\text { Área } \\
\text { Adubada } \\
(\%)\end{array}$ & $\begin{array}{c}\text { Área } \\
\text { Total } \\
\text { (ha) }\end{array}$ & $\begin{array}{c}\text { Área } \\
\text { Adubada } \\
(\%)\end{array}$ & $\begin{array}{c}\text { Área } \\
\text { Total } \\
\text { (ha) }\end{array}$ & $\begin{array}{c}\text { Área } \\
\text { Adubada } \\
(\%)\end{array}$ \\
\hline 1970 & 00 & 00 & 00 & 00 & 72771 & 92 & 26710 & 25 & 2086248 & 37 \\
\hline 1980 & 00 & 00 & 00 & 00 & 632252 & 98 & 883440 & 98 & 6266723 & 97 \\
\hline 1995 & 8038 & 81 & 426505 & 97 & 839574 & 99 & 3373425 & 99 & 4830697 & 95 \\
\hline \multicolumn{11}{|c|}{ Parte (B) - Percentual da área com plantio simples } \\
\hline & $\begin{array}{l}\text { Área } \\
\text { Total } \\
\text { (ha) }\end{array}$ & $\begin{array}{c}\text { Área com } \\
\text { Plantio } \\
\text { Simples } \\
(\%)\end{array}$ & $\begin{array}{l}\text { Área } \\
\text { Total } \\
\text { (ha) }\end{array}$ & $\begin{array}{c}\text { Área com } \\
\text { Plantio } \\
\text { Simples } \\
(\%)\end{array}$ & $\begin{array}{l}\text { Área } \\
\text { Total } \\
\text { (ha) }\end{array}$ & $\begin{array}{c}\text { Área com } \\
\text { Plantio } \\
\text { Simples } \\
(\%)\end{array}$ & $\begin{array}{l}\text { Área } \\
\text { Total } \\
\text { (ha) }\end{array}$ & $\begin{array}{c}\text { Área com } \\
\text { Plantio } \\
\text { Simples } \\
(\%)\end{array}$ & $\begin{array}{c}\text { Área } \\
\text { Total } \\
\text { (ha) }\end{array}$ & $\begin{array}{c}\text { Área com } \\
\text { Plantio } \\
\text { Simples } \\
(\%)\end{array}$ \\
\hline 1970 & 00 & 00 & 00 & 00 & 72771 & 97 & 26710 & 82 & 2086248 & 40 \\
\hline 1980 & 00 & 00 & 00 & 00 & 632252 & 98 & 883440 & 98 & 6266723 & 84 \\
\hline 1995 & 8038 & 96 & 426505 & 99 & 839574 & 99 & 3373425 & 99 & 4830697 & 96 \\
\hline \multicolumn{11}{|c|}{ Parte (C) - Percentual da área com plantações menores de 10 hectares } \\
\hline & $\begin{array}{c}\text { Área } \\
\text { Total } \\
\text { (ha) } \\
\end{array}$ & $\begin{array}{c}\text { Área } \\
>10 \text { ha } \\
(\%)\end{array}$ & $\begin{array}{c}\text { Área } \\
\text { Total } \\
\text { (ha) }\end{array}$ & $\begin{array}{c}\text { Área } \\
>10 \text { ha } \\
(\%)\end{array}$ & $\begin{array}{l}\text { Área } \\
\text { Total } \\
\text { (ha) }\end{array}$ & $\begin{array}{c}\text { Área } \\
>10 \text { ha } \\
(\%)\end{array}$ & $\begin{array}{l}\text { Área } \\
\text { Total } \\
\text { (ha) }\end{array}$ & $\begin{array}{c}\text { Área } \\
>10 \text { ha } \\
(\%)\end{array}$ & $\begin{array}{c}\text { Área } \\
\text { Total } \\
\text { (ha) }\end{array}$ & $\begin{array}{c}\text { Área } \\
>10 \text { ha } \\
(\%)\end{array}$ \\
\hline 1970 & 00 & 00 & 00 & 00 & 72771 & 00 & 26710 & 37 & 2086248 & 19 \\
\hline 1980 & 00 & 00 & 00 & 00 & 632252 & 04 & 883440 & 02 & 6266723 & 18 \\
\hline 1995 & 8038 & 05 & 426505 & 00 & 839574 & 00 & 3373425 & 00 & 4830697 & 11 \\
\hline
\end{tabular}

Quadro 27 - Cultura do soja

Fonte: IBGE (1970 - 1995) 


\section{ANEXO D - Demonstrações Algébricas}

\section{Demonstração dos Valores de $s_{K}$ e $s_{L}$ substituídos na equação (76)}

A partir da função de produção dada pela expressão (44) definida como, $Y=A .\left(K^{\alpha} L^{\beta} S^{1-\alpha-\beta}\right)$ tem-se que:

$K^{\alpha}=Y \cdot A^{-1} \cdot L^{-\beta} \cdot S^{\alpha+\beta-1}$

ou,

$$
\begin{aligned}
& K=Y^{1 / \alpha}\left(A \cdot L^{\beta} \cdot S^{1-\alpha-\beta}\right)^{-\frac{1}{\alpha}}, \text { neste caso: } \\
& K=\frac{Y^{\frac{1}{\alpha}}}{A^{\frac{1}{\alpha}} \cdot L^{\frac{\beta}{\alpha}} \cdot S^{\frac{1-\alpha-\beta}{\alpha}}}
\end{aligned}
$$

Dividindo a equação (44) por K e em seguida multiplicando por $S$ (propensão marginal a poupar), tem-se que:

$$
s \frac{Y}{K}=S \cdot A \cdot K^{\alpha-1} \cdot L^{\beta} \cdot S^{1-\alpha-\beta}
$$

Substituindo a equação (103) na equação (104), tem-se:

$$
\begin{aligned}
& S \frac{Y}{K}=S \cdot A \cdot \frac{Y^{\frac{\alpha-1}{\alpha}}}{A^{\frac{\alpha-1}{\alpha}} L^{\frac{\beta(\alpha-1)}{\alpha}} S^{\frac{(1-\alpha-\beta)(\alpha-1)}{\alpha}} \cdot L^{\beta} \cdot S^{1-\alpha-\beta}} \\
& S \frac{Y}{K}=S \cdot \frac{A}{A^{\frac{\alpha-1}{\alpha}}} \cdot Y^{\frac{\alpha-1}{\alpha}} \cdot \frac{L^{\beta}}{L^{\frac{\beta(\alpha-1)}{\alpha}}} \cdot \frac{S^{1-\alpha-\beta}}{S^{\frac{(1-\alpha-\beta)(\alpha-1)}{\alpha}}} \\
& S \frac{Y}{K}=S \cdot A^{\frac{1}{\alpha}} \cdot Y^{\frac{\alpha-1}{\alpha}} \cdot L^{\frac{\beta}{\alpha}} \cdot S^{\frac{1-\alpha-\beta}{\alpha}}
\end{aligned}
$$




$$
\begin{aligned}
& s \frac{Y}{K}=s \cdot\left(A \cdot Y^{\alpha-1} \cdot L^{\beta} \cdot S^{1-\alpha-\beta}\right)^{1 / \alpha} \\
& s \frac{Y}{K}=s \cdot\left(\frac{A \cdot Y^{\alpha-1} \cdot L^{\beta}}{S^{\beta+\alpha-1}}\right)^{1 / \alpha} \\
& s \frac{Y}{K}=s \cdot\left(\frac{A \cdot Y^{\alpha-1} \cdot L^{\beta}}{S^{\alpha-1} S^{\beta}}\right)^{1 / \alpha}
\end{aligned}
$$

Mas como $\frac{Y^{\alpha-1}}{S^{\alpha-1}}=y^{\alpha-1}$ e $\frac{L^{\beta}}{S^{\beta}}=l^{\beta}$, tem-se:

$$
s \frac{Y}{K}=s\left(A y^{\alpha-1} l^{\beta}\right)^{1 / \alpha}
$$

Por definição, $s_{K}=\frac{\pi}{Y}=\frac{K \cdot P M g K}{Y}$ mas, $P M g K=\frac{\partial Y}{\partial K}$. Então:

$$
s_{K}=\frac{K}{Y} \cdot \frac{\partial Y}{\partial K}
$$

Da função de produção $Y=A \cdot\left(K^{\alpha} L^{\beta} S^{1-\alpha-\beta}\right)$, equação (44), obtém-se que:

$$
\frac{\partial Y}{\partial K}=\alpha \cdot A \cdot K^{\alpha-1} \cdot L^{\beta} \cdot S^{1-\alpha-\beta}
$$

Substituindo a equação (107) na equação (106), tem-se que:

$$
\begin{aligned}
& s_{K}=\frac{K}{Y} \cdot \alpha \cdot A \cdot K^{\alpha-1} \cdot L^{\beta} \cdot S^{1-\alpha-\beta} \\
& s_{K}=\frac{\alpha \cdot A \cdot K^{\alpha} \cdot L^{\beta} \cdot S^{1-\alpha-\beta}}{Y} \text {, sabendo que } Y=A \cdot\left(K^{\alpha} L^{\beta} S^{1-\alpha-\beta}\right), \text { tem-se } \\
& s_{K}=\frac{\alpha \cdot Y}{Y}=\alpha
\end{aligned}
$$


Sabendo que $S_{L}=\frac{L \cdot P M g L}{Y}$ e que

$s_{L}=\frac{L}{Y} \cdot \frac{\partial Y}{\partial L}$

mas, $\frac{\partial Y}{\partial L}=\beta \cdot A \cdot K^{\alpha} \cdot L^{\beta-1} \cdot S^{1-\alpha-\beta}$. Substituindo esta expressão na equação (109), tem-se que:

$$
\begin{aligned}
& s_{L}=\frac{L}{Y} \cdot \beta \cdot A \cdot K^{\alpha} \cdot L^{\beta-1} \cdot S^{1-\alpha-\beta}=\frac{\beta \cdot Y}{Y}, \text { portanto, } \\
& S_{L}=\frac{\beta \cdot Y}{Y}=\beta
\end{aligned}
$$

Substituindo agora as equações (110) e (108) na equação (76) do capítulo 5, chega-se à equação (77) do capítulo 5, definida como:

$$
\hat{y}=g+\alpha\left[\frac{s \widetilde{y}}{\widetilde{k}}-\frac{b}{e^{b(t+\theta)}-1}-\delta-g\right]+\beta\left[n-\frac{b}{e^{b(t+\theta)}-1}-g\right]
$$




\section{ANEXO E - Passagem da equação (95) para a equação (96) ${ }^{24}$}

Na expressão (95) - dada por, $\log \widetilde{y}_{t+1}=-\lambda \log \widetilde{y}^{*}{ }_{t}+(1+\lambda) \log \tilde{y}_{t}-$ chamamos, $\log \widetilde{y}_{t}=Z_{\mathrm{t}}$ para todo $\mathrm{t}$ e $-\lambda \log \tilde{y}_{t}^{*}=\phi$. Como $\log \tilde{y}_{t}^{*}$ é constante, $\phi$ também é constante

$Z_{t+1}=(1+\lambda) Z_{t}+\phi \quad$ ou $\quad Z_{t}=(1+\lambda) Z_{t-1}+\phi$

Se $\mathrm{t}=1$, tem-se que: $\mathrm{Z}_{1}=(1+\lambda) \mathrm{Z}_{0}+\phi$

Se $\mathrm{t}=2$, tem-se que: $\mathrm{Z}_{2}=(1+\lambda) \mathrm{Z}_{1}+\phi$

$$
\begin{aligned}
& Z_{2}=(1+\lambda)\left[(1+\lambda) Z_{0}+\phi\right]+\phi \\
& Z_{2}=(1+\lambda)^{2} Z_{0}+(1+\lambda) \phi+\phi
\end{aligned}
$$

Se $\mathrm{t}=3$, tem-se que: $Z_{3}=(1+\lambda) Z_{2}+\phi$

$$
\begin{aligned}
& Z_{3}=(1+\lambda)\left[(1+\lambda)^{2} Z_{0}+(1+\lambda) \phi+\phi\right]+\phi \\
& Z_{3}=(1+\lambda)^{3} Z_{0}+(1+\lambda)^{2} \phi+(1+\lambda) \phi+\phi
\end{aligned}
$$

Se $\mathrm{t}=\mathrm{T}$, tem-se que:

$$
\begin{aligned}
& Z_{T}=(1+\lambda)^{\mathrm{T}} Z_{0}+(1+\lambda)^{\mathrm{T}-1} \phi+(1+\lambda)^{\mathrm{T}-2} \phi+\ldots+(1+\lambda) \phi+\phi \\
& \mathrm{Z}_{\mathrm{T}}=(1+\lambda)^{\mathrm{T}} \mathrm{Z}_{0}+\phi\left[(1+\lambda)^{\mathrm{T}-1}+(1+\lambda)^{\mathrm{T}-2}+\ldots+(1+\lambda)+1\right] \\
& \mathrm{Z}_{\mathrm{T}}=(1+\lambda)^{\mathrm{T}} \mathrm{Z}_{0}+\phi\left\{\left[1-(1+\lambda)^{\mathrm{T}}\right] / 1-(1+\lambda)\right\} \\
& \mathrm{Z}_{\mathrm{T}}=(1+\lambda)^{\mathrm{T}} \mathrm{Z}_{0}-(\phi / \lambda)\left[1-(1+\lambda)^{\mathrm{T}}\right]
\end{aligned}
$$

Como: $(1+\lambda)=\exp [\mathrm{T} \log (1+\lambda)]$ e pela expansão de Taylor do $\log (1+\lambda)$ em torno do valor de $\lambda=0$ temos que o $\log (1+\lambda) \approx \lambda$, então: $\quad(1+\lambda)^{\mathrm{T}}=\mathrm{e}^{\lambda \mathrm{T}}$. Assim: $Z_{T}=e^{\lambda T} Z_{0}-(\phi / \lambda)\left(1-e^{\lambda T}\right)$, revertendo a notação acima, tem-se que: $\log \tilde{y}_{T}=e^{\lambda T} \log \tilde{y}_{0}+\left(1-e^{\lambda T}\right) \log \tilde{y}_{t}^{*}$ que é a equação (96)

\footnotetext{
${ }^{24}$ Esta passagem encontra-se em Valdéz (1999)
} 


\section{REFERÊNCIAS BIBLIOGRÁFICAS}

ASSOCIAÇÃO DOS FUMICULTORES DO BRASIL (AFUBRA). Maiores produtores mundiais de fumo. http://www.afubra.com.br (14 jun. 2004)

AZZONI, C.R. Crescimento econômico e crescimento das rendas regionais: o caso brasileiro à luz da Nova Teoria do Crescimento. In: ENCONTRO NACIONAL DE ECONOMIA, Florianópolis, 1994. Anais: ANPEC, v.1, p.185-205.

AZZONI, C.R. Economic growth and regional income inequality in Brazil. Annals of Regional Science, v.35, n.1, p.133-152, 2001.

BACHA, C.J.C. Economia e política agrícola no Brasil. Piracicaba: Editora Atlas, 2004. 238p.

BAIRAM, E.I.; McRAE, S.D. Testing the convergence hypothesis: a new approach. Economic Letters, v.64, n.3, p.351-355, 1999.

BALL, V.E.; BUREAU, J.C.; BUTAULT, J.P.; WITZKE, H.P. The stock de capital in European Comunity agriculture. European Review of Agricultural Economics, v.20, n.4, p.437-450, 1993.

BARRO, R.; SALA-i-MARTIN, X. Economic growth and convergence across the United States. Cambridge: National Bureau of Economic Research, 1990. 39p. (Texto para discussão, 3419) 
BARRO, R.J. Economic growth in a cross section of countries. Quarterly Journal, v.56, n.2, p.407-43, 1991.

BARRO, R.J. Macroeconomics. 4.ed. New York: Wiley, 1993. 599p.

BARRO, R.J.; SALA-i-MARTIN, X. Convergence across states and regions. Brookings Papers on Economic Activity, v.1, p.107-158, 1991.

BARRO, R.J.; SALA-i-MARTIN, X. Convergence. Journal of Political Economy, v.100, n.2, p.223-51, 1992.

BARRO, R.J.; SALA-i-MARTIN, X. Economic growth. New York: McGraw-Hill, 1995. 539p.

BARRO, R.J.; SALA-i-MARTIN, X. Technological diffusion, convergence and growth. Journal of Economic Growth, v.2, p.1-26, 1997.

BARROS, A.L.M. Capital, produtividade e crescimento da agricultura: o Brasil de 1970 a 1995. Piracicaba, 1999. 149p. Tese (Doutorado) - Escola Superior de Agricultura "Luiz de Queiroz", Universidade de São Paulo.

BARROS, P.P.; GAROUPA, N. Portugal-European union convergence: some evidence. European Journal of Political Economy, v.12, n.1, p.545-553, 1995.

BAUMOL, W.J. Productivity growth, convergence, and welfare: what the long-run data show. American Economic Review, v.76, n.5, p.1072-85, 1986.

BAUMOL, W.J.; WOLFF, E.N. Productivity growth, convergence, and welfare: reply. American Economic Review, v.78, n.5, p.1155-59, 1988. 
BEN-DAVID, D. Equalizing exchange, trade liberalization and income convergence, Quarterly Journal of Economics, v.108, n.3, p.653-679,1993.

BERNARD, A.B.; JONES, C.J. Comparing apples to oranges: productivity convergence theory and evidence and mesasurement across industries and countries. American Economic Review, v.86, n.5, p.1216-1238, 1996 b.

BERNARD, A.B.; JONES, C.J. Productivity across industries and countries: time series theory and evidence. Review of Economics and Statistics, v.78, n.1, p.135-146, Feb.1996a.

BONELLI, R.; PESSOA, E.P. O papel do estado na pesquisa agrícola no Brasil. São Paulo: IPEA, jul. 1998. p.1-40. (Texto para discussão, 576)

BRASIL. Ministério da Agricultura e Reforma Agrária. Secretaria Nacional de Irrigação. Departamento Nacional de Metereologia. Normais climatológicas. Brasília, 1992. 84p.

CANÇADO, R.P. Migrações e convergência no Brasil: 1960-91. Revista Brasileira de Economia, v.53, n.2, p.211-236, abr./jun. 1999.

CASS, D. Optimum growth in an aggregative model of capital accumulation. Review of Economic Studies, v.32, n.3, p.233-240, July 1965.

CLEMENTE, A.; HIGACHI, H.Y. Economia e desenvolvimento regional. São Paulo: Editora Atlas, 2000. 260p.

COBB, C.W.; DOUGLAS P.H. A theory of production. American Economic Review, v.18, n.1, p.139-165, 1928. 
COMPANHIA NACIONAL DE ABASTECIMENTO (CONAB). Indicadores agropecuários. http://www.conab.gov.br (08 set. 2004)

CUNHA, A.S.; DAGUER, R.J. Crescimento agrícola: área versus produtividade. In: CONGRESSO BRASILEIRO DE ECONOMIA E SOCIOLOGIA RURAL, Curitiba, 1982. Anais. Curitiba: Sober, 1982. v.2, p.329-381.

DE LONG, B.J. Productivity growth, convergence, and welfare: comment. American Economic Review, v.78, n.5, p.1138-54, dez. 1988.

DIAS, G.L.S.; AMARAL, C.M. Mudanças estruturais na agricultura brasileira: 1980-1998. Santiago do Chile: Cepal, 2001. p.1-33. (Série Desarrollo Productivo, 99)

DIXON, R. Hybrid corn revisited. Econometrica, v.48, n.6, p.1451-1461, Sep. 1980.

DRENNAN, M.P.; LOBO, J.A. Simple teste for convergence of metropolitan income in the United States. Journal of Urban Economics, v.46, n.3, p.350-359, 1999.

ELLERY JUNIOR, R.G.; FERREIRA, P.C.G. Crescimento econômico e convergência entre a renda dos estados brasileiros. In: ENCONTRO BRASILEIRO DE ECONOMETRIA, Florianópolis, 1994. Anais. Florianópolis: SBE, 1994. p.264286.

EMPRESA BRASILEIRA DE PESQUISA AGROPECUÁRIA (EMBRAPA). Embrapa soja. http://www.cnpso.embrapa.br (12 maio 2004)

FAO. Agricultura. http://www.fao.org. (04 Sep. 2004)

FERREIRA, P.C.G.; ELLERY JUNIOR, R.G. Convergência entre a renda per capita dos estados brasileiros. Revista de Econometria, v.16, n.1, p.83-103, abr. 1996. 
FNP CONSULTORIA E COMÉRCIO. Agrianual: anuário da agricultura brasileira. São Paulo, 2002. p.112-536.

FREITAS, C.A.; BACHA, C.J.C.; FOSSATTI, D.M. Análise do crescimento desigual do setor agropecuário brasileiro em termos de produtos e estados, períodos de 1970 a 2000 (compact disc). In: CONGRESSO DA SOCIEDADE BRASILEIRA DE ECONOMIA E SOCIOlOGIA RURAL, 42., Passo Fundo, 2004. Anais. Passo Fundo: Sober, 2004. p.1-20

FUENTE, A. de la. The empirics of growth and convergence: a seletive review. Journal of Economic Dynamics and Control, v.21, n.1, p.23-73, 1997.

FUNDAÇÃO INSTITUTO BRASILEIRO DE GEOGRAFIA E ESTATÍSTICA. Anuário estatístico do Brasil. Rio de Janeiro: IBGE, 1973-1989.

GALOR, O. Convergence ? Inferences from theoritical models. Economic Journal, v.106, n.437, p.1056-1069, July 1996.

GASQUES, J.G.; BASTOS, E.T. Crescimento da agricultura. Boletim de Conjuntura IPEA, n.60, p.85-93, mar. 2003.

GASQUES, J.G.; CONCEIÇÃO, J.C.P.R. Produtividade total dos fatores na agricultura. Preços Agrícolas, v. 14, n.165, p.3-7, jul. 2000.

GASQUES, J.G.; CONCEIÇÃO, J.C.P.R. Transformações estruturais da agricultura e produtividade total dos fatores. São Paulo: IPEA, 2000, p.1-60. (Texto para discussão, 768)

GEZICI, F.; HEWINGS, G. Regional convergence and the performance of peripherial areas in Turkey. Urbana, 2001. p.1-32. http://www.uiuc.edu/unit/real (25 Mar. 2003) 
GOLDIN, I.; REZENDE, G.C. A agricultura brasileira na década de 80: crescimento numa economia em crise. Rio de Janeiro: IPEA, 1993. 199p.

GONZALES, B.C.R.; COSTA, S.M.A. Agricultura brasileira: modernização e desempenho. Teoria e Evidência Econômica, v.5, n.10, p.7-35, maio 1998.

GORDON, R.J. Macroeconomia. 7.ed. Porto Alegre: Bookman, 2000. 422p.

GRILICHES, Z. Education, human capital, and growth: a personal perpective. Journal of Labor Economics, v.15, n.1, p.330-344, 1997.

GRILICHES, Z. Hybrid corn and the economics of innovation. Science, v.132, n.3, p.275-280, July 1960.

GRILICHES, Z. Hybrid corn: an exploration in the economics of technological change. Econometrica, v.25, n.4, p.501-522, Oct. 1957.

GRILICHES, Z. Technology, education and productivity. An Internacional Center for Economic Growth Publication, n.18, p.1-45, 1994.

GUIMARÃES NETO, L. Desigualdades e políticas regionais no Brasil: caminhos e descaminhos. Planejamento e Políticas Públicas, n.15, p.41-93, jun.1997.

GUISE, J.W.B. Factors associated with variation in the aggregate average yield of New Zeland wheat (1918-1967). American Journal of Agricultural Economics, v.4, n.51, p866-881, Nov.1969.

GUTIERREZ, L. Convergence in US and EU agriculture. European Review and Agricultural Economics, v.27, n.2, p.187-206, 2000 
HARROD, R.F. An essay in dynamic theory. Economic Journal, v.49, n.193, p.14-33, 1939. http://www.mre.gov.br/cdbrasil/itamaraty/web/port/ economia/agric/producao/feijao/apresent.htm (02 set. 2004)

INSTITUTO BRASILEIRO DE GEOGRAFIA E ESTATÍSTICA (IBGE). Sidra. http://www.ibge.sidra.com (22 jul. 2003)

JONES, C.I. Introdução à teoria do crescimento econômico. Rio de Janeiro: Campus, 2000. 178p.

JONES, H.G. Modernas teorias do crescimento econômico. São Paulo: Editora Atlas, 1979. 265p.

JONES, L.E.; MANUELLI, R.E. Endogenous growth theory: an introduction. Journal of Dynamics and Control, v.21, n.1, p.1-22, 1997.

KALDOR, N. A model of economic growth. The Economic Journal, v.67, n.268, p.591-624, Dec. 1957.

KING, R.; REBELLO, S. Transitional dymanics and economic growth in the neoclassical model. American Ecomonic Review, v.83, n.4, p.908-931. 1993.

LEVINE, R.; RENELT, D.A. Sensitivity analysis of cros-country regressions. American Economic Review, v.82, n.4, p.942-963, 1992.

LUCAS, R. On the mechanics of economic development. Journal of Monetary Economic, v.22, n.1, p.3-42, 1988. 
LUSIGI, A.; THIRTLE, C. Convergence of per capita incomes and agricultural productivity in thirty-two africam countries. Journal of International Development, v.10, n.1, p.105-15, Jan. 1998. http://www.bbk.ac.Uk/ manop/man/ docs/piesse99-04.pdf (31 Mar. 2003)

MAHL, D.; OPAZO, M.A.; SÁ, J.C.M.; SANTOS, S.R. Análise de experimentos de adubação através de aproximações de Mitscherlich. In: CONGRESSO BRASILEIRO DE ENGENHARIA AGRÍCOLA, 29., Fortaleza, 2000. Anais. Fortaleza: CONBEA, 2000. p.1-3.

MANKIW, N.G.; ROMER, D.; WEIL, D.N.A. Contribution to the empirics of economic growth. Quarterly Journal of Economics, v.107, n.2, p.407-35, 1992.

MARTINS, N.M. de A. A Lei "Robin Hood" como instrumento para redução das heterogeneidades das regiões mineiras: análise de seus objetivos e resultados através de um exercício de convergência. Nova Economia, p.55-119. 1999. Número especial.

McCUNN, A.; HUFFMAN, E.E. Convergence in US productivity growth for agriculture: implications of interstate research spillovers for funding agricultural research. American Journal Agricultural Economics, v.82, n.2, p.370-388, May 2000.

MELO, F.B.H. Produtividade da terra: os casos do milho e algodão no estado de São Paulo. In: BARROS, J.R.M. de; GRAHM, D.H. (Ed.). Estudos sobre a modernização da agricultura brasileira. São Paulo: IPEA, 1977. p.57-106. (Série Monografias)

MICHELIS, L.; PAPADOPOULOS, A.P.; PAPANIKOS, G.T. Regional convergence in Greece in the 1980's: an econometric investigation. www.soc.uoc.gr/appapa/research/greececonv1.pdf(15 Feb. 2003) 
MICHELLON, E. Cadeia produtiva e desenvolvimento regional: uma análise a partir do setor têxtil do algodão no noroeste do Paraná. Maringá: Clichetec, 1999. 167p.

MUNDLAK, Y.; LARSON, D.; BUTZER, R. The determinants of agricultural production: $\quad$ a $\quad$ cross-country analysis. http://www.worldbank.org/html/dec/Publications/Workpapers/WPS1800series/wps1 827/wps1827.pdf (15 Feb. 2003)

ORTIGUEIRA, S.; SANTOS, M.S. On the speed of convergence in endogenous growth models. American Economic Review, v.87, n.3, p.383-399, Jun. 1997.

PERSSON, J. Convergence across the Swedish countrie, 1911-1993. European Economic Review, v.41, n.9. p.1835-1852, Dec. 1997.

PESSÔA, A.S.M. Feijão. http://www.mre.gov.br/cdbrasil/itamaraty/web/port/ economia/agric/producao/feijao/apresent.htm (02 set. 2004)

QUAH, D,T.; DURLAUF, S.N. The new empirics of economic growth. http://econ.lse.ac.uk/ dquah/dp0384.html (25 Mar. 2003)

QUAH, D.T. Empirics for economic growth and convergence, European Economic Review, v.40, n.6, 1353-1375.

QUAH, D.T. Enpirical cross-section dynamics in economic growth. European Economic Review, v.1, n.37, p.426-434, Apr. 1993.

QUAH, D.T. Galton's fallacy and tests of the convergence hypotesis. http://econ.lse.ac.uk/staff/dquah/p/dp-93galfall.pdf (01 Apr. 2003)

REBELO, S. Long run analysis and long growth. Journal of Political Economic, v.9, n.3, p.500-521, 1991. 
REZENDE, G.C. Agricultura e ajuste externo no Brasil: novas considerações. Pesquisa e Planejamento Econômico, v.19, n.3, p.553-578, dez. 1989.

RIBEIRO, E.P.; PORTO JUNIOR, S.da S. Crescimento e convergência: uma análise empírica para a região Sul. http://www8.ufrgs.br/ppge/anpecsul2000/ textospdf/artigo51.pdf. (20 Abr. 2003)

ROMER, P.M. Endogenous tecnological change. Journal of Political Economy, v.98, n.5, p.S71-S102, 1990.

ROMER, P.M. Growth based on increasing returns due to specialization, American Economic Review, v.77, n.2, p.56-62, May 1987.

ROMER, P.M. Increasing returns and long run growth. Journal of Political Economy, v.94, n.5, p.1002-1037, 1986.

SALA-i-MARTIN, X. Lectures notes on economic growth (I): introduction to the literature and neoclassical models. Cambridge: National Bureau of Economic Research, 1990a. (Texto para discussão, 3563)

SALA-i-MARTIN, X. Lectures notes on economic growth (II): give prototype models of endogenous growth. Cambridge: National Bureau of Economic Research, 1990b. (Texto para discussão, 3564)

SALA-i-MARTIN, X. Regional cohesion: evidence and theories of regional growth and convergence. European Economic Review, v.40, n.6, p.1325-1352, 1996.

SALA-i-MARTIN, X. The classical approach to convergence analysis. Economic Journal, v.106, n. 437, p.1019-1036, July 1996. 
SILVA, G.L.S.P. Evolução e determinantes da produtividade agrícola: o caso da pesquisa e da extensão rural em São Paulo. Piracicaba, 1982. 229p. Tese (Doutorado) - Escola Superior de Agricultura "Luiz de Queiroz", Universidade de São Paulo.

SOLOW, R.M. Technical change and the aggregate production function. Review of Economic and Statistics, v.39, n.1, p. 312-320, 1957.

SOLOW, R.M. A contribution to the theory of economic growth. Quarterly Journal of Economics, v.70, p.65-94, 1957.

SOLOW, R.M. Perpectives on growth theory. Journal of Economic Perpectives, v.8, n.3, p.45-54, 1994.

SOUZA, N. de J.; PORTO JUNIOR, S. da S. Crescimento regional e novos testes de convergência para os municípios da região nordeste do Brasil. http://www8.ufrgs.br/decon/hp/virtuais/sabino/pasta/artigos/ crescimento.pdf (18 abr. 2003)

STERN, N. The determinants of growth. Economic Journal, v.101, n.404, p.122-133, 1991.

SUMMERS, R.; HESTON, A. The penn world table (Mark 5): an expanded set of international comparisons, 1950-1988. Quarterly Journal of Economics, v.106, n.2, p.327-368, 1991.

SURARIYANTO, K.; THIRTLE, C. Asian agricultural productivity and convergence. Journal of Agricultural Economics, v.52, n.3, p.96-110, Sep. 2001.

ESTADOS UNIDOS. Department of Agriculture (USDA). Data. http://www.ers.usda.gov/data/sdp. (02 Sep. 2004) 
VALDÉZ, B.D. Economic growth: theory, empirics and policy. Corwall: MPG Books Ltd, 1999, 197p. 
APÊNDICES 
APÊNDICE 1 - Produtividade agrícola: cultura do algodão herbáceo (toneladas/ha)

\begin{tabular}{|c|c|c|c|c|c|c|c|c|c|c|c|c|c|c|c|c|c|c|c|}
\hline & 1960 & 1961 & 1962 & 1963 & 1964 & 1965 & 1966 & 1967 & 1968 & 1969 & 1970 & 1973 & 1974 & 1975 & 197 & 1977 & 1978 & 1979 & \\
\hline $\mathrm{O}$ & 000 & 0000 & 0000 & 0000 & 0000 & 0000 & 0000 &, 0000 & 0000 & 0000 &, 0000 & 2000 & 2000 & 1900 & 2000 & 0000 & 0000 & 1,2701 & 1,2431 \\
\hline $\bar{C}$ & $\overline{000}$ & 0000 & 0000 & 000 & 0000 & 0000 & 0000 & 0000 & 0000 & 0000 & 0000 & 0,0000 & 0000 & 0000 & D,000 & 0000 & 0000 & 000 & 00 \\
\hline M & 000 & 000 & 0000 & 0000 & 0000 & 0000 & 0000 & 0000 & 0,0000 & 0000 & 0000 & 0,0000 & 0000 & 0000 & 0,000 & 0000 & 0000 & 0000 & $\overline{000}$ \\
\hline $\mathrm{R}$ & 000 & 0000 & 0000 & 0000 & 0000 & 0000 & 0000 & 0000 & 0,0000 & 0000 & 0000 & 0,0000 & 0,0000 & 0000 & 0,000 & 0000 &, 000 & $\overline{000}$ & $\overline{000}$ \\
\hline A & 2054 & 2044 & 2179 & 2254 & 2132 & 2572 & 2029 & 3142 & 0,1829 & 2457 & 2263 & 0,3889 & ,1607 & ,5814 & 0,587 & ,6096 & ,5621 & 345 & 5347 \\
\hline$\overline{\mathrm{P}}$ & 000 & 0000 & 0000 & 0000 & 0000 & 0000 & 0000 & 0000 & $\overline{0000}$ & 0000 & 0000 &, 0000 & 00 & 0000 & 000 & 00 & & 000 & 00 \\
\hline $\mathrm{A}$ & $\overline{709}$ & 7740 & 3767 & 995 & (7796 & 3726 & 2288 & 2282 & 2313 & 23. & 2266 & 0,1778 & ,2946 & ,2204 & , 248 & & , 23, & 0,2446 & 0,6667 \\
\hline & & $\overline{72}$ & 416 & 002 & 4790 & 3955 & 2232 & ,3451 & 3446 & 3004 & 0905 & 0,3250 &, 3660 & 504 & 0,3632 & 28 & 26. & 0,4451 & 4396 \\
\hline $\mathrm{CE}$ & 069 & 4175 & 3815 & 3944 & 3072 & 3096 & 2511 & 2926 & 0,3060 & 2778 & 1466 & 0,4819 & 0,0900 & 3500 & 0,2250 & 0,2700 & 3300 & 0,2100 & 950 \\
\hline RN & 087 & 2921 & 2489 & 911 & 2219 & ,2453 & 2029 & 2460 & 0,2225 & 2032 & 32 & 0,3000 & 2542 & 2649 & 0,2923 & | & 3314 & |1981, & 540 \\
\hline $\mathrm{PB}$ & 04 & 416 & 334 & 789 & 2846 & $8 \mid$ & 2589 & 21 & 6 & 59 & 46 &, 5025 & 52 & 277 & 2647 & 0,3090 & 4050 & 9,4972 & 876 \\
\hline PE & 918 & 2885 & 236 & 477 & 2220 & 2879 & & 41 & 2893 & 4 & 23 & 1 & 00 & 00 & 2670 & 20 & 2963 & 2583 & 113 \\
\hline$\overline{\mathrm{AL}}$ & 012 & 3152 & 2988 & 587 & 2370 & $\overline{79}$ & 81 & 3079 & 2923 & 67 & 81 & 1 & 360 & 085 & 2700 & 10 & 2821 & 20 & 0,188 \\
\hline $\mathrm{E}$ & 431 & 992 & 0,3385 & 2834 & 3221 & $\overline{06}$ & 2937 & 74 & 0,2912 & 327 & 2157 & 0,2560 & 2571 & 2695 & 2850 & 3000 & 256 & 1030 &, 160 \\
\hline$\overline{\mathrm{BA}}$ & 715 & 4689 & 4158 & 4435 & 4444 & $\overline{735}$ & 4 & 5464 & 0,6103 & 6506 & 6657 & 4708 & 5415 & 5420 & 3600 &, 4500 & 5560 & 4900 &, 880 \\
\hline$\overline{\mathrm{MG}}$ & 24 & 236 & 5468 & 79 & 3906 & 4745 & 3327 & 52 & 2 & 5494 & 6004 & 6681 & 6200 & 7806 & 4579 & ,7902 & 0,6965 & 6928 & ,038 \\
\hline ES & 077 & 6133 & 6441 & 5361 & 7206 & 7238 & 6454 & 8712 & 9458 & 5469 & 5493 & 4049 & 5547 & 6016 & 6285 & 0000 & 0000 & 0000 &, 000 \\
\hline RJ & $\overline{424}$ & 3530 & 3412 & 3414 & 3490 & 3264 & 252 & 4258 & 3848 & 4503 & 4497 & 8717 & 7536 & 7570 & 7546 & ,6706 &, 7045 & ,7075 & 7155 \\
\hline $\mathrm{SP}$ & 036 & 043 & 234 & 1,0933 & 9249 & 351 & 393 & 9982 & 1481 & 1740 & 1233 & 1,2254 & 3100 & 3277 & 4886 & 8127 & 1204 & 7888 &, 7875 \\
\hline PR & 0196 & 1,2886 & 1,2831 & 1,0965 & 9058 & \begin{tabular}{l|}
1,0052 \\
\end{tabular} & 1655 & 1,0972 & 1,5796 & 2446 & 1,1751 & 1,4887 & 1,5500 & 1,4146 & 1,5480 & 1,4344 & 1,0672 & ,6345 & 1,6712 \\
\hline$\overline{S C}$ & 2500 & 0,2381 & 2381 & 0,2703 & 2727 & 3182 & 2857 & 3571 & 0,4167 & 0000 & 0,0000 & 0,0000 & 0,0000 & 0,0000 & 0,0000 & 0,0000 & 0,0000 & 0000 & $\overline{0000}$ \\
\hline $\mathrm{RS}$ & 899 & 0,0000 & 0000 & 0,0000 & 0000 & 0000 & 0,0000 & 0,0000 & 0,0000 & 0000 &, 0000 & 0,0000 & 0,0000 & 0,0000 & 0,0000 & 0,0000 & 0,0000 & 0000 & 0000 \\
\hline MT & 000 & 4307 & 0,9020 & 0,8909 & 9358 & 1,0546 & 0,8555 & 0,7214 & 0,7094 & 9102 & 0,9133 & 1,0062 & 1,0060 & 1,0216 & 1,1904 & 1,3090 & 0,9530 & ,4988 & 5126 \\
\hline G0 & 414 & 631 & 5486 & 6239 & 6025 & 6241 & 68. & 0,7460 & 0,8707 & 1409 & 1,2255 & 0510 & 2600 & 1,6000 & 1,8000 & 1700 & 8200 & 5400 & $\overline{0019}$ \\
\hline & 000 & 000 & 00 & 000 & 0000 & 0000 & 0000 & 0000 & 0000 & 0000 & 0000 & 0000 & 00 & 0000 & 00 & 00 & 0000 & 00 & \\
\hline
\end{tabular}




\section{APÊNDICE 1 - Produtividade agrícola: cultura do algodão herbáceo (toneladas/ha)}

\begin{tabular}{|c|c|c|c|c|c|c|c|c|c|c|c|c|c|c|c|c|c|c|c|c|c|}
\hline & 1981 & 1982 & 1983 & 1984 & 1985 & 1986 & 1987 & 1988 & 1989 & 1990 & 1991 & 1992 & 1993 & 1994 & 1995 & 1996 & 1997 & 1998 & 1999 & 2000 & 2001 \\
\hline RO & 1,3982 & 1,3982 & 1,3986 & 1,1397 & 1,1485 & \begin{tabular}{|l|}
1,0417 \\
\end{tabular} & 2,0485 & \begin{tabular}{|l|}
1,3765 \\
\end{tabular} & \begin{tabular}{|l|}
1,3953 \\
\end{tabular} & \begin{tabular}{|l|}
1,0424 \\
\end{tabular} & 1,2327 & \begin{tabular}{|l|}
1,5329 \\
\end{tabular} & 1,5466 & \begin{tabular}{|l|}
1,5153 \\
\end{tabular} & 1,4174 & \begin{tabular}{|l|}
1,1052 \\
\end{tabular} & 1,1145 & \begin{tabular}{|l|}
1,1781 \\
\end{tabular} & $\begin{array}{l}1,1573 \\
\end{array}$ & 0,8999 & 1,1230 \\
\hline $\mathrm{AC}$ & $\overline{0000}$ & 0,0000 & 0,0000 & \begin{tabular}{|l|}
0,0000 \\
\end{tabular} & \begin{tabular}{|c|}
0,0000 \\
\end{tabular} & \begin{tabular}{|l|}
0,00000 \\
\end{tabular} & 0,0000 & \begin{tabular}{|l|}
0,0000 \\
\end{tabular} & 0,0000 & 0,0000 & 0,0000 & \begin{tabular}{|l|}
0,0000 \\
\end{tabular} & 0,2000 & 6667 & 0,5625 & ,5600 & 0,5800 & \begin{tabular}{|l|}
0,5600 \\
\end{tabular} & 0,5600 & ,5500 &, 6023 \\
\hline AM & 0000 & 0,0000 & 0000 & 0,0000 & 0000 & \begin{tabular}{|l|l|}
0,0000 \\
\end{tabular} & 0000 & \begin{tabular}{|l|l|}
0,0000 \\
\end{tabular} & 0,0000 & 0,0000 & 0000 & 0000 & $\overline{0000}$ & 0000 & 0,0000 & 0400 & 2000 & 1154 & 0000 & 0000 & 70 \\
\hline RR & $\overline{0000}$ & 0,0000 & 0000 & 0,0000 & 0000 & 0,0000 & 0000 & \begin{tabular}{|l|l}
0,0000 \\
\end{tabular} & 0000 & \begin{tabular}{|l|l}
0,0000 \\
\end{tabular} & 0,0000 & 0,0000 & 0,0000 & 0000 & 0,0000 &, 0000 & 0,0000 &, 0000 & 0,0000 &, 0000 &, 0000 \\
\hline PA & 316 & 0,6008 & 0,4880 & 0,4371 & 3769 & 0,4534 & 5202 & \begin{tabular}{|l|}
0,5773 \\
\end{tabular} & 5627 & \begin{tabular}{|l|}
0,5506 \\
\end{tabular} & 0,5874 & 5644 & 0,5226 & ,4147 & 0,7057 & 8081 & 0,6680 &, 4174 & 0,5677 & 0,8000 & 0,0000 \\
\hline $\mathrm{P}$ & $\overline{000}$ & 0,0000 & 000 & 0,0000 & 0000 & 0,0000 & 0000 & \begin{tabular}{|l|}
0,0000 \\
\end{tabular} & 0000 & 0,0000 & 0,0000 & \begin{tabular}{|l|l|}
0,0000 \\
\end{tabular} & 0,0000 & 0,0000 & 0,0000 & 0,0000 & 0,0000 & 0,0000 & 0,0000 & 0,0000 & 0,0000 \\
\hline $\mathrm{MA}$ & 248 & 0,2471 & 179 & 0,4672 & 025 & 5755 & 873 & 8822 & 5367 & 500 & 367 & 1986 & 3533 & 5000 & 0000 & 154 & 1,6500 & ,6429 & \begin{tabular}{|l|}
0,9719 \\
\end{tabular} & 1,5000 &, 22 \\
\hline PI & 567 & 0,2112 & 679 & 0,5126 & 6628 & 5518 & 3513 & 4319 & 2493 & 2385 & 5430 & 1925 & ,0635 & 7329 &, 585 & ,3849 & 0,4096 & 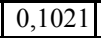 & 0,8695 &, 3608 & 0,3457 \\
\hline $\mathrm{EE}$ & 250 & 0,4652 & 341 & ,6722 & 743 & 1954 & 1871 & \begin{tabular}{|l|}
0,5266 \\
\end{tabular} & 2449 & 1035 & 4599 & \begin{tabular}{|l|l|}
0,3032 \\
\end{tabular} & 0555 & 0,4875 & 0,4557 & \begin{tabular}{|l|}
0,8302 \\
\end{tabular} & 0,8285 & 0,2682 & 0,6605 & 0,6940 & $0,49 \mathrm{C}^{\circ}$ \\
\hline $\mathrm{N}$ & 553 & 0,2050 & 883 & 4871 & 295 & 0,0990 & 3025 & 4163 & 2579 & 2154 & 6664 & 2816 & 949 & 7773 & 032 & 2763 & 2645 & 1023 & \begin{tabular}{|l|}
0,1961 \\
\end{tabular} &, 5301 & ,227 \\
\hline PB & 258 & 0,1610 & 0952 & 6466 & 2705 & 1177 & 1811 & 5508 & 4868 & 3215 & 6440 & 4349 & 2826 & 8510 & 0,6966 & 6548 & 0,8704 & 2096 & \begin{tabular}{|l|l}
0,4252 \\
\end{tabular} &, 7163 & 31 \\
\hline $\mathrm{PE}$ & $\overline{904}$ & 0,2421 & 1612 & 0,5860 & ,5684 & 0,3106 & 1607 & \begin{tabular}{|l|}
0,4323 \\
\end{tabular} & 4038 & \begin{tabular}{|l|}
0,2129 \\
\end{tabular} & 3090 & 3248 & 1519 & 5215 & 0,3815 & ,5405 & 0,4432 & ,1439| & 0,2360 & 0,5389 & 0,136 \\
\hline $\mathrm{AL}$ & 904 & 0,2515 & 1781 & 3030 & 2931 & \begin{tabular}{|l|}
0,2433 \\
\end{tabular} & 1436 & 0,0836 & 2396 & 1138 & 384 & 0780 & 0129 & 1309 & 310 & 2365 &, 1953 & 2495 & 0,1935 & 408 & 432 \\
\hline SE & 291 & 0,1640 & 2399 & 0,4927 & 4235 & \begin{tabular}{|l|}
0,2696 \\
\end{tabular} & 1737 & 0,1400 & 2930 & \begin{tabular}{|l|}
0,2217 \\
\end{tabular} & 1475 & 1355 & 65 & 2454 & 1274 & 4747 & 0,1525 & 0248 & \begin{tabular}{|l|}
0,1684 \\
\end{tabular} & 0000 & 000 \\
\hline BA & 8725 & 0,7160 &,, 7306 & 0,6249 & \begin{tabular}{|l|}
1,2480 \\
\end{tabular} & \begin{tabular}{|l|}
1,0910 \\
\end{tabular} & 0,5203 & \begin{tabular}{|l|}
0,9813 \\
\end{tabular} & 4344 & 0,5816 & ,7807 & \begin{tabular}{|l|}
0,5642 \\
\end{tabular} &, 8102 & 0,9399 & 0,4837 & ,3874 & 0,4593 & 0,3689 & \begin{tabular}{|l|}
1,1746 \\
\end{tabular} & 2,3712 & 2,9012 \\
\hline $\mathrm{MG}$ & 8533 & 0,8403 & 1,3296 & \begin{tabular}{|l|}
0,7705 \\
\end{tabular} & \begin{tabular}{|l|}
1,3669 \\
\end{tabular} & \begin{tabular}{|l|}
1,0488 \\
\end{tabular} & \begin{tabular}{|l|}
0,4562 \\
\end{tabular} & \begin{tabular}{|l|l|}
0,8318 \\
\end{tabular} & 6154 & \begin{tabular}{|l|}
0,7261 \\
\end{tabular} & ,9036 & 0,7045 & 0,7965 & 9380 & 0,8092 & 3345 & 1,6345 & , 4815 & 1,5755 & 2,0229 & 1,6926 \\
\hline ES & 0000 & 0,0000 &, 0000 & \begin{tabular}{|l|}
0,0000 \\
\end{tabular} & 0,0000 & \begin{tabular}{|l|l|}
0,0000 \\
\end{tabular} & 0,0000 & 0,0000 & 0,0000 & 0,0000 &, 0000 & 0,0000 & 0,0000 & 0,0000 & 0,0000 & 0,0000 & 0,0000 &, 0000 & 0,0000 &, 0000 & 0,0000 \\
\hline RJ & 8000 & 0,0000 &, 0000 & \begin{tabular}{|l|l|}
0,0000 \\
\end{tabular} & 0,0000 & \begin{tabular}{|l|l}
0,0000 \\
\end{tabular} & 0,0000 & \begin{tabular}{|l|l}
0,0000 \\
\end{tabular} & 0,0000 & \begin{tabular}{|l|}
0,0000 \\
\end{tabular} & 0,0000 & 0,0000 & 0,0000 & \begin{tabular}{|l|l|}
0,000 \\
\end{tabular} & 0,0000 & \begin{tabular}{|l|l|}
0,0000 \\
\end{tabular} & 0,0000 & 0,0000 & 0,0000 & 0,0000 & 0,0000 \\
\hline SP & 8234 & 1,6642 & 1,5038 & 2,0807 & 1,8363 & \begin{tabular}{|l|}
1,9699 \\
\end{tabular} & 7434 & \begin{tabular}{|l|}
2,0230 \\
\end{tabular} & 1,8894 & \begin{tabular}{|l|}
1,5960 \\
\end{tabular} & 1,8009 & 1,7288 & 1,5778 & 1,7062 & 1,7334 & 1,5000 & 1,9800 & 1,5700 & 2,1450 & 2,2538 & 2,4585 \\
\hline PR & 1,9000 & 2,0001 & 1,5809 & 1,8995 & 1,9179 & 1,8516 & 1,8442 & 1,9215 & 1,9400 & \begin{tabular}{|l|}
1,7399 \\
\end{tabular} & 1,6571 & 1,3808 & 1,2988 & \begin{tabular}{|l|}
1,7980 \\
\end{tabular} & 1,8743 & 1,5780 & 1,9215 & \begin{tabular}{|l|}
1,5073 \\
\end{tabular} & 2,2663 & 2,3184 & 2,4543 \\
\hline SC & 0,0000 & 0,0000 & 0,0000 & 0,0000 & 0,0000 & \begin{tabular}{|l|l|}
0,0000 \\
\end{tabular} & 0,0000 & \begin{tabular}{|l|l}
0,0000 \\
\end{tabular} & 0,0000 & \begin{tabular}{|l|}
0,0000 \\
\end{tabular} & \begin{tabular}{|l|l|}
0,0000 \\
\end{tabular} & \begin{tabular}{|l|l|}
0,0000 \\
\end{tabular} & 0,0000 & \begin{tabular}{|l|}
0,0000 \\
\end{tabular} & 0,0000 & \begin{tabular}{|l|}
0,0000 \\
\end{tabular} & 0,0000 & \begin{tabular}{|l|}
0,0000 \\
\end{tabular} & 0,0000 & 0,0000 & 0,0000 \\
\hline RS & 0,0000 & 0,0000 & 0,0000 & \begin{tabular}{|l|l|}
0,0000 \\
\end{tabular} & 0,0000 & \begin{tabular}{|l|l|}
0,0000 \\
\end{tabular} & 0,0000 & 0,0000 & 0,0000 & 0,0000 & 0,0000 & 0,0000 & 0,0000 & $\mid 0,0000$ & 0,0000 & 0,0000 & 0,0000 & $\mid 0,0000$ & 0,0000 & $\mid 0,0000$ & 0,0000 \\
\hline \begin{tabular}{|l|}
$\mathrm{MT}+\mathrm{M}$ \\
$\mathrm{S}$ \\
\end{tabular} & 1,5520 & 1,4132 & 1,3659 & \begin{tabular}{|l|}
1,5962 \\
\end{tabular} & 1,5336 & \begin{tabular}{|l|}
1,2363 \\
\end{tabular} & 1,3248 & 1,3655 & 1,5318 & \begin{tabular}{|l|}
1,4872 \\
\end{tabular} & 1,3513 & \begin{tabular}{|l|l|}
1,1836 \\
\end{tabular} & 1,3676 & \begin{tabular}{|l|}
1,5760 \\
\end{tabular} & 1,4429 & \begin{tabular}{|l|l|}
1,4003 \\
\end{tabular} & 1,9438 & \begin{tabular}{|l|}
2,3376 \\
\end{tabular} & 3,0190 & 3,6849 & 6623 \\
\hline $\mathrm{GO}+\mathrm{TO}$ & 1,8646 & 1,6836 & \begin{tabular}{|l|l|}
2,1329 \\
\end{tabular} & \begin{tabular}{|l|}
1,9833 \\
\end{tabular} & 1,8113 & \begin{tabular}{|l|}
2,4791 \\
\end{tabular} & 2,2896 & \begin{tabular}{|l|}
1,8448 \\
\end{tabular} & 2,2924 & \begin{tabular}{|l|}
1,6732 \\
\end{tabular} & 1,9353 & 1,5475 & 2,4772 & \begin{tabular}{|l|}
1,8727 \\
\end{tabular} & 2,2562 & 1262 & 2,2708 & \begin{tabular}{|l|}
1,3907 \\
\end{tabular} & 2,3481 & 2,6311 & 3,0584 \\
\hline DF & 0,0000 & 0,0000 & \begin{tabular}{|l|l}
0,0000 \\
\end{tabular} & \begin{tabular}{|l|l|}
0,0000 \\
\end{tabular} & \begin{tabular}{|l|l}
0,0000 \\
\end{tabular} & \begin{tabular}{|l|l|}
0,0000 \\
\end{tabular} & \begin{tabular}{|l|l}
0,0000 \\
\end{tabular} & 0,0000 & 0,0000 & \begin{tabular}{|l|}
0,0000 \\
\end{tabular} & \begin{tabular}{|l|l|}
0,0000 \\
\end{tabular} & 0,0000 & 0,0000 & \begin{tabular}{|l|l|}
0,0000 \\
\end{tabular} & 0,0000 & 0,0000 & 0,0000 & 0,0000 & 0,0000 & 3,5213 & 2,94 \\
\hline
\end{tabular}

Fonte: IBGE 


\section{APÊNDICE 2 - Produtividade agrícola: cultura do arroz (toneladas/ha)}

\begin{tabular}{|c|c|c|c|c|c|c|c|c|c|c|c|c|c|c|c|c|c|c|c|}
\hline & \begin{tabular}{|l|}
1960 \\
\end{tabular} & 1961 & 1962 & $\begin{array}{ll}1963 \\
\end{array}$ & 1964 & \begin{tabular}{l|l|}
1965 \\
\end{tabular} & 1966 & 1967 & $\begin{array}{l}1968 \\
\end{array}$ & 1969 & \begin{tabular}{|l|l|}
1970 \\
\end{tabular} & \begin{tabular}{|l|l|}
1973 \\
\end{tabular} & 1974 & 1975 & $\begin{array}{l}1976 \\
\end{array}$ & 1977 & 1978 & \begin{tabular}{|l|}
1979 \\
\end{tabular} & 19 \\
\hline RO & 706 & 248 & 117 & 117 & 190 & 890 & 413 & 3848 & 7925 & 7926 & 0096 & 1,6892 & 6756 & 6084 & ,6081 & ,5891 & ,5494 & ,6370 & ,6440 \\
\hline $\mathrm{AC}$ & 72 & 260 & 65 & 25 & 796 & 100 & 552 & 535 & 900 & 321 & 362 & 4304 & 011 & 016 & 5000 & 4000 & 4000 & 1,5000 & 50 \\
\hline$\overline{\mathrm{AM}}$ & 88 & 889 & 867 & 393 & 6067 & 013 & 72 & 4446 & 5042 & 230 & 142 & 5478 & 4646 & 3549 & 5006 & 5006 & 5006 & 4623 & 048 \\
\hline RR & 079 & 3063 & 2277 & 5005 & 1,5014 & 5000 & 5000 & 5000 & 5000 & 5006 & 7001 & 1,0000 & 4332 & 6682 & 1,6052 & 7044 & 1,3833 & 1,4068 & ,4854 \\
\hline PA & 776 & 7937 & 8010 & 8617 & 8112 & 9178 & 9157 & 0,9611 & ,0075 & 9892 & 9796 & 1,0281 & 1,0501 & 1,0670 & 1,1852 & 1,3246 & 1,3785 & 1,5367 & 1,2666 \\
\hline $\mathrm{AP}$ & 4422 & 0,6723 & 0,7500 & 0,6607 & \begin{tabular}{|c|}
0,6278 \\
\end{tabular} & 0,6053 & 0,6235 & 0,9409 & 0,8189 & 0,8309 & 0,7739 & 0,6811 & 0,8815 & 0,9841 & 0,9471 & 0,8978 & 0,9053 & 0,9007 & 0,9087 \\
\hline MA & 0472 & 1,5635 & 1,5863 & 1,5416 & 1,3768 & 1,3870 & 1,1403 & 1,1772 & 1,3415 & 1,2993 & 1,2197 & 1,2792 & 1,3200 & 1,4688 & 1,4270 & 1,5096 & 1,4741 & 1,2535 & 1,2958 \\
\hline PI & 9124 & 1,2163 & 1,1686 & \begin{tabular}{|l|}
1,2787 \\
\end{tabular} & 1,2552 & \begin{tabular}{|l|}
1,2118 \\
\end{tabular} & 0,9056 & 1,2902 & 1,2917 & 1,1883 & 0,6861 & 1,1168 & 0,5400 & 1,3000 & \begin{tabular}{|l|l|}
0,9100 \\
\end{tabular} & 1,1830 & 1,0081 & 0,7313 & 0,4259 \\
\hline CE & 190 & 1,8237 & 1,7871 & 1,9017 & 1,8941 & 1,9138 & 1,5263 & 1,8504 & 1,7429 & 1,7282 & 5339 & 1,4271 & 1,3757 & 1,5000 & 1,0000 & 1,4000 & 1,2000 & 1,1121 &, 7200 \\
\hline RN & 88 & 1,1157 & 9846 & 422 & 0606 & 1527 & 0,7456 & 2037 & 1,0614 & 0,6608 & 118 & 1,1367 & 0,6994 & 0,6839 & \begin{tabular}{|c|}
0,4995 \\
\end{tabular} & 1,2393 & 0,9389 & 0,2324 & 0,1688 \\
\hline PB & 208 & 1,0646 & 1333 & 1,0523 & $0,9551]$ & 1,8715 & 1,1427 & 1,6976 & ,5638 & 3428 & 5294 & 1,2709 & 1327 & 1,4596 & 0,6882 & 1,0290 & 0,6746 & 0,6951 &, 4951 \\
\hline $\mathrm{PE}$ & 109 & \begin{tabular}{|l|l|}
1,4102 \\
\end{tabular} & 4287 & , 8818 & 2,0050 & 1,6254 & 7370 & 1,9261 & ,9615 & 7876 & , 0936 & 8211 & 5435 &, 0316 & 2,0360 & 1,7171 & 1,5381 & 1,6254 & 1,4730 \\
\hline $\mathrm{AL}$ & 217 & 1,5956 & 4046 & 1,4460 & 0,9115 & 1,0431 & 8707 & 7033 & 6567 & 1,6011 & 2535 & 1868 & 1822 & 5260 & 0680 & 1,4000 & ,7795 & 2,1971 & ,2728 \\
\hline $\mathrm{SE}$ & 1440 & 2,4302 & 2,2474 & 2,1692 & 2,2483 & \begin{tabular}{|l|}
2,2693 \\
\end{tabular} & 2,1949 & 2,2777 & 2,1164 & $\begin{array}{l}1,9664 \\
\end{array}$ & 1,9421 & 2,2970 & 2,2707 & 2,3015 & 2,1003 & 2,1000 & 2,5372 & 2,6327 & 3505 \\
\hline BA & 412 & 1,2099 & 0511 & 1,2127 & 1,3195 & 1,4957 & 2,0419 & 2,2319 & 1,8185 & 1,5804 & 1,4699 & 1,2971 & 1,3718 & 1,4658 & 1,2000 & 1,2000 & 1,2000 & 1,7000 & 1,4000 \\
\hline MG & 159 & 1,5170 & 1,4764 & 1,1205 & 1,2994 & 1,4574 & 1,1570 & 1,2567 & \begin{tabular}{|l|l|}
1,2908 \\
\end{tabular} & 1,2092 & 1,3296 & 1,0596 & 1,0654 & 0,9493 & 1,1284 & 0,8971 & 1,0194 & 1,2945 & 1,4055 \\
\hline ES & 013 & 1,6020 & 1,6115 & 1,2874 & 1,3514 & 1,3257 & 1,1071 & 1,3207 & 1,3093 & 1,2437 & 1,3885 & 1,5833 & 1,5000 & 1,5116 & 1,1300 & 1,4000 & 1,8000 & 1,4000 & 1,7530 \\
\hline RJ & 712 & 1,4911 & 4239 & 1,3377 & 1,5490 & \begin{tabular}{|l|l|}
1,6738 \\
\end{tabular} & 1,1056 & 1,2808 & \begin{tabular}{|l|}
1,4147 \\
\end{tabular} & 1,3266 & 1,4995 & \begin{tabular}{|l|l|}
1,9492 \\
\end{tabular} & 1,6016 & 1,8662 & 1,5060 & 1,8000 & 2,2978 & 2,5839 &, 7752 \\
\hline SP & 44 & 1,5222 & 5112 & 1,3471 & 1,0878 & 1,3930 & 2219 & 1,4978 & 1,1082 & 9918 & 1,4973 & 1,1382 & 1,2524 & 0,9738 & 1,3864 & 1,0375 & 0,7204 & 1,0246 & 1,4000 \\
\hline PR & 984 & 1,3548 & 1,2951 & \begin{tabular}{|l|l|}
1,4409 \\
\end{tabular} & 1,1727 & 1,4027 & 1,2905 & 1,2190 & 0,9148 & 1,0854 & 1,2770 & 1,3998 & 1,3440 & 1,7260 & 1,7509 & 1,6042 & 0,5483 & 0,8850 & 1,6336 \\
\hline $\mathrm{SC}$ & 019 & 2,7833 & 2,2940 & 2,6248 & 2,6932 & 2,5490 & 2,4108 & 2,7115 & 2,6522 & 2,5954 & 2,4864 & 2,0742 & 2,2781 & 2,3423 & 2,0391 & 2,2472 & 2,0926 & 2,2092 & 2,7935 \\
\hline RS & 2,6023 & 3,0657 & 3,0992 & 3,3096 & 3,0170 & 2,9011 & 3,1115 & 3,2780 & 3,3568 & 3,3094 & 3,5820 & 3,4474 & 3,5583 & 3,8492 & 3,6031 & 3,7191 & 3,7288 & 3,1905 & 3,8288 \\
\hline $\begin{array}{l}\text { MT+M } \\
\text { S }\end{array}$ & 1,4060 & 1,4772 & 1,2991 & 1,5146 & 1,5865 & 1,5715 & 1,3091 & 1,6031 & 1,5637 & 1,5511 & 1,9202 & 1,6573 & 1,6171 & 1,2977 & 1,0894 & 1,3549 & 0,9150 & 1,0805 & ,2013 \\
\hline & 248 & 90 & 54 & 96 & 904 & 467 & 032 & 5181 & 538 & 832 & 081 & 1,2631 & 00 & 0,9159 & 1,1532 & 0,7982 & 0,8254 & 1,2405 & 2264 \\
\hline DF & 0,0000 & 1,2522 & 1,5000 & 0,8727 & 1,1639 & 1,1586 & 1,0875 & 1,2000 & 1,2000 & 1,2000 & 1,2000 & 2,0084 & 0,9600 & 1,0409 & 1,0588 & 1,2450 & 1,2479 & 1,0316 & 0,9500 \\
\hline
\end{tabular}




\section{APÊNDICE 2 - Produtividade agrícola: cultura do arroz (toneladas/ha)}

\begin{tabular}{|c|c|c|c|c|c|c|c|c|c|c|c|c|c|c|c|c|c|c|c|c|c|}
\hline & 1981 & 1982 & 1983 & 1984 & 1985 & 1986 & 1987 & 1988 & 1989 & 1990 & 1991 & 1992 & 1993 & 1994 & 1995 & 1996 & 1997 & 1998 & 1999 & 2000 & 01 \\
\hline RO & 7326 & 1,6958 & 1,3421 & 1,5046 & 1,4696 & 1,7581 & 1,5581 & 1,6390 & \begin{tabular}{|l|l|}
1,6657 \\
\end{tabular} & ,6042 & \begin{tabular}{|l|}
1,6191 \\
\end{tabular} & ,6282 & 1,6781 & 1,7484 & 1,7667 & 1,2783 & 1,2801 & 3822 & 1,5617 & 1,5955 & \begin{tabular}{|l|}
1,7671 \\
\end{tabular} \\
\hline$\overline{\mathrm{AC}}$ & & 1,4515 & 31 & 24 & 341 & $\overline{98}$ & 047 & 82 & 59 & 99 & 12 & & 75 & 775 & 60 & 504 & 38 & & 300 & & \\
\hline $\bar{M}$ & & & & & 7 & & & & & & & & & & & & & & & & \\
\hline $\bar{R}$ & & 1,1814 & 000 & 594 & 8 & 1895 & 55 & 45 & 4256 & 8282 & 957 & & 00 & & 04 & & & & 00 & 1781 & \\
\hline PA & 96 & 3223 & 917 & 2966 & 3557 & 3708 & 2520 & 1.1726 & 2361 & 1169 & 2210 & 1635 & 4682 & 41 & 1,4440 & 4617 & 1,4446 & 1,2378 & 1,3305 & 83 & 1,612 \\
\hline $\mathrm{AP}$ & 635 & 0,9984 & 3373 & 2273 & 1192 & 4977 & 6801 & 9710 & 6991 & 6123 & 8200 & 7713 & 671 & 7639 & 7307 & 0,7329 & 0,7911 & 0,8000 & 0,7657 & 7773 & 812 \\
\hline MA & 6720 & 1,3494 & 5964 & 1,3961 & 9699 & 1,3788 & 6405 & 1,3545 & 1757 & \begin{tabular}{|l|l|}
0,6731 \\
\end{tabular} & 2784 & 5013 & 8043 & 1,3282 & 1,2142 & 1,3545 & 1,3379 & 0,8759 & 1,4371 & 1,5192 & 1,3601 \\
\hline PI &, 4565 & 0,9221 & 0,3593 & 1,2666 & 1,2836 & 1,5352 & 7234 & 1,5493 & 1,3747 & 0,5832 & 1,3833 & 0,4200 & \begin{tabular}{|l|}
0,6915 \\
\end{tabular} & 1,3944 & 1,3613 & 1,2586 & 0,9579 & 0,5887 & 1,4329 & 1,4474 & 1,0266 \\
\hline $\mathrm{CE}$ & 0400 & 1,2186 & 1,8461 & 2,0368 & 2,4072 & 2,4890 & 2143 & 2,3038 & 1999 & 1,6832 & 2,1042 & 1,5751 & 1,3660 & 2,4319 & 2,5557 & 2,1733 & 2,2907 & 2,0090 & 2,4131 & 2,5321 & 1,2026 \\
\hline $\mathrm{RN}$ & 5957 & 0,4004 & 0,2661 & 1,2179 & 1,1344 & 1,4445 & 5512 & 1,5192 & 3839 & 0,9826 & ,4988 & 6822 &, 0083 &, 5640 & 1,6865 & 1849 & 0,9416 & 1227 & 0,6851 & ,6742 & 3274 \\
\hline PB & 0,6358 & 0,8219 & 5806 & 1,7023 & 5888 & 1,7466 & 3992 & 1,7577 & 7983 & 57 &, 0864 & 1,1949 & 4,8844 & 2,0409 & 1,5213 & 1,3226 & 1,1986 &, 2980 & 0,6219 & 1,4899 & 0,1757 \\
\hline $\bar{E}$ & 801 & 4918 & 4401 & 3,7612 & 3,4512 & 3,7450 & ,7855 & 3,4283 & 739 & 3,4083 & ,4999 & 3107 & 4,2873 & 3,9684 & 3,8666 & 0151 & 4,1021 &, 2615 & 3,8430 & 4,1022 & 4,908 \\
\hline $\mathrm{AL}$ & 681 & 2,1010 & 9988 & 2,1973 & 2,8147 & 3,1386 & 6073 & 3,34 & 1103 & \begin{tabular}{|l|l|}
3,3204 \\
\end{tabular} & 3331 & 3,1958 & 61 & 1,5273 & 2,9968 &, 5392 & 3,8689 & 4,0316 & 4,2920 & 4,8093 & 5,780 \\
\hline$\overline{\mathrm{SE}}$ & 3011 & 2,7619 & 2,2265 & 2,8969 & 2,8780 & 2,8750 & 8447 & 3,1469 & 0366 & 3,0435 & 3226 & 2097 & 3,8454 & 5303 & 3,2495 & 8663 & 3,9819 & 3960 & 6686 & 2721 & 8502 \\
\hline BA & 7900 & 0,6854 & 0,6992 & 0,6054 & 1,3782 & 1,2960 & ,4998 & 0,8961 & 1025 & $\mid 0,8101$ & 4809, & 1,2323 & 1,2927 & 1,7037 & 1,6549 & 1,2716 & 1,5748 & 1,5790 & \begin{tabular}{|l|l}
1,4577 \\
\end{tabular} & 1,7108 & 1076 \\
\hline MG & 0838 & 1,2990 & 1,4752 & 1,0832 & 1,5806 & 1,5856 & 4887 & 1,5470 & 6245 & \begin{tabular}{|l|l|}
1,3131 \\
\end{tabular} &, 7835 & 1,6627 & ,7094 & ,7617 & 1,7526 & ,5668 & 1,7924 & 1,8407 & 1,8900 & 2,0112 & 1,8683 \\
\hline ES & 8578 & 2,3607 & 2,6722 & 2,6990 & 2,7871 & 3,0753 & 3,0367 & 3,0866 & 2,9929 & 2,7720 & 3,0586 & 2,5526 & 3,0902 & 3,1958 & 2,3710 &, 4301 & 2,3849 & 2,4204 & 2,6837 & 2,8060 & 2,9553 \\
\hline RJ & 8345 & 2,9809 & 3,0444 & 3,1087 & 3,2856 & 3,2958 & 3,1819 & 3,2238 & 3,4737 & 1,8420 & 3,2023 & 3,2138 & 3,4948 & 3,5031 & 3,0301 & 3,2890 & 3,1391 & 2,6718 & 2,8006 & 2,9958 & 3,0206 \\
\hline SP & 2060 & 1,5000 & 1,8479 & 1,1704 & 1,6647 & 1,7350 & 8212 & 1,8528 & 8954 & 1,4131 & 1,7492 & 1,7797 & 1,8946 & 1,9446 & 1,9480 & 0453 & 2,1875 & 1839 & 1,7761 & 1,8352 &, 5834 \\
\hline PR & 950 & 1,2600 & 7020 & 1,2332 & 1,4800 & 1,4714 & 6895 & 6792 & 8582 & 61 & 1,1203 & 19 & 1,8247 & 0596 & 2,0525 & 950 & 2,0180 & 34 & 2808 & 2491 & 3192 \\
\hline SC & 699 & 2,6143 & 7712 & 3,2528 & 3,0987 & 3,2079 & 2691 & 3,5329 & 3,5859 & 3,7152 & 1,0385 & .5621 & 4,0856 & 4,4387 & 4,5638 & 4,6446 & 4,9539 & 5,3551 & 5,9927 & 5,9007 & 6,507 \\
\hline RS & 0061 & 4,1488 & 3,4884 & 4,3044 & 4,4482 & 4,1104 & 4,4351 & 4,7858 & 4,9360 & 4,5573 & \begin{tabular}{|l|l|}
4,6735 \\
\end{tabular} & 5,0830 & 5,0587 & 4,3257 & 5,0808 & 5,0158 & 5,0866 & 4,1662 & 5,6889 & 5,1938 & 5,5122 \\
\hline \begin{tabular}{|l} 
MT+ \\
MS
\end{tabular} & 1,0935 & 1,2081 & 1,2256 & 1,1538 & 1,3033 & 1,3217 & 1,3825 & 1,3379 & \begin{tabular}{|l|l|}
1,5074 \\
\end{tabular} & 1,1639 & 1,5771 & 1,4122 & 1,2110 & 1,8001 & 1,9256 & 1,8807 & 2,1283 & 2,2962 & 2,4831 & 2,7027 &, 721 \\
\hline GC & 216 & 2369 & 1,0977 & 1,0080 & 969 & 1,2687 & 2696 & 4116 & 5457 & 0 & 793 & 1,4805 & 1,3309 & 380 & 9346 & 563 & , 765 & 46 & 1145 & 2952 & 17 \\
\hline DF & 0,7400 & 0,8780 & 1,0900 & 0,9736 & 1,2694 & 0,865 & 1,1239 & 1,2478 & 0,8350 & 0,8369 & 1,4300 & 1,3475 & 1,1399 & 1,6049 & 1,3138 & 1,245 & 1,20 & $1,880^{\prime}$ & 2,47 & 2,975 & 1,103 \\
\hline
\end{tabular}

Fonte: IBGE 


\section{APÊNDICE 3 - Produtividade agrícola: cultura da batata-inglesa (toneladas/ha)}

\begin{tabular}{|c|c|c|c|c|c|c|c|c|c|c|c|c|c|c|c|c|c|c|c|}
\hline & 1960 & 1961 & 1962 & 1963 & 1964 & 1965 & 1966 & 1967 & 1968 & 1969 & 1970 & 1973 & 1974 & 1975 & 1976 & 1977 & 1978 & 1979 & 1980 \\
\hline RO & 0000 & 0,0000 & 0,0000 & 0,0000 & 0,0000 & 0,0000 & 0,0000 & 0,0000 & 0,0000 & 0,0000 & 0,0000 & 2,9737 & 3,0000 & 0,0000 & 0,0000 & 0,0000 & 0,0000 & 0,0000 & 0,0000 \\
\hline $\mathrm{C}$ & 0000 &, 0000 & 0,0000 & 0,0000 & 0,0000 & 0,0000 & 0,0000 & 0,0000 & 0,0000 & 0,0000 & 0,0000 & 0,0000 & 0,0000 & 0,0000 & 0,0000 & 0,0000 & 0,0000 & 0,0000 & 0,0000 \\
\hline$\overline{A M}$ & 0000 & 0,0000 & 0,0000 & 0,0000 & 0,0000 & 0,0000 & 0,0000 & 0,0000 & 0,0000 & 0,0000 & 0,0000 & 0,0000 & 0,0000 & 0,0000 & 0,0000 & 0,0000 & 0,0000 & 0,0000 & 0,0000 \\
\hline $\mathrm{R}$ & 0000 & 0000 & 0,0000 & 0000 &, 0000 &, 0000 & 0,0000 & 0,0000 & 0,0000 & 0,0000 & 0,0000 &, 0000 & 0,0000 & 0,0000 &, 0000 & 0,0000 &, 0000 & 0,0000 & 0,0000 \\
\hline PA & 0000 & 0,0000 & 0,0000 & , 0000 & 0000 & , &, 0000 & 0000 & 0,0000 & 0,0000 & , 0000 &, 0000 & 0,0000 & 0,0000 & 0,0000 & 0,0000 & 0,0000 & 0,0000 & 0,000 \\
\hline $\mathrm{P}$ & 000 & 0,0000 & 0,000 & 0000 & 100 & 00 & 0,00 & 0,0000 & 0,0000 & $0,0 \mathrm{c}$ & 000 & , 0000 & 0,0000 &, 0000 & ,, 0000 & 0,0000 & 000 & 0,0000 & 0,0 \\
\hline $\mathrm{MA}$ & 0000 & 0,0000 & 0,0000 & 0000 & 0000 & 00000 & 0,0000 & 0 & 0000 & 0,0000 &, 0000 & 0,0000 & 0,0000 & 0,0000 & 0,0000 & 0,0000 & 0,0000 & 0,0000 & 0,0 \\
\hline PI & 000 & 0,0000 & 0,0000 & 0000 & 0000 & 0000 & 0,0000 & 000 & 0000 & 0 & 0000 & 0,0000 & 0,0000 & 0000 & 0,0000 & 0,0000 & 0,0000 & 0,0000 & 0,0 \\
\hline CE & 7594 & 1,4912 & 1,6534 & 3687 & 1,8840 & ,7097 & 1,5231 & 5248 & 1,9268 & 1,8315 &, 1346 & 1,0344 & 3,9231 & 1304 & 1,8571 & 3,2381 & 年, & 3,9412 & \\
\hline RN & 0,0000 & 0,0000 & 0,0000 & 0,0000 & 0,0000 & 0,0000 & 3,0000 & 3,0000 & 3,6000 & 3,0000 & 2,8000 & 3,0000 & 0,0000 & 0,0000 & 0,0000 & 0,0000 & 0,0000 & 0,0000 & 0,0000 \\
\hline PB & 4952 & 3,5127 & 3,1265 & 1,7679 & 2,9095 & 1,5540 & 1,1365 & 2,2936 & 1,3470 & 1,0851 & 1,5777 & 3,1919 & 3,9439 & 8,2161 & 3,1629 & 2,3265 & 2,7390 & 4,5098 & 0160 \\
\hline PE & 5532 & 1,7244 & 7065 & ,7849 & 1,8095 & 7283 & 2,3620 & 2,9127 & 2,8222 & 2,8296 & 2,4217 & 2,2496 & 1,9018 & 8724 & 1,9333 & 1,9514 & 1,7500 & 2,0000 & 0,0000 \\
\hline $\mathrm{AL}$ & 1429 & 2,4286 & 2,4048 & 2,2727 & 1,7000 & 8269 & 3,0556 & 3704 & 3,3077 & 3,2692 & 0,6000 & 0,0000 & 0,0000 & 0,0000 & 0,0000 & 0,0000 & 0,0000 & 0,0000 & 0,0000 \\
\hline$\overline{\mathrm{SE}}$ & 163 & 13,9904 & 10,1983 & 6325 & 7,3647 &, 7725 & 4077 & 4,7099 & 4,8180 & 4,8267 & 4,8000 & 4,8222 & 4,6486 & 3,5165 & 2,0000 & 5,2979 & 7,4727 & 7,0147 & 7,5273 \\
\hline BA & 2144 & 3,3073 & 0253 & 3,7600 & 2,9271 & 2,3590 & 3,8152 & 3,7729 & 5,4454 & 5,4880 & 5,3991 & 2,8828 & 2,6364 & 2,7377 & 2,8089 & 2,6988 & 2,9740 & $\mid 10,2792$ & 10,8000 \\
\hline MG & 9396 & 2750 & 2318 & 6,0849 & 7,0699 & 6,7477 & ,7334 & 7,4946 & 7,7252 & 7,9676 & 8,3493 & 6,5361 & 10,9588 & 9,7276 & 9,8386 & 9,8964 & 12,0814 & \begin{tabular}{|l|}
12,8524 \\
\end{tabular} & 14,035 \\
\hline ES & 4205 & 8,6584 & 8,7957 & 7,9615 & 9,0462 & 9,0798 & 8,9046 & 9,8679 & 9,7659 & 10,4597 & 8,8690 & 8,1952 & 6,4552 & 7,6630 & 7,1774 & 7,0975 & 7,6099 & 6,0957 & 9,0000 \\
\hline RJ & 3169 & 3,3520 & 3,2586 & 3,2044 & 3,3137 & 3,3177 & 3,2006 & 2,8653 & 2,1205 & 2,2111 & 2,1652 & 1,8726 & 4,8785 & 4,5641 & 2,0000 & 5,1718 & 5,4361 & 6,1709 & 6,6543 \\
\hline SP & 1630 & 8,1811 & 8,0207 & 8,7568 & 7,7612 & 6352 & 9,0890 & 7302 & 8,6944 & 7,9046 & 8,7869 & 11,5199 & 2,3780 & 2,5301 & 13,3289 & 4,4981 & 3,7121 & 16,3482 & 8,0084 \\
\hline PR & 1587 & 5,2482 & 5,4186 & 0715 & 6,7353 & 7,0859 & 7,9020 & 8,3620 &, 4257 &, 5394 & 4562 & 7,2871 & \begin{tabular}{|l|l}
10,3704 \\
\end{tabular} & 0,1121 & 12,5222 & 11,9067 & 11,0123 & 11,2146 & 12,2393 \\
\hline C & 982 & 3,3759 & 2,9660 & 3,3722 & 3,4105 & 3,6000 & 5,8542 & 6,5003 & 6,6713 & 6,6006 & 6,6972 & 6,7970 & 7,7326 & 7,3588 & 7,7836 & 8,0735 & 7,3149 & 8,6529 & 7,2076 \\
\hline RS & 4,5455 & 4,6652 & 5,0551 & 4,4860 & 5,1571 & 5,2687 & 5,3293 & 4,7172 & 5,2327 & 5,3635 & 5,6338 & 6,0255 & 6,0064 & 6,4935 & 6,3892 & 6,3541 & 5,9559 & 6,6296 & 5,3174 \\
\hline MT+ & 4068 & 1,088 & 1,1111 & 1,3478 & 2,2000 & 3,9286 & 4,9048 & 8,7000 & 2,0000 & 3,2500 & 2,0833 & 0,0000 & 2,0000 & 2,0000 & 0,0000 & 0,0000 & 0,0000 & 0,0000 & 0,00 \\
\hline $\mathrm{GO}+^{+}$ & 5433 & 4,5953 & 5,5233 & 0373 & 5,2247 & 5,7730 &, 1937 & 2849 & 6,2483 & 6,2008 & 6,0769 & 5,3590 & 5,1646 & 5,0000 & 5,4000 & 6,0159 & 0,0714 & 14,6535 & 5,4762 \\
\hline $\mathrm{DF}$ & 0,0000 & 0,0000 & 0,0000 & 0,0000 & 3,5111 & 3,4800 & 3,3091 & 3,6000 & 3,6066 & 3,6000 & 3,6000 & 8,1250 & 6,0000 & 8,1176 & 8,0000 & 6,2963 & 7,0000 & 16,0828 & 17,756 \\
\hline
\end{tabular}




\section{APÊNDICE 3 - Produtividade agrícola: cultura da batata-inglesa (toneladas/ha)}

\begin{tabular}{|c|c|c|c|c|c|c|c|c|c|c|c|c|c|c|c|c|c|c|c|c|c|}
\hline & 881 & 82 & 983 & 8. & 985 & 986 & 1987 & 1988 & 1989 & 1990 & 1991 & 1992 & 1993 & 1994 & 1995 & 199 & 1997 & 1998 & 1999 & 2000 & \\
\hline $\mathrm{O}$ & & 000 & 00 & & & & & & $\overline{000}$ & & & & & & & & & & & & \\
\hline & 000 & 000 & 000 & 00 & 000 & 0000 & 1000 & 000 & $\overline{0000}$ & 0000 & 0000 & 0000 & 0000 & 000 & 000 & , & , & , & & & \\
\hline M & 000 & 0000 & 0000 & 0000 & 0000 & 0000 & 0000 & 0,0000 & 0,0000 & 0,0000 & 0,0000 & 0,0000 &, 0000 & ,, 0000 &, 0000 & 0,0000 & 0,0000 &, 0000 &, 0000 &, 0000 &, 0 \\
\hline$\overline{\mathrm{R}}$ & 0000 & 0000 & 0000 & 0000 & 0000 & 0000 & 0000 & 0,0000 & 0,0000 & 0,0000 & 0,0000 & 0,0000 & 0,0000 & 0,0000 & 0,0000 & 0,0000 & 0,0000 &, 0000 &, 0000 &, 000 &, 06 \\
\hline $\mathrm{A}$ & 0000 & 0000 & 0000 & 0000 & 0,0000 & 0,0000 & 0,0000 & 0,0000 & 0,0000 & 0,0000 & 0,0000 & 0,0000 & 0,0000 & 0,0000 & 0,0000 & 0,0000 & 0,0000 & 0,0000 &, 0000 & 0000 & ,, $0 \mathrm{C}$ \\
\hline AP & 000 & 0000 & 0000 & 0000 & 0,0000 & 0,0000 & 000 & 0 , & 0,0000 & 0,00 & 0,0000 & 0,0000 & 0,0000 & 00 & 0,0000 & 0,0000 & 0,0000 & 0,0000 & 00 & 00 &, 0 \\
\hline A & 0000 & 0,0000 & 0,0000 & 0,0000 & 0,0000 & 0,0000 & 0,0000 & 0,0000 &, 00 & 0,0000 &, 0000 & 00 & 0,0000 & 0,0000 & 0,0000 & 0,0000 & 0,0000 & 00 & 000 & 000 & , 0 \\
\hline P & 0000 & 0,0000 & 000 & 0,0000 & 0,0000 & 0,0000 & 000 & 1000 & 0, & 0,0000 & $0,0 \mathrm{c}$ &, 0000 & 0,0000 & 0,0000 & 0,0000 & 0,0000 & 0,0000 & 0,0000 & 0,0000 & 0,0000 & 0,00 \\
\hline $\mathrm{CE}$ & 000 & 0000 & 0000 & 0000 & , 0000 & 0,0000 & 0,0000 & 0000 & 00 & 8,3333 & 8,0563 & 8,1964 & 3,1000 & 3,0000 & 3,0000 & 7,8571 & 0,0000 & 0,0000 & 000 & 6,0000 & \\
\hline $\mathrm{RN}$ & 000 & 000 & 0000 & 0000 & 0,0000 & 0,0000 & , 0000 & 0,0000 & 0 , & 0,0000 & 0,0000 & 0,0000 & 0,0000 & 0,0000 & 000 & 0,0000 & 00 & 000 & 000 & 0,0000 & \\
\hline PB & 3930 & 3092 & 1419 & 0312 & $6,9599 \mid$ & 7,5789 & 2159 & 8,0342 & 8,0000 & 7,8717 & 8,8617 & 3,0253 & 3,2137 & 9,6118 & 6,3180 & 7,4682 & 3,0986 & 1,9868 & 5,6873 &, 2399 & 2,5 \\
\hline & 000 & 0000 & 0000 & 0000 & 0000 & 0000 & 0000 & 0,0000 & 0000 & .7727 & 2558 & 5278 & 6642 & 2500 & 2,7333 &, 1822 & ,6463 & ,6364 & & & 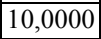 \\
\hline & 000 & 0000 & 0000 & 000 & 0000 & 0000 & 0000 & 0000 & 00 & 00 & 0,0000 & 0,0000 & 00 & 0,0000 & 0000 & 00 & 0000 & 0000 & 0,0000 &, 0000 & 0,0 \\
\hline $\mathrm{E}$ & 5952 & 1739 & 0000 & 8172 & 2308 & 8795 & 4,4762 & 2,9423 & 8,1463 & 9,0156 & 9706 & 7419 & 1905 & 7,0759 & 6977 & 8,1290 & 9,3208 & 3571 & 7,4688 & 4,0000 & $\overline{0,0}$ \\
\hline & 5 & 3 & 27 & 53 & 41 & 0000 & 00 & 861 & 4,7481 & 13 & 65 & 09 & 77 & 77 & 46 & 18 & 10 & 4694 & 17 & 8,1340 & 5,9 \\
\hline MG & 7215 & 9566 & 8633 & 7 & 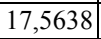 & 2216 & 0753 & 16 & 44 & 05 & 77 & 64 & 86 & 47 & 20 & 0,0361 & 0,7625 & 2,3811 & 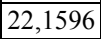 & 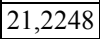 & 23,53 \\
\hline ES & 200 & 1504 & 3365 & 214 & 285 & 0108 & 771 & 2950 & 12,9486 & 0798 & 2,6904 & 3474 & 495 & 13,9639 & 271 & 13,8765 & 13,9500 & 14,223 & 368 & 247 & 15,73 \\
\hline $\mathrm{RJ}$ & 2257 & 3208 & 3654 & 2126 & 0646 & 6066 & 2137 & 11,1763 & 9,2172 & 9,1517 & 9,9617 & 2769 & 2754 & 6973 & 231 & 9,6175 & 9,5500 & 9,8481 & 39 & 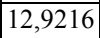 & 3,22 \\
\hline SP & 8342 & 9475 & 17,0283 & 5112 & 6008 & 7550 & 1472 & 7402 & 20,4031 & 1314 & 21,2642 & 3096 & 0453 &, 2995 & 3097 & 660 & 4263 &, 0987 & 1,5465 & 8997 &, 0 \\
\hline PR & 7349 & 8619 & 9,3963 & 4526 & 7596 & 2840 & 3,2017 & 13,2274 & 12,6897 & 14,8250 & 15,5080 & 15,2285 & 2554 & 2407 & ,7671 & 7074 & 357 & 5103 &, 7788 & 7,7886 & 8,166 \\
\hline SC & 2918 & 8,4802 & \begin{tabular}{|c|}
6,9661 \\
\end{tabular} & 9,3626 & 9,6015 & 7,6185 & 8,9267 & 9,3020 & 9,2408 & 9,9615 & 8,8000 & 9,6818 & 10,9900 & 10,9610 & 10,2318 & 10,6145 & 0,2123 & 10,3362 & 10,2256 & 11,3636 & 2,202 \\
\hline RS & 0322 & 5,3654 & 5,6641 & 6,6364 & 6,3591 & 4,4861 & 6,9634 & 7,4371 & 7,6145 & 8,1318 & 7,0429 & 8,1226 & 8,8876 & 8,8537 & 9,9249 & 6,8128 & 9,3187 & 7,7254 & 9,3381 & 9,8950 & 10,367 \\
\hline MT+ & 000 & 0000 & 0000 & 000 & 000 & 8571 & 6667 & 2162 & 8,2500 & 5,4000 & 4,8750 & 0,6667 & 5,0000 & 5,7778 & 0000 &, 0000 & 000 & 0,000 & 0,000 & 0,000 & 00 \\
\hline $\mathrm{GO}+$ & 7,3333 & , 4808, & 640 & 655 & 552 & 18,3500 & 72 & 40 & 00 & 55 & 67 & 00 & 46,0690 & 743 & 85 & 19,1704 & 25,3543 & 31,2883 & 28,4190 & {$[2, / 30$} & או \\
\hline $\mathrm{DF}$ & 0000 & 330 & 500 & 9520 & 0343 & 6327 &,, 5229 & 19,3680 & 9825 & 5372 & 2402 & 0496 & 592 & 3728 & 45 & 347 & 31,755 & 30 & 154 &, 726 & 32,019 \\
\hline
\end{tabular}

Fonte: IBGE 


\section{APÊNDICE 4 - Produtividade agrícola: cultura do café côco (toneladas/ha)}

\begin{tabular}{|c|c|c|c|c|c|c|c|c|c|c|c|c|c|c|c|c|c|c|c|}
\hline & 1960 & 1961 & 1962 & \begin{tabular}{|l|}
1963 \\
\end{tabular} & 1964 & 1965 & 1966 & 1967 & 1968 & \begin{tabular}{|l|}
1969 \\
\end{tabular} & 1970 & \begin{tabular}{|l|}
1973 \\
\end{tabular} & 1974 & \begin{tabular}{|l|l|}
1975 \\
\end{tabular} & 1976 & 1977 & 1978 & 1979 & 1980 \\
\hline RO & 0000 & 0,0000 & 0,0000 & 0,0000 & 0,0000 & 0,0000 & 0,0000 & 0,0000 & 0,0000 & 0,0000 & 0,0000 & 0,0000 & 0,0000 & 3,1500 & 2,2326 & 2,2000 & 1,4121 & 1,3217 & 1,3557 \\
\hline $\mathrm{AC}$ & 0661 & 0,3972 & 0,3950 & 0,3617 & 0,3648 & 0,3360 & 0,4005 & 0,3260 & 0,3354 & 0,3973 & 0,3322 & 0,5000 & 0,2949 & 1,3882 & 1,3733 & 0,7857 & 0,5113 & 0,8123 & 0,9464 \\
\hline AM & 1970 & 0,1818 & 0,1600 & 0,1558 & 0,1622 & 0,1642 & 0,1930 & 0,3404 & 0,5957 & 0,3333 & 0,4444 & 0,3636 & 0,4308 & \begin{tabular}{|c|}
0,4268 \\
\end{tabular} & 0,4111 & 0,4111 & 0,5000 & \begin{tabular}{|c|}
0,5000 \\
\end{tabular} & 0,9412 \\
\hline RR & 0000 & \begin{tabular}{ll|}
0,0000 \\
\end{tabular} & 0,0000 & 0,0000 & 0,0000 & 0,0000 & 0,0000 & \begin{tabular}{l|l|}
0,0000 \\
\end{tabular} & 0,0000 & \begin{tabular}{ll|}
0,0000 \\
\end{tabular} & 0,0000 & 0,0000 & 0,0000 & \begin{tabular}{l|l|}
0,0000 \\
\end{tabular} & 0,0000 & \begin{tabular}{|c|}
0,0000 \\
\end{tabular} & 0,0000 & \begin{tabular}{l|l}
0,0000 \\
\end{tabular} & 0,0000 \\
\hline PA & 6893 & 0,6903 & 7028 & 0,7057 & 7012 & 0,7018 & 7103 & 0,7540 & 7517 & 0,7352 & 7655 & 0,7854 & 0,7503 & 0,6793 & 0,6986 & 0,8702 & 0,8946 & 0,8949 & 0,9042 \\
\hline AP & 000 & 0000 & 6561 & 6561 & 561 & 6561 & 6688 & 0,6688 & 6688 & 0,6122 & 159 & 0,2800 & 3333 & 0,4000 & 750 & 3750 & 333 & 3333 & 15 \\
\hline MA & 533 & 0,4675 & 304 & 4 & 2326 & ,2747 & 2658 & \begin{tabular}{|c|}
0,4217 \\
\end{tabular} & 2840 & \begin{tabular}{|l|}
0,2037 \\
\end{tabular} & 1818 & \begin{tabular}{l|l|}
0,1905 \\
\end{tabular} & 2273 & 0,2405 & 0,2152 & \begin{tabular}{|c|}
0,7975 \\
\end{tabular} & ,2353 & \begin{tabular}{|l|}
0,2888 \\
\end{tabular} & 0,4977 \\
\hline PI & 569 & 0,0000 & 0,0000 & 0,0000 & 0000 & 0,0000 & $\overline{0000}$ & \begin{tabular}{l|l|}
0,0000 \\
\end{tabular} & 0000 & \begin{tabular}{l|l|}
0,0000 \\
\end{tabular} & 0000 & 0,0000 & 529 & 0,3889 & 684 & 2917 & 333 & 3929 & 0,3939 \\
\hline $\mathrm{CE}$ & 000 & 0,4182 & 0,5208 & 0,5089 & 0,3838 & $\begin{array}{l}0,4392 \\
\end{array}$ & 4138 & \begin{tabular}{|c|}
0,5773 \\
\end{tabular} & 6160 & 0,6256 & 0,6038 & \begin{tabular}{|c|}
0,5680 \\
\end{tabular} & ,5229 & 0,3645 & 0,5559 & 6435 & 0,6212 &, 6156 & 0,6124 \\
\hline $\mathrm{RN}$ & 0,0000 & 0,0000 & 0,0000 & 0,0000 & 0,0000 & 0,0000 & 0,0000 & 0,0000 & 0,0000 & 0,0000 & 0,0000 & 0,0000 & 0,0000 & 0,0000 & 0,0000 & 2,2333 & 2,5000 & 1,6979 & 0,4853 \\
\hline PB & 1,2692 & 1,4327 & 1,2966 & \begin{tabular}{|l|l|}
1,3013 \\
\end{tabular} & 1,2685 & 1,2813 & 1,2126 & 1,2334 & 2,1008 & 2,2490 & 2,4183 & \begin{tabular}{|l|l|}
1,2900 \\
\end{tabular} & 0,5122 & 0,5096 & 0,5093 & 0,5521 & 0,4912 & 0,4974 & 0,4790 \\
\hline $\mathrm{PE}$ & 0,5496 & 0,5784 & 0,5373 & 0,4484 & 0,4178 & 0,4205 & 0,4964 & $\begin{array}{l}0,4832 \\
\end{array}$ & 0,5239 & 0,5264 & 0,5473 & \begin{tabular}{|c|}
0,7145 \\
\end{tabular} & 0,8388 & \begin{tabular}{|c|}
0,8257 \\
\end{tabular} & 0,8508 & \begin{tabular}{|c|}
0,8160 \\
\end{tabular} & 0,8543 & \begin{tabular}{|c|}
0,8100 \\
\end{tabular} & 0,6901 \\
\hline $\mathrm{AL}$ & 7482 & 0,5986 & 0,5709 & 5481 & 0,5518 & $\begin{array}{l}0,5790 \\
\end{array}$ & 0,4941 & \begin{tabular}{|c|}
0,2917 \\
\end{tabular} & 0,3189 & 0,3101 & 0,3221 & \begin{tabular}{|c|c|c|}
0,631 \\
\end{tabular} & 0,5748 & \begin{tabular}{|c|}
0,5871 \\
\end{tabular} & 0,4410 & 0,4358 & 0,4179 & \begin{tabular}{|c|}
0,4519 \\
\end{tabular} & 0,3778 \\
\hline SE & 4834 & 5041 & 0,3651 & 4022 & 0,4765 & 0,4812 & 0,2940 & 0,2826 & 0,3412 & 0,3650 & 0,3203 & 0,3469 & 0,3699 & 0,3699 & 0,3699 & 0,0000 & 0,0000 & 0,0000 & 0,0000 \\
\hline BA & 6078 & 0,4886 & 0,4674 & 4923 & 0,4988 & 0,4837 & 0,4536 & 0,5505 & 0,6641 & 0,7266 & 0,7086 & 0,5276 & 0,5647 & 0,5861 & 0,6517 & 0,7201 & 0,8560 & 0,8830 & 0,8792 \\
\hline $\mathrm{MG}$ & 5211 & 0,6758 & 0,6060 & 0,5940 & 0,4633 & 0,6323 & 1,1224 & 0,7241 & 0,8253 & 0,5636 & 1,4771 & \begin{tabular}{|c|}
0,7593 \\
\end{tabular} & 2,0279 & \begin{tabular}{|c|}
0,7683 \\
\end{tabular} & 0,7561 & 1,5931 & 1,3390 & 1,8122 & 0,8760 \\
\hline ES & 9294 & \begin{tabular}{|c|}
0,8899 \\
\end{tabular} & 0,9559 & \begin{tabular}{|c|}
0,8598 \\
\end{tabular} & 0,7898 & 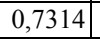 & 0,7089 & \begin{tabular}{|l|}
0,3973 \\
\end{tabular} & 0,9221 & \begin{tabular}{|l|}
0,3123 \\
\end{tabular} & 1,2567 & 0,5714 & 0,8515 & 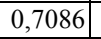 & 0,7281 & \begin{tabular}{|c|c|c|}
0,697 \\
\end{tabular} & 0,9848 & \begin{tabular}{|l|}
1,0006 \\
\end{tabular} & 1,0736 \\
\hline RJ & ,7663 & 0,7679 & 0,7063 & 0,6666 & 0,6685 & 0,6605 & 0,6080 & 0,5492 & 0,6136 & 0,5776 & 0,6939 & 0,6949 & 0,7947 & 0,7781 & 1,0293 & 0,9312 & 1,3035 & 2,0918 & 2,5468 \\
\hline SP & 0,7082 & 0,8345 & 0,5512 & 0,8128 & 0,3325 & \begin{tabular}{|c|}
0,9233 \\
\end{tabular} & 0,8649 & \begin{tabular}{|l|}
1,2274 \\
\end{tabular} & 0,7241 & \begin{tabular}{ll|}
0,9602 \\
\end{tabular} & 0,7662 & \begin{tabular}{|l|}
1,3375 \\
\end{tabular} & 1,8097 & \begin{tabular}{|l|}
1,2839 \\
\end{tabular} & 0,5425 & \begin{tabular}{|l|}
1,4187 \\
\end{tabular} & 1,3822 & 1,2874 & 1,0236 \\
\hline PR & 1,4590 & 1,4765 & 1,5765 & 0,7850 & 0,7189 & 1,3653 & 0,6927 & 1,2804 & 0,8455 & 1,2969 & 0,1870 & 0,5681 & 1,3367 & 1,3007 & 0,1238 & 0,3453 & 0,9253 & 0,3764 & 0,5200 \\
\hline SC & 1,0162 & 1,0487 & 1,0392 & 0,9991 & 0,9501 & 1,0647 & 0,9809 & 1,1481 & 1,1912 & 1,1505 & 1,2451 & 0,6776 & 0,7171 & 0,8482 & 0,8376 & 0,8620 & 0,9401 & 1,7629 & 2,4906 \\
\hline RS & 0,0000 & 0,0000 & 0,0000 & 0,0000 & 0,0000 & 0,0000 & 0,0000 & 0,0000 & 0,0000 & 0,0000 & 0,0000 & 0,0000 & 0,0000 & |0,0000 & 0,0000 & 0,0000 & 0,0000 & 0,0000 & 0,0000 \\
\hline MT+ & 1,2566 & $\begin{array}{l}1,5812 \\
\end{array}$ & 2,0864 & \begin{tabular}{|l|}
2,3850 \\
\end{tabular} & 2,4382 & 2,7036 & 1,7091 & \begin{tabular}{ll|}
1,4412 \\
\end{tabular} & 0,9911 & 1,2232 & 1,2800 & 0,7520 & 0,8970 & 1,0924 & 1,3414 & 1,1044 & 1,0461 & 1,1588 & 1,0290 \\
\hline $\mathrm{GO}^{+}$ & 4147 & 1,5306 & 1,2606 & 1,4124 & $1,34 / 1$ & 1,4091 & 1,3097 & | & 1,4583 & 1,2094 & 1,1305 & 0,6873 & 1,2411 & 0,6650 &, 7121 & 1,1006 & 1,1591 & 1,1486 & ,2904 \\
\hline DF & 0,0000 & 0,0000 & 0,0000 & 0,0000 & 0,2402 & 0,2389 & 0,2404 & 0,2412 & 0,2353 & 0,2412 & 0,2412 & 0,0000 & 0,3500 & 0,3882 & 0,9059 & 1,2308 & 1,2479 & 0,5021 &, 903 \\
\hline
\end{tabular}




\section{APÊNDICE 4 - Produtividade agrícola: cultura do café côco (toneladas/ha)}

\begin{tabular}{|c|c|c|c|c|c|c|c|c|c|c|c|c|c|c|c|c|c|c|c|c|c|}
\hline & 981 & 1982 & 1983 & 1984 & 1985 & 1986 & 1987 & 1988 & 1989 & 1990 & 1991 & 1992 & 1993 & 1994 & 1995 & 1996 & 1997 & 1998 & 1999 & 2000 & 20 \\
\hline RO & 0001 & 0025 & 1093 & 0144 & 2593 & 2018 & 1248 & 5900 & 0182 & 1729 & 1,1002 & 1,1236 & 1608 & 1,2130 & 1,2432 & 9508 & 95 & 0,8895 & 1,0678 & 1,0420 & 1,1470 \\
\hline $\mathrm{AC}$ & 543 & 7727 & 8602 & $813 \varepsilon^{8}$ & 8555 & 3109 & 8040 & 9716 & 9866 & 0,9938 & 0,8938 & 9231 & 9559 & 0,9417 & 0,9720 & 1356 & 1,2039 & 1,1798 & 1,9649 & 1,5398 & 1,9569 \\
\hline$\overline{\mathrm{AM}}$ & \begin{tabular}{|l|}
5529 \\
\end{tabular} & 8529 & 7941 & 0,6935 & 0,7222 & 0,7183 & 0,8174 & 0,7967 & 8207 & 0,7692 & 0,9443 & ,9467 & 9678 & 0,9690 & 0,9775 & 6044 & 8447 & 0,6602 & 0,7253 & \begin{tabular}{|c|}
0,7253 \\
\end{tabular} & 0,6344 \\
\hline $\mathrm{RR}$ & 0000 & 0000 & 0000 & 0000 & 0000 & 0000 & 0,0000 & 0000 & $\overline{0000}$ & 0,0000 & 0,0000 & 0000 & 0000 & 0,0000 & 0,0000 &, 0000 &, 0000 & 0,0000 & 0,0000 &, 0000 &, 0000 \\
\hline PA & 147 & 924 & 568 & 1617 & 1,5112 & 7580 & 6429 & 6564 & 2145 & 5978 & 2,6037 & 2,1018 & 8869 & 1,2485 & 1,2476 & 1010 & 2,3635 & 2,0944 & 2,1205 & 2,0312 & 1,3247 \\
\hline $\mathrm{AP}$ & 517 & 864 & 6358 & 6000 & 7308 & 7241 & 0000 & 0000 & 0000 & 0000 & 0,0000 & 0000 & 0000 & 0,0000 & 0,0000 & , & 0,0000 & 0,0000 & 0,0000 & 0,0000 & 0,0000 \\
\hline A & 65 & 600 & 4 & 0,4898 & 3904 [ & 0 & 17 & 667 & 58 & 43 & 60 & 41 & 33 & 27 & 43 & 15 & 00 & 00 & 00 & 100 & 2,9429 \\
\hline PI & 773 & 130 & 000 & 4000 & 3947 & 13 & 3158 & 2973 & 3056 & 2973 & 0,1957 & 1818 & 1818 & 0,1818 & 0,1765 & 3684 & ,3684 & 3750 & 0,2727 &, 4000 & ,3333 \\
\hline$\overline{\mathrm{CE}}$ & 89 & 96 & 761 & 0,2028 & 2691 & 6 & 292 & 8462 & 0,8449 & 48 & 84 & 35 & 386 & 6 & 0,6466 & 5143 & 0,4533 & 4528 & 0,5409 & 6230 & 0,6393 \\
\hline RN & 449 & 5556 & 769 & 1429 & 1429 & |429| & 1622 & 1905 & 1500 & $|667|$ & 0,2000 & 0000 & 0000 & 0000 & 0,0000 & 0000 & 0000 & 0,0000 & 0,0000 & , & 0000 \\
\hline PB & 516 & 3682 & 3066 & 0,4946 & 0,3704 & 0,3704 & 0,2692 & 0,4776 & 4776 & 0,4516 & 0,4516 & 0,6176 & 0000 & 7407 & 0,7619 & 0,5000 & 5246 & 0,3187 & 0,6538 & 0,8077 & 1,0625 \\
\hline $\mathrm{PE}$ & 5580 & 7600 & 5800 & 5356 & 5355 & 5463 & \begin{tabular}{|l|}
0,4389 \\
\end{tabular} & 0,4265 & 5787 & 5433 & 0,5458 & 0,4014 & 4595 & 4444 & 5523 & 4854 & 5015 & 3074 & 91 & 5287 & 8869 \\
\hline$\overline{\mathrm{AL}}$ & 59 & 4409 & 2987 & 0,30 & 5060 & 0,5181 & \begin{tabular}{|c|}
0,4767 \\
\end{tabular} & 0,42 & 0,4688 & 4242 & 0,3382 & 0,2500 & 1837 & 1800 & 0,2000 &, 2200 & 0,2000 & 0,2200 & 0,1190 & 0,1190 & 0,1739 \\
\hline SE & 000 & 000 & 000 & 0000 & 0000 & 0000 & 0000 & 0,0000 & 0000 & 0000 & 0,0000 & 0000 & 0000 & 0000 & 0,0000 &, 0000 & 0,0000 & 0,0000 & 0,0000 & 0,0000 & 0,0000 \\
\hline BA & 433 & 026 & 5991 & 6537 & 2854 & 0,9561 & 0,8208 & 0,8569 & 7832 & 8223 & 0,8483 & 0,8047 &, 6125 & 1,4094 & 0,8016 & 0,6930 &, 7513 & 0,5628 & 0,9889 & 0,9683 & 1,1360 \\
\hline MG & 835 & 9987 & 8052 & 1412 & 2,0541 & 9039 & 1,8751 & 1566 & 2188 & 0581 & 1,2259 & 1,1585 & 1,2864 & 3812 & 1,0990 & 1,5956 & 1,2949 & 1,8606 & 1,6133 & 1,6537 & 1,6026 \\
\hline ES & 125 & 1286 & 4347 & 1828 & \begin{tabular}{|c|}
1,39844 \\
\end{tabular} & 1,1522 & 1,0146 & \begin{tabular}{|l|l|}
1,0808 \\
\end{tabular} & 9397 & 8573 & 1,0594 & 1,0932 & 0,9943 & 0,9603 & 0,7929 & 1,3783 & 1,0618 & 1,3330 & 1,2427 & \begin{tabular}{|l|l|}
1,9617 \\
\end{tabular} & 1,7982 \\
\hline $\mathrm{RJ}$ & 8832 & 2,6912 & 1420 & 7995 & \begin{tabular}{|c|}
1,9907 \\
\end{tabular} & 2,0160 & 2,3930 & 3809 & 3387 & \begin{tabular}{|l|}
1,3717 \\
\end{tabular} & 1,3263 & 1,3350 & 1,6485 & 1,5273 & 1,3461 & 1,3974 & 1,4103 & 1,4591 & 1,4653 & 1,5779 & 1,3247 \\
\hline SP & 3421 & 1,2130 & 1,2286 & 1851 & 1,3234 & 0,3951 & 1,3559 & 0,8141 & 7229 & 1,1455 & 0,9571 & 0,8775 & 1,1724 & 1,5007 & 0,8501 & 1,6203 & 1,4164 & 1,9769 & 1,6028 & 2,0590 & ,6682 \\
\hline PR & 3273 & 5372 & 1,3873 & 1176 & 1,3645 & 0,6187 & 1,9627 & 0,5409 & 0826 & 7294 & 1,0534 & 0,7406 & 0,8789 & 8639 & 0,1956 & 1,1399 & ,7171 & 2,1173 & 2,0688 & 1,8631 & 8679 \\
\hline SC & 2243 & 2538 & 1,6328 & 8697 & 9881 & 3051 & 8764 & 9644 & 1350 & 1895 & 2,0333 & 2,6000 & 2,6000 & 6000 & 2,6000 & ,4304 & 3913 & 2,0435 & 2,0435 & 2,0000 & 0000 \\
\hline $\mathrm{RS}$ & 000 & $\overline{0000}$ & 0,0000 & 0,0000 & 0,0000 & 0,0000 & 0 & 0,0000 & 0000 & 0,0000 & 0,0000 & 0,0000 & 0,0000 & $\overline{0000}$ & 0,0000 & 0,0000 & 0,0000 & 0,0000 & 0,0000 & 0,0000 & 0000 \\
\hline & 2030 & 8525 & $\begin{array}{l}0,9948 \\
\end{array}$ & 1,0636 & 1,2355 & 1,1148 & 1,3106 & 0,8047 & 7748 & 1,0890 & 0,8959 & 0,9873 & 1,0942 & 1,0073 & 1,0444 & 0,8387 & ,9878 & 1,2628 & 0,7945 & 0,6712 & 2324 \\
\hline $\mathrm{GO}^{-1}$ & 841 & 1,0674 & 2275 & 0102 & 1868 & 0121 & 1,2780 & .5374 & 7338 & 1,1483 & 1,0863 & 0861 & 9502 & 1,0921 & 0,8655 & 9691 & 0272 & 1,1768 & 1,1471 & 1,3416 & ,9300 \\
\hline $\mathrm{DF}$ & 0,7177 & 1,2000 & 1,2000 & 1,2000 & 1,2000 & 1,2100 & 1,5155 & 1,5858 & 1,4203 & 1,4100 & 0,9766 & 0,9052 & 1,4125 & 8756 & 2,1406 & ,9962 & 1,628 & 1,8511 & 1,6931 & 1,7292 & 089 \\
\hline
\end{tabular}

Fonte: IBGE 


\section{APÊNDICE 5 - Produtividade agrícola: cultura da cana-de-açúcar (toneladas/ha)}

\begin{tabular}{|c|c|c|c|c|c|c|c|c|c|c|c|c|c|c|c|c|c|c|c|}
\hline & 1960 & 1961 & 1962 & 1963 & 1964 & 1965 & 1966 & 1967 & 1968 & 1969 & 1970 & 1973 & 1974 & 1975 & 1976 & 1977 & 1978 & 1979 & 198 \\
\hline RO & 0270 &, 5000 & ,6279 & 6629 & | & 4884 & 5,4172 & ,3158 & 16,3158 & 2697 & 16,3312 & 6154 & 3257 &, 0100 & 3,0000 & 3,0000 & 18,0000 & 25,0547 & 31,0856 \\
\hline $\mathrm{AC}$ & 0048 & 1,4205 & 2879 & 4312 &, 5362 &, 0000 & 40,3093 & 8066 & 38,3117 & 8286 & 41,0475 &, 0000 & 31,0442 & 2,1500 & 19,8788 & 21,4655 & 19,5450 & 23,2697 & 8,8197 \\
\hline $\mathrm{AM}$ & 4288 & 9,9795 & ,7495 & 1,9149 & 3610 & 36,7290 & 37,3200 & 40,7977 & 39,4038 & , 4425 & 38,2287 & 6,0730 & 31,4824 & 32,1994 & 37,3707 & 5,9709 & 36,3670 & 7,5763 & 5971 \\
\hline $\mathrm{P}$ & 5000 & 0,0000 & 8889 & 0000 & 0000 & 0000 & 0000 & 0000 & 50,0000 &, 0000 & 50,0000 & ,9572 &, 0000 & 25,0000 & 1176 & 3387 & 25,8500 & 2,9167 & 4,3333 \\
\hline $\mathrm{A}$ & 0231 & 2084 & 5700 & 6573 & 3902 & 1183 & ,7809 & 1903 & 17,2531 &, 0050 & 17,0034 & 2,9867 & 30,5970 & 0,3683 & 28,5695 & 51,4175 & 59,7413 & 3,5039 & 50,6028 \\
\hline $\mathrm{AP}$ & 2797 & 2 & 5769 & 6 & 23 & 0 & 15 & 8 & 77 & 26,2759 & 94 & 43 & 99 & 00 & 13,7742 & 3,5789 & 13,5217 & 13,8750 & 14,4255 \\
\hline MA & 24 & 10 & 672 & 51 & 685 & 26,4888 & , 7818 & 772 & 85 & 8982 & 3900 & ,3607 & 27,4266 & 72 & 24,7860 & 1474 & ,6751 & 06 & 48,9166 \\
\hline PI & 2963 & 6862 & 8839 & 3763 & 8973 & 0110 & 3,9691 & 6622 & 25,1661 & 4,8167 & $20,3881]$ & 3,7693 & 26,5203 & 25,7827 & 26,2430 & 25,6500 & 26,6178 & 26,0449 & 24,7905 \\
\hline $\mathrm{CE}$ & 1703 & 0514 & 0300 & 6324 & 8072 & 3342 & ,6464 & ,8346 & 41,0364 & ,0916 & 36,9266 & 8531 & 36,7059 & 35,0000 & 35,0000 & 35,0000 & 40,0000 & 31,4778 & 0000 \\
\hline $\mathrm{RN}$ & 1446 & 9886 & 2101 & 48,8325 & 3,4566 & 47,1712 & 46,9195 & ,1273 & 50,3081 & 49,9732 & 48,8896 & 29,3770 & 46,0363 & 57,6662 & 67,2335 & 62,4896 & 63,4042 & 46,8676 & 9,4039 \\
\hline PB & 4078 & 5,8663 & 47,2098 & 43,4818 & 0725 & 5711 & 40,9838 & ,2951 & 46,0122 & 1463 & 42,0085 & 9,0786 &, 7425 & 40,9023 & 43,4789 & 53,0564 & 6,5340 & 49,1037 & 5494 \\
\hline $\mathrm{PE}$ & 8639 &, 1400 & 1304 & & 215 & 402 & 34 & 383 & 44,5456 & 21 & 49 & 47,4 & 0000 & $\overline{88,0}$ & 80 & 48,0 & 8,0000 & 49 , & 48,0537 \\
\hline $\mathrm{L}$ & 2298 & 1,2365 & ,5832 & 44,6022 & 5,1701 & 41,9281 & 45,7010 & 44,6670 & 47,0406 & 48,0648 & 44,6421 & 47,7201 & 45,1773 & 46,0838 & 46,0800 & 50,2010 & 50,5152 & 52,0000 & 49,0000 \\
\hline SE & 0488 & ,6266 & 2019 & 88,6339 & 10,8629 & 4247 & 4,6441 & 1,4232 & 34,4437 & 34,3026 & 33,3085 & 41,4569 & 55,1129 & 53,0000 & 46,0900 & 55,0000 & 58,0013 & 56,1030 & 77,3500 \\
\hline BA & 9022 & 1203 & ,5993 & 2749 & 7529 & 2475 & 44,8962 & 2683 & 49,9475 &, 4788 & 47,0234 &, 9083 & 42,0000 & 42,0000 & 38,0000 & 38,0000 & 38,0000 & 41,2500 & 1,9921 \\
\hline MG & 2634 & 4 & 4835 & 31,4397 & 2,3981 & 30,5477 & (6,4984 & 37,8314 & 37,5079 & 88,4466 & 38,6881 & 35,2950 & 38,0000 & 32,6369 & 36,1526 & 40,5598 & 40,1361 & 41,8762 & 43,6447 \\
\hline ES & 0755 & 8,3446 & 1123 & 26,4549 & ,9111 & 27,7730 & ,2197 & 2,3098 & 8,9974 & ,9002 & 29,1678 & 35,0512 & 30,9998 & 31,0000 & 31,0000 & 31,0000 & 31,0000 & 33,7431 & 31,0000 \\
\hline $\mathrm{RJ}$ & 9511 & 1,9164 & 2,2281 & 35,6949 & 2,7064 & 44,6321 & 42,7073 & 42,3082 & 39,6172 & 2,0114 & 40,9468 & 4,7371 & 35,2093 & 45,0000 & 39,6000 & 47,0000 & 48,3819 & 48,5667 & 88,2164 \\
\hline SP & 5437 & 4430 & 9526 & 1532 & 7375 & 55,2894 & 2514 & 8471 & 54,8619 & 2235 & 9182 &, 7042 & 8390 & 57,3269 & 5000 & 65,4950 &, 9346 & 67,0747 & 2,4484 \\
\hline PR & 9818 & 9813 & 6358 & 2601 & 11198 & 75,2267 & ,6634 & ,9549 & 3,7369 &, 7475 & 2,6632 &, 6658 & 57,0000 & 0,1066 & 1070 & 0,1200 &, 8308 & 2,0584 & 7629 \\
\hline$\overline{\mathrm{SC}}$ & 6516 & 1,0714 & 4,7015 & 30,8316 & 2,6116 & 33,0419 & 35,7412 & 36,5344 & 36,5229 & 37,0609 & 40,7449 & 37,4699 & 48,7727 & 44,7075 & 49,8265 & 48,5670 & 49,9749 & 53,9048 & 51,7127 \\
\hline RS & 7350 & 18,8701 &, 1351 & 20,4174 & 0,3717 & 1,5826 & 3,1893 & 21,9167 & 22,8711 & 23,3358 & 23,8065 & 24,1064 & 22,5510 & 21,4664 & 23,7632 & 23,5000 & 23,5012 & 28,1378 & 7,0115 \\
\hline MT- & 6225 & 46,0304 &, 1874 & 44,1868 & 0,3830 & 40,4870 & 41,0976 & 43,0062 & 50,5618 & 46,9504 & 50,9032 & 48,5860 & 36,8786 & 37,8823 & 40,4161 & 42,3880 & 57,7473 & 43,3873 & 0,7529 \\
\hline $\mathrm{GO}^{-}$ & 42,9493 & 44,0852 & 46,5606 & 46,8530 & ,4518 & 0,0146 & 2,8916 & 3652 & 41,3627 & 1,9373 & 43,1418 & 5,6826 & 45,0000 & 40,0000 & 0,0000 & 42,0000 & 50,7000 & 4,0000 & 588 \\
\hline $\mathrm{DF}$ & 0,0000 & 0,0000 & 0,0000 & 0,0000 & 14,0496 & 2043 & 995 & 20,0000 & 20,0000 & 20,0000 & 20,0000 & 40,5143 & 12,0000 & 13,2039 & 111 & 22,2013 & 22,200 & 20,000 & 21,906 \\
\hline
\end{tabular}




\section{APÊNDICE 5 - Produtividade agrícola: cultura da cana-de-açúcar (toneladas/ha)}

\begin{tabular}{|c|c|c|c|c|c|c|c|c|c|c|c|c|c|c|c|c|c|c|c|c|c|}
\hline & 1981 & 1982 & 1983 & 1984 & 1985 & 1986 & 1987 & 1988 & 1989 & 1990 & 1991 & 1992 & 1993 & 1994 & 1995 & 1996 & 199 & 1998 & 195 & 2000 & 2001 \\
\hline 20 & & & & & & 685 & & & & & & & & & & & & & & & \\
\hline $\mathrm{C}$ & & & & & & & & & & & & & & & & & & & & & \\
\hline $\mathrm{M}$ & & 00 & 0000 & 6 & & 82 & & & 3 & 0 & 7 & 433 & 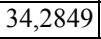 & L & (1) & 85 & 01 & & 0 & & $5.4,2$ \\
\hline $\mathrm{R}$ & 00 & 000 & 5000 & 0000 & 0000 & 594 & 364 & 4510 & 9,2051 & 0000 & 873 & 9,9254 & 0000 & 0000 & 0,0000 & 0,0000 & 0000 & 9746 & 2188 & 2,218 & 2,47 \\
\hline PA & 8512 & 1973 & 3536 & 1564 & 7026 & 0535 & 1985 & ,9067 & 55,2741 & ,0614 & 5624 & 9786 & 53,8323 & 55,5281 & 52,9840 & ,9462 & 2794 &, 4864 & 1192 & 64,4943 & 65 \\
\hline AP & 4930 & 4118 & 2941 & 0000 & 8049 & 9487 & 0000 & 0000 & 25,0000 & 0000 & 0000 &, 0000 &, 0000 & 15,0000 & 18,0000 &, 7778 & 2597 & 3,4756 & 1528 & 21,3971 & 22,3 \\
\hline MA & 9658 & 7345 & 3935 & ,5199 & 46,7885 & 4920 & 3724 & 8696 & 54,7685 & 6357 & 9129 & 0817 & 52,0625 & ,7718 & 55,7408 & 1303 & ,5661 & ,8077 & ,4044 & 55,7355 & 35,73 \\
\hline PI & 9979 & 4745 & 6579 & ,4478 & 47,7278 & .6741 & 7162 & 0229 & 52,4239 & 7069 & 5781 & ,6724 & 4491 & 1242 & 59,2732 & 1485 & 199 & 6059 & 4880 & 54,6324 & 56,78 \\
\hline $\mathrm{E}$ & 00 & 86 & 00 & 5 & 4 & 2158 & 190 & 07 & 29 & 88 & 74 & 4462 & 99 & 70 & 6917 & 18 & 142 & $24 \mid$ & 81 & 8837 & 1,35 \\
\hline $\mathrm{RN}$ & 5 & & 2443 & 8 & 6 & 01 & 0 & 3429 & 7 & 1 & 2 & 32 & 40 & 62 & 13 & 70 & 27 & 86 & 6 & 781 & 0,37 \\
\hline B & 97 & 998 & 8339 & 0 & 04 & 1467 & 370 & 03 & 4668 & 24 & 31 & 85 & 65 & 40,0938 & 10 & 85 & 11 & 44 & 49 & 42,8436 & 49,19 \\
\hline$E$ & 690 & 80 & 150 & 9000 & 8831 & 4674 & 344 & 991 & 405 & 665 & 38 & 463 & 27 & 29 & 486 & 83 & 25 & 269 & 047 & 690 & 4 \\
\hline $\mathrm{AL}$ & 994 & 153 & 5848 &, 5585 & 3403 & 5090 & 4 & ,3964 & 15 & 969 & 55 & $/ 8$ & 62 & 59 & 670 & 61 & 89 & 173 & 000 & 804 & 62,10 \\
\hline SE & 181 & 7451 & ,735 & $24 c^{2}$ & 5544 & 7189 & 4902 & 850 & 0 & 2688 & 746 & 6051 & 6294 & 983 & 03 & 81 & 07 & 155 & 230 & , & 64,70 \\
\hline $\mathrm{BA}$ & 536 & 71170 & 36,2622 & 30,0000 & 40,5856 & 0000 & 1500 & 45,8616 & 44,8949 & 42,7804 & 6504 & 3892 & 47,2968 & $30,446 /$ & 52,3019 & 53,0226 & 52,6181 & 51,2090 & 52,9449 & 52,9929 & 54,677 \\
\hline MG & 174 & 684 & \begin{tabular}{|l}
53,08 \\
\end{tabular} & 55,0889 & 57,8337 & 5085 & 7148 & 75 & 57,9535 & 133 & 132 & 64 & 41 & 799 & 62,5 & 04 & 726 & 5414 & 62,6290 & 63,9377 & 64,266 \\
\hline ES & & 55 & 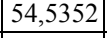 &, 5360 & 73 & 34 & 72 & 9 & 47,6 & 4 & 83 & 27 & 1 & 55 & 5 & 44 & 14 & 92 & 44 & 849 & 53,15 \\
\hline $\mathrm{RJ}$ & & & 5 & 3 & & ,2946 & 86 & 11 & 44,4 & 88 & & 92 & & 87 & & & 78 & 07 & & 44,6147 & 31,42 \\
\hline SP & & & 0 & & 4 & 34 & 173 & & 73,9624 & 687 & 62 & 36 & 07 & 23 & 77. & 84 & 3137 & 96 & 01 & 76,0789 & 77,49 \\
\hline PR & 7120 & 0006 & 1267 & 69,2614 & ,0051 & ,6902 & 2515 & 7588 & 74,2603 & 6194 & 162 & |9707, & 9923 & 8730 & 79,8755 & ,3027 & 8608 & 8337 & ,0980 & , 8877 & 1,13 \\
\hline $\mathrm{SC}$ & 2244 & 0467 & 44,6670 & 47,7406 & 47,3979 & 2720 & 5842 & ,9481 & 59,1326 & 7397 & 3224 & 9550 & 8554 & 3953 & 47,5418 & 8785 &, 7203 & 376 & 4109 & 30,9911 & 7,48 \\
\hline $\mathrm{RS}$ & 7649 & 6426 &, 6244 & 25,5117 & 30,2706 & ,6361 & 0185 & 29,5004 & 30,3036 & 9559 & 5368 & 9485 & 1996 & 8273 & 30,6370 & 2460 & 3036 & 5131 & 5063 &, 1562 & 33,366 \\
\hline MT+ & 8635 & 2618 & 52,9117 & 54,9844 & 8716 & ,2145 & 2803 & 57,6927 & 59,8943 & 3791 & 130 & 7172 & 636 & 3980 & 168 & 9205 & 2091 & 7865 & 3704 & 1468 & 70,157 \\
\hline $\mathrm{GO}+$ &, 7706 & 61,1116 & 66,1710 & 68,2362 & 66,9380 & 67,8907 & 68,4239 & 67,8542 & 69,0341 & 63,2450 & 62,9725 & 66,5955 & 63,4917 & 73,3625 & 65,5450 & 71,8301 & 72,1443 & \begin{tabular}{|l|l|}
70,1133 \\
\end{tabular} & 62,7236 & 72,2284 & 78,313 \\
\hline DF &, 5000 &, 0000 & 18,0000 & 18,0000 & 18,0000 & 8,0000 & 7,0000 & 18,0000 & 18,0000 & 0,0000 & 2700 & 0,0000. & 88,7115 & 46,4203 & 69,6162 & 21,6515 & 6,4896 & 7,4154 & 46,9195 & $44,460 \mathrm{~s}$ & 4,1 \\
\hline
\end{tabular}

Fonte: IBGE 


\section{APÊNDICE 6 - produtividade agrícola: cultura do feijão (toneladas/ha)}

\begin{tabular}{|c|c|c|c|c|c|c|c|c|c|c|c|c|c|c|c|c|c|c|c|}
\hline & 1960 & 1961 & 1962 & 1963 & 1964 & 1965 & 1966 & 1967 & 1968 & 1969 & \begin{tabular}{|l|}
1970 \\
\end{tabular} & \begin{tabular}{|l|}
1973 \\
\end{tabular} & |1974 & \begin{tabular}{|l|}
1975 \\
\end{tabular} & 1976 & 1977 & 1978 & 1979 & 1980 \\
\hline RO & 1,1322 & 1,0627 & 1,1466 & \begin{tabular}{|l|}
1,2318 \\
\end{tabular} & 1,1403 & 1,1126 & 1,0166 & 1,0118 & 0,7130 & 0,7087 & 0,7109 & 1,3909 & 1,3892 & 1,4990 & 0,8334 & 0,6600 & 0,6454 & 0,5848 & 0,4650 \\
\hline $\mathrm{AC}$ & 1108 & 1,1666 & 1,0613 & 1,0996 & 1,0004 & 1,0524 & 1,1127 & 0,9236 & 1,0217 & 1,0315 & 0,7746 & 1,0004 & 0,7222 & 0,7628 & 1,0000 & 0,6500 & 0,7000 & 0,4641 & 0,5630 \\
\hline AM & 1,3506 & 1,3236 & 1,2158 & 1,4066 & 1,4543 & \begin{tabular}{|l|l|}
1,4268 \\
\end{tabular} & $\begin{array}{ll}1,1543 \\
\end{array}$ & 1,3025 & 1,2498 & 1,2074 & 1,2342 & 1,3178 & 0,9586 & 1,1297 & 1,0000 & 1,1000 & \begin{tabular}{l|l}
1,0000 \\
\end{tabular} & 1,0000 & 1,0000 \\
\hline RR & 0,6312 & \begin{tabular}{ll|}
0,6892 \\
\end{tabular} & 0,5890 & \begin{tabular}{|l|l|}
0,6923 \\
\end{tabular} & 0,6988 & 0,7000 & 0,6875 & 0,7000 & 0,7000 & 0,6957 & 0,4808 & 0,5976 & 0,5594 & 0,5467 & 0,5046 & 0,5315 & \begin{tabular}{|c|}
0,4348 \\
\end{tabular} & 0,4069 & 0,4421 \\
\hline PA & 6025 & \begin{tabular}{|c|}
0,6988 \\
\end{tabular} & 0,6796 & $\mid 0,6597$ & 0,6840 & 0,7072 & 0,6370 & 0,7296 & 0,7507 & 0,6819 & 0,8119 & 0,7207 & 0,7022 & 0,7087 & 0,7218 & 0,7493 & \begin{tabular}{|c|}
0,7189 \\
\end{tabular} & 0,7182 & 0,6719 \\
\hline AP & 301 & 0,8854 & 0,7969 & \begin{tabular}{|c|}
0,9672 \\
\end{tabular} & 16 & \begin{tabular}{|l|l|}
1,0909 \\
\end{tabular} & 1705 & 1,1882 & 1,2527 & 1,2637 & 2929 & 0,4082 & 357 & 0,5500 & 5231 & 0,5395 & ,5522 & 42 & 0,5424 \\
\hline MA & 446 & 0,6454 & 0,6109 & 0,6081 & 0,6290 & \begin{tabular}{|c|}
0,6336 \\
\end{tabular} & 0,6146 & 0,6258 & 0,5902 & 0,6118 & ,5898 & 0,5421 & 0,4662 & 0,4699 & 0,5125 & 0,5122 & \begin{tabular}{|c|}
0,5041 \\
\end{tabular} & 0,5017 & 0,4333 \\
\hline PI & 935 & 0,9208 & 0,6981 & 0,6180 & 0,5254 & 0,5837 & 0,3739 & 0,5549 & 0,5439 & 0,4470 & 0,2612 & 0,5503 & 0,3000 & 0,3412 & 0,1700 & 0,3800 & |0,2966 & 0,2629 & 0,1433 \\
\hline $\mathrm{CE}$ & 215 & \begin{tabular}{|l|}
0,5243 \\
\end{tabular} & 0,5379 & 0,5921 & 0,4150 & \begin{tabular}{|c|}
0,5582 \\
\end{tabular} & 0,4025 & 0,5977 & \begin{tabular}{|l|l|}
0,5821 \\
\end{tabular} & 0,5364 & 2032 & 0,3595 & 0,2401 & 0,3550 & 0,1800 & 0,3000 & 0,3000 & 0,3062 & 0,1500 \\
\hline $\mathrm{RN}$ & 0,4607 & 0,4182 & 0,4117 & 0,4230 & 0,2941 & 0,4027 & 0,3773 & 0,5751 & 0,4733 & 0,3948 & 0,2221 & 0,3913 & 0,1980 & 0,2658 & 0,1897 & 0,3655 & 0,2870 & 0,1663 & 0,0665 \\
\hline PB & 0,5357 & 0,4756 & 0,4550 & 0,5354 & 0,4670 & 0,5381 & 0,3659 & 0,6054 & 0,5275 & 0,4820 & 0,3016 & 0,5065 & 0,3199 & 0,2980 & 0,1532 & 0,3053 & 0,3242 & 0,2571 & 0,1049 \\
\hline PE & 0,5139 & \begin{tabular}{l|l}
0,4402 \\
\end{tabular} & 0,4434 & 0,4714 & 0,3904 & 0,4837 & 0,4149 & 0,5978 & 0,5511 & 0,5188 & 0,3360 & 0,5311 & 0,4800 & 0,4850 & 0,2870 & 0,4710 & 0,4040 & 0,4451 & 0,2760 \\
\hline $\mathrm{AL}$ & 0,4956 & \begin{tabular}{|c|}
0,5701 \\
\end{tabular} & 0,5315 & \begin{tabular}{|c|}
0,4172 \\
\end{tabular} & 0,4424 & \begin{tabular}{|c|}
0,3862 \\
\end{tabular} & 0,5178 & 0,5257 & 0,3910 & 0,5146 & 0,1608 & 0,5192 & 0,4900 & 0,2071 & 0,1500 & 0,4400 & \begin{tabular}{|c|}
0,3801 \\
\end{tabular} & 0,5420 & 0,1900 \\
\hline SE & 0,4918 & \begin{tabular}{l|l}
0,5035 \\
\end{tabular} & 0,6243 & \begin{tabular}{|c|}
0,5935 \\
\end{tabular} & 0,4326 & \begin{tabular}{|l|}
0,2855 \\
\end{tabular} & 0,4437 & 0,3531 & 0,3912 & 0,2935 & 0,2500 & 0,4957 & 0,3620 & 0,3212 & 0,1800 & 0,3600 & 0,2740 & 0,4900 & 0,1450 \\
\hline BA & 0,7680 & 0,6770 & 0,7101 & 0,6154 & 0,6971 & 0,6922 & 0,8334 & 0,7655 & 0,7804 & 0,7842 & 0,8105 & 0,7566 & 0,6439 & 0,5785 & 0,2902 & 0,3702 & 0,4200 & 0,4807 & 0,5932 \\
\hline MG & 0,6744 & \begin{tabular}{|l|l|}
0,6443 \\
\end{tabular} & 0,5027 & \begin{tabular}{|c|}
0,4777 \\
\end{tabular} & 0,5077 & 0,5915 & 0,5425 & 0,5760 & 0,5534 & 0,5181 & 0,5566 & 0,5922 & \begin{tabular}{|c|}
0,4938 \\
\end{tabular} & 0,5018 & 0,4786 & 0,4735 & 0,4961 & 0,4685 & 0,4965 \\
\hline ES & 0,6785 & 0,6337 & 0,5598 & \begin{tabular}{|c|}
0,5529 \\
\end{tabular} & 0,6337 & \begin{tabular}{|c|}
0,5871 \\
\end{tabular} & 0,4728 & 0,5485 & 0,5390 & 0,4907 & 0,4781 & 0,5462 & 0,5298 & 0,5034 & 0,3662 & 0,4736 & 0,4795 & 0,3965 & 0,5928 \\
\hline $\mathrm{RJ}$ & 0,5737 & \begin{tabular}{|c|}
0,5441 \\
\end{tabular} & 0,4386 & \begin{tabular}{|c|}
0,4627 \\
\end{tabular} & 0,5440 & \begin{tabular}{|l|}
0,5873 \\
\end{tabular} & 0,5884 & 0,5814 & 0,4674 & 0,5470 & 0,5942 & 0,5784 & 0,6068 & 0,5933 & 0,6000 & 0,6000 & \begin{tabular}{|c|}
0,6000 \\
\end{tabular} & 0,7375 & 0,6437 \\
\hline SP & 0,6165 & 0,6262 & 0,5721 & 0,5791 & 0,5055 & 0,6245 & 0,6331 & 0,5908 & 0,5699 & 0,5553 & 0,6420 & 0,5451 & 0,4537 & 0,4674 & 0,5828 & 0,5768 & 0,4743 & 0,6546 & 0,6160 \\
\hline PR & 0,7811 & 0,8434 & 0,8261 & 0,8842 & 0,8650 & 0,9186 & 0,8559 & 0,8577 & \begin{tabular}{|c|}
0,8084 \\
\end{tabular} & \begin{tabular}{|c|c|}
0,6948 \\
\end{tabular} & 0,9235 & $\begin{array}{l}0,6563 \\
\end{array}$ & 0,6732 & 0,7914 & 0,7148 & 0,7125 & 0,6815 & 0,6744 & 0,5671 \\
\hline $\mathrm{SC}$ & 1,0232 & 1,0497 & 1,0074 & \begin{tabular}{|c|}
0,9969 \\
\end{tabular} & 1,0465 & 1,0677 & 0,9276 & 1,0585 & 1,0052 & 0,9353 & 0,8862 & 0,7412 & 0,7374 & 0,9150 & 0,6263 & 0,7120 & 0,6307 & 0,8284 & 0,5033 \\
\hline RS & 0,8480 & 0,8556 & 0,8592 & \begin{tabular}{|c|}
0,8898 \\
\end{tabular} & 0,8230 & \begin{tabular}{|l|l|}
0,9443 \\
\end{tabular} & 0,8966 & 0,9229 & \begin{tabular}{|c|}
0,8298 \\
\end{tabular} & 0,8032 & 0,9433 & 0,8004 & $\begin{array}{l}0,8068 \\
\end{array}$ & 0,8293 & 0,7709 & 0,6257 & 0,6495 & 0,7667 & 0,3910 \\
\hline $\mathrm{MT}+\mathrm{M}$ & 0,9103 & \begin{tabular}{|l|l|}
0,9268 \\
\end{tabular} & 0,7489 & \begin{tabular}{|c|}
0,8590 \\
\end{tabular} & 0,8375 & \begin{tabular}{|c|}
0,9910 \\
\end{tabular} & 1,0178 & 0,8676 & 0,8396 & 0,6992 & 0,8859 & 0,8932 & 0,7449 & 0,8560 & 0,7292 & 0,7669 & \begin{tabular}{|c|}
0,5331 \\
\end{tabular} & 0,7183 & 0,3969 \\
\hline $\mathrm{GO}+$ & 9760 & 0,8694 & 0,7388 & 0,8156 & 0,8401 & 0,9529 & 0,8790 & 0,9597 & 0,9436 & 0,6100 & 0,6831 & 0,4809 & 0,4920 & 0,5045 & 0,4862 & 0,4092 & 0,3775 & 0,3626 & 0,2281 \\
\hline $\mathrm{DF}$ & 0,0000 & 0,0000 & 0,0000 & 0,6667 & 0,7229 & $\begin{array}{c}0,7178 \\
\end{array}$ & 0,7503 & 0,9000 & 0,9000 & 0,9000 & 0,9000 & 1,2019 & 0,3398 & 0,3490 & 0,3577 & 0,5064 & 0,5000 & 0,6494 & J, \\
\hline
\end{tabular}




\section{APÊNDICE 6 - Produtividade agrícola: cultura do feijão (toneladas/ha)}

\begin{tabular}{|c|c|c|c|c|c|c|c|c|c|c|c|c|c|c|c|c|c|c|c|c|c|}
\hline & 1981 & 982 & 983 & 1984 & 1985 & 1986 & 1987 & 1988 & 1989 & 1990 & 1991 & 1992 & 1993 & 1994 & 1995 & 1996 & 1997 & 1998 & 1999 & 2000 & 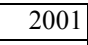 \\
\hline RO & 086 & & & & & & & & & & & & & & & & & & 057 & & 670 \\
\hline $\mathrm{IC}$ & & 70 & & & 60 & 886 & & 98 & & 763 & & 30 & 71 & & & 345 & 27 & & & 182 & 66 \\
\hline $\mathrm{M}$ & 033 & 425 & 598 & $855^{\circ}$ & 56 & 7549 & 719 & 634 & 861 & 613 & 8783 & 7011 & 296 & 90 & 0,7768 & 362 & 8732 & 83 & 8293 & 8273 & 79 \\
\hline $\mathrm{RR}$ & 352 & 120 & 138 & 918 & 4893 & 98 & 944 & 1336 & 000 & 4200 & 519 & 3168 & 000 & 5279 & 3000 & 1,55 & 2684 & 2941 & ,3000 & 288 & 28 \\
\hline A & 720 & 5819 & 4742 & 5868 & 5354 & 5624 & 6021 & 5535 & 5925 & 6024 & 0,5686 & 5131 & 5761 & 5406 & 0,5711 & 6220 & 6236 & 0,5253 & 0,6097 &, 6120 & ,7011 \\
\hline AP & 345 & 4246 & 4490 & 3814 & 6145 & 5473 & 4660 & 6549 & 5374 & 4265 & 0,1858 & 1887 & 3393 & 3413 & 0,4222 & 4712 & 2800 & 0,3000 & 0,4244 & 3810 & 6289 \\
\hline MA & 431 & 5000 & 2732 & 3988 & 3535 & 0,4793 & 0,3784 & 44571 & 4659 & 0,3807 & 0,4763 & 2512 & 3633 & 3624 & 0,3559 & 3285 & 3410 & 2798 &, 4188 &, 4450 & 4625 \\
\hline PI & 694 & 1752 & 0857 & 3174 & 2054 & 0,2485 & 1780 & 3574 & 2829 & 1612 & 0,3538 & 1139 & 1051 & 3501 & 2619 & 2851 & 2173 & 0942 & 3219 & 2964 & 1502 \\
\hline$E$ & 300 & 834 & 490 & 3595 & 2072 & 284 & 1447 & 3316 & 205 & 80 & 0,3060 & 87 & 0668 & 3824 & 019 & 53 & 3123 & 1255 & 291 & 3451 &, 1667 \\
\hline $\mathrm{N}$ & 9935 & 8 & 60 & 4475 & 0,2567 & 6 & 8833 & ),3793 & 0 & 26 & 17 & 72 & 37 & 58 & 119 & 331 & 2952 & 1067 & 349 & 4644 & 1156 \\
\hline B & 129 & 341 & 371 & 4348 & 2627 & 3209 & 285 & 3344 & 084 & 432 & 0,3358 & 2260 & 1746 & 11 & 27 & 2780 & 4128 & $0421]$ & 1324 & ,4648 & 0784 \\
\hline$E$ & 793 & 411 & 100 & 0,4450 & 9311 & 3241 & 030 & 2615 & 744 & 07 & 2504 & 567 & 70 & 0,4119 & 98 & 59 & 3493 & 1717 & 317 & 3241 & 1756 \\
\hline $\mathrm{AL}$ & 837 & 300 & 768 & 4625 & 3293 & the & 2494 & 2301 & 2174 & 592 & 0,3036 & 2863 & 536 & 11 & 4606 & 91 & 3889 & 4000 & 3945 & 3943 & 5397 \\
\hline SE & 809 & 5033 & 002 & 4376 & 2491 & 375 & 3951 & 3150 & 3424 & 3495 & 0,4249 & 2702 & 1965 & 6012 & 0,6734 & 5318 & 5786 & 5615 &, 5905 & 5128 & 3305 \\
\hline $\mathrm{BA}$ & 594 & 3253 & 0,2291 & $23 / 5$ & 0,4826 & 0,5033 & 0,2044 & 0,3340 & 3048 & $3 / 86$ & 0,4911 & ,5513 & 4332 & 4046 & 0,4301 &, 4366 & 5856 & 0,3645 & 0,4238 & 0,6534 & ,3593 \\
\hline MG & 218 & 500 & 4344 & 4375 & 0,3811 & 0,4353 & 0,4758 & 5181 & 4891 & 560 & 001 & 0,5249 & 6887 & 5977 & 0,6548 & 0,5778 & 7752 & 0,7836 & 0,8589 & 0,9324 &, 9296 \\
\hline ES & 22 & 996 & 258 & 632 & 0,4180 & 0 & 9 & 894 & 00 & 44 & 994 & 7776 & 18 & 89 & 0,6858 & 991 & 7670 & 7879 & 7751 & 7761 & 7708 \\
\hline $\mathrm{RJ}$ & 218 & 5609 & 690 & 5214 & 5425 & 5602 & 6733 & 0,7238 & 6967 & 585 & 0,7328 & ,7006 & 83 & 7417 & 0,7293 & 0,7611 & 7309 & 0,7730 & 0,7653 & 0,7405 & 0,7543 \\
\hline $\mathrm{P}$ & 04 & 828 & 847 & 217 & 7771 & 6561 & 6373 & 8820 & 8782 & 393 & 9053 & 9328 & 056 & 8842 & 0,9999 & 0,9555 & 0381 & 1,2209 & 1,1228 & 1,1205 & 1,4611 \\
\hline PR & 694 & 7577 & 4960 & 0,6466 & 0,6903 & 0,3405 & 0,5189 & 6169 & 4218 & 4331 & 0,5451 & 0,7738 & 8204 & 8610 & 0,6638 & 0,8104 & 8381 & 0,8649 & 0,8576 & 8989 & 1,0738 \\
\hline $\mathrm{SC}$ & 705 & 8711 & 1639 & 7881 & 7686 & 4919 & 6650 & 6976 & 7579 & 5503 & 0,4698 & ,9489 & 8264 & 9572 & 0,8108 & 0,8413 & 9340 & 6541 & ,7933 & 1,0598 & 1,1289 \\
\hline $\mathrm{RS}$ & 5003 & 6876 & 4932 & 0,6767 & $\begin{array}{l}0,6764 \\
\end{array}$ & 0,2737 & 0,4997 & ,7127 & 7520 & 6555 & 0,4336 & 0,8489 & 7676 & 8504 & 0,8551 & 0,4699 & $\begin{array}{l}7378 \\
\end{array}$ & 0,6370 & 0,7819 & 0,7927 & 0,9432 \\
\hline MT & 358 & 1808 & 3558 & 4291 & 4936 & 4322 & 249 & 0,4456 & 5650 & 370 & 5427 & 5403 & 727 & 5005 & 6513 & 0,6716 & 8180 & 8798 & 7501 & 6433 & 1435 \\
\hline $\mathrm{GO}+$ & 969 & 0,4059 & 0,3949 & 0,3886 & 0,3796 & 0,2849 & 0,4499 & 0,3827 & 5263 & 6268 & 0,6607 & 0,7268 & 8147 & 8875 & 0,9041 & 1,2203 & 1,5599 & 1,5788 & 1,2795 & 1,7177 & 1,6994 \\
\hline $\mathrm{DF}$ & 0,4043 & 5243 & 5959 & 0,6013 & 0,6272 & 4802 & 0,8490 & 0,7470 & 9832 & 1856 & 1,3621 & 1,0569 & 1,5449 & 1,7331 & 1,7415 & 1,6418 & 1,9332 & 1,8795 & 1,9160 & 2,2094 &, 0892 \\
\hline
\end{tabular}

Fonte: IBGE 
APÊNDICE 7 - Produtividade agrícola: cultura do fumo (toneladas/ha)

\begin{tabular}{|c|c|c|c|c|c|c|c|c|c|c|c|c|c|c|c|c|c|c|c|}
\hline & \begin{tabular}{|l|}
1960 \\
\end{tabular} & 1961 & 1962 & 1963 & 1964 & 1965 & 1966 & 1967 & 1968 & 1969 & \begin{tabular}{|l|}
1970 \\
\end{tabular} & \begin{tabular}{|l|l|}
1973 \\
\end{tabular} & \begin{tabular}{|l|}
1974 \\
\end{tabular} & \begin{tabular}{|l|}
1975 \\
\end{tabular} & 1976 & \begin{tabular}{|c|}
1977 \\
\end{tabular} & \begin{tabular}{|l|}
1978 \\
\end{tabular} & 1979 & 1980 \\
\hline RO & 1,3333 & 1,3500 & 1,3500 & 1,3500 & 1,3500 & 1,3333 & 1,3333 & 0,0000 & 0,0000 & 0,0000 & 0,0000 & \begin{tabular}{|c|}
0,5995 \\
\end{tabular} & 0,4748 & \begin{tabular}{|c|}
0,4813 \\
\end{tabular} & 1,1667 & 1,1667 & 0,0000 & 0,0000 & 0,0000 \\
\hline $\mathrm{AC}$ & 6311 & 0,6250 & 0,6130 & 0,6118 & 0,5287 & 0,6270 & 0,6398 & 0,6485 & 0,7966 & 0,6972 & 0,7285 & 0,0000 & 0,0000 & 0,0000 & 0,5455 & \begin{tabular}{|l|l|}
0,5453 \\
\end{tabular} & 0,6153 & \begin{tabular}{|c|}
0,5969 \\
\end{tabular} & 0,6163 \\
\hline$\overline{\mathrm{AM}}$ & \begin{tabular}{|c|}
0,7940 \\
\end{tabular} & 0,8000 & 0,8000 & 0,8140 & 0,7616 & 0,7730 & 0,7692 & 0,5986 & 0,7010 & 0,7152 & 0,7323 & \begin{tabular}{|l|}
0,8663 \\
\end{tabular} & 0,7773 & 0,7412 & 0,6020 & \begin{tabular}{|c|}
0,6179 \\
\end{tabular} & 0,5696 & \begin{tabular}{|c|}
0,5612 \\
\end{tabular} & 0,5975 \\
\hline $\mathrm{RR}$ & \begin{tabular}{l|l}
0,5000 \\
\end{tabular} & 0,0000 & 0,0000 & 0,0000 & 0,0000 & 0,0000 & 0,0000 & 0,0000 & 0,6000 & \begin{tabular}{|l|}
1,6667 \\
\end{tabular} & 1,7143 & \begin{tabular}{|l|}
1,7407 \\
\end{tabular} & 1,1923 & 0,0000 & 0,5833 & \begin{tabular}{|c|}
0,6000 \\
\end{tabular} & 0,0000 & \begin{tabular}{|c|}
0,6444 \\
\end{tabular} & 0,6667 \\
\hline PA & 9902 & 6862 & 0,7023 & 0,6951 & 0,6686 & ,6785 & 0,5648 & ,6003 & 0,6166 & 0,6283 & 0,6310 & 0,6944 & 0,5743 & 0,5818 & 0,5814 & 0,5299 & 0,5206 & 0,5464 & 0,5203 \\
\hline AP & 857 & 581 & 0,2647 & 759 & 0,2692 & 667 & 2571 & 2667 & 2667 & 2667 & 0,2692 & 0,0000 & 0,0000 & 0,0000 & 0000 & 0000 & 8000 & 6000 & 55 \\
\hline MA & 427 & 549 & 0,6511 & 6318 & 0,6963 & 0,6541 & 6283 & 6138 & 0,6323 & 6528 & 0,5954 & 0,5944 & 0,6356 & \begin{tabular}{|c|}
0,6064 \\
\end{tabular} & 0,6485 & \begin{tabular}{|c|}
0,5695 \\
\end{tabular} &, 7784 & \begin{tabular}{|c|}
0,7042 \\
\end{tabular} & 0,6375 \\
\hline PI & $\begin{array}{l}148 \\
\end{array}$ & 0,4327 & 0,4129 & 0,4749 & 0,4586 & 0,5086 & 0,4766 & 4983 & 0,4964 & 4611 & 0,3817 & \begin{tabular}{l|l|}
0,4123 \\
\end{tabular} & 0,7175 & \begin{tabular}{|c|}
0,5127 \\
\end{tabular} & 0,4983 & $4 / 99$ & 0,4808 & 4356 & 4063 \\
\hline$\overline{\mathrm{CE}}$ & 5836 & 0,6431 & 0,6500 & 0,6199 & 0,5982 & 0,5925 & 0,7090 & 6318 & 0,6243 & 6328 & 0,5649 & \begin{tabular}{|c|}
0,8703 \\
\end{tabular} & 0,5059 & 6000 & 0,6000 & \begin{tabular}{|c|}
0,5000 \\
\end{tabular} & 0,4800 & 4800 & 0,4000 \\
\hline $\mathrm{RN}$ & 0,5526 & 0,5981 & 0,6154 & 0,6852 & 0,8269 & 0,8829 & 0,3678 & 0,3836 & 0,3636 & 0,4135 & 0,3590 & 0,7083 & 0,4407 & 0,4595 & 0,5161 & 0,3077 & 0,3077 & 0,3333 & 0,7059 \\
\hline PB & 0,7636 & 0,7253 & 0,5938 & 0,5295 & 0,6429 & 0,5856 & 0,5973 & 0,5960 & 0,6674 & 0,9007 & 1,0126 & 0,7512 & 1,3394 & 1,1199 & 1,2133 & 1,2643 & 1,3843 & 1,3424 & 1,2494 \\
\hline$\overline{\mathrm{PE}}$ & \begin{tabular}{|l|}
0,2975 \\
\end{tabular} & 0,2913 & 0,5663 & 0,4878 & 0,5501 & 0,5101 & 0,8600 & 0,7131 & 0,7076 & 0,7780 & 0,7643 & \begin{tabular}{|c|}
0,7288 \\
\end{tabular} & 0,7665 & \begin{tabular}{|c|}
0,7723 \\
\end{tabular} & 0,7548 & \begin{tabular}{|c|}
0,6674 \\
\end{tabular} & 0,7994 & \begin{tabular}{|c|}
0,7729 \\
\end{tabular} & 0,7421 \\
\hline$\overline{\mathrm{AL}}$ & \begin{tabular}{|c|}
0,7895 \\
\end{tabular} & 0,8631 & 0,8457 & \begin{tabular}{|c|}
0,8395 \\
\end{tabular} & 0,8157 & 0,8023 & 0,6923 & 1,0975 & 1,1808 & 0,9437 & 0,8856 & \begin{tabular}{|c|}
0,9179 \\
\end{tabular} & 0,9220 & \begin{tabular}{|c|}
0,6454 \\
\end{tabular} & 0,9360 & \begin{tabular}{|c|}
0,9900 \\
\end{tabular} & 0,9807 & \begin{tabular}{|c|}
0,9000 \\
\end{tabular} & $\begin{array}{l}0,8298 \\
\end{array}$ \\
\hline SE & 0,8315 & 0,8138 & 0,9890 & 0,8043 & 0,6587 & 1,3091 & 0,7958 & 1,1176 & 0,8347 & 0,8483 & 0,8916 & 0,7334 & 0,9500 & 0,9899 & 1,0050 & 0,9450 & 1,1800 & 1,1740 & 1,1839 \\
\hline BA & 8841 & 0,6019 & 0,7130 & 6954 & 0,7365 & 0,7856 & 0,7703 & 7500 & 0,7910 &, 7427 & 0,7749 & 0,6496 & 0,7500 & 0,7500 & 0,6900 & 0,6300 & 0,9600 & |0,7600 & 0,8000 \\
\hline MG & \begin{tabular}{|l|l|}
580 \\
\end{tabular} & 0,5638 & 0,5355 & 0,4413 & 0,6025 & 0,6090 & 0,4845 & 4385 & 0,4698 & 0,5012 & 0,5269 & 0,8520 & 0,8500 & \begin{tabular}{|l|l|}
1,1831 \\
\end{tabular} & 0,7490 & 0,6799 & 0,6954 & 0,7215 & 0,7063 \\
\hline ES & \begin{tabular}{|l|l|}
143 \\
1
\end{tabular} & 0,8255 & 0,7933 & 0,7593 & 0,7875 & 0,8161 & 0,8133 & 0,7698 & 0,6972 & 0,6730 & 0,6647 & \begin{tabular}{|c|}
0,7245 \\
\end{tabular} & 0,3390 & \begin{tabular}{|c|}
0,6531 \\
\end{tabular} & 0,6098 & \begin{tabular}{|l|l|}
0,7813 \\
\end{tabular} & 0,7667 & \begin{tabular}{|l|l|}
0,8000 \\
\end{tabular} & 0,7500 \\
\hline $\mathrm{RJ}$ & \begin{tabular}{|l|}
0,5028 \\
\end{tabular} & 0,4465 & 0,4858 & 0,1790 & 0,4892 & 0,5443 & 0,4383 & 0,1905 & 0,1790 & 0,1698 & 0,1682 & $\begin{array}{ll}0,1452 \\
\end{array}$ & 0,7857 & \begin{tabular}{|c|}
0,8056 \\
\end{tabular} & 0,8286 & \begin{tabular}{|c|}
0,8148 \\
\end{tabular} & 1,2500 & \begin{tabular}{|l|}
1,3448 \\
\end{tabular} & 1,5556 \\
\hline SP & \begin{tabular}{|l|l|}
0,7540 \\
\end{tabular} & 0,6247 & 0,5902 & 0,5025 & 0,5248 & 0,5991 & 0,6484 & 0,7082 & 0,6320 & 0,7504 & 0,7408 & \begin{tabular}{|l|}
1,2503 \\
\end{tabular} & 0,5348 & \begin{tabular}{|l|}
1,2041 \\
\end{tabular} & 1,4317 & \begin{tabular}{l|l|}
1,1259 \\
\end{tabular} & 2,4476 & \begin{tabular}{|c|}
0,7017 \\
\end{tabular} & 0,4194 \\
\hline PR & 0,9458 & 1,3427 & \begin{tabular}{|l|l|}
1,3958 \\
\end{tabular} & 1,3142 & 1,4345 & 1,5249 & 1,2268 & 1,4929 & 1,4568 & 1,4622 & 1,3936 & 1,3980 & 1,5500 & 1,4320 & 1,0750 & 1,5716 & 1,4097 & 1,7325 & 1,7361 \\
\hline $\mathrm{SC}$ & 1,1636 & 1,1701 & 1,1080 & 1,1157 & 1,1832 & 1,1691 & 1,3636 & 1,5173 & 1,5314 & 1,5755 & 1,5275 & 1,3768 & 1,6352 & 1,6035 & 1,2108 & 1,4882 & 1,4393 & 1,8359 & 1,6623 \\
\hline $\mathrm{RS}$ & \begin{tabular}{|c|}
0,8572 \\
\end{tabular} & 0,8678 & 0,9375 & 1,0155 & 0,9186 & 1,0293 & 0,9018 & 0,9882 & 0,9771 & 1,0609 & 1,0223 & \begin{tabular}{l|l|}
1,1342 \\
\end{tabular} & 1,5733 & \begin{tabular}{|l|}
1,2674 \\
\end{tabular} & 1,2533 & \begin{tabular}{|l|}
1,2374 \\
\end{tabular} & 1,3510 & \begin{tabular}{|l|l|}
1,3290 \\
\end{tabular} & 1,3764 \\
\hline $\mathrm{MT}+1$ & \begin{tabular}{|l|l|}
0,5559 \\
\end{tabular} & 0,5899 & 0,6000 & 0,6124 & 0,6376 & 0,6274 & 0,5482 & 0,7109 & 0,7172 & 0,6721 & 0,6767 & \begin{tabular}{|c|}
0,6396 \\
\end{tabular} & 0,9414 & 0,9125 & 0,5793 & 0,7000 & 0,6933 & \begin{tabular}{|c|}
0,6622 \\
\end{tabular} & 0,6082 \\
\hline MT & 0,7377 & 7752 & 0,7714 & 7733 & 0,7986 & ,7951 & 0,8611 & $814 /$ & 0,8395 & 8477 & 0,7386 & 0,8800 & 8699 & 0,8400 & , & $0,6 / 99$ & ,7200 & 0,6357 &, 6015 \\
\hline $\mathrm{DF}$ & 0,0000 & 0,0000 & 0,0000 & 0,0000 & 0,0000 & 0,0000 & 0,0000 & 0,0000 & 0,0000 & 0,0000 & 0,0000 & 0,0000 & 0,0000 & 1,0000 & 1,0000 & 1,0000 & 0,0000 & 0,0000 & $0,000 \mathrm{c}$ \\
\hline
\end{tabular}




\section{APÊNDICE 7 - Produtividade agrícola: cultura do fumo (toneladas/ha)}

\begin{tabular}{|c|c|c|c|c|c|c|c|c|c|c|c|c|c|c|c|c|c|c|c|c|c|}
\hline & 881 & 1982 & 983 & 1984 & 1985 & 1986 & 1987 & 1988 & 1989 & 1990 & 1991 & 1992 & 1993 & 1994 & 1995 & 1996 & 1997 & 1998 & 1999 & 2000 & 2001 \\
\hline $\mathrm{O}$ & 000 & 000 & 000 & 0,0000 & 0,0000 & 000 & 000 & (2000t &, 0000 &, 0000 & 000 & 000 & 000 & 000 &, 0000 & 000 & 000 &, 0000 &, 0000 &, 0000 &, 0000 \\
\hline $\mathrm{C}$ & 302 & 349 & 513 & 495 & 5499 & 210 & 272 & 295 & 90 & 3 & 377 & 33 & 34 & 34 & 7764 & 90 & 90 & 20 & 52 & 91 & 8246 \\
\hline$\overline{\mathrm{AM}}$ & & 181 & 9 & 0075 & 35 & 6 & 6185 & 21 & 0 & & & 57 & 88 & 14 & 86 & 19 & 1 & 44 & & & \\
\hline & & 0 & & 667 & & & & & & & & & & 0 & 00 & & & 00 & & & \\
\hline & & & & & & & & & & & & & & & & & & & & & \\
\hline$P$ & 000 & 00 & 00 & 000 & & 0 & 10 & 000 & & & & & 0000 & & & & & 5000 & & & \\
\hline A & 373 & 679 & 720 & 5500 & 46 & 508 & 9953 & 5123 & 55 & 27 & 402 & & & & 0,5 & 00 & & 000 & 4828 & 00 & 000 \\
\hline & 691 & (3693 & 8881 & 4624 & 1512 & 694 & 1885 & 5299 & 5816 & 5341 & 0,6000 & 5714 & 47 & 6163 &, 7324 & 0000 & 33 & 9000 & 9130 & 9048 & 7143 \\
\hline & 000 & 4425 & 3793 & 6024 & 2715 & 397 & 2360 & 6211 & 6698 & 6826 & 0,6885 & 7171 & 7431 & 7789 & 0,7885 & 8596 & 8365 & 8138 & 8,8077 & 8160 & 9151 \\
\hline & 333 & 500 & 6667 & 222 & 1756 & 3889 & 4717 & 3750 & 4952 & $167 \mathrm{C}$ & 5301 & 4398 & 74 & 154 & 6058 & 6538 & 6360 & 2079 &, 6588 & 6725 & 6262 \\
\hline B & 739 & 860 & 1152 & 33 & 10 & 226 & 53 & 7083 & 7301 & 25 & 97 & 14 & 89 & 19 & \begin{tabular}{ll|}
7718 \\
\end{tabular} & 6579 & 98 & 5185 & 8063 & 6595 & 7104 \\
\hline $\mathrm{E}$ & 578 & 7962 & 6 & 8128 & 7901 & 8793 & 4 & .7238 & 55 & 0 & 83 & 74 & 0 & 2 & 0,5091 & 00 & 73 & 67 & 2500 & 7000 & 500 \\
\hline$\overline{\mathrm{AL}}$ & 565 & 9436 & 92 & 0,9955 & $\overline{8}$ & 9 & 8003 & ,7906 & 2 & 1625 & 0,7254 & 09 & 77 & 66 & 0,9755 & 9276 & 39 & 1238 & 1251 & 8964 & 797 \\
\hline $\mathrm{SE}$ & 840 & 8070 & 6 & 1,1951 & 2 & 0 & 1,0786 & , 0777 & 0761 & 1,0733 & 1,1886 & 70 & 2 & 1 & 1,5943 & 01 & 1 & 1,4776 & 5283 & 5726 & 195 \\
\hline$B A$ & 361 & 500 & 941 & 375 & 98 & 200 & 28 & 7428 & 7208 & 191 & 6996 & 36 & 55 & 0,8087 & 7266 & 83 & 593 & 7728 & 716 & 8096 & 834 \\
\hline MG & 908 & 721 & 5715 & 7035 & 6666 & 900 & 26 & 6727 & 6460 & 5123 & 6015 & 6113 & 6280 & 6161 & 5130 & 6565 & 125 & 8022 & 7253 & 6367 & 6997 \\
\hline ES & 750 & 7750 & 0000 & 1250 & 1250 & 750 & 0000 & 0000 & 0000 & 0000 & 0,0000 & $\overline{0000}$ & 0000 & 0000 & 0,0000 & 0000 & 000 & 0000 &, 0000 & 0000 & 0000 \\
\hline RJ & 333 & 5000 & 1429 & 2,0000 & 6667 & 5000 & 5000 & 5000 & 0000 & 0000 & 0,0000 & 0000 & 0000 & 0000 & 0,0000 & , & 0000 & 0,0000 & 0,0000 &, 0000 & 0000 \\
\hline SP & 3000 & (5675 & 0,5789 & 0,5498 & 5251 & $\$ 210$ & 4173 & 5643 & 4505 & 4551 & 0,4324 & 5042 & 4583 & 0,4881 & 0,4928 & 4478 & 4821 & 4048 & 0,4924 & ,4924 &, 4841 \\
\hline & 568 & 133 & 5290 & 1,7893 & 89 & 132 & 24 & 9752 & 8387 & 16 & 8147 & ,9624 & 8986 & 9160 & 1,6145 & 7118 & 997 & 4800 & , 8829 & 9038 & ,9748 \\
\hline & & 507 & 777 & 6606 & & 4406 & 37 & 7348 & 971 & 3090 & 7077 & 8234 & 7946 & 62 & 6758 & 6170 & 53 & 226 & 9396 & 594 & 902. \\
\hline & & & & & & 20 & & 59 & & & 46 & 81 & 20 & 12 & 120 & 95 & 00 & 99 & 2,0189 & 0269 & 005 \\
\hline MII & 122 & 324 & 796 & 407 & 043 & 172 & 52 & 555 & 4000 & 00 & 1053 & 2727 & 67 & 4000 & 527 & 4000 & $\overline{0000}$ & 0000 & ,0000 & $\overline{0000}$ & $\overline{000}$ \\
\hline & 0,610 & 5108 & 5267 & 5161 & 53 & 5441 & 5019 & 4643 & 358 & 0000 & 2500 & 2500 & 0000 & 3000 & 25 & 6512 & 6667 & 460 & 500 & 00 & 000 \\
\hline DF & & 0000 & 00 & 0,0000 & & 1000 & & & 0000 & 0,0000 & $0,000 \mathrm{c}$ & (2) & 0000 & & 0,000 & 0,0000 & & 0,000 & 00 & 000 & , \\
\hline
\end{tabular}

Fonte: IBGE 


\section{APÊNDICE 8 - Produtividade agrícola: cultura da laranja (mil frutos/ha)}

\begin{tabular}{|c|c|c|c|c|c|c|c|c|c|c|c|c|c|c|c|c|c|c|c|}
\hline & 1960 & 1961 & 1962 & 1963 & 1964 & 1965 & 1966 & 1967 & 1968 & 1969 & 1970 & 1973 & 1974 & 1975 & 1976 & 1977 & 1978 & 1979 & 1980 \\
\hline RO & 3,7500 & 27,0000 & 29,5000 & 29,7500 & 0,2162 &, 2162 & 2432 &, 2703 &, 7838 & 26,7143 & 5,0000 & 51,7241 & 5,9714 & 48,0769 & 9,0000 & 63,2267 & 61,7310 & 55,8102 & 56,4448 \\
\hline $\mathrm{AC}$ & 54,7265 & 49,5664 & 49,0678 & 49,4958 & 48,6777 & 45,8943 & 47,8175 & 47,1774 & 48,8682 & 56,5891 & 65,0000 & 44,8056 & 66,0638 & 64,0404 & 89,5082 & 83,7097 & 78,3704 & 75,7681 & 83,1951 \\
\hline $\mathrm{AM}$ & 94,3046 & 107,7308 & 75,0528 & 77,5345 & 68,5333 & 69,4796 & 67,9142 & 71,5929 & 83,0964 & 84,3180 & 82,0259 & 52,5121 & 51,1912 & 46,2110 & 74,4144 & 105,5549 & 111,2143 & 110,5876 & 100,6014 \\
\hline RR & 100,0000 & 5,0000 & 0,0000 & 58,3333 & 70,8333 & 70,8333 & 61,3636 & 40,9091 & 60,0000 & 100,0000 & 115,7895 & 71,7647 & 30,0200 & 33,9773 & 59,9744 & 45,5833 & 36,2083 & 33,5600 & 3103 \\
\hline A & ,3048 & 90,9451 & 0,0000 & 95,1402 & 91,1771 & 91,5730 & 89,8326 & 103,7803 & 111,4988 & 104,3942 & 109,5902 & 72,7193 & 96,1021 & 118,8612 & 96,3593 & 104,4162 & 113,8895 & 115,1461 & 112,0712 \\
\hline AP & 149,7143 & 150,4000 & 139,2632 & 152,9474 & 161,5652 & 153,6923 & 179,2258 & 113,7059 & 122,5294 & 131,5556 & 134,1905 & 78,3881 & 42,4500 & 44,9333 & 41,9231 & 40,0377 & 33,8596 & 40,0000 & 40,0000 \\
\hline MA & 97,1185 & 92,6944 & 96,9460 & 96,2640 & 97,9362 & 974 & 290 & 442 & 481 & 179,1744 & 172, & 75,9565 & 72 & 117,7846 & 117,2241 & 114,7648 & 19 & 116 & 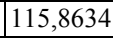 \\
\hline PI & 0141 & 6,4548 & , & 88,9259 & 99,0843 & 124,8998 & 109,6353 & 109,2420 & 257 & 112,8121 & 95,2097 & 78,6395 & 90,8531 & 101,7511 & 107,8204 & 119,2991 & 4101 & 108,8445 & 103,7471 \\
\hline EE & 5400 & 2734 & 63,9616 & 66,1878 & 329 & 72,6231 & 416 & 91,9515 & 916 & 784 & 78,6511 & 49 & 842 & 379 & 99,9052 & 100,0000 & 100,0000 & 80,0000 & 0 \\
\hline RN & 45,8424 & 42,7094 & 44,7548 & 39,2905 & 41,8008 & 44,1619 & 40,1375 & 50,5819 & 41,7775 & 33,9208 & 32,0823 & 36,1130 & 54,5309 & 57,1204 & 58,6608 & 65,8152 & 63,2967 & 61,9266 & 02 \\
\hline PB & 134,0653 & 124,7568 & 120,2274 & 122,1049 & 119,6520 & 127,2636 & 114,1735 & 141,1537 & 121,0237 & 120,8556 & 125,6742 & 61,8252 & 118,1336 & 113,4506 & 65,7869 & 83,0465 & 112,7500 & 101,7500 & 107,2500 \\
\hline $\mathrm{PE}$ & 67,8887 & 68,2156 & 63,4040 & 64,3922 & 58,2641 & 58,8306 & 62,5424 & 71,9133 & 71,3023 & 68,1322 & 64,0945 & 63,4543 & 75,8452 & 64,8000 & 64,8000 & 64,8000 & 71,1841 & 65,0000 & 67,9900 \\
\hline $\mathrm{AL}$ &, 9009 & 66,6323 & 62,3920 & 59,8641 & 56,5750 & 59,7407 & 56,6282 & 10 & 10 & 91,6 & 84, & 97, & 78,3564 & 78,1222 & 73,3125 & 71,8702 & 72,3875 & 76,6214 & 74,2767 \\
\hline SE & 66,7985 & 67,6865 & 67,9236 & 70,9583 & 70,3722 & 67,3594 & 50,8273 & 77,1173 & 79,0468 & 76,1585 & 44,9189 & 45,7351 & 79,9000 & 66,4999 & 68,3000 & 72,0000 & 110,0074 & 80,7290 & 103,0240 \\
\hline BA & 69,9412 & 65,2780 & 76,5855 & 75,9513 & 78,5850 & 78,5086 & 75,2486 & 72,4738 & 71,0489 & 73,4988 & 71,6787 & 62,3087 & 69,8040 & 72,0000 & 69,0000 & 69,0000 & 72,1800 & 78,0000 & 81,0000 \\
\hline MG & 72,7422 & 72,0805 & 73,4316 & 72,9112 & 70,0649 & 74,7326 & 71,6164 & 75,6936 & 81,6529 & 85,0972 & 85,0114 & 72,7906 & 70,1250 & 72,9444 & 76,1427 & 74,7205 & 72,3182 & 69,2216 & 71,0037 \\
\hline ES & 8839 & 40,3790 & 43,3914 & 53,1935 & 48,4747 & 47,6417 & 48,0753 & 47,5619 & 47,7213 & 45,9612 & 49,8923 & 68,9274 & 50,0000 & 115,0000 & 115,0000 & 115,0000 & 115,0000 & 115,0000 & 88,5000 \\
\hline $\mathrm{RJ}$ & 84,1388 & 82,1599 & 78,9773 & 89,8276 & 88,9501 & 87,8744 & 80,3059 & 75,2885 & 70,5507 & 77,7236 & 75,3603 & 59,0960 & 76,6059 & 75,0740 & 75,0740 & 75,0000 & 77,5330 & 80,8257 & 66,1872 \\
\hline SP & 66,7423 & 69,0245 & 66,8269 & 70,2099 & 64,7515 & 70,7899 & 68,3315 & 71,1493 & 78,7135 & 75,9741 & 41,9646 & 49,5918 & 90,3756 & 77,7235 & 90,4969 & 87,6381 & 87,2250 & 92,5354 & 99,1929 \\
\hline PR & 13,5352 & 08,1606 & 114,4160 & 112,2130 & 93,6870 & 19,9877 & 110,4026 & 103,9864 & 109,8074 & 112,4441 & 110,0312 & 90,7196 & 96,0000 & 87,3550 & 107,8674 & 92,9969 & 83,2641 & 86,1003 & 85,8087 \\
\hline SC & 104,3452 & 101,0013 & 98,8419 & 96,5813 & 96,8456 & 100,3212 & 108,5049 & 120,0359 & 128,3889 & 131,5672 & 134,7408 & 121,4738 & 119,9755 & 132,3275 & 110,0000 & 110,6541 & 128,3073 & 153,1510 & 153,4123 \\
\hline RS & 67,0905 & 68,3808 & 69,4933 & 65,8770 & 60,8685 & 66,4721 & 51,1462 & 64,2633 & 61,5452 & 66,2647 & 67,7921 & 63,0025 & 63,0360 & 71,7063 & 72,1304 & 76,2500 & 72,3739 & 75,3498 & 79,5000 \\
\hline $\begin{array}{l}\text { MT+ } \\
\text { MS }\end{array}$ & 48,1525 & 44,4585 & 122,1375 & 21,0035 & 95,0450 & 131,0938 & 121,9931 & 121,3940 & 83,2199 & 74,3345 & 79,2794 & 71,4805 & 71,4340 & 70,3621 & 76,7639 & 85,5569 & 82,7401 & 92,2368 & 90,0557 \\
\hline GO+ & 61,3675 & 4,4695 & 68,2897 & 65,2047 & ,5048 & 66,8851 &, 7890 & 72,6833 & 4,9976 & ,5714 & 1,3401 & 111,6606 & 2,0000 & 72,0000 & 72,0000 & 66,0000 & 68,0000 & 75,0000 & 77,1534 \\
\hline DF & 0000 & 123,6667 & 0,0000 & 37,5000 & 38,4615 &, 4545 &, 0000 &, 8148 &, 0909 &, 6825 & 9,6825 & 65,0317 &, 0000 & 8549 & 3,9268 & 25,8667 & 92,1585 & 60,1467 & 71,7935 \\
\hline
\end{tabular}


APÊNDICE 8 - Produtividade agrícola: cultura da laranja (mil frutos/ha)

\begin{tabular}{|c|c|c|c|c|c|c|c|c|c|c|}
\hline & 1981 & 1982 & 1983 & 1984 & 1985 & 1986 & 1987 & 1988 & 1989 & 1990 \\
\hline RO & 54,8403 & 53,7427 & 52,6636 & 53,3012 & 49,3434 & 48,0524 & 47,9829 & 51,1176 & 51,3994 & 62,6032 \\
\hline $\mathrm{AC}$ & 74,3372 & 69,8791 & 87,1398 & 90,1158 & 100,8932 & 105,2500 & 101,4476 & 106,3394 & 104,4425 & 100,4958 \\
\hline $\mathrm{AM}$ & 101,3904 & 97,1099 & 99,9638 & 88,5398 & 89,6752 & 79,5476 & 81,6198 & 81,8050 & 89,8073 & 72,9346 \\
\hline $\mathrm{RR}$ & 50,0000 & 55,0000 & 28,0000 & 28,0000 & 28,0000 & 14,2810 & 14,2753 & 14,2805 & 14,2356 & 13,6000 \\
\hline $\mathrm{PA}$ & 115,1687 & 114,8239 & 100,3514 & 166,1635 & 127,2763 & 236,6898 & 180,0365 & 178,9109 & 103,0673 & 108,5867 \\
\hline $\mathrm{AP}$ & 40,0000 & 36,4835 & 37,4138 & 46,1333 & 41,0185 & 41,3448 & 48,1864 & 66,6714 & 50,5455 & 38,2267 \\
\hline MA & 113,8215 & 118,3317 & 117,3823 & 115,0318 & 109,9025 & 109,9302 & 107,5009 & 104,5025 & 105,7975 & 100,1512 \\
\hline PI & 109,8452 & 102,5739 & 64,1474 & 115,7790 & 117,0328 & 132,9977 & 108,6933 & 125,2695 & 125,4222 & 123,2865 \\
\hline $\mathrm{CE}$ & 50,0000 & 100,0000 & 47,0439 & 62,1103 & 52,0000 & 61,8924 & 54,5367 & 57,5443 & 56,4938 & 55,3870 \\
\hline $\mathrm{RN}$ & 57,1093 & 42,7513 & 35,4742 & 43,7970 & 66,9452 & 58,0244 & 57,5214 & 53,8756 & 52,9364 & 50,7652 \\
\hline $\mathrm{PB}$ & 117,3590 & 95,5517 & 78,2460 & 84,7304 & 77,9261 & 74,3934 & 65,2300 & 73,9423 & 74,7752 & 74,1239 \\
\hline $\mathrm{PE}$ & 63,1178 & 64,2901 & 59,5312 & 60,7694 & 62,4391 & 59,4785 & 55,8831 & 57,6034 & 57,6295 & 54,5354 \\
\hline $\mathrm{AL}$ & 75,2339 & 80,1393 & 62,5788 & 58,5549 & 59,3675 & 59,5359 & 53,8394 & 53,0897 & 54,1673 & 44,8014 \\
\hline SE & 106,1404 & 106,1447 & 83,2499 & 97,8288 & 103,2360 & 107,4610 & 106,8636 & 109,8930 & 108,5221 & 106,9051 \\
\hline BA & 89,7570 & 87,9880 & 70,8643 & 68,0000 & 78,0000 & 78,0016 & 70,0935 & 71,0000 & 74,0255 & 73,7146 \\
\hline MG & 73,3014 & 70,1741 & 64,9872 & 65,7099 & 61,3194 & 61,5173 & 66,2399 & 72,7422 & 63,5572 & 60,0107 \\
\hline ES & 88,4860 & 75,8908 & 81,1806 & 83,4551 & 82,3715 & 81,7184 & 80,8820 & 80,8177 & 68,7151 & 65,6197 \\
\hline RJ & 66,8861 & 63,7750 & 64,1686 & 64,6918 & 64,0245 & 63,7329 & 62,4342 & 63,1948 & 71,6742 & 71,2301 \\
\hline SP & 104,0053 & 103,7770 & 100,0000 & 110,7464 & 116,4895 & 99,1170 & 107,7098 & 97,1266 & 106,1296 & 100,0553 \\
\hline $\mathrm{PR}$ & 87,3985 & 89,9595 & 83,7528 & 82,4742 & 82,9769 & 83,4065 & 81,8432 & 82,0677 & 92,3305 & 98,1887 \\
\hline $\mathrm{SC}$ & 165,5414 & 160,6214 & 137,1523 & 73,0904 & 74,1174 & 74,4068 & 75,0000 & 108,9275 & 151,8903 & 141,0173 \\
\hline $\mathrm{RS}$ & 87,4541 & 82,5483 & 86,4407 & 86,2373 & 86,4920 & 82,4003 & 89,4339 & 75,4625 & 82,9573 & 80,5915 \\
\hline $\mathrm{MT}+\mathrm{MS}$ & 82,6955 & 73,8417 & 80,5689 & 79,1819 & 79,9625 & 73,7955 & 64,9983 & 63,8264 & 65,1129 & 65,6511 \\
\hline $\mathrm{GO}+\mathrm{TO}$ & 80,0000 & 74,7201 & 77,9640 & 74,9281 & 73,8941 & 76,1940 & 73,2131 & 73,3733 & 73,2452 & 72,0888 \\
\hline $\mathrm{DF}$ & 68,6891 & 50,0000 & 50,0000 & 50,0000 & 50,0000 & 50,0000 & 50,0000 & 50,6995 & 50,0000 & 50,0000 \\
\hline
\end{tabular}


APÊNDICE 8 - Produtividade agrícola: cultura da laranja (mil frutos/ha)

\begin{tabular}{|c|c|c|c|c|c|c|c|c|c|c|c|}
\hline & 1991 & 1992 & 1993 & 1994 & 1995 & 1996 & 1997 & 1998 & 1999 & 2000 & 2001 \\
\hline RO & 66,9509 & 69,3579 & 71,5020 & 64,1535 & 66,4189 & 49,3834 & 51,7211 & 70,0624 & 63,0812 & 68,3920 & 60,6338 \\
\hline $\mathrm{AC}$ & 100,2750 & 102,9083 & 103,1704 & 107,2112 & 103,2367 & 44,8902 & 40,6615 & 45,9537 & 46,3187 & 45,9896 & 52,4212 \\
\hline $\mathrm{AM}$ & 56,7560 & 34,7072 & 38,6167 & 30,4936 & 29,8637 & 22,2604 & 37,4946 & 40,3293 & 39,4878 & 40,5818 & 32,7480 \\
\hline RR & 12,8527 & 8,8696 & 0,0000 & 18,6567 & 25,0000 & 9,3563 & 14,5983 & 6,2500 & 28,3375 & 28,1250 & 62,5000 \\
\hline PA & 129,6361 & 64,3524 & 89,6091 & 99,9286 & 100,4555 & 100,5999 & 97,3778 & 91,3941 & 94,1979 & 89,8346 & 103,7680 \\
\hline AP & 42,2667 & 49,2763 & 45,0612 & 44,7561 & 44,7241 & 67,4627 & 62,2652 & 59,1133 & 55,8406 & 52,7613 & 64,3652 \\
\hline MA & 98,3251 & 91,7115 & 93,8808 & 93,8584 & 91,8347 & 44,0824 & 33,5524 & 35,7775 & 37,7799 & 38,6767 & 41,4349 \\
\hline PI & 122,8206 & 83,6933 & 79,1872 & 112,1019 & 113,2127 & 52,1460 & 72,2414 & 54,3615 & 56,3520 & 55,6800 & 59,6918 \\
\hline $\mathrm{CE}$ & 62,6995 & 70,4549 & 61,7127 & 65,1249 & 59,8693 & 46,8170 & 46,8589 & 51,1056 & 51,2006 & 52,1961 & 59,0408 \\
\hline $\mathrm{RN}$ & 49,0377 & 48,2620 & 43,0472 & 43,9280 & 42,4805 & 44,9231 & 45,3272 & 44,4920 & 44,0415 & 43,8618 & 56,6754 \\
\hline PB & 75,5443 & 76,0955 & 50,4287 & 53,8995 & 53,6539 & 36,8693 & 41,0685 & 31,8433 & 34,3850 & 37,7058 & 50,2292 \\
\hline $\mathrm{PE}$ & 59,0430 & 56,2384 & 46,8153 & 53,5047 & 52,0848 & 37,3163 & 39,1907 & 36,2354 & 36,3782 & 37,2476 & 27,6360 \\
\hline $\mathrm{AL}$ & 45,7326 & 43,9585 & 47,6372 & 32,1183 & 47,5411 & 48,6486 & 51,1365 & 49,3114 & 49,0064 & 48,7707 & 54,9744 \\
\hline SE & 124,8801 & 102,4894 & 114,3195 & 106,1803 & 84,0523 & 78,8079 & 103,0267 & 75,3429 & 58,5035 & 61,3181 & 73,0031 \\
\hline $\mathrm{BA}$ & 73,1251 & 76,6857 & 70,1001 & 78,2344 & 78,6751 & 79,1218 & 82,6984 & 75,8881 & 67,6526 & 68,8423 & 109,3270 \\
\hline MG & 60,1753 & 49,3912 & 66,4148 & 63,3915 & 63,8401 & 60,1866 & 64,0073 & 62,6146 & 62,3081 & 63,1198 & 81,9555 \\
\hline ES & 65,6049 & 73,0361 & 67,6763 & 70,4024 & 66,7890 & 72,6338 & 67,5965 & 60,3233 & 63,9265 & 65,5638 & 67,0544 \\
\hline $\mathrm{RJ}$ & 51,7082 & 50,9734 & 49,7523 & 49,2349 & 51,8273 & 64,8326 & 68,0891 & 69,2609 & 74,6405 & 74,7997 & 90,9436 \\
\hline SP & 100,1136 & 105,7646 & 131,2803 & 103,2596 & 129,7985 & 121,8986 & 128,7783 & 111,0909 & 124,8001 & 145,9999 & 145,4234 \\
\hline PR & 96,0467 & 91,2875 & 93,7580 & 97,7074 & 104,2659 & 114,4987 & 135,7844 & 136,1934 & 135,5047 & 136,5168 & 137,7926 \\
\hline SC & 113,6830 & 141,6141 & 147,2822 & 111,9236 & 129,0522 & 52,9233 & 80,3248 & 75,2045 & 64,9193 & 73,2989 & 81,2395 \\
\hline RS & 76,4335 & 80,3859 & 81,9826 & 80,3110 & 79,0919 & 65,8967 & 76,7067 & 71,1130 & 71,5787 & 73,3648 & 80,1502 \\
\hline $\mathrm{MT}+\mathrm{I}$ & 66,5162 & 59,7722 & 72,8169 & 67,9432 & 71,1751 & 62,5113 & 65,8349 & 62,7382 & 61,9111 & 64,8440 & 69,1935 \\
\hline GO+ TO & 54,7090 & 65,9051 & 87,0867 & 88,1549 & 74,3447 & 59,1996 & 74,1421 & 76,6377 & 68,6992 & 83,6943 & 111,2124 \\
\hline $\mathrm{DF}$ & 49,2000 & 22,3233 & 32,5991 & 34,4466 & 53,1712 & 57,7515 & 57,7524 & 89,6578 & 107,3446 & 131,5046 & 141,1990 \\
\hline
\end{tabular}

Fonte: IBGE 


\section{APÊNDICE 9 - Produtividade agrícola: cultura da mandioca (toneladas/ha)}

\begin{tabular}{|c|c|c|c|c|c|c|c|c|c|c|c|c|c|c|c|c|c|c|c|}
\hline & 1960 & 1961 & 1962 & 1963 & 1964 & 1965 & 1966 & 1967 & 1968 & 1969 & 1970 & 1973 & 1974 & 1975 & 1976 & 1977 & 1978 & 1979 & 1980 \\
\hline RO & 9,8355 & 3,5797 & 8,2854 & 3,2566 & 3,4573 & 17,6637 & 18,6069 & 7,5386 & 7,4419 &, 2120 & ,2381 &, 7423 & 0000 & 1,3461 & 13,2808 & 15,5172 & 13,7668 & 15,8750 & 15,6190 \\
\hline $\mathrm{AC}$ & 0,3526 & 18,5480 & 21,0693 & 20,7047 & 21,2195 & 20,7213 & 20,2777 & 21,3318 & 19,7858 & 9,9173 & 20,9861 & 10,2396 & 14,2345 & 13,3251 & 14,0000 & 14,0000 & 15,0000 & 14,0472 & 14,5700 \\
\hline AM & ,9839 & 19,7662 & 25,7072 &, 5315 & 24,6871 & 26,6086 & 26,7603 & 0344 & 3150 & 3524 & 5711 & 21,7442 & 21,0000 & 14,2308 & 12,2456 & 12,0001 & 12,0000 & 12,0000 & 12,0000 \\
\hline $\overrightarrow{\mathrm{RR}}$ & 2701 & 0,0000 & 0,0000 &, 0000 & 0789 & 4,5604 & 5,0000 & 5,0000 & 5,0000 & 5,0000 & 0,0000 & \begin{tabular}{|c|}
10,6934 \\
\end{tabular} & 12,0000 & 10,2872 & $\begin{array}{ll}11,0859 \\
\end{array}$ & 11,7084 & 12,3274 & 11,3230 & 4,3039 \\
\hline PA & 58 & 6155 & 2102 & 222 & 53 & 56 & 596 & 6568 & ,6489 & 075 & 809 & 1628 & 9,8643 & 10,0999 & 10,7326 & 10,7301 & 7150 & 12,9996 & 87 \\
\hline $\mathrm{AP}$ & 5053 & 9,7014 & 9611 & 8507 & 7727 & 4007 & 113 & 4274 & 30 & 260 & 5571 & 10,5206 & 10,0000 & 10,0000 & 000 & 00 & 10,0000 & 10,0000 & \\
\hline MA & 9,8732 & 9,3193 & 0391 & ,1611 & 5566 & 0,8850 & 9156 & 9871 & 0518 & 4065 & 311 & 0514 & (5828 & 8,4923 & 8,6765 & 8,7502 & 8,5955 & 8,8817 & $\overline{8,9}$ \\
\hline PI & 8206 & 10,4295 & 2289 & ,5227 & , 6023 & 1,0366 & 9,5099 & 2266 & 8826 & 4511 & 0641 & 4861 & 7,5000 & 7,7813 & 1610 & 750 & 8,7688 & 8,8510 & 8,0169 \\
\hline CE & 13,2790 & 16,9051 & 15,5648 & 16,2582 & 15,0426 & 15,5823 & 15,4666 & 16,1048 & ,5,5487 & 5,7218 & 13,5367 & 14,2734 & 8,0000 & 10,0000 & 10,0000 & 10,0000 & 9,0000 & 7,0000 & 7,0000 \\
\hline $\mathrm{RN}$ & 5,6693 & 5,6614 & 5,8999 & 5,6130 & 5,0887 & 4,9491 & 5,4313 & 6,2448 & 6,4132 & 6,7545 & 6,4766 & 6,2524 & 4,7600 & 7,9126 & 7,9420 & 8,0408 & 8,3281 & 8,3993 & 8,9958 \\
\hline PB & 11,4537 & 10,9831 & 11,1916 & 10,6518 & 10,0666 & 10,7002 & 9,1566 & 10,7772 & 10,0338 & 10,0264 & 10,3827 & 9,8414 & 9,8146 & 8,8340 & 8,6140 & 8,7570 & 9,1073 & 8,4143 & 8,4483 \\
\hline $\mathrm{PE}$ & 9,1558 & 9,2660 & 11,0181 & 10,6263 & 10,6832 & 10,1072 & 9,9942 & 10,9497 & 11,3280 & 12,4264 & 11,6953 & 10,6351 & 10,0000 & 10,0000 & 9,6080 & 10,1513 & 10,0000 & 10,4043 & 8,4001 \\
\hline $\mathrm{AL}$ & 9,7417 & 10,6549 & 3775 & 2161 & 9,4970 & 9,7727 & 10,1449 & 11,4368 & ,1870 & 1,2533 & 8,3362 & 10,4974 & 10,0359 & 10,2970 & 9,0000 & 10,3000 & 10,3021 & 10,0000 & 9,0499 \\
\hline SE & 4993 & 15,9615 & , & 1,1823 & 0541 &, 2317 & 9157 &, 2944 & 5324 &, 4734 & 17,4741 & 15,4942 & 12,0000 & 12,0000 & 12,0000 & 11,0000 & 12,9020 & 12,9640 & 13,8090 \\
\hline BA & 8419 & ,4964 &, 2605 & 3721 &, 2552 & 15,6586 & 8589 & 7,0000 & ,2662 &, 7650 & 7,7768 & 14,0136 & 16,0000 & 17,0000 & 15,0000 & 15,0000 & 15,0000 & 16,0000 & 16,0000 \\
\hline $\mathrm{MG}$ & 3087 & 15,9974 & ,2333 &, 7971 & 16,0133 & 5,9888 & 16,0179 & 7,0793 & 7,1254 & 8379 & 6,6136 & 14,9112 & 14,8252 & 16,3123 & 15,7908 & 15,4973 & 15,0779 & 14,9729 & 15,0912 \\
\hline ES & 4206 & 16,6010 &, 2970 & 13,3558 & 13,6416 & 13,2772 & 13,8722 & 3,5971 & 1,1653 & 5,6287 & 5,6735 & 7,7321 & 14,0000 & 14,0000 & \begin{tabular}{|c|}
13,9498 \\
\end{tabular} & 14,0000 & 14,0000 & 14,9627 & 15,0055 \\
\hline $\mathrm{RJ}$ & ,4499 & 11,5996 & 12,4641 & 11,1978 & 11,7449 & 12,2149 & 12,9331 & 12,9326 & 12,8103 & 12,4213 & 12,6264 & 12,6050 & 13,1952 & 13,5000 & 13,2000 & 14,4223 & 14,3025 & 13,7790 & 14,0222 \\
\hline SP &, 4645 & 18,6354 & 17,5256 & 19,5620 & 18,3448 & 19,6399 & 18,7517 & 19,1507 & 18,8715 & 18,2790 & 18,8190 & 17,3544 & 18,2815 & 18,7013 & 20,6780 & 21,7125 & 21,1268 & 19,8921 & 18,4955 \\
\hline PR & 16,6084 & 14,8682 & 16,9560 & 17,3813 & 22,8734 & 22,9528 & 19,7172 & 18,1181 & 21,9529 & 21,9154 & 24,0108 & 20,5702 & 21,2690 & 19,6269 & 18,2000 & 17,6677 & 17,4806 & 18,8883 & 19,7319 \\
\hline SC & 16,3405 & 16,1598 & 15,3917 & 16,2551 & 16,7819 & 16,0879 & 18,7806 & 21,3267 & ,6704 & 1,1736 & 1,1267 & 14,2230 & 14,9686 & 16,6489 & 16,1291 & 14,9428 & 15,5835 & 16,7611 & 16,3160 \\
\hline RS &, 9653 & 11,4765 & 11,9359 &, 0085 & 12,3095 & 11,7597 & 12,1034 & 12,3796 & 12,4851 & 12,7837 & 12,5352 & 11,8113 & 11,9480 & 11,8830 & 12,0875 & 11,4881 & 11,9066 & 10,8100 & 11,1709 \\
\hline & ,3188 &,, 5753 & 9,0418 & , 8060 & 15,9579 & 17,3405 & 17,6895 & 18,7783 & 1,7046 & , 8165 & 22,8437 & 17,8427 & 15,0000 & 15,0000 & 15,0000 & 15,0000 & 15,0000 & 15,0000 & 15,6408 \\
\hline & 3814 &, 2932 & 16,6832 &, 0781 & 16,8304 & 17,1845 & 17,4501 & 17,6073 & 17,6054 & 7,3534 & 7,4004 & 14,7832 & 14,0000 & 14,0000 & 16,0000 & 4,0000 & 3,8000 & 4,0000 & 14,3218 \\
\hline DF & 0,0000 & 15,0000 & 10,0000 & 20,0000 & 16,6702 & 17,7154 & 16,8000 & 18,0000 & 17,9960 & 17,9637 & 18,0000 & 15,0903 & 5,1503 & 5,2294 & 5,1879 & 10,4610 & 15,0000 & 12,0000 & 11,000 \\
\hline
\end{tabular}




\section{APÊNDICE 9 - Produtividade agrícola: cultura da mandioca (toneladas/ha)}

\begin{tabular}{|c|c|c|c|c|c|c|c|c|c|c|c|c|c|c|c|c|c|c|c|c|c|}
\hline & 881 & 1982 & 1983 & 1984 & 1985 & 1986 & 1987 & 1988 & 1989 & 1990 & 1991 & 1992 & 1993 & 1994 & 1995 & 1996 & 199 & 1998 & 1999 & 2000 & \\
\hline RO & 3388 & 3966 & 8065 & 3456 & 8613 & 379 & 5099 & $00 \varsigma_{-1}$ & 2392 & 869 & 61 & 531 & 0729 & 2921 & 705 & & $J 6$ & 194 & 6398 & & \\
\hline $\mathrm{AC}$ & 7368 & 9946 & ,5699 & 17,8320 & 4526 & 4556 & 7070 & ,5385 &, 8807 & 5819 & 3856 & 3827 & 8558 & ,6493 & 18,2869 & 4365 & _,6455, & 3,1291 & 5,7532 & 8560 & 7,57 \\
\hline$\overline{\mathrm{AM}}$ & 5771 & ,9983 & 0013 & 11,9798 & \begin{tabular}{|l|}
12,0001 \\
\end{tabular} & 8000 & 8260 & 11,8584 & \begin{tabular}{|l|}
11,6421 \\
\end{tabular} & 6534 & 4583 & 8521 & 11,6902 & \begin{tabular}{|l}
11,9697 \\
\end{tabular} & 12,4269 & 9,1469 & 9,2396 & 9,2544 & 15 & 0512 & $\overline{0,04}$ \\
\hline $\mathrm{R}$ & 1503 & 8457 & 8460 & 13,8601 & 8459 & 7,4561 & 4562 & 2036 & \begin{tabular}{|l|}
13,8176 \\
\end{tabular} & 8175 & 5481 & 0976 & 0,0000 & \begin{tabular}{|l|}
11,1838 \\
\end{tabular} & \begin{tabular}{|l|}
13,8170 \\
\end{tabular} & 5,6733 & 3,1860 & 6667 & 7730 & 2,4468 & 8,8827 \\
\hline & 3497 & 7760 & ,0457 & 12,3056 & 0242 & 4067 & 6095 & 1164 & \begin{tabular}{|l|}
13,0846 \\
\end{tabular} & 12,2490 & 12,3360 & 6,6765 & 2,8196 & 12,1800 & 11,6140 & 11,7204 &, 3885 & 13,2020 & 591 & 13,4956 & 13,9741 \\
\hline $\mathrm{AP}$ & 000 & 70 & 2387 & 4603 & 8239 & 7362 & 3340 & 1408 & 50 & 8890 & 840 & 7294 & 322 & 39 & 9470 & 3108 & 3413 & 10,0000 & 10,0353 & 1171 & $9,332\}$ \\
\hline A & 66 & 14 & 87 & 0697 & 40 & 78 & 00 & 39 & 39 & 33 & 637 & 84 & 94 & 8,0999 & 59 & 7640 & 49 & 6647 & 336 & 881 &, $8<5$ \\
\hline PI & 710 & 9351 & 6351 & 10,9552 & 1464 & 9606 & 2967 & ,6422 & 14,1285 & 13,4475 & 1088 & 6697 & 4215 & 3413 & 13,7336 & 8231 & 10,7440 & 7,0246 & 0269 & 11,4195 & 10,404 \\
\hline E & 00 & 353 & 277 & 2470 & 4 & 9269 & 8840 & 7101 & 7476 & ,9207 & 2383 & 9457 & 0759 & 7,8691 & 7,8192 & 5129 & .7167 & , 8860 & , 44425 &, 4754 & 8,6800 \\
\hline RN & 409 & 9,4240 & 7,8990 & 1979 & \begin{tabular}{|l|}
10,0252 \\
\end{tabular} & $9,9487 \mid$ & 5775 & 0283 & 0925 & 4758 & 1599 & 5194 & 9894 & 6592 & , & 8357 & 4197 & 3757 & 8899 & ג & 8,2 \\
\hline $\mathrm{PB}$ & 4053 & 8,2395 & 7,7666 & 9,1702 & 9,2644 & 9,2079 & 9,0743 & 9,2810 & 8,7023 & 7,3391 & 8,9220 & 8445 & 7,3927 & 9,4483 & 9,1723 & 6,4986 & 7,8743 & 5,1949 & 6,9659 & 8,0454 & 8,5 \\
\hline $\mathrm{PE}$ & 725 & 9,5310 & 8,2800 & 10,1203 & 2017 & 10,1268 & 7249 & 9,9903 & 10,0 & 9,3920 & 9,9488 & 6388 & 6621 & 67 & 9,7409 & 5,9896 & 5,2782 & D,5/5 & 7,2814 & 8,4722 & 8,53 \\
\hline $\mathrm{AL}$ & 4094 & 2125 & 8,9505 & 9,4974 & 9,2189 & 8,9497 & 8,6660 & 9,8500 & 10,6 & 1 & 63 & 7266 & 1 & 72 & 4 & 52 & 11,5908 & 12,4289 & 03 & 82 & 4,1 \\
\hline SE & 51 & 6257 & 0 & 12,8488 & 90 & 6490 & 3372 & 50 & \begin{tabular}{|l|l}
14,3980 \\
\end{tabular} & 88 & 57 & 91 & 8 & 15 , & 14, & 39 & 68 & 4,7 & 21 & 14,6911 & 4,5 \\
\hline $\mathrm{BA}$ & 00 & 4000 & 612 & 139 & 0000 & 0000 & 5446 & 7368 & 12,5288 & 6671 & 4074 & 4187 & 89 & \begin{tabular}{|l}
11,9051 \\
\end{tabular} & 11,9515 & 11,8704 &, 0318 & 11,0965 & 55 & 310 &, 91 \\
\hline $\mathrm{G}$ & 08 & 3660 & 387 & 409 & 2851 & 3192 & 3770 & 75 & 4232 & 075 & 7610 & 1562 & 504 & 12,7347 & 12,7739 & 8,0954 & 8602 & 11,8546 & 537 & 12,9362 & 12,89 \\
\hline $\mathrm{ES}$ & 000 & 8628 & 9444 & 17,3761 & 8123 & 7559 & 2680 & 4496 & 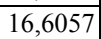 & 6251 & 0112 & 8918 & 7,0955 & 16,8050 & \begin{tabular}{|l|}
15,8824 \\
\end{tabular} & 8131 & ,9110 & 13,4205 & 5,1776 & \begin{tabular}{|l|l|}
15,7049 \\
\end{tabular} & 15,669 \\
\hline RJ & 119 & 2651 & 8178 & 15,8902 & 4705 & 3596 & 9781 & ,4663 & \begin{tabular}{|l|}
16,2526 \\
\end{tabular} & 8545 & 9016 & 9023 & 8168 & ,5819 & 15,9381 & 77757 & 8065 & 6,0141 & 15,7993 & 15,3331 & 14,058 \\
\hline SP & 1429 & 9629 & ,6998 & 21,1546 & 3617 & 1469 & 5617 & 19,9616 & 21,4409 & 6865 & 3770 & ,3393 & 2,9632 & 22,5021 & 23,2586 & 22,5264 &, 0125 & 1,4050 & 1,8032 & 22,3780 & 24,844 \\
\hline PR & 7458 & 5030 & 7939 &, 6268 & 0800 & 8135 & 6976 & 21,7654 & 20,8511 & 4483 & 0522 & 5269 & 5574 & 21,6967 & 21,4892 & 1877 & 3056 & 0,9074 & 1,2028 & 20,6593 &, 915 \\
\hline SC & 7587 & 4382 & 0139 & 3,1208 & 3671 & 4341 & 1244 & 16,7827 & 17,2802 & 17,1939 & 17,3561 & 7,9175 & 18,0326 & 17,5863 & 17,5573 &, 6718 & 4,7069 & 16,1686 & 17,9237 & 17,8354 & 18,664 \\
\hline $\mathrm{RS}$ & 3375 & 12,2268 & 12,2067 & 11,0804 & 11,8795 & 11,8607 & 12,7864 & 13,5542 & 13,5713 & 14,2198 & 13,4233 & 14,6195 & 14,8316 & 14,9568 & 14,8374 & 10,1065 & 13,6385 & 13,3285 & 14,0032 & 14,3405 & 14,8176 \\
\hline & 3373 & 15,0828 & 14,8986 & 15,0837 & 15,8541 & 17,0466 & 17,4407 & 17,3722 & \begin{tabular}{|l|}
16,6475 \\
\end{tabular} & 14,9000 & 15,7940 & 15,5879 & 15,7067 & 16,4664 & 16,5771 & 3,3534 & 6,5561 & 16,2086 & 16,6324 & 15,4443 & 15,425 \\
\hline & 2971 & 0841 & 0815 & 14,3824 & 2245 & 1410 & 2093 & 14,4998 & \begin{tabular}{|l|}
14,6914 \\
\end{tabular} & 9730 & 3,9007 & 61 & 265 & 14,7508 & 14, & 84 & 3,7061 & 4,3432 & 4,0750 & 410 & 3,692 \\
\hline DF & 9,5993 & 0000 & 8,0000 & 8,0000 & 0000 & 718 & 0000 & 0000 & 0000 & 0000 & 000 & 292 & 185 & 14,4616 & 50 & 69 & 05 & 4,863 & 15,3173 & 4513 & 15,000 \\
\hline
\end{tabular}

Fonte: IBGE 


\section{APÊNDICE 10 - Produtividade agrícola: cultura do milho (toneladas/ha)}

\begin{tabular}{|c|c|c|c|c|c|c|c|c|c|c|c|c|c|c|c|c|c|c|c|}
\hline & 1960 & 1961 & 1962 & 1963 & 1964 & 1965 & 1966 & \begin{tabular}{|c|}
1967 \\
\end{tabular} & 1968 & 1969 & 1970 & 1973 & 1974 & 1975 & \begin{tabular}{|l|}
1976 \\
\end{tabular} & 1977 & 1978 & \begin{tabular}{l|l|}
1979 \\
\end{tabular} & 1980 \\
\hline RO & 514 & ,8899 & 8893 & 9725 & 0,9701 & 0,7292 & 0,7282 & 1,0394 & 0,7234 & 0,6102 & 0,8839 & 1,6033 & 1,6774 & 1,6787 & 1,6871 & 1,5000 & 1,5272 & 1,4850 & 1,7060 \\
\hline$\overline{\mathrm{AC}}$ & 6666 & 1,5910 & 1,6088 & 6305 & 1,5396 & 1,4749 & 1,5252 & 1,4641 & 1,5332 & 1,5549 & 1,5363 & 1,6187 & 1,1724 & 1,1427 & 1,2000 & 1,2000 & 1,1500 & 1,2000 & 1,3180 \\
\hline AM & 4790 & 1,4945 & 1,4607 & 1,4022 & 1,3488 & 1,3511 & \begin{tabular}{|l|}
1,3875 \\
\end{tabular} & 1,2023 & $\begin{array}{l}1,1879 \\
\end{array}$ & 1,2706 & 1,2215 & 1,4867 & 1,4071 & 1,3552 & 1,0240 & \begin{tabular}{l|l}
1,0000 \\
\end{tabular} & 1,0000 & , 0106 & 1,299 \\
\hline RR & 6865 & 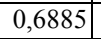 & 0,5180 & 0,6906 & 0,6901 & 0,6909 & \begin{tabular}{|c|}
0,6908 \\
\end{tabular} & 0,6893 & 0,6893 & 0,6897 & 0,9867 & 0,9467 & 1,2000 & 1,1323 & 0,9432 & \begin{tabular}{|l|}
1,0195 \\
\end{tabular} & 0,9129 & 1,0262 & 0,9565 \\
\hline PA & 4441 & 6607| & 0,6924 & 6877 & 0,6912 & 69991 & 0,6571 & 0,7494 & 1,8255 & $0,8371]$ & 8217 &, 8602 & 0,9349 & 0,8336 & |, 8563 & 0,8011 & , 8257 & 0,9476 & 0,944 \\
\hline AP & 37 & 657 & 871 & 00 & 803 & 704 & 0545 & 10 & 650 & 190 & 83 & 10 & 8641 & ,9369 & 155 & $\begin{array}{l}7985 \\
\end{array}$ & ,7891 & ,7724 & 0,7643 \\
\hline MA & 791 & 8282 & 8912 & 8826 & 8363 & 8424 & 7216 & 6954 & 0,6953 & ,6998 & 6561 & 0,6084 & 6000 & 0,5864 & | & \begin{tabular}{|c|}
0,5963 \\
\end{tabular} & 0,5694 & ,5667 & J,54 \\
\hline PI & 927 & 9780 & 8285 & 9677 & 7729 & 79 & \begin{tabular}{|c|}
0,5715 \\
\end{tabular} & 7299 & 0,7322 & 6681 & 128 & 580 & 100 & 0,7221 & 600 & 6600 & ,5773 & 4435 & , \\
\hline $\mathrm{CE}$ & 922 & 8844 & 0,9256 & 327 & 7501 & 9183 & 0,6645 & 5591 & 0,8876 & 284 & 15 & 0,6008 & 200 & 000 & 4250 & 6600 & 400 & 4220 & 0,2400 \\
\hline $\mathrm{RN}$ & 8879 & 0,5422 & 0,5422 & 5543 & 0,3860 & 0,5612 & 0,4463 & 0,8070 & 0,6040 & 0,5011 & 0,2137 & 0,5975 & 0,4383 & 0,4175 & 0,2488 & 0,5068 & 0,3599 & 0,1215 & 0,0434 \\
\hline PB & 988 & 0,7562 & 0,7095 & 0,7803 & 0,7274 & 0,9050 & 0,6493 & 0,9154 & 0,8115 & 0,8014 & 0,4411 & 0,7091 & 0,6480 & 0,5522 & 0,3616 & 0,6578 & 0,5169 &, 4023 & 0,1172 \\
\hline $\mathrm{PE}$ & 3234 & 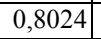 & 0,6996 & 0,7230 & 0,7277 & 0,8304 & \begin{tabular}{|c|}
0,6811 \\
\end{tabular} & 0,9447 & 0,8359 & 0,8074 & 0,5053 & 0,7419 & 0,7800 & 0,7300 & 0,5500 & $\begin{array}{l}0,7970 \\
\end{array}$ & 0,7080 & 0,5410 & 0,3060 \\
\hline $\mathrm{AL}$ & 6714 & 0,7462 & 0,6670 & 0,5124 & 0,5459 & 0,5456 & 0,5525 & 0,7609 & 0,5363 & 0,6266 & 0,2034 & 0,5243 & 0,5046 & 0,5050 & 0,3570 & 0,6046 & 0,5379 & 0,4282 & 0,2651 \\
\hline SE & 670 & 6711 & 0,7402 & 6128 & 7108 & 0,4593 & \begin{tabular}{|c|}
0,6645 \\
\end{tabular} & 0,7152 & 0,6828 & 0,7546 & 3729 & 0,8299 & 0,7482 & 0,7222 & 0,4800 & \begin{tabular}{ll|}
0,7200 \\
\end{tabular} & 0,5540 & 0,6470 & 0,3680 \\
\hline BA & 294 & 6825 & 0,7957 & 6580 & 0,8086 & 7704 & 0,9890 & 0,9643 & 0,9761 & 0,9273 & 9451 & 0,8643 & 0,8400 & 0,8117 & 0,6832 & 0,6744 & 0,7381 & 0,7130 & 0,6712 \\
\hline MG & 942 & 3727 & 1,3525 & 3250 & 1,1585 & 1,4177 & 1,3148 & 1,3838 & 1,3696 & 1,2672 & 4310 & 1,3067 & 1,8051 & 1,4313 & 1,3910 & 1,5237 & 1,4387 & 1,6346 & 1,7250 \\
\hline ES & 105 & 8869 & 0,9027 & 8423 & 0,9411 & 1,0037 & 6867 & 1,0912 & 1,1268 & 0,8395 & 2068 & 1,0695 & 1,2000 & 1,1300 & 0,8300 & \begin{tabular}{ll|}
1,2600 \\
\end{tabular} & 1,2600 & 1,2300 & 1,3472 \\
\hline RJ & 8907 & 0,8929 & 0,8579 & 0,8175 & 0,7715 & 0,8362 & 0,7993 & 1,0012 & 0,7937 & 0,6200 & ,1204 & 0,9986 & 1,0965 & 1,0382 & 0,9000 & 0,9000 & 0,8996 & 1,1885 & 1,0924 \\
\hline SP & ,5136 & 1,5538 & 1,5417 & 1,5492 & 1,1264 & 1,6845 & 1,7103 & 1,7452 & 1,7725 & 1,6051 & 1,9514 & 2,0198 & 2,0372 & 1,8987 & 2,1792 & 2,2222 & 1,7498 & 2,1593 & 2,3309 \\
\hline PR & 1,5363 & 1,5316 & 1,5555 & 1,6103 & 1,4205 & 1,6550 & 1,6445 & 1,6657 & 1,7684 & 1,7470 & 1,8900 & 1,8828 & 1,6839 & 1,9830 & 2,2073 & 2,1500 & 1,2837 & 1,9680 & 2,5350 \\
\hline SC & 1,8690 & 1,9070 & 1,7988 & 1,7910 & 1,7780 & 1,8362 & 1,6360 & 1,8395 & 1,6689 & 1,8413 & 1,9194 & 1,9501 & 2,3691 & 2,2405 & 2,4398 & 2,5143 & 1,5790 & 1,7625 & 2,6697 \\
\hline RS & 1,3005 & \begin{tabular}{|l|}
1,3772 \\
\end{tabular} & 1,3739 & 1,3874 & 1,2489 & 1,4223 & \begin{tabular}{|l|}
1,3975 \\
\end{tabular} & 1,4328 & $\begin{array}{l}1,1804 \\
\end{array}$ & 1,2910 & ,3739 & 1,3940 & 1,4662 & 1,5532 & 1,5462 & \begin{tabular}{|l|}
1,6019 \\
\end{tabular} & 1,3192 & 1,0370 & 1,698 \\
\hline MT+ & 1,2069 & 2930 & 1,4232 & 1,6402 & 1,3437 & 1,3633 & 1,3328 & 1,1516 & 1,2959 & 1,4837 & ,5441 & 1,5498 & 1,5742 & 1,5537 & 1,5228 & 1,5580 & 1,3050 & 1,4643 & 1,7221 \\
\hline vot & $6 / 15$ & 6593 & 1,5360 & 7856 & 1,6957 & 1,7401 & $1,5 / 84$ & 1,5494 & 1,6327 & 1,4801 & $1,4 / 48$ & 1,5691 & 8600 & 1,9200 & , & 1,8000 & 1,3000 & 1200 & 2,180 \\
\hline DF & 0,0000 & 1,6579 & 1,8000 & 1,5000 & 1,1923 & 1,1571 & 1,2000 & 1,0800 & 1,0802 & 1,0802 & 1,0800 & 1,5005 & 1,2002 & 1,1133 & 1,1007 & 1,1990 & 1,3000 & 1,2500 & $1,40 \mathrm{C}$ \\
\hline
\end{tabular}




\section{APÊNDICE 10 - Produtividade agrícola: cultura do milho (toneladas/ha)}

\begin{tabular}{|c|c|c|c|c|c|c|c|c|c|c|c|c|c|c|c|c|c|c|c|c|c|}
\hline & 981 & 1982 & 1983 & 1984 & 1985 & 1986 & 1987 & 1988 & \begin{tabular}{|l|}
1989 \\
\end{tabular} & 1990 & 1991 & 1992 & 1993 & 1994 & 1995 & 1996 & 1997 & 1998 & 1999 & 2000 & \\
\hline RO & 053 & 6879 & 1566 & 7748 & 6254 & ,7545 & 213 & 6564 & 6663 & 1,7477 & 1,7112 & ,7756 & 8142 & 8451 & 1,8622 & 1,4377 & 4329 & ,5001 & 1,5999 & 1,5709 & ,61 \\
\hline $\mathrm{C}$ & 515 & 2774 & 1982 & 5334 & 1,1294 & 2151 & 2382 & 4802 & 1,5931 & 1,6340 & 1,5404 & 7663 & 6764 & 5062 & 1,5096 & 1,2534 & ,2141 & ,2924 & 1,4489 & 1,5207 & 1,52 \\
\hline $\mathrm{MM}$ & 3001 & 1,2999 & 1996 & 6063 & 1,4672 & ,7792 & 8152 & 6809 & 1,3349 & 1,5814 & 1,5000 & ,9119 & 8881 & 1,4620 & 1,5899 & 1,2634 & 1,2639 & 1,3100 & 1,4551 & 4764 & 1,47 \\
\hline$R$ & 0747 & 6700 & 3149 & 8291 & 0,8290 & 6239 & 6306 & 1,0282 & 1,0470 & 0,8997 & 0,8350 & 7592 & 0,0000 & 0,8484 & 1,2000 & 1,2543 & 1,0800 &, 9369 & 1,3000 & 1,2829 & 1,5 \\
\hline PA & 727 & 893 & ,9384 & 0959 & 1,0964 & 1614 & 2097 & 2416 & 1,3607 & 1,1676 & , 1503 & 1505 & 3077 & 1,2558 & 1,3650 & 1,3717 & 1,4714 & ,3858 & 1,5367 & 1,2677 & 1,515 \\
\hline$P$ & 53 & 7139 & 24 & 020 & 68 & 45 & 0177 & 6 & 1239 & 4 & 0,7549 & 65 & 369 & 0,6683 & 0,5966 & 1,3692 & 0,6500 & 0,7000 & 0,7077 & 0,7000 & $0, / 1$ \\
\hline MA & 111 & 5486 & 18 & 92 & 0,3479 & 47 & 2188 & 20 & 40 & 22 & 0,5998 & 92 & 50 & 0,6239 & 0,5558 & 87 & 0,6101 & 533 & 8124 & 78 & 0,99 \\
\hline PI & 44 & 3443 & 0,1209 & 0,6008 & 121 & 1908 & 3196 & 4 & 0,8487 & 22 & 0,8104 & 15 & 504 & 9065 & 8489 &, 0560 & . & 2207 & $84 / 0$ & 8330 & 0,32 \\
\hline $\mathrm{E}$ & 300 & 000 & 200 & 608 & 136 & 5370 & 26001 & 7018 & 4602 & 1910 & 5792 & 713 & 0691 & 6893 & 1204 & , //191 & $5 / 11$ & 1912 &, 7477 & 0163 & \\
\hline KN & 8488 & 444 & $0 / 05$ & 5288 & 3551 & 4433 & 0994 & +868 & 5000 & 1228 & 4521 & 00 & 1160 & 6679 & 6113 & , 4800 & 3427 & 1017 & $\mid 2259$ & 5911 & \\
\hline PB & 228 & 244 & 1274 & 0,6659 & 5644 & 5833 & 2091 & 5433 & 0,4927 & 1551 & 0,4987 & 3379 & 1843 & 0,8698 & 6137 & 0,5789 & 79 & 0300 & 1084 & 7137 & \\
\hline PE & 247 & 4030 & 0,1560 & 0,8300 & 6508 & 7101 & 24 & 5913 & 3994 & 0,3307 & 0,3858 & 54 & 69 & 759 & 0,5544 & 0, & 99 & 1196 & 1438 &, 4663 & 0,0 \\
\hline$\overline{\mathrm{AL}}$ & 356 & 3518 & 0 , & 0,4962 & 4630 & 4026 & 2655 & 3741 & 3536 & 3991 & 0,3976 & 3081 & 0,0926 & 0,4413 & 0,3553 & 0,3836 & 0,4501 & 0,3397 & 0,3244 & 0,5894 & 0,379 \\
\hline $\mathrm{SE}$ & 978 & 558 & 0, & 8626 & 0411 & 9903 & 6478 & 290 & 9757 & 0,3738 & 0,6081 & 2908 & 2242 & 0,9019 & 0,7312 & 1,1514 & 1,0630 & 0,9741 & \begin{tabular}{|l|}
1,3495 \\
\end{tabular} & 1,0073 & 0,49 \\
\hline $\mathrm{BA}$ & 3152 & 4600 & 4 & 3300 & 8687 & 6407 & 2383 & 8929 & 4963 & 3036 & 7621 & 8674 & 9698 & 9547 & 1,3442 & 1,1948 & 1,5420 & 2115 & 1,3405 & 1,9600 & 1,44 \\
\hline MG & 244 & 3321 & 8883 & 6616 & 0041 & 0773 & 0861 & 1348 & 2,2247 & 1,5793 & 3930 & 4297 & 5706 & 4702 & 2,5015 & 2,5724 & 2,9421 & ,9368 & 3,0443 & 3,4116 & 3,30 \\
\hline ES & 600 & ,5855 & 1,4223 & 5983 & 7679 & 9412 & 0067 & 8310 & 1,9912 & 1,5728 & 4861 & 2011 & 4676 & 2,0120 & 1,1990 & 2,2389 & 2,3514 & 2457 & 3865 & 2,4688 & 2,464 \\
\hline $\mathrm{RJ}$ & 1674 & 3655 & 1,4522 & 4220 & 5293 & 5496 & 4754 & 6559 & 1,7398 & 0,9484 & 1,7401 & 1,8556 & 1,9463 & 8398 & 1,3279 & 1,9330 & 0163 & 9653 & ,9364 & 1,9569 & 1,865 \\
\hline SP & 3396 & 5493 & 2,5998 & 3370 & $\overline{5248}$ & 4469 & 6999 & 8663 & 2,8365 & 2,4029 & 2,8113 & 2,6015 & 2,7307 & 2,4440 & 3,3582 & 3,0673 & 3,2396 &, 3235 &, 1346 & 2,8220 & 3,74 \\
\hline PR & 4806 & 2,3850 & 2,1250 & 2,2068 & 4878 & 8874 & 6851 & 2,4480 & 2,4780 & 2,4701 & 1,9770 & 2,8427 & 2,9976 & 2,8599 & 3,3294 & 3,2295 & 3,0965 & 5579 & 3,4636 & 2,7582 & 4,488 \\
\hline SC & 2,7501 & 2,3712 & 1,5881 & 2,5009 & 2,3163 & 2,1119 & 2,4035 & 2,4003 & 2,6773 & 2,6360 & 1,4441 & 2,9993 & 3,1383 & 3,2089 & 3,4394 & 3,0425 & 3,5930 & 3,3639 & 3,4427 & 4,1201 & 4,404 \\
\hline RS & 2,0942 & 1,6996 & 1,7846 & 1,8943 & 0394 & 1,2702 & 9809 & 1,5674 & 2793 & 2,4024 & 1,0998 & 2,7539 & 2,6434 & 2,7598 & 3,1508 & 1,7614 & 2,4758 & 2,8631 & 1561 & 2,5597 & 3,66 \\
\hline & 1,7206 & 1,7470 & 1,7167 & 1,7456 & 1,9107 & 9433 & 4194 & 3489 & 2,5883 & 2,2412 & 2,5887 & 2,3954 & 2,5408 & ,4157 & 2,8035 & 3,0064 & 3,0399 & 2,7267 & 2,8775 & 2,3228 & 3,609 \\
\hline & 454 & 1794 & 1834 & 2135 & 3031 & 6612 & 6212 & 6906 & 3,2241 & 1,9585 &, $11 / 4$ & , 2549 & 3011 & 3164 & 3,7548 &, 1600 & 8334 & ,6258 & ,9231 & 4,1832 & 4,38 \\
\hline DF & 1,2356 & 5018 & 5770 & 5613 & 000 & 1411 & 6920 & 3280 & 3,4440 & 000 & & 3,5320 & 190 & 1200 & 4186 & 4,0991 &, 811 & 4,69 & 6614 & 115 &,+ 26 \\
\hline
\end{tabular}

Fonte: IBGE 
APÊNDICE 11 - Produtividade agrícola: cultura do soja (toneladas/ha)

\begin{tabular}{|c|c|c|c|c|c|c|c|c|c|c|c|c|c|c|c|c|c|c|c|}
\hline & 1960 & 1961 & 1962 & 1963 & 1964 & 1965 & 1966 & 1967 & 1968 & 1969 & 1970 & \begin{tabular}{|l|}
1973 \\
\end{tabular} & 1974 & 1975 & 1976 & 1977 & 1978 & 1979 & 1980 \\
\hline RO & 0000 & 0000 &, 0000 & 0,0000 & 0,0000 & 0,0000 & 0,0000 & 0,0000 & 0,0000 & 0,0000 & 0,0000 & 0,0000 & 0,0000 & 0,0000 & 0,0000 & 0,0000 & 0,0000 & 0,0000 & 0,0000 \\
\hline $\mathrm{AC}$ & 000 & 0,0000 & 0,0000 & 0,0000 & 0,0000 & 0000 & 0,0000 & 0,0000 & 0,0000 & 0,0000 &, 0000 & 0,0000 & 0,0000 & 0,0000 & 0,0000 & 0,0000 & 0,0000 & 0,0000 & 0,00 \\
\hline AM & 0000 & 0,0000 & 0,0000 & 0,0000 & 0,0000 & 0,0000 & 0,0000 & 0,0000 & 0,0000 & 0,0000 & 0,0000 & 0,0000 & 0,0000 & 0,0000 & 0,0000 & 0,0000 & 0,0000 & 0,0000 & 0,0000 \\
\hline RR & 0000 & 0,0000 & 0,0000 & 0,0000 & $\begin{array}{l}0,0000 \\
\end{array}$ & 0,0000 & 0,0000 & 0,0000 & 0,0000 & 0,0000 & 0,0000 & 0,0000 & 0,0000 & 0,0000 & $\begin{array}{l}0,0000 \\
\end{array}$ & 0,0000 & 0,0000 & 0,0000 & 0,0000 \\
\hline PA & 0000 & 0,0000 & 0,0000 & , 0000 & 0000 & 0000 &, 0000 & 0,0000 & 0,0000 & 0,0000 &, 0000 & 0,0000 & 0,0000 & 0,0000 & 0,0000 & 0,0000 & 0000 & 0,0000 & 0,0000 \\
\hline AP & 000 & 0000 & 0000 & 0000 & 0000 & 00 & 0000 & 00 & 0000 & 0,0000 & 0000 & 0000 & 000 & 0000 &, 0000 & 000 & 00000 & 0,0000 & 0000 \\
\hline MA & 000 & 0000 & $\overline{0000}$ & 0000 & 0000 & 0000 &, 0000 & 0000 & $\overline{0000}$ & 0,0000 & 0,0000 & 0,0000 & ,, 0000 & 0000 & 0,0000 & 0,0000 & 1,7188 & 2,0000 & , 2000 \\
\hline PI & 000 & 0000 & 0000 & $\overline{0000}$ & 0000 & 0000 & 0000 & 0000 & $\overline{0000}$ & 0,0000 & 0000 & 0000 & 0,0000 & 0000 & 0000 & 00 & 2700 & 2222 & 000 \\
\hline $\mathrm{CE}$ & 000 & 0000 & 0,0000 & $\overline{0000}$ & 0,0000 & 0000 & 0000 & 0,0000 & 0000 & 0,0000 &, 0000 & 0000 & 0,0000 & 0000 & 0,0000 &, 0000 & 0000 & 0000 & 0000 \\
\hline $\mathrm{RN}$ & 0000 & 0,0000 & 0,0000 & 0,0000 & 0,0000 & 0,0000 & 0,0000 & 0,0000 & 0,0000 & 0,0000 & 0,0000 & 0,0000 & 0,0000 & 0,0000 & 0,0000 & 0,0000 & 0,0000 & 0,0000 & 0,0000 \\
\hline PB & 0000 & 0,0000 & 0,0000 & 0,0000 & 0,0000 & 0,0000 & 0,0000 & 0,0000 & 0,0000 & 0,0000 & 0,0000 & 0,0000 & 0,0000 & 0,0000 & 0,0000 & 0,0000 & 0,0000 & 0,0000 & 0,0000 \\
\hline $\mathrm{PE}$ & 0000 & 0,0000 & 0,0000 & 0,0000 & 0,0000 & 0,0000 & 0,0000 & 0,0000 & 0,0000 & 0,0000 & 0,0000 & 0,0000 & 0,0000 & 0,0000 & \begin{tabular}{ll|}
0,0000 \\
\end{tabular} & 0,0000 & 0,0000 & 0,0000 & 0,0000 \\
\hline $\mathrm{AL}$ & 000 & 0,0000 & 0,0000 & 0,0000 & 0000 & 0,0000 & 0,0000 & 0,0000 & 0,0000 & 0,0000 & 0,0000 & 0,0000 & 0,0000 & 0,0000 & 0,0000 & 0,0000 & 0,0000 & 0,0000 & 0,0000 \\
\hline SE & 000 & 0000 & 0,0000 &, 0000 & 0,0000 & 0,0000 & 0,0000 & 0,0000 & 0,0000 & 0,0000 & 0,0000 & 0,0000 & 0,0000 & 0,0000 & 0,0000 & 0,0000 & 0,0000 & 0,0000 & 0,0000 \\
\hline BA & 542 & 4545 & 7428 & 4571 & 0472 & 2,0705 & 0751 & 1,9087 & 0,4881 & 1,5333 & 1,5625 & 1,7895 & 1,2395 & 0,9366 & 0,9000 & 1,1693 & 1,5715 & 1,4738 & 1,1668 \\
\hline $\mathrm{MG}$ & 4922 & 5387 & 0,4834 &, 3583 & 4184 & 0,4351 &, 3547 & 0,9407 & 1,0557 & 0,8613 & 1,1438 & 1,5923 & 1,2000 & 1,1530 & 1,3245 & 1,0578 & 1,2228 & 1,6649 & 1,7830 \\
\hline ES & 000 & 0000 & 0,0000 & 0,0000 & 0000 & 0,0000 & 0000 & 0,0000 & 0,0000 & 0,0000 & 0,0000 & 0,0000 & 0,8779 & 1,3009 & 1,2000 & 0,0000 &, 0000 & 0,0000 & 0,0000 \\
\hline RJ & 0000 & 0,0000 & 0,0000 & 0,0000 & 0,0000 & 0,0000 & 0,0000 & 0,0000 & 0,0000 & 0,0000 & 0,0000 & 0,0000 & 0,0000 & 0,0000 & 0,0000 & 0,0000 & 0,0000 & 0,0000 & 0,0000 \\
\hline SP & 1,1667 & 1,2008 & 1,1468 & 1,1621 & 1,0651 & 1,4559 & 1,4835 & 1,3812 & 1,3470 & 1,2948 & 1,4494 & 1,6383 & 1,5582 & 1,7331 & 1,9416 & 1,7093 & 1,3341 & 1,5834 & 1,9599 \\
\hline PR & 1,4556 & 1,4005 & 1,3231 & 1,3481 & 1,0943 & 1,2858 & 1,5275 & 1,3659 & 1,3647 & 1,2389 & 1,2097 & 1,6222 & 1,9320 & 2,2213 & 2,1600 & 2,1364 & 1,3413 & 1,7091 & 2,2400 \\
\hline SC & 1,6941 & 1,6786 & 1,7147 & 1,5469 & 1,5766 & 1,5015 & 1,3325 & 1,2513 & 1,2885 & 0,9876 & 0,8035 & 1,2107 & 1,1822 & 1,2924 & 1,2078 & 1,3586 & 0,8676 & 0,8942 & 1,3812 \\
\hline RS & 1,1824 & 1,1118 & 1,0877 & 0,9263 & 0,8249 & 1,1985 & , 1610 & 1,1221 & 0,7766 & $\begin{array}{ll}1,1469 \\
\end{array}$ & 1,1212 & 1,2951 & 1,3971 & 1,5060 & 1,5495 & 1,6269 & 1,2168 & 0,9003 & 1,4388 \\
\hline $\mathrm{MT}+$ & 0,9211 & 1,4242 & 0,8513 & 0912 & \begin{tabular}{|l|l|}
, 0313 \\
\end{tabular} & 0,9391 & , 3003 & 1,1568 & 1,2752 & 1,0772 & 1,5485 & 1,1953 & 1,7557 & 1,4033 & 1,5196 & 1,6870 & 0,9590 & 1,4243 & 1,6411 \\
\hline Un & 0000 & 0000 & 0,0000 & .0000 & 00000 & 00000 & 00000 & , & , & 1,2022 & 1,2452 & 1,5051 &, 9000 & , 3200 & 1,4800 & , & 1,0400 & 1,8500 & 8523 \\
\hline DF & 0,0000 & 0000 & 0,0000 & 0,0000 & 0,0000 & 0,0000 & 0,0000 & 0,0000 & 0,0000 & 0,0000 & 0,0000 & 0,0000 & 1,7692 &, 0000 & 1,1852 & 1,0000 & 1,7971 & 1,8595 & 1,924 \\
\hline
\end{tabular}




\section{APÊNDICE 11 - Produtividade agrícola: cultura do soja (toneladas/ha)}

\begin{tabular}{|c|c|c|c|c|c|c|c|c|c|c|c|c|c|c|c|c|c|c|c|c|c|}
\hline & 981 & 1982 & 1983 & 1984 & 1985 & 1986 & 1987 & 1988 & \begin{tabular}{|l|}
1989 \\
\end{tabular} & 1990 & 1991 & 1992 & 1993 & \begin{tabular}{|l|l|}
1994 \\
\end{tabular} & 1995 & 1996 & 1997 & 1998 & 1999 & 2000 & \\
\hline $\mathrm{RO}$ & 000 & 000 & 000 & 000 & 3348 & 4500 & 9918 & 9922 & 9967 & 1,9940 & 0553 & 2,3797 & 1113 & 3819 & 2,4000 & 1,8924 & 9756 &, 0008 & 2,0641 & 3,0697 & thents \\
\hline C & 0000 & 0000 & 0000 & 0000 & 0000 & 0000 & 0000 & 0000 & 0000 & 0,0000 & 0000 &, 0000 & 0000 & 0000 & 0,0000 & 0,0000 & ,0000 & 2,5000 &, 5000 & 0,0000 &,, $0 c$ \\
\hline $\mathrm{MM}$ & 0000 & 0000 & 0000 & 0000 & 0,0000 & 0000 & 0000 & $\overline{0000}$ & 0,0000 & 0,0000 & 0,0000 & 0,0000 & 0000 & 0,0000 & 0,0000 & 0,5102 &, 5000 &, 7495 & 1,3748 & 1,3472 &, 31 \\
\hline$R$ & 0000 & 0000 & 0000 & 0000 & 0000 & 0000 & 0000 & 0000 & 0,0000 & 0,0000 & 0000 & 0000 &, 0000 & 0,0000 & 0,0000 &, 0000 & 0000 &, 0000 &, 0000 & 0,0000 & 0,00 \\
\hline PA & 0000 & 0000 & 0000 & 0000 & 0000 & 0000 & 0000 & 0000 & 0000 & 0,0000 &, 0000 &, 0000 & 0000 & 0000 & 0,0000 & 0,0000 &, 3530 & ,3228 & 1,3734 & 1,1694 & 2,2 \\
\hline $\mathrm{P}$ & 000 & 0000 & 0 & 0000 &, 0000 & $\overline{0000}$ & 0000 & 0 & 1,7674 & 0000 & 00 & 00 & 00 & 0,0000 & 0,0000 &, 0000 & 0000 & , & 0,0000 & 0,0000 & $0,0 t$ \\
\hline MA & 970 & 0000 & 26 & 7837 & 1,1086 & ,5653 & 0259 & 41 & 09 & 0,2729 & 29 & 76 & 14 & 60 & 17 & 58 & 82 & 340 & D04 & 47 & 2,30 \\
\hline PI & 000 & 000 & 000 & ,4304 & ,3138 & 93 & 000 & 000 & 1,6576 & 580 & 5000 & 522 & 704 & 6051 & 1,5800 & 451 & 1576 & 8365 & 5682 & 5238 & 2,04 \\
\hline $\mathrm{E}$ & 000 & 000 & 0000 & 000 & 0000 & 0000 & 0000 & 0000 & 0000 & 0,0000 & 0000 & 0000 & 0000 & ,0000 & 0,0000 & , & 2222 & 0000 & , & 0000 &, 00 \\
\hline $\mathrm{N}$ & 000 & 0000 & 0000 & 0000 & 0000 & 0000 & 0000 & 0000 & 0000 & 0,0000 & 0000 & 0000 & 0000 & 0000 & 0000 & 0000 & 0000 &, 0000 & 0000 & , 0000 & \\
\hline PB & 0000 & 0000 & 0,0000 & 0,0000 & 0000 & 0000 & 0000 & 0000 & 0,0000 & 0,0000 & 0,0000 &, 0000 & 0000 & 0000 & 0,0000 & 0,0000 &, 0000 &, 0000 & 0000 & 0000 & 00 \\
\hline PE & 0000 & 0000 & 0,0000 & 0,0000 & 0000 & 0000 & 0000 & 000 & 0000 & 0,4444 & 0,0000 & 00 & 0000 & 0000 & 2,3889 & 0,0000 &, 0000 & 0,0000 & 0000 & 0,0000 & 0,0 \\
\hline$\overline{\mathrm{AL}}$ & 0000 & 000 & 0,0000 & 0,0000 & 0000 & 4507 & 0450 & 1711 & 1,1517 & 0,0000 & 0,0000 & 0,0000 & 0,0000 & 0,0000 & 0,0000 & 0,0000 & 0,0000 & 0,0000 & 0,0000 & 0,0000 & 0,00 \\
\hline $\mathrm{SE}$ & 000 & 000 & 0000 & 0,0000 & 6865 & 4663 & 9882 & 5000 & 6000 & 0,0000 & 0,0000 & 0,0000 &, 0000 & 0,0000 & 0,0000 & 0,0000 & 0,0000 & 0,0000 & $\overline{0,0000}$ & 0,0000 & $\overline{0,00}$ \\
\hline $\mathrm{BA}$ & 308 & 000 & 6000 & 3005 & 2000 & 4110 & 8688 & 5029 & 5054 & 0,6122 & 1000 & 5000 & 5543 & 0122 & 2,2800 & 1,6161 & 2,2200 &, 1456 & 1,9828 & 4001 &, 0 \\
\hline MG & 729 & 7022 & 8525 & 6677 & 9742 & 8167 & 9126 & 9246 & 9908 & 1,3410 & 0481 & 2,0618 & 9878 & 1453 & 1,9869 & 1,9322 &, 1908 & 2,2687 & ,3277 & 3978 & 2,19 \\
\hline ES & 000 & 000 & 0,0000 & 0000 & $\overline{0000}$ & 0000 & 0000 & 0000 & 0,0000 & 0,0000 & 0000 & $\overline{0000}$ & 0000 & 0000 & 0,0000 & ,0000 &, 0000 &, 0000 &, 0000 & 0000 & 00 \\
\hline $\mathrm{RJ}$ & 0000 & 0000 & 0,0000 & 0000 & 0000 & 0000 & 0000 & 0000 & 0000 & 0,0000 & 0000 & 0000 & 0000 & 0000 & 0,0000 &, 0000 &, 0000 &, 0000 &, 0000 & 0000 &, 00 \\
\hline SP & 9006 & 9250 & 2,0553 & 8021 & 9263 & 9288 & 0000 & 9549 & 2,2785 & 1,6700 & 1,9534 & 8336 & 1,9922 & 2222 & 2,2368 & 2,1900 & 2,4500 & ,9497 & ,7301 & 2,2245 & 2,55 \\
\hline PR & 1989 & 2,0001 & 2,1340 & 1,8922 & 2,0092 & 1,4900 & 2177 & 2470 & 2,0964 & 2,0487 & 1,7839 & 1,9001 & 2,2975 & 4664 & 2,5810 & 2,6984 & 2,5785 & 2,5564 & 7808 & 2,5152 & 3,05 \\
\hline SC & 1,3396 & 1,1996 & 1,1278 & 1,3700 & 1,3422 & 1,3021 & 1,2586 & 1,3448 & 1,5136 & 1,4525 & 0,9312 & 1,7896 & 1,9763 & 1,9991 & 2,1719 & 2,4191 & 2,4029 & 2,3537 & 2,1382 & 2,4701 & 2,68 \\
\hline RS & 1,5953 & 1,1924 & 1,5484 & 1,4870 & 1,5704 & 1,0080 & 5821 & 1,0570 & 7159 & 1,7939 & 0,7089 & 1,9612 & 1,9710 & 7061 & 1,9438 & 1,6629 & 1,6158 & 2,0346 & 1,4624 & 1,5786 & 2,33 \\
\hline MT & 1,7523 & 1,8351 & 1,9657 & 1,7780 & 0041 & 8339 & 0787 & 0737 & 2,2137 & 1,7974 & 2,1195 & 2,2896 & 2,3285 & 2,4660 & 2,2978 & 2,5239 & 2,6786 & 2,5385 & 2,7687 & 2,8061 & 3,02 \\
\hline & 3201 & $76 / 8$ & 8698 & 4564 & $84 / 2$ & $814 /$ & 9535 & 1,9366 & $2,0 / 41$ & 1,2537 & 0735 & 1734 & 0300 & 0687 & 1,9040 & ,2201 & 3757 & 4533 & 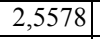 & 2,7355 & 61 \\
\hline DF & 1,6700 & 1,9030 & 2,0000 & 30 & 280 & 160 & 530 & 9150 & 1830 & $48 / 4$ & 2,3480 & 2,2100 & 1260 & 1600 & 1,966 & 1,931 & لــ & , 4244 & 31 & ,76 & 2,05 \\
\hline
\end{tabular}

Fonte: IBGE 
APÊNDICE 12- Dados sobre a Taxa de Crescimento dos Anos de Escolaridade do Trabalhador da Agropecuária

\begin{tabular}{|l|c|c|}
\hline \multicolumn{1}{|c|}{ ESTADOS } & $\begin{array}{c}\text { Taxa de Crescimento: } \\
\mathbf{1 9 7 5 - 2 0 0 2}\end{array}$ & $\begin{array}{c}\text { Taxa de Crescimento: } \\
\mathbf{1 9 8 0 - 2 0 0 2}\end{array}$ \\
\hline RO & 0,091 & 0,086 \\
\hline AC & 0,071 & 0,081 \\
\hline AM & 0,072 & 0,082 \\
\hline RR & 0,080 & 0,077 \\
\hline PA & 0,056 & 0,060 \\
\hline AP & 0,082 & 0,093 \\
\hline MA & 0,058 & 0,065 \\
\hline PI & 0,059 & 0,064 \\
\hline CE & 0,066 & 0,075 \\
\hline RN & 0,084 & 0,097 \\
\hline PB & 0,053 & 0,059 \\
\hline PE & 0,076 & 0,086 \\
\hline AL & 0,062 & 0,070 \\
\hline SE & 0,069 & 0,076 \\
\hline BA & 0,069 & 0,079 \\
\hline MG & 0,093 & 0,095 \\
\hline ES & 0,088 & 0,081 \\
\hline RJ & 0,087 & 0,081 \\
\hline SP & 0,104 & 0,104 \\
\hline PR & 0,103 & 0,102 \\
\hline SC & 0,071 & 0,076 \\
\hline RS & 0,074 & 0,067 \\
\hline MT & 0,104 & 0,105 \\
\hline GOs & 0,113 & 0,120 \\
\hline DF & 0,117 & 0,118 \\
\hline F & & \\
\hline
\end{tabular}

Fonte: valores calculados a partir dos dados de Freitas el. al. (2004) 
APÊNDICE 13 - Dados sobre deficiência

hídrica: média aritmética

\begin{tabular}{|l|c|}
\hline RO & 57,4 \\
\hline AC & 61,8 \\
\hline AM & 284,8 \\
\hline RR & 733,4 \\
\hline PA & 266 \\
\hline AP & 299 \\
\hline MA & 402,7 \\
\hline PI & 506,4 \\
\hline CE & 843,9 \\
\hline RN & 605,2 \\
\hline PB & 931,6 \\
\hline PE & 454,2 \\
\hline AL & 731 \\
\hline SE & 327,3 \\
\hline BA & 311,6 \\
\hline MG & 174,8 \\
\hline ES & 153,2 \\
\hline RJ & 112,5 \\
\hline SP & 78,8 \\
\hline PR & 64,4 \\
\hline SC & 252,2 \\
\hline MT & \\
\hline GO & 71 \\
\hline DF & \\
\hline
\end{tabular}

